\title{
Needed Improvements in Standards and Transparency for Staff Promotion
}

\author{
Geri Richmond \\ Celeste Rohlfing \\ Jean Stockard \\ Jane Tucker \\ Barbara Butterfield \\ Maya Noviski \\ Priscilla Lewis \\ COACh
}

This publication is available free of charge from: https://doi.org/10.6028/NIST.GCR.21-029

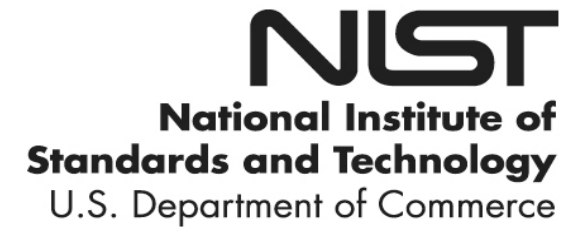




\title{
Needed Improvements in Standards and Transparency for Staff Promotion
}

\author{
Prepared for \\ U.S. Department of Commerce \\ National Institute of Standards and Technology \\ Gaithersburg, MD 20899 \\ By \\ Geri Richmond \\ Celeste Rohlfing \\ Jean Stockard \\ Jane Tucker \\ Barbara Butterfield \\ Maya Noviski \\ Priscilla Lewis \\ COACh \\ University of Oregon
}

This publication is available free of charge from:

https://doi.org/10.6028/NIST.GCR.21-029

April 2021

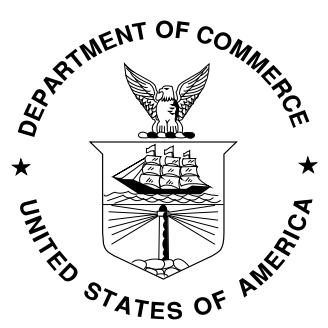

U.S. Department of Commerce Gina M. Raimondo, Secretary

National Institute of Standards and Technology James K. Olthoff, Performing the Non-Exclusive Functions and Duties of the Under Secretary of Commerce for Standards and Technology \& Director, National Institute of Standards and Technology 


\section{Disclaimer}

This publication was produced as part of contract 1333ND19PNB670633 with the National Institute of Standards and Technology. The contents of this publication do not necessarily reflect the views or policies of the National Institute of Standards and Technology or the US Government. 


\section{NIST: Needed Improvements in Standards and Transparency for Staff Promotion}

COACh Team: Geri Richmond

Celeste Rohlfing Jean Stockard Jane Tucker Barbara Butterfield Maya Noviski Priscilla Lewis 
NIST Compiled Report

Abstract

In 2019, COACh, an organization dedicated to developing equitable opportunities in science and engineering, contracted with NIST to "design and implement a data-driven study to examine the causes of inequity in promotions ... and develop draft recommendations." This document compiles reports of that work. A companion report by Maya Noviski, NIST GCR 21-030 "Supporting Women and Under-Represented Minorities in the Sciences: Implementing Equitable Approaches to organizational Change" summarizes scholarly literature that informed final recommendations. The work began with "listening sessions" with NIST scientific staff and administrators (mainly ZPs and ZTs), which revealed that many employees held strong views about promotion opportunities and process. This was followed by analyses of NIST personnel actions from 2000 to 2019. (Reports in Part I.) In contrast to views often expressed in the listening sessions and implicit in the wording of the call for proposals, extensive statistical analyses found little evidence that women were disadvantaged in promotions or salaries. A survey of ZP employees supported these conclusions. (Reports in Part II.) However, extensive statistical analyses and examination of open-ended comments indicated less than half of the employees believed that the promotion criteria were understood by employees or appropriate for the NIST mission or their unit or that the promotion process was fair. The concerns were more often expressed by those at lower pay bands. Within bands, gender differences in views were minimal. Focus groups with ZP staff and Group Leaders, as well as interviews with ZT staff, confirmed the conclusions from the HR data and survey and provided examples of issues with the promotion criteria and process. Direct quotes informed our conclusions and expanded our recommendations for change. (Reports in part III.) The recommendations are designed to help develop a more transparent promotion process that is seen as fair and equitable by all staff (Part IV). Appendices include material for leaders implementing change or those interested in replicating the work.

Keywords: Promotion; STEM; Inequity; Women; Minorities, Professional Development 
Table of Contents

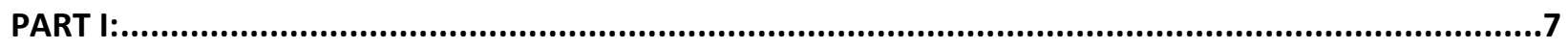

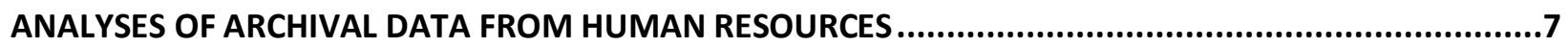

REPORT 1: NIST PROMOTION PATTERNS: ANALYSIS OF PERSONNEL RECORDS ............................................11

REPORT 2: GENDER DIFFERENCES IN SALARIES OF NIST ZP EMPLOYEES: ANALYSIS OF PERSONNEL DATA...................30

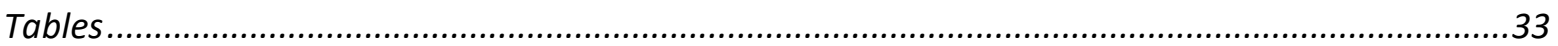

REPORT 3: ZT AND ZP I AND II EMPLOYEES AT NIST: ANALYSIS OF PERSONNEL DATA ......................................37

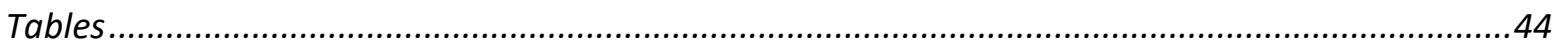

REPORT 4: FEDERAL EMPLOYEE VIEWPOINT SURVEY: COMPARISON OF VIEWS WITHIN NIST LABS ..........................57

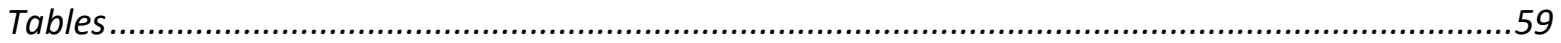

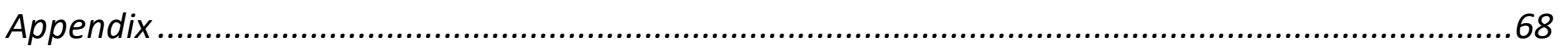

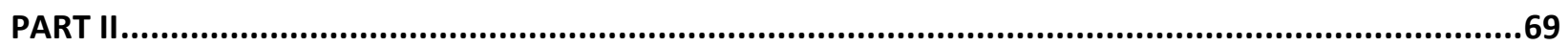

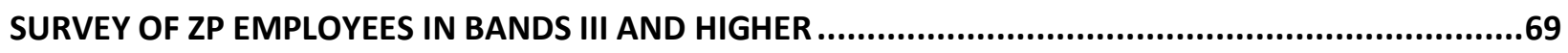

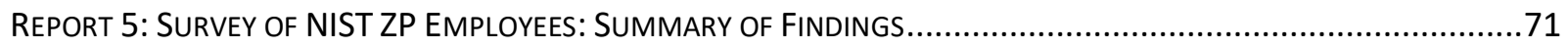

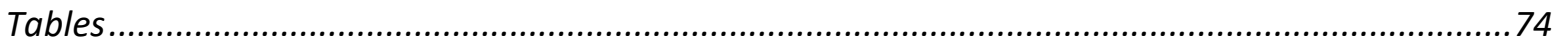

REPORT 6: ANALYSIS OF A COACH-SPONSORED SURVEY TO NIST ZP EMPLOYEES DISTRIBUTED IN MARCH, 2020 ......78

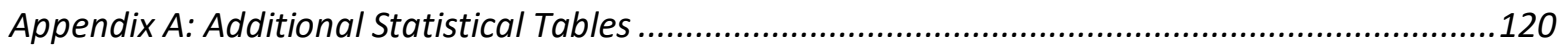

Appendix B: Open-Ended Comments Regarding Other Professional Development Experiences ......171

Appendix C: Open-Ended Comments Regarding Professional Development Experiences That Would

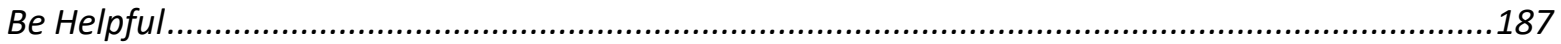

REPORT 7: OPEN-ENDED COMMENTS REGARDING PROMOTION ON NIST SURVEY ......................................207

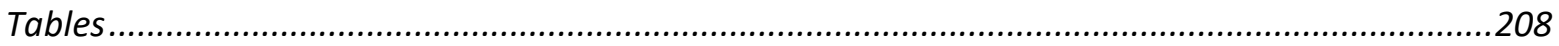

Appendix: Open-Ended Comments Regarding Promotion Process, Policy, and Experiences ............210

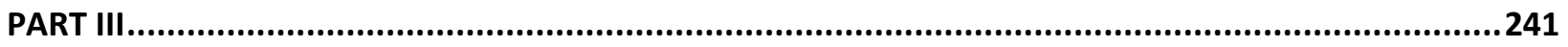

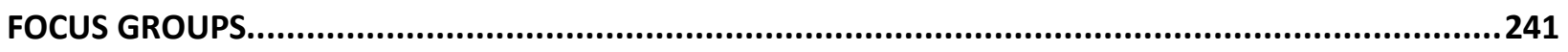

REPORT 8: SUMMARY OF FOCUS GROUPS CONDUCTED WITH NIST ZP STAFF IN NOVEMBER 2020...................242

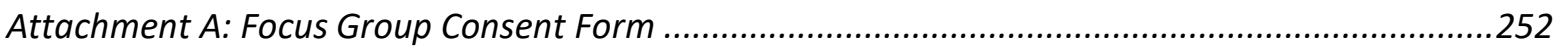

Attachment B: Gender Composition of Focus Group Participants..............................................253

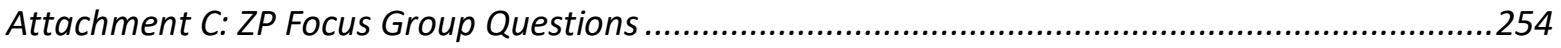

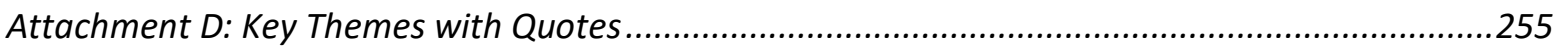

Attachment E: ZP Focus Group Coding Methodology and Process ..............................................260

REPORT 9: FOCUS GROUPS CONDUCTED WITH GROUP LEADERS IN DECEMBER 2020 ......................................265

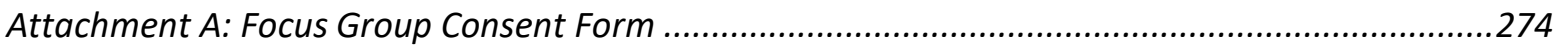

Attachment B: Group Leaders Focus Group Questions............................................................275

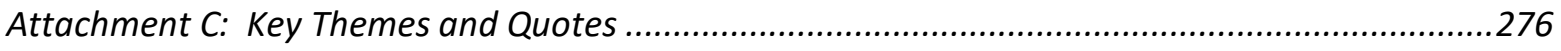

Attachment D: Quantitative Analysis of Transcripts of Group Leader Focus Groups.......................279

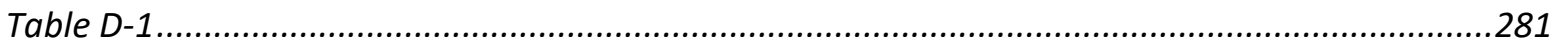

REPORT 10: SUMMARY OF ZT FOCUS GROUPS/INTERVIEWS IN OCTOBER 2020 .........................................28

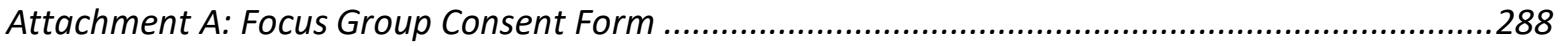

Attachment B: ZT Focus Group Questions .............................................................................28

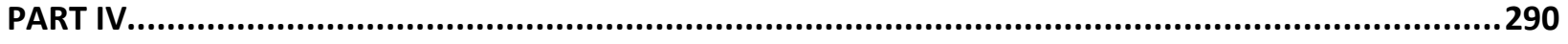


RECOMMENDATIONS FOR CHANGE........................................................................................290

REPORT 11: EQUITY ACTION PLAN......................................................................................290

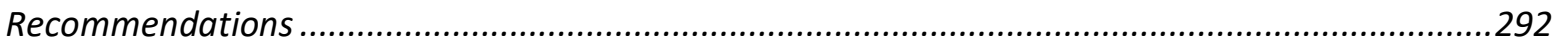

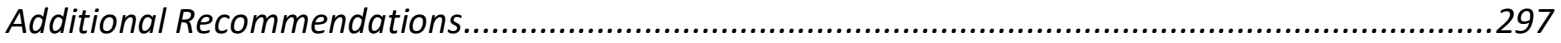

Appendix A: Professional Development Opportunities and Coursework ........................................298

Appendix B: Focus Group Guide for Group Leaders...................................................................302

Appendix D: COACh Communication Plan for Roll-Out of Equity Action Plan .................................319

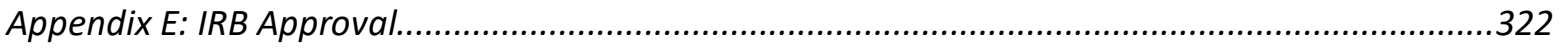

Appendix F: The NIST Request for Proposal, Selected Excerpts ...................................................326 


\title{
Authors
}

Report 2: $\quad$ Gender Differences in Salaries of NIST ZP Employees: Analysis of Personnel Data (J. Stockard, May 8, 2020)

Report 3: $\quad$ ZT and ZP I and II Employees at NIST: Analysis of Personnel Data (J. Stockard, June 1, 2020) Report 4: $\quad$ Federal Employee Viewpoint Survey: Comparison of Views within NIST Labs (J. Stockard, February 2, 2020)

Part II: $\quad$ Survey of ZP Employees Bands III and Higher

Introduction

Report 5: $\quad$ Survey of NIST ZP Employees: Summary of Findings (J. Stockard, May 12, 2020)

Report 6: $\quad$ Analysis of a COACh-Sponsored Survey to NIST ZP Employees Distributed in March 2020 (J. Stockard, May 20, 2020)

Report 7: $\quad$ Open-Ended Comments Regarding Promotion on NIST Survey (C. Rohlfing, J. Tucker, and J. Stockard, September 14, 2020)

Part III: $\quad$ Focus Groups

Report 8: $\quad$ Summary of Focus Groups Conducted with NIST ZP Staff (M. Noviski and J. Tucker, February 5, 2021)

Report 9: $\quad$ Summary of Focus Groups Conducted with Group Leaders in December 2020 (M. Noviski and J. Tucker, February 5, 2021)

Report 10: Summary of ZT Focus Groups/Interviews in October 2020 (M. Noviski and J. Tucker, February 5, 2021)

\section{Part IV: $\quad$ Recommendations for Change}

Report 11: Equity action plan (March 25, 2021)

\author{
Appendices: \\ A \\ Professional Development Opportunities and Coursework Requested by Group \\ Leaders, ZP and ZT Staff (J. Tucker and C. Rohlfing, March 25, 2021) - professional \\ development \\ B Focus group guide (J. Tucker) \\ C Survey distributed in March 2020 \\ D Communications Plan (February 2021) \\ E IRB approval and consent forms for surveys and focus groups \\ $\mathrm{F} \quad$ Excerpts from the Request for Proposal (RFP)
}




\section{Introduction}

In early 2019, the National Institute of Standards and Technology (NIST) solicited proposals to conduct an "Analysis of Equity Disparity and Resolution to Known Equity Disparity Regarding STEM Career Advancement." It called for "an expert, outside party to design and implement a data-driven study to examine the causes of inequity in promotions at NIST, and to develop draft recommendations." In late 2019, the contract to conduct this study was awarded to COACh (Committee on the Advancement of Women in Chemistry), a grassroots organization based out of the University of Oregon with a mission to increase the number and success of women and underrepresented groups in science and engineering. This document includes reports of our data analyses and recommendations. A separate document, NIST GCR 21-030, includes a review and annotated bibliography of scholarly and policy-related literature that informed our work entitled, "Supporting women and Under-Represented Minorities in the Sciences: Implementing Equitable Approaches to Organizational Change" by Maya Noviski.

The COACh team included both physical and social scientists, with a broad range of skills and expertise. Members included:

- Geraldine Richmond, Presidential Chair in Science and Professor of Chemistry at the University of Oregon, and the founding and current director of COACh.

- Celeste Rohlfing, a chemist who worked at DOE national labs, was the Deputy Assistant Director of the Mathematical and Physical Sciences Directorate at the National Science Foundation, and retired as Chief Operating Officer from American Association for the Advancement of Science.

- Jean Stockard, a quantitative sociologist, who is Professor Emerita at the University of Oregon and senior research director for COACh.

- Jane Tucker, a specialist in organizational development, and Principal at J. Tucker Associates.

- Barbara Butterfield, a specialist in human resources and leadership training, and Senior Consultant at Sibson.

- Maya Noviski, a candidate for Master of Public Administration at the University of Oregon, and highly skilled in examining social science and policy related literature.

- Priscilla Lewis, with an academic degree in business administration, is the COACh Coordinator at the University of Oregon.

While most of the reports in this document were authored by only some of the team members, all on the team provided feedback and consultation in each element of the work.

We took a deliberate, multi-step approach to understanding issues related to promotion for the permanent Federal STEM workforce at NIST, specifically those classified as ZT, ZP, and ST. These correspond approximately to positions as technicians, scientists and engineers, and NIST Fellows. All of our activities were reviewed and approved by the University of Oregon and NIST Institutional Review Boards (IRB) for Research on Human Subjects. Throughout the work, as 
explained in the reports that follow, we were very careful to ensure that responses were confidential, both in the way in which data were gathered and in the written reports.

In late 2019, shortly after the contract was awarded, we met with NIST management and staff to understand more about the promotion process and views of potential issues related to equity. In-person visits were made to the NIST campuses in Gaithersburg, MD and Boulder, Colorado, and videoconferences and phone conversations were held with those at other locations. We interviewed management-level employees in all areas that had scientific staff, met with staff who were actively involved in equity-related issues, and also held sessions open to all interested staff and management. From these listening sessions, it became apparent that many NIST employees held strong views regarding the promotion process. These views informed hypotheses that were tested in following steps.

Shortly after the listening sessions, the NIST Office of Human Resources provided data on personnel actions at NIST from 2000 to 2019. These data were used to examine the extent to which there were disparities in promotion opportunities at NIST and, especially, the way in which these were related to status characteristics of gender and minority identification. This analysis was guided, in large part, by sentiments that had been expressed in the listening sessions. Contrary to what many had expressed in the listening sessions, the analysis of the HR data did not support this perception. For instance, there was little evidence from the available data that women remained in a pay band for significantly longer periods than men, that they were significantly less likely to hold supervisory positions, or that they had lower salaries at the time of hire. We also reviewed summaries of responses to questions regarding workplace climate in the Federal Employee Viewpoint Survey (FEVS). Detailed reports of these analyses are in Part I (Reports 1 to 4 ).

The next major step of our work was an internet-based survey of all ZP employees at pay band III and up, distributed in April 2020. Over 600 employees responded, representing about a third of those who received the invitation to participate. More than 250 of the respondents gave extensive open-ended comments. Analysis of respondents' reports of their time at pay band and years before obtaining promotion were similar to the results from the HR data. Our analyses of views regarding the promotion process indicated that concerns were not limited to certain subsets of employees. Instead, widespread concerns were voiced by both men and women and by employees at all pay bands. Only a minority voiced positive views, and early-career employees were least likely to believe that the promotion process was fair or transparent. Detailed reports of these analyses are in Part II (Reports 5 to 8).

The final data collection step of our work was focus groups with ZP and ZT staff and Group Leaders. The groups were designed to learn more about employee and supervisor views of the promotion process and help inform our recommendations for avenues for change. Part III includes the reports of these efforts and analyses of these qualitative data (Reports 9 to 11). 
Our recommendations for developing a more transparent promotion process that is seen as fair and equitable by all staff are detailed in Part IV. Appendices to this document include supplementary material that could be helpful to managers as well as those interested in replicating this work in other organizations: A) courses and professional development opportunities that ZT staff, ZP staff, and Group Leaders believe are valuable to career progress and potential for promotion; B) a guide for conducting focus groups; C) questions included in the March 2020 survey; D) a communications plan submitted to NIST management in February 2021; E) the approval from Institutional Review Boards and the consent forms used for the work; and F) excerpts from the Request for Proposal (RFP) that was the basis for the contract.

Our work was informed by a thorough literature review on equity within organizations and organizational change. A separate document (NIST GCR 21-030) includes this review and an extensive annotated bibliography, "Supporting Women and Under-represented Minorities in the Sciences: Implementing Equitable Approaches to Organizational Change", by Maya Noviski.

Throughout the 18-month project, all on the COACh team were extraordinarily impressed by the excellence and goodwill of NIST staff and management: their dedication to science, their concern for fellow employees, and the extent to which they value their contributions to NIST and the nation as a whole. We were also impressed with, and grateful for, the welcome that they provided to us and the support for our endeavors. We especially thank Heather Evans, Danni Leicht, and Jim Olthoff for giving generously of their time and guidance. It is not easy to step back and examine potential problems within an organization, let alone to ask that recommendations for change be data-based. We submit these documents with the greatest respect for all NIST employees and with the hope that these suggestions will help further the NIST core values of perseverance, integrity, inclusivity, and excellence. 


\section{Part I: \\ Analyses of Archival Data from Human Resources}

COACh was given two data sets from the NIST Human Resources office: 1) a "yearly data" set on pay band classification and demographic characteristics of NIST employees in 2000, 2005, 2010, 2015 and 2019; and 2) a "personnel action" data set that listed all personnel actions from 2000 to 2019. Three reports were generated from these data, looking at data regarding promotion of ZP employees in Bands III, IV, and V (Report 1), gender differences in salaries of ZP employees (Report 2), and experiences of ZT employees and ZP employees at Bands I and II (Report 3). We were also given aggregated data (at the OU level) from the Federal Employment Viewpoint Survey (FEVS), and our analysis of those data are given in Report 4. The paragraphs below summarize key findings from these analyses.

\section{ZP Employees Bands III to V (Report 1)}

Overall, the percentage of women classified as ZP and in Bands III to V increased slightly from 2000 to 2019 (from $20 \%$ in 2000 to $25 \%$ in 2019). The percentage of women at Band III displayed very little change (from $28 \%$ in 2000 to $29 \%$ in 2019), but the percentage at Band IV increased markedly (from $19 \%$ to $26 \%$ ) and, by 2015 , exceeded the percentage of women in the total group. The percentage of women at Band $V$ also increased over time but by 2019, was still markedly smaller than their representation in the total group (Table 1). Employees identified as Underrepresented Minorities (URMs) comprised only a very small percentage of NIST ZP employees, representing less than $6 \%$ of the total in each of the years. The number was too small to allow additional analyses, highlighting the potentially very serious issue of underrepresentation of this group (Table 2).

Preliminary conversations with NIST employees indicated a perception that women faced "blocks" to their advancement, as in remaining at Band for longer periods of time or having fewer opportunities for supervisory posts. However, we found little support for this hypothesis, especially in recent years (Tables 3 to 5 ).

Employees also suggested that there were differences in the pattern of gender representation across Bands between NIST sites and operating units. We found no indication of differences by site, but some differences by operating unit (Tables 6 and 7).

Employees had also expressed concerns regarding a relatively large proportion of the NIST work force being eligible for retirement and overly represented in the highest ranks, and these perceptions were substantiated (Tables 8 to 10). To help control for this factor subsequent analyses in this report were conducted for both the total group of employees and omitting retirees.

Regression analyses were used to examine gender differences in rank when years of employment at NIST was equalized (Tables 11 to 15). Analyses for 2015 and 2019 data controlled 
for operating unit. ${ }^{1}$ Results for the more recent year showed that men had slightly greater odds of being at a higher pay band. However, the pattern varied across operating units especially regarding the transition from III to IV. In the one organizational unit found to be an outlier in bivariate analyses the odds in favor of men were 1.66 for the total group and 1.63 for the sample not yet eligible for retirement. In other operating units, men had smaller odds than women of making the transition (odds ratios of .92 and .84 respectively). Men were more likely than women with similar years of experience to make the transition from IV to $\mathrm{V}$, but the odds in favor of men were again larger in the one operating unit ( 1.79 for total group and 1.40 for those not eligible for retirement) than in the other units ( 1.51 for total group and 1.26 for those not eligible for retirement, details in Table 15). ${ }^{2}$

A distribution of employees across the pay bands within an organization can result from patterns of hiring and retention as well as the process of promotion. Analysis of the personnel action file indicated little change from 2000 to 2019 in the probability that women would be hired and a slight tendency for a greater rate of separations. However, there was no indication that women were less likely than men to experience promotions (Table 16). Minorities were hired more frequently than their representation in the total group, but they experienced higher separation rates, and the rates of separation increased markedly over time. Promotion and conversion rates were higher than or similar to their representation within the labor force (Table 17).

The personnel action file also included information on the time that had elapsed since a prior personnel action. Men had somewhat longer periods, paralleling results regarding time in band obtained from the yearly file (Mean=6.6 for women, 7.7 for men, $t=2.80, p=.005$ (two-tail); Cohen's $d=.19$ ).

NIST employees had also suggested that women in postdoctoral positions were less likely to move to regular positions within the organization. However, the personnel data file indicated that women in postdoctoral positions were slightly more likely to have positions converted to regular positions ( $41 \%$ for women and $38 \%$ for men) and less likely to be separated ( $50 \%$ for women and $52 \%$ of men).

\section{Gender Differences in ZP Salaries (Report 2)}

This report examined a suggestion that women ZP employees at NIST had lower salaries than men with similar employment characteristics, such as pay band, years of employment and operating unit. They also suggested that the gender differences first appeared at the time of hire

\footnotetext{
${ }^{1}$ To simplify presentations, these analyses focused on the transition from Band III to Band IV and from Band IV to Band V. Logistic regressions were used to calculate the odds that men would be at the higher Band (IV rather than III or V rather than IV) if employees had been employed at NIST for an equal number of years. With the 2015 and 2019 data mixed model logistic regressions were used with operating unit as a random effect.

2 The odds in favor of men for the transition from IV to $V$ were near or at traditional levels of statistical significance $(.05)$ for the total sample, but not for the group that was not yet at retirement age.
} 
and then became larger over time. The yearly and personnel data sets were analyzed to examine this issue.

In fall 2019, men NIST employees classified as ZPs had, on average, higher salaries than women, and differences were stronger at higher pay bands (a difference of .07 SD at Band III, .13 at Band IV, and .23 at Band V and higher). The magnitude of the gender difference varied from one OU to another. (See Tables 1 and 3.) However, at each Band men had longer tenure than women (i.e. had been at band for more time). (See Table 2).

Mixed model regressions were used to estimate differences in salaries with OU and years of employment controlled. Separate analyses were conducted for employees in Bands III, IV, and $\mathrm{V}$ and higher. Operating unit was a random variable. Results indicated that men had higher salaries than women at each band (\$680 for those at Band III, \$870 at Band IV, and \$220 at the highest bands), but none of these differences was large enough to be statistically significant.

Among ZP employees at Band III and employed for 5 years or less, the pattern of gender differences in salaries was not consistent, differing between those most recently hired and those with more experience. Among those with less than one-year experience women had higher salaries, but among those with more experience, men had higher average salaries (Table 5).

Data from the personnel action file were used to examine gender differences in salaries at the time of hire from 2000 to 2019 for those hired at Band III and Band IV. The data indicated no clear pattern in gender differences in salary at the time of hire. In some years women earned more and in others men did, and the differences were rarely large enough to be statistically significant or substantively strong. Unfortunately, it was not possible to separate results by operating unit. However, from this admittedly limited, analysis there appears to be little support for the suggestion that women routinely received lower salaries at hire than do men. (Table 6)

\section{ZT and ZP I and II Employees (Report 3)}

From 2000 to 2019 the number of ZT employees declined (Table 1), but the proportion of ZT employees at higher bands increased. At the same time, the percentage of women and those who identified as URM within this group declined slightly (Table 3). Net of years of employment at NIST, men and non-URM were at higher bands, but there was less disparity in 2019 than in earlier years (Tables 8 to 12). Gender disparities were greater for the transition from III to IV than from II to III, paralleling results with the analyses of ZP employees at higher Bands. Disparities in hiring and retention appear to have contributed to the declining representation of women and minorities over time. In addition, hiring has not kept pace with the national pool of STEM employees who are women or identify as URM (Tables 13 and 14). Women and those who identified as URM were slightly more likely than others to be eligible for retirement (Table 6). This finding differs from that with the ZP's in Bands III and higher and could exacerbate issues of their representation in the future. 
In 2019 there were fewer than 100 ZP employees at Bands I and II, and the majority were described as "trainees." This number was deemed too small for extensive statistical analyses. Women and URM employees were more often at Band II than Band I, but the representation of women at Band II declined significantly from 2000 to 2019 (from 49\% to 24\%, see Tables 15 and 16). As with the ZT's, women and minority ZP's in Bands I and II appeared to be less often hired and more often separate from NIST than would be expected given their representation in the ZT Band I and II workforce (Table 17). Promotions or conversion of positions rarely occurred for employees in these ranks (Tables 18 and 19).

\section{Federal Employment Viewpoint Survey (Report 4)}

This short report summarized data on 71 questions regarding workplace climate from the Federal Employment Viewpoint Survey (FEVS) in laboratory operating units (OUs) at NIST using aggregate data from the $4^{\text {th }}$ level sub agency reports (i.e. comparing average values across OUs). The analysis indicated that responses to questions involving promotion, evaluation, commitment to diversity, and managerial practices were significantly more negative in OU-C. Employees in that OU were also significantly less likely to believe that the findings of the FEVS would be used to improve the agency. 


\section{Report 1: NIST Promotion Patterns: Analysis of Personnel Records ${ }^{3}$}

This report summarizes analyses of two data sets provided to our research team: 1) data on the pay band classification of employees in 2000, 2005, 2010, 2015 and 2019, called the "yearly data set" and examined in the first major section of this report; and 2) a listing of all personnel actions from 2000 to 2019, called the "personnel action data set" and examined in the second major section. All analyses are limited to scientific and technical employees (ZP classification) in Bands III, IV, and V. They were designed to examine the concern that the proportion of women and under-represented minorities (URM) at higher pay bands may not have changed markedly from 2000 to 2019. A final section provides reflections upon the findings.

\section{Analysis of Yearly Data Set}

The yearly data set provided the data that motivated COACh's contract with NIST. A previous analysis of the data that we were given displayed graphs depicting the percentage of women and URM employees at each pay band in each of the five years. The first sub-section provides the numbers that we believe were used in those graphs. Subsequent subsections address concerns that were voiced during our recent visit to NIST, including a worry that women may have been blocked in advancement opportunities, that patterns of equity may vary across NIST sites and/or operating units, and that the somewhat unique nature of the age distribution of NIST employees may be related to patterns of inequity. In the final section multivariate statistics are used to provide estimates of gender discrepancies in advancement across the three pay bands.

\section{Pay Band by Gender and URM Status}

Table 1 reports the representation of women at each band and in the total group of ZP employees at NIST in each of the five years. Over time more women have been employed at NIST, with the percentage of women in the ZP group growing from 20\% in 2000 to 25\% in 2019. Interestingly, the percentage of women at Band III displayed very little change over time (from $28 \%$ in 2000 to $29 \%$ in 2019), but there was marked change in the percentage of women at Bands IV and V. By 2015 the percentage of women at Band IV exceeded the percentage in the total set of employees. The percentage of women at Band $V$ increased over time but by 2019, was still markedly smaller than their representation in NIST as a whole.

Table 2 provides parallel information regarding under-represented minorities. Most notably, URMs comprised only a very small percentage of NIST ZP employees, representing less than $6 \%$ of the total in each of the years. The percentage of URM employees at Band III declined slightly over time, while the percentage at Bands IV and V increased. However, given the relatively small numbers involved in these comparisons, most of the remaining analyses focus on

\footnotetext{
${ }^{3}$ This report was written by J. Stockard and was completed on January 8, 2020.
} 
differences between men and women. This omission is not meant to imply that the issue of disparities related to minority status is unproblematic. In fact, the issue appears to be very serious, but the numbers are so small that statistical analyses regarding multiple variables could be seen as problematic and unreliable.

\section{Blocked Advancement?}

Some of the conversations that our team had with NIST employees revealed a concern that women might face impediments to advancing through the pay band structure in the organization. We examined this issue by looking at gender differences in the number of years of employment at NIST, the years spent in band, and whether or not employees held supervisory positions.

If women have been blocked in advancement opportunities at NIST one could expect that those at lower bands would have been employed at NIST for longer periods of time; and the data reported in Table 3 assess this possibility. The top lines report the average years of NIST employment of men and women employees for each band and year. The bottom three lines report the results of an analysis of variance testing the hypothesis that differences by band and gender were greater than would be expected by chance. As would be expected, the F-ratios associated with band were highly significant. At all time periods, employees at higher bands had more years of NIST experience and those at lower bands had fewer years of experience. In all years at Band III and in 2005 through 2019 at Band IV women had more experience than men, as would be expected by the "blocked advancement" hypothesis. However, the differences were markedly smaller in more recent years and, especially at Band IV, very small. At Band V women tended to have fewer years of experience than men. The varying patterns of gender differences by band was large enough in 2000 and 2005 to result in the significant interaction effect shown in the last line of Table 3 for those years.

The second method of examining the blocked advancement hypothesis focused on the average years that employees had been at a pay band. (These data were only available for 2010 and later.) A longer period at band could indicate the presence of blocks to advancements. Results for this test are in Table 4 and follow the format used for Table 3. The results do not support the hypothesis. In almost all comparisons, men had been at band longer than women, and these differences were significant for 2010 and 2019. There were no significant interactions.

As a final way to examine the blocked advancement hypothesis we examined gender differences in holding supervisory positions, with results shown in Table 5. (Again, data were only available for 2010 and later.) Chi-square values test the hypothesis that the representation varies by gender. In each year men were slightly more likely than women to hold supervisory posts, but this difference was not large enough to be statistically significant.

Taken together, the data in Tables 3 to 5 provide relatively little support for the blocked advancement hypothesis, especially in recent years. There was relatively little indication in these years that, within each band, women had longer tenures at NIST than men, that they had 
remained at band for longer periods, or that they were significantly less likely to be in supervisory positions.

\section{Differences by Site and Operating Unit}

Some of the employees that we talked with suggested that issues of equity differed between NIST sites and by operating unit, and we also examined that hypothesis. Table 6 parallels the construction of Table 1, comparing the percentage of women in the total set of ZP employees with those in each band. The top panel gives results for the Maryland campus, and the bottom panel gives results for the Colorado campus. In both sites women were over-represented in Band III and under-represented in Band V, but the discrepancies were smaller in 2019 than in earlier years - a pattern that was documented for the total set of ZP employees in Table 1.

Table 7 examines differences by operating unit for 2015 and 2019, the only years for which reliable information on operating unit was available. Each row reports data for a different operating unit. Data in columns report the percentage of women at each pay band and as the total workforce within an operating unit. The row in each panel labeled "total" reports the percentage of women among NIST ZP employees as a whole. Thus, the percentages for each operating unit can be compared to these total figures. Analysis of variance was used to examine the extent to which the representation of women varied by band, operating unit and year. The results, which are summarized in the footnote to Table 7 , indicated that there was a significant operating unit by band interaction; that is, that the distribution of women by pay band differed from one operating unit to another. The results with OU-C are most striking. In total about $30 \%$ of OU-C ZP employees in 2019 were women, but 39\% were at Band III and only $17 \%$ at Band V. Differences were smaller in other operating units. And, in some operating units women were less likely to be at Band III than would be expected given their overall representation (OU-D) or "overrepresented" at Band V (OUs B and D).

\section{$\underline{\text { Age Structure }}$}

A number of people with whom we talked mentioned the relatively large proportion of NIST employees who continued to work in the organization after becoming eligible for retirement and wondered if this might be related to advancement opportunities for those who were younger. The percentage of NIST employees who were eligible for retirement varied over time from $7 \%$ in 2000 and $11 \%$ in 2005 , to $20 \%$ in $2010,24 \%$ in 2015 , and $17 \%$ in 2019 . The majority (71\%) of those who were eligible had been employed at NIST or other government agencies for at least 20 years and were 60 years old or older. One fourth of those who were eligible had been employed for five years and were 62, and the remainder had shorter employment tenures but were 66 years old or older. Those who were eligible for retirement were much more likely than other employees to be at the highest band (Table 8), to have been employed at NIST for longer periods of time, and to be men rather than women (Table 9). In addition, in 2019 OU-G had more employees eligible for retirement than other operating units, while OU-D had substantially fewer 
who were eligible (Table 10). In the multivariate analyses summarized in the next section results are presented for all employees and when those who were eligible for retirement were excluded.

\section{$\underline{\text { Regressions of Pay Band on Gender and Control Variables }}$}

Multiple regression techniques were used to develop a more parsimonious understanding of the association of gender and advancement within NIST. To simplify the presentation the analysis focused on the transition from Band III to Band IV and from Band IV to Band V. Logistic regressions were used to calculate the odds that men would be at the higher Band (IV rather than III or V rather than IV) if employees had been employed at NIST for an equal number of years.

Tables 11 and 12 show the results obtained with simple logistic regressions for each of the years in the data set. Table 11 reports the adjusted odds of being in Band IV rather than Band III and Table 12 reports the odds of being in Band V rather than Band IV. The top panel of each table reports results for the total group and the bottom panel reports results when those who were eligible for retirement were omitted.

Results in Table 11 indicate that among the total group of employees men had greater odds than women of being in Band IV rather than III (odds ratios greater than 1.0) when years employed at NIST was controlled. This difference was statistically significant from 2000 to 2010, but substantially smaller and insignificant in 2015 and 2019. Among employees who were not yet eligible for retirement men had greater odds of being in Band IV rather than Band III in 2000 to 2010 and in 2019, but this was again only statistically significant in from 2000 to 2010. In addition, the odds in favor of men were smaller among this group and the odds for 2015 were approximately equal for men and women (odds ratio $=0.99$ ).

Results in Table 12 indicate that men had greater odds than women of being at Band $\mathrm{V}$ rather than Band IV, once years employed at NIST was controlled. This advantage was statistically significant in all years for the total sample but only for 2000 and 2015 for the analysis that omitted employees who were eligible for retirement.

Tables 13 and 14 present results of mixed model logistic regressions that control for differences among the operating units (using operating unit as a random variable); and thus, should be seen as more accurate than results shown in Tables 11 and 12 . Because reliable information on operating unit was only available for 2015 and 2019, results are only given for those years. The top panels of these tables report results for 2015 and the bottom panels have results for 2019. Columns on the left give results for the total sample, and columns on the right give results for the sub-sample not yet eligible for retirement.

Table 13 reports the comparison of Bands III and IV. Men had slightly greater odds of being at Band IV than Band III in three of the four comparisons, but none of these comparisons was statistically significant and the odds ratios were relatively small, especially for the group of employees who were not yet eligible for retirement (.93 in 2015 and 1.06 in 2019). Table 14 reports results for the comparison of Bands IV and V. Men had greater odds of being in Band V 
than Band IV in all comparisons, and this was significant with both samples in 2015 and with the total group in 2019.

Because the gender disparities appeared to be more striking within the OU-C division, we conducted one additional set of multivariate analyses, regressing pay band on gender and years at NIST for those who were in OU-C and those in other operating units. Results, in Table 15, are reported only for 2019, assuming that the most current findings would be of greatest interest. The differences in results for OU-C and other operating units is especially notable for the transition from Band III to Band IV. In OU-C the odds in favor of men were 1.66 for the total group and 1.63 for the sample not yet eligible for retirement. In other operating units, men had smaller odds than women of making the transition (odds ratios of .92 and .84 respectively). In all comparisons men were more likely than women with similar years of experience to make the transition from IV to $\mathrm{V}$, but the odds in favor of men were larger in OU-C than in the other operating units. In all analyses, the odds of men attaining the higher pay band were greater within OU-C than in the other operating units. In addition, as in other analyses, the odds in favor of men were smaller in the sample of employees not yet eligible for retirement.

\section{Personnel Actions}

The second data set provided to COACh was a listing of all personnel actions within NIST from 2000 to late 2019. Data were organized by type of personnel action. Thus, individuals might be included in the file more than one time if they had more than one action over the time period. Also, if individuals did not have a personnel action they would not be in the file. Yet, this data file was useful to examine personnel decisions related to career advancement in addition to promotion. A distribution of employees across the pay bands within an organization can result from a variety of factors - most especially the hiring process and retention of employees who are hired, as well as the process of promotion. To facilitate comparisons of the data from the personnel file with the yearly data discussed in the previous section the actions were grouped into five categories corresponding to the years available for the yearly data: 2000 to June 30, 2002 (for 2000); July 1, 2002 to June 30, 2007 (for 2005); July 1, 2007 to June 30, 2012 (for 2010); July 1, 2012 to June 30, 2017 (for 2015); and July 1, 2017 and later (for 2019).

Table 16 reports the frequency of different types of personnel actions for women in each type period. The numbers in the table are the percentage of a given action that involved women; the corresponding numbers for men could be calculated by subtracting from 100 . For each type of action chi-square values were calculated, testing the hypothesis that the probability that women would experience a given action varied over time (the association of gender and time). None of these associations were significant. In other words, over time, there was no change in the probability that women experienced a given action. The final column, labeled "total," is the percentage of women in the NIST scientific labor force, as obtained from the yearly data.

The data regarding hiring and separations are especially noteworthy. Over the 19 years in the data set, there were 3,000 hiring events and about one-quarter involved women. However, 
the largest percentage was in the earliest year and there was no indication that the hiring of women increased over time, even though it is quite possible that the potential pool of women with PhDs in relevant fields increased over that period. Over time one-fourth of all the separations from NIST employment involved women and the percentage of women experiencing separation was slightly greater than their overall representation in the labor force in each of the time periods. The data regarding promotion indicate that the percentage of promotion actions involving women was slightly larger than the percentage of women within the NIST labor force in each of the years. Thus, although there was not an increase in hiring of women and women may have been more likely to leave NIST, they did not appear less likely than men to be promoted.

The personnel action file also included information on the time that had elapsed since a prior personnel action. These data were used to test the hypothesis that women might have to wait longer for promotion than men. But, contrary to the hypothesis, men had somewhat longer periods of time, paralleling results regarding time in band discussed in the previous section. The average for women was 6.6 years and for men was 7.7 years ( $t=2.80, p=.005$ (two-tail); Cohen's $d=.19$ ). Data regarding postdocs was also available and used to examine the possibility that women were less likely to convert their postdocs to regular positions or that they might be more likely to be separated from employment. Again, however, there were no differences in experiences of men and women. Regarding conversions, $41 \%$ of women postdocs and $38 \%$ of men had positions converted; with separation, $50 \%$ of women postdocs and $52 \%$ of men were separated. Thus, women post-docs were slightly less likely to be separated and more likely to be converted to regular positions.

Table 17 looks at personnel actions involving under-represented minorities, using the same format as used with Table 16. While the data regarding hiring indicate that minorities were hired more frequently than their representation in the total group, they experienced higher separation rates, and the rates of separation increased markedly over time. Promotion and conversion rates were higher than or similar to their representation within the labor force.

\section{Summary Thoughts}

The analysis presented above provided several key conclusions regarding gender disparities in pay bands of ZP employees (looking only at Bands III, IV, and V) from 2000 to 2019. Over this time period the percentage of women at Band IV increased to match the percentage of women in the total group of employees although, by 2019, women were still under-represented at Band V. There was little evidence from the available data that women remained in band for significantly longer periods than men or that they were significantly less likely to hold supervisory positions. Overall patterns were similar in the Colorado and Maryland sites. But issues of inequity appear to be much more serious within OU-C than in other operating units. A substantial proportion of NIST employees are eligible for retirement and the vast majority of these employees are at higher bands. When analyses are limited to those who are not eligible for retirement inequities are generally smaller. Analysis of the personnel data file indicated little 
increase in the hiring of women over time and that women were more likely to leave NIST employment than would be expected given their representation in the employee pool.

The number of under-represented minorities was too small to allow reliable bivariate or multivariate statistical analyses, and this small number must be noted. In addition, the analysis of the personnel data file indicated a declining number of hires of URM employees over time and higher rates of separation than would be expected given the employee pool. There did not appear to be discrepancies, at least from the personnel action data, in rates of promotion.

Several issues might be noted for further consideration. First, the extent of gender disparities in promotion patterns does not appear to be quite as serious as was implied in the request to which COACh responded. It is, of course, possible that NIST has other analyses that would contradict the data shown here, but it appears that women have become more likely to be promoted over time and that disparities that occur are concentrated within one operating unit and involve the movement from Band IV to Band V rather than from Band III to Band IV.

At the same time, our conversations with NIST employees indicated a perception that there was a problem and this perception should not be discounted. One could hypothesize that employees of many different characteristics perceive that there are issues with advancement at NIST. In other words, it is possible that issues regarding promotion are more widespread and involve all employees, not just women or under-represented minorities. This possibility can and should be examined with our survey work.

The findings related to the age of employees must also be noted. Around a fifth of NIST employees are eligible for retirement and they are disproportionately men and in the highest band. This age structure, coupled with an apparent (or perceived) cap on the proportion of employees who can attain Band $\mathrm{V}$ would seem to make the probability of advancement much smaller for all employees, both men and women.

Finally, the lack of increase over time in the hiring of women and under-represented minorities, and the higher rates of separation for these employees, must be noted. We realize that we were only charged with examining promotions. However, as noted above, promotions can only occur if people are hired and retained in the organization. 


\section{Tables}

Table 1

Women as Percent of Employees by Band and Year

\begin{tabular}{llllll} 
Band & $\underline{2000}$ & $\underline{2005}$ & $\underline{2010}$ & $\underline{\underline{2015}}$ & $\underline{2019}$ \\
III & 28.0 & 27.0 & 32.7 & 27.8 & 29.3 \\
IV & 19.3 & 20.1 & 22.0 & 26.2 & 26.1 \\
V & 11.9 & 14.5 & 15.2 & 15.3 & 17.7 \\
Total (\%) & 19.5 & 19.5 & 22.9 & 23.9 & 24.8 \\
Total (N) & 1549 & 1464 & 1509 & 1893 & 1962 \\
\hline
\end{tabular}

Table 2

Under-Represented Minority Employees as Percent of All Employees by Band and Year

\begin{tabular}{lccccc}
\hline Band & $\underline{2000}$ & $\underline{2005}$ & $\underline{2010}$ & $\underline{2015}$ & $\underline{2019}$ \\
III & 8.4 & 6.8 & 5.1 & 6.9 & 7.0 \\
IV & 4.8 & 6.4 & 6.1 & 5.7 & 6.6 \\
V & 1.9 & 1.9 & 2.5 & 2.9 & 2.6 \\
Total & 4.9 & 5.2 & 4.8 & 5.3 & 5.7 \\
Total (N) & 1549 & 1464 & 1509 & 1893 & 1962 \\
\hline
\end{tabular}


Table 3

Average Years of Employment at NIST Employees by Band, Gender, and Year

\begin{tabular}{|c|c|c|c|c|c|c|c|c|c|c|}
\hline \multirow[b]{2}{*}{ Band } & \multicolumn{2}{|c|}{$\underline{2000}$} & \multicolumn{2}{|c|}{$\underline{2005}$} & \multicolumn{2}{|c|}{$\underline{2010}$} & \multicolumn{2}{|c|}{$\underline{2015}$} & \multicolumn{2}{|c|}{$\underline{2019}$} \\
\hline & Women & Men & Women & Men & Women & Men & Women & Men & Women & Men \\
\hline III & 9.9 & 6.6 & 10.1 & 7.5 & 7.5 & 6.5 & 6.9 & 5.0 & 6.3 & 5.3 \\
\hline IV & 13.2 & 13.3 & 14.7 & 14.2 & 15.2 & 14.0 & 13.7 & 13.4 & 13.5 & 13.3 \\
\hline V & 15.6 & 19.7 & 15.3 & 19.2 & 17.9 & 19.0 & 20.5 & 20.4 & 18.8 & 21.9 \\
\hline Total & 12.4 & 13.7 & 13.6 & 14.5 & 12.9 & 13.8 & 12.8 & 13.3 & 12.4 & 13.8 \\
\hline F-Band & $59 * * *$ & & $47^{* * *}$ & & $128 * * *$ & & $179 * * *$ & & $193 * * *$ & \\
\hline F-Gend & 0.19 & & 0.07 & & 0.39 & & 1.64 & & 1.23 & \\
\hline F-Int. & $8.76 * * *$ & & $7.70 * * *$ & & 1.33 & & 1.00 & & $4.03^{*}$ & \\
\hline
\end{tabular}

$* * *$ indicates $\mathrm{p}<.001, * *$ indicates $\mathrm{p}<.01, *$ indicates $\mathrm{p}<.05$

Table 4

Average Years at Band by Band, Gender, and Year

\begin{tabular}{|c|c|c|c|c|c|c|}
\hline \multirow[b]{2}{*}{ Band } & \multicolumn{2}{|c|}{$\underline{2010}$} & \multicolumn{2}{|c|}{$\underline{2015}$} & \multicolumn{2}{|c|}{2019} \\
\hline & Women & $\underline{\text { Men }}$ & Women & Men & Women & Men \\
\hline III & 4.4 & 4.9 & 4.5 & 4.1 & 4.3 & 4.5 \\
\hline IV & 8.5 & 9.8 & 7.9 & 9.5 & 8.4 & 9.5 \\
\hline V & 8.5 & 9.8 & 10.3 & 10.5 & 9.2 & 11.2 \\
\hline Total & 7.0 & 8.7 & 7.3 & 8.5 & 7.4 & 8.8 \\
\hline F-Band & $63.03 * * *$ & & $68.63 * * *$ & & $65.71 * * *$ & \\
\hline F-Gender & $6.19 * *$ & & 1.14 & & $6.82^{* *}$ & \\
\hline F-Int. & 0.53 & & 2.73 & & 1.21 & \\
\hline
\end{tabular}

$* * *$ indicates $\mathrm{p}<.001, * *$ indicates $\mathrm{p}<.01, *$ indicates $\mathrm{p}<.05$. Data provided only for 2010 and later.

Table 5

Percent Holding Supervisory Posts by Year and Gender

\begin{tabular}{|c|c|c|c|c|c|c|}
\hline & \multicolumn{2}{|c|}{$\underline{2010}$} & \multicolumn{2}{|c|}{$\underline{2015}$} & \multicolumn{2}{|c|}{$\underline{2019}$} \\
\hline & Women & Men & Women & $\underline{\text { Men }}$ & Women & Men \\
\hline$\%$ yes & 11.6 & 13.8 & 11.6 & 13.0 & 13.1 & 14.7 \\
\hline Chi-square & 1.41 & & 0.75 & & 0.78 & \\
\hline Prob. & 0.24 & & 0.39 & & 0.38 & \\
\hline
\end{tabular}


Table 6

Women as Percent of Employees by Band, Year, and Site

\begin{tabular}{|c|c|c|c|c|c|}
\hline \multicolumn{6}{|c|}{ Maryland } \\
\hline Band & $\underline{2000}$ & $\underline{2005}$ & $\underline{2010}$ & $\underline{2015}$ & 2019 \\
\hline III & 28.7 & 26.3 & 32.7 & 28.7 & 29.0 \\
\hline IV & 20.4 & 20.6 & 23.0 & 26.9 & 26.3 \\
\hline V & 13.1 & 16.1 & 16.6 & 16.6 & 18.6 \\
\hline Total (\%) & 20.3 & 20.5 & 23.6 & 24.6 & 25.0 \\
\hline Total (N) & 1317 & 1232 & 1389 & 1562 & 1603 \\
\hline \multicolumn{6}{|c|}{ Colorado } \\
\hline Band & $\underline{2000}$ & $\underline{2005}$ & $\underline{2010}$ & $\underline{2015}$ & $\underline{2019}$ \\
\hline III & 26.0 & 27.8 & 24.2 & 19.5 & 24.0 \\
\hline IV & 11.6 & 17.0 & 16.5 & 20.9 & 21.6 \\
\hline V & 4.0 & 6.3 & 8.2 & 6.6 & 12.7 \\
\hline Total (\%) & 14.9 & 16.6 & 16.5 & 17.3 & 20.1 \\
\hline Total (N) & 222 & 217 & 224 & 277 & 308 \\
\hline
\end{tabular}

Note: Other sites not included because of small sample size. 
Table 7

Percentage of Women by Band and Operating Unit, 2015 and 2019

\begin{tabular}{lccccc}
\hline \multicolumn{5}{c}{2015} \\
\hline A & Band III & Band IV & Band V & Total & N \\
B & 19.6 & 37.2 & 28.0 & 33.3 & 351 \\
C & 11.9 & 20.9 & 12.5 & 16.5 & 133 \\
D & 38.6 & 26.1 & 13.0 & 28.8 & 490 \\
E & 9.1 & 12.5 & 22.2 & 13.3 & 60 \\
F & 19.8 & 17.8 & 10.1 & 15.8 & 374 \\
G & 20.8 & 15.3 & 15.4 & 16.8 & 185 \\
Total & 28.9 & 29.3 & 17.2 & 24.6 & 301 \\
N & 27.8 & 26.3 & 15.3 & 23.9 & 1894 \\
\hline & 493 & 918 & 483 & & \\
\hline A & & 2019 & & & \\
B & 31.5 & 31.4 & 37.3 & 32.2 & 388 \\
C & 16.7 & 14.5 & 26.7 & 17.0 & 88 \\
D & 38.8 & 27.7 & 16.7 & 29.5 & 482 \\
E & 13.3 & 15.4 & 44.4 & 18.4 & 76 \\
F & 19.6 & 21.4 & 11.6 & 18.1 & 432 \\
G & 20.3 & 20.0 & 13.8 & 18.0 & 194 \\
Total & 31.3 & 31.4 & 15.7 & 25.4 & 303 \\
N & 29.3 & 26.1 & 17.7 & 24.8 & 1963 \\
\hline Note: N & 474 & 997 & 492 & & \\
\hline
\end{tabular}

Note: $\mathrm{N}$ refers to the total number of employees in a given Band or operating unit. Analysis of variance with operating unit, Band, and year as factors revealed significant main effect for operating unit $(F=8.33, d f=6,3,814)$ and the interaction of operating unit and Band $(F=3.35, d f=12,3,815$, $\mathrm{p}=.0001)$. 
Table 8

ZP Employee Band by Year and Retirement Eligibility

\begin{tabular}{|c|c|c|c|c|c|}
\hline \multicolumn{6}{|c|}{ Not Eligible for Retirement } \\
\hline Band & $\underline{2000}$ & $\underline{2005}$ & $\underline{2010}$ & $\underline{2015}$ & $\underline{2019}$ \\
\hline III & 26.6 & 22.7 & 30.2 & 32.3 & 28.4 \\
\hline IV & 49.7 & 51.8 & 48 & 49.5 & 52.3 \\
\hline V & 23.7 & 25.5 & 21.8 & 18.2 & 19.2 \\
\hline Total & 100 & 100 & 100 & 100 & 100 \\
\hline $\mathrm{N}$ & 1,436 & 1,306 & 1,311 & 1,441 & 1,624 \\
\hline \multicolumn{6}{|c|}{ Eligible for Retirement } \\
\hline Band & $\underline{2000}$ & $\underline{2005}$ & 2010 & $\underline{2015}$ & $\underline{2019}$ \\
\hline III & 0.0 & 6.3 & 6.2 & 6.0 & 3.5 \\
\hline IV & 37.2 & 38.6 & 44.6 & 45.2 & 43.4 \\
\hline V & 62.8 & 55.1 & 49.2 & 48.8 & 53.1 \\
\hline Total & 100 & 100 & 100 & 100 & 100 \\
\hline $\mathrm{N}$ & 113 & 158 & 325 & 453 & 339 \\
\hline
\end{tabular}

Table 9

Gender and Average Years NIST Employment by Retirement

Eligibility and Year

\begin{tabular}{cccccc}
\hline & \multicolumn{2}{c}{ \% Male } & & \multicolumn{2}{c}{ Mean Years at NIST } \\
\cline { 1 - 2 } Year & Not Eligible & Eligible & & Not Eligible & Eligible \\
\cline { 2 - 3 } \cline { 5 - 6 } & 79.5 & 92.9 & & 12.3 & 28.7 \\
2000 & 78.7 & 91.1 & 12.8 & 26.7 \\
2010 & 75.2 & 84.9 & 11.3 & 23.2 \\
2015 & 74.6 & 81.0 & 9.8 & 24.0 \\
2019 & 73.4 & 84.1 & 11.0 & 25.5 \\
Total & 76.2 & 84.8 & 11.4 & 24.9 \\
\hline
\end{tabular}




\begin{tabular}{|c|c|c|c|c|}
\hline \multirow{3}{*}{$\frac{\text { Operating }}{\text { unit }}$} & \multicolumn{2}{|c|}{$\underline{2015}$} & \multicolumn{2}{|c|}{$\underline{2019}$} \\
\hline & & & & \\
\hline & Not Elig & Eligible & $\underline{\text { Not eligible }}$ & Eligible \\
\hline A & 78.6 & 21.4 & 85.6 & 14.4 \\
\hline B & 80.4 & 19.6 & 83.0 & 17.0 \\
\hline C & 78.8 & 21.2 & 83.0 & 17.0 \\
\hline D & 83.3 & 16.7 & 97.4 & 2.6 \\
\hline$E$ & 75.1 & 24.9 & 82.6 & 17.4 \\
\hline$F$ & 70.8 & 29.2 & 80.9 & 19.1 \\
\hline G & 69.8 & 30.2 & 76.2 & 23.8 \\
\hline Total & 76.1 & 23.9 & 82.7 & 17.3 \\
\hline $\mathrm{N}$ & 1441 & 453 & 1,624 & 339 \\
\hline Chi-Square & \multicolumn{2}{|c|}{$15.94, p=0.01$} & \multicolumn{2}{|c|}{$22.99, p=.001$} \\
\hline
\end{tabular}


Table 11

Logistic Regression of Band IV versus Band III on Gender and Years at NIST by Year and Sample

\begin{tabular}{|c|c|c|c|c|c|c|c|c|c|c|}
\hline \multicolumn{11}{|c|}{ Total Group } \\
\hline & \multicolumn{2}{|c|}{$\underline{2000}$} & \multicolumn{2}{|c|}{$\underline{2005}$} & \multicolumn{2}{|c|}{$\underline{2010}$} & \multicolumn{2}{|c|}{$\underline{2015}$} & \multicolumn{2}{|c|}{$\underline{2019}$} \\
\hline Ind. Var. & $\underline{\mathrm{OR}}$ & $\underline{z}$ & $\underline{\mathrm{OR}}$ & $\underline{z}$ & $\underline{\mathrm{OR}}$ & $\underline{Z}$ & $\underline{\mathrm{OR}}$ & $\underline{z}$ & $\underline{\mathrm{OR}}$ & $\underline{Z}$ \\
\hline Male & $1.82 * * *$ & 3.86 & $1.64 * *$ & 2.97 & $1.84 * * *$ & 4.09 & 1.12 & 0.85 & 1.22 & 1.49 \\
\hline Yrs NIST & $1.09 * * *$ & 9.46 & $1.08 * * *$ & 8.83 & $1.11^{* * *}$ & 11.8 & $1.11^{* * *}$ & 12.56 & $1.13^{* * *}$ & 12.36 \\
\hline Constant & $.54 * * *$ & -3.82 & $.67^{*}$ & -2.24 & $.43 * * *$ & -5.66 & $.67^{* *}$ & -3.04 & $.62^{* * *}$ & -3.55 \\
\hline$N$ & 1138 & & 1044 & & 1190 & & 1272 & & 1471 & \\
\hline Pseudo R² & 0.085 & & 0.08 & & 0.13 & & 0.13 & & 0.14 & \\
\hline \multicolumn{11}{|c|}{ Only Employees Not Eligible for Retirement } \\
\hline & \multicolumn{2}{|c|}{$\underline{2000}$} & \multicolumn{2}{|c|}{$\underline{2005}$} & \multicolumn{2}{|c|}{$\underline{2010}$} & \multicolumn{2}{|c|}{$\underline{2015}$} & \multicolumn{2}{|c|}{$\underline{2019}$} \\
\hline Ind. Var. & $\underline{\mathrm{OR}}$ & $\underline{\mathrm{Z}}$ & $\underline{\mathrm{OR}}$ & $\underline{Z}$ & $\underline{\mathrm{OR}}$ & $\underline{z}$ & $\underline{\mathrm{OR}}$ & $\underline{\mathrm{Z}}$ & $\underline{\mathrm{OR}}$ & $\underline{z}$ \\
\hline Male & $1.77 * * *$ & 3.68 & $1.61^{* *}$ & 2.77 & $1.70 * * *$ & 3.39 & 0.99 & -0.09 & 1.14 & 0.92 \\
\hline Yrs NIST & $1.08 * * *$ & 8.66 & $1.09 * * *$ & 8.67 & $1.11^{* * *}$ & 10.79 & 1.15 & 11.76 & $1.16^{* * *}$ & 11.96 \\
\hline Constant & $.56^{* * *}$ & -3.53 & $.65^{*}$ & -2.4 & $.42 * * *$ & -5.61 & $.59 * * *$ & -3.72 & $.55 * * *$ & -4.22 \\
\hline$N$ & 1096 & & 973 & & 1025 & & 1179 & & 1312 & \\
\hline Pseudo $\mathrm{R}^{2}$ & 0.07 & & 0.08 & & 0.12 & & 0.13 & & 0.14 & \\
\hline
\end{tabular}

Note: OR refers to odds ratio and $z$ to the $z$-value used to calculate probability. ${ }^{* * *}$ indicates $p<.001,{ }^{* *} p<.01,{ }^{*} p<.05$. 
Table 12

Logistic Regression of Band V versus Band IV on Gender and Years at NIST by Year and Sample

\begin{tabular}{|c|c|c|c|c|c|c|c|c|c|c|}
\hline \multicolumn{11}{|c|}{ Total Group } \\
\hline \multirow[b]{2}{*}{ Ind. Var. } & \multicolumn{2}{|c|}{$\underline{2000}$} & \multicolumn{2}{|c|}{$\underline{2005}$} & \multicolumn{2}{|c|}{$\underline{2010}$} & \multicolumn{2}{|c|}{$\underline{2015}$} & \multicolumn{2}{|c|}{$\underline{2019}$} \\
\hline & $\underline{O R}$ & $\underline{Z}$ & $\underline{\mathrm{OR}}$ & $\underline{Z}$ & $\underline{\mathrm{OR}}$ & \multirow{2}{*}{$\begin{array}{c}\underline{Z} \\
2.93\end{array}$} & \multirow{2}{*}{$\frac{\underline{\mathrm{OR}}}{2.01^{* * *}}$} & \multirow{2}{*}{$\begin{array}{c}\underline{Z} \\
4.55\end{array}$} & \multirow{2}{*}{$\frac{\mathrm{OR}}{1.56^{* *}}$} & \multirow{2}{*}{$\begin{array}{c}\underline{Z} \\
3.02\end{array}$} \\
\hline Male & $1.65^{* *}$ & 2.72 & $1.41^{*}$ & 2.04 & $1.61^{* *}$ & & & & & \\
\hline Yrs NIST & $1.06 * * *$ & 8.9 & $1.04^{* * *}$ & 6.86 & $1.05^{* * *}$ & 7.73 & $1.06^{* * *}$ & 10.96 & $1.07^{* * *}$ & 12.51 \\
\hline Constant & $.14^{* * *}$ & -9.75 & $.21^{* * *}$ & -8.42 & $.17^{* * *}$ & -9.44 & $.11^{* * *}$ & -12.81 & $.11^{* * *}$ & -13.62 \\
\hline $\mathrm{N}$ & \multicolumn{2}{|l|}{1167} & \multicolumn{2}{|l|}{1157} & \multicolumn{2}{|l|}{1220} & \multicolumn{2}{|l|}{1401} & \multicolumn{2}{|l|}{1489} \\
\hline Pseudo $\mathrm{R}^{2}$ & \multicolumn{2}{|l|}{0.06} & \multicolumn{2}{|l|}{0.04} & \multicolumn{2}{|l|}{0.04} & \multicolumn{2}{|l|}{0.09} & \multicolumn{2}{|l|}{0.1} \\
\hline \multicolumn{11}{|c|}{ Only Employees Not Eligible for Retirement } \\
\hline & \multicolumn{2}{|c|}{$\underline{2000}$} & \multicolumn{2}{|c|}{$\underline{2005}$} & \multicolumn{2}{|c|}{$\underline{2010}$} & \multicolumn{2}{|c|}{$\underline{2015}$} & \multicolumn{2}{|c|}{$\underline{2019}$} \\
\hline Ind. Var. & $\underline{\mathrm{OR}}$ & $\underline{Z}$ & $\underline{\mathrm{OR}}$ & $\underline{Z}$ & $\underline{\mathrm{OR}}$ & $\underline{Z}$ & $\underline{\mathrm{OR}}$ & $\underline{Z}$ & $\underline{\mathrm{OR}}$ & $\underline{Z}$ \\
\hline Male & $1.65^{* *}$ & 2.6 & 1.33 & 1.59 & 1.39 & 1.79 & $1.93 * * *$ & 3.41 & 1.29 & 0.21 \\
\hline Yrs NIST & $1.06 * * *$ & 7.67 & $1.05^{* * *}$ & 1.05 & $1.06 * * *$ & 6.18 & $1.08 * * *$ & 8.63 & $1.08 * * *$ & 0.01 \\
\hline Constant & $.14^{* * *}$ & -9.44 & $.20 * * *$ & 0.2 & $.16^{* * *}$ & -8.42 & $.08 * * *$ & -11.49 & $.10 * * *$ & 0.02 \\
\hline $\mathrm{N}$ & 1054 & & 1009 & & 915 & & 975 & & 1162 & \\
\hline Pseudo $\mathrm{R}^{2}$ & 0.05 & & 0.03 & & 0.04 & & 0.08 & & 0.09 & \\
\hline
\end{tabular}

Note: OR refers to odds ratio and $z$ to the $z$-value used to calculate probability. ${ }^{* * *}$ indicates $p<.001, * * p<.01, * p<.05$. 
Table 13

Mixed Model Logistic Regressions of Band IV Versus Band III, by Year and Sample

\begin{tabular}{|c|c|c|c|c|}
\hline \multicolumn{5}{|c|}{2015} \\
\hline & \multicolumn{2}{|c|}{$\underline{\text { Total Sample }}$} & \multicolumn{2}{|c|}{$\underline{\text { Not Eligible for Retirement }}$} \\
\hline Ind. Var. & $\underline{\mathrm{OR}}$ & $\underline{Z}$ & $\underline{\mathrm{OR}}$ & $\underline{Z}$ \\
\hline Male & 1.08 & 0.50 & 0.93 & -0.48 \\
\hline Yrs. NIST & $1.12^{* * *}$ & 12.58 & $1.16^{* * *}$ & 11.68 \\
\hline Constant & 0.79 & -0.87 & 0.7 & -1.19 \\
\hline \multicolumn{5}{|c|}{2019} \\
\hline & \multicolumn{2}{|c|}{ Total Sample } & \multicolumn{2}{|c|}{ Not Eligible for Retirement } \\
\hline Ind. Var. & $\underline{\mathrm{OR}}$ & $\underline{Z}$ & $\underline{\mathrm{OR}}$ & $\underline{Z}$ \\
\hline Male & 1.15 & 1.00 & 1.06 & 0.37 \\
\hline Yrs. NIST & $1.14 * * *$ & 12.61 & $1.18^{* * *}$ & 12.12 \\
\hline Constant & 0.69 & -1.3 & 0.61 & -1.67 \\
\hline
\end{tabular}

In both years there were 7 operating units. In 2015, total $n=1411$, number of employees per operating unit ranged from 51 to 390 with an average of 202. In 2015 the reduced sample had 1,179 employees, 44 to 332 per operating unit, average of 168. In 2019 there were 1,471 employees in the total sample, 67 to 374 per operating unit, with an average of 210; for the reduced sample there were 1,312 employees, 63 to 332 per operating unit with an average of 187.

$* * *$ indicates $\mathrm{p}<.001, * *$ indicates $\mathrm{p}<.01, *$ indicates $\mathrm{p}<.05$ 
Table 14

Mixed Model Logistic Regressions of Band V Versus Band IV, by Year and Sample

\begin{tabular}{|c|c|c|c|c|}
\hline \multicolumn{5}{|c|}{2015} \\
\hline & \multicolumn{2}{|c|}{ Total Sample } & \multicolumn{2}{|c|}{ Not Eligible for Retirement } \\
\hline Ind. Var. & $\underline{\mathrm{OR}}$ & $\underline{Z}$ & $\underline{\mathrm{OR}}$ & $\underline{z}$ \\
\hline Male & $1.83^{* * *}$ & 3.82 & $1.85^{* *}$ & 3.12 \\
\hline Yrs. NIST & $1.06 * * *$ & 10.33 & $1.07^{* * *}$ & 8.29 \\
\hline Constant & $.11^{* * *}$ & -8.8 & $.08 * * *$ & -9.52 \\
\hline \multicolumn{5}{|c|}{2019} \\
\hline & \multicolumn{2}{|c|}{$\underline{\text { Total Sample }}$} & \multicolumn{2}{|c|}{$\underline{\text { Not Eligible for Retirement }}$} \\
\hline Ind. Var. & $\underline{\mathrm{OR}}$ & $\underline{Z}$ & $\underline{O R}$ & $\underline{Z}$ \\
\hline Male & $1.43^{*}$ & 2.37 & 1.20 & 1.06 \\
\hline Yrs. NIST & $1.07^{* * *}$ & 11.67 & $1.08^{* * *}$ & 9.7 \\
\hline Constant & $.11^{* * *}$ & -8.43 & $.10 * * *$ & -8.53 \\
\hline
\end{tabular}

In both years there were 7 operating units. In 2015, total $n=1401$, number of employees per operating unit ranged from 49 to 300 with an average of 200. In 2015 the reduced sample had 975 employees, 39 to 228 per operating unit, average of 139 . In 2019 there were 1,489 employees in the total sample, 61 to 335 per operating unit, with an average of 213; for the reduced sample there were 1,162 employees, 56 to 278 per operating unit with an average of 166 .

$* * *$ indicates $\mathrm{p}<.001, * *$ indicates $\mathrm{p}<.01, *$ indicates $\mathrm{p}<.05$ 
Table 15

Logistic Regression of Bands on Gender and Years of Employment, OU-C and Other Operating units, Total Group and Those Not Eligible for Retirement, 2019

\begin{tabular}{|c|c|c|c|c|c|c|c|c|}
\hline \multicolumn{9}{|c|}{ Band IV Versus Band III } \\
\hline & \multicolumn{4}{|c|}{ Total Sample } & \multicolumn{4}{|c|}{ Not Eligible for Retirement } \\
\hline \multirow[b]{3}{*}{ Ind. Var. } & \multicolumn{4}{|c|}{ Other Operating } & \multicolumn{4}{|c|}{ Other Operating } \\
\hline & \multicolumn{2}{|c|}{ units } & \multicolumn{2}{|c|}{$\underline{\mathrm{OU}-\mathrm{C}}$} & \multicolumn{2}{|c|}{$\underline{\text { units }}$} & \multicolumn{2}{|c|}{$\underline{\mathrm{OU}-\mathrm{C}}$} \\
\hline & $\underline{\mathrm{OR}}$ & $\underline{Z}$ & $\underline{\mathrm{OR}}$ & $\underline{Z}$ & $\underline{\mathrm{OR}}$ & $\underline{z}$ & $\underline{\mathrm{OR}}$ & $\underline{Z}$ \\
\hline Male & 0.92 & -0.48 & 1.66 & 1.85 & 0.84 & -0.98 & 1.63 & 1.65 \\
\hline Yrs NIST & $1.11 * * *$ & 9.13 & $1.21 * * *$ & 8.4 & $1.13^{* * *}$ & 8.84 & $1.30 * * *$ & 8.42 \\
\hline Constant & 1.18 & 0.98 & $.12 * * *$ & -7.09 & 1.09 & 0.5 & $.08 * * *$ & -7.4 \\
\hline $\mathrm{N}$ & 1097 & & 374 & & 980 & & 332 & \\
\hline \multicolumn{9}{|l|}{ Pseudo } \\
\hline$R^{2}$ & $.10 * * *$ & & $.29 * * *$ & & $.11 * * *$ & & $.31 * * *$ & \\
\hline \multicolumn{9}{|c|}{ Band V Versus Band IV } \\
\hline & \multicolumn{4}{|c|}{ Total Sample } & \multicolumn{4}{|c|}{ Not Eligible for Retirement } \\
\hline & \multicolumn{4}{|c|}{ Other Operating } & \multirow{2}{*}{\multicolumn{2}{|c|}{$\frac{\text { Other Operating }}{\text { units }}$}} & \multirow{2}{*}{\multicolumn{2}{|c|}{$\underline{\mathrm{OU}-\mathrm{C}}$}} \\
\hline & \multicolumn{2}{|c|}{ units } & \multicolumn{2}{|c|}{$\underline{\mathrm{OU}-\mathrm{C}}$} & & & & \\
\hline Ind. Var. & $\underline{\mathrm{OR}}$ & $\underline{Z}$ & $\underline{\mathrm{OR}}$ & $\underline{z}$ & $\underline{\mathrm{OR}}$ & $\underline{Z}$ & $\underline{\mathrm{OR}}$ & $\underline{Z}$ \\
\hline Male & $1.51 *$ & 2.47 & 1.79 & 1.85 & 1.26 & 1.23 & $\overline{1.40}$ & 0.94 \\
\hline Yrs NIST & $1.08 * * *$ & 11.71 & $1.05^{* * *}$ & 4.43 & $1.08 * * *$ & 9.25 & $1.09 * * *$ & 4.39 \\
\hline Constant & $.10 * * *$ & -12.31 & $.13 * * *$ & -5.65 & $.10 * * *$ & -11.06 & $.09 * * *$ & -5.47 \\
\hline $\mathrm{N}$ & 1190 & & 299 & & 941 & & 221 & \\
\hline \multicolumn{9}{|l|}{ Pseudo } \\
\hline$R^{2}$ & 0.11 & & 0.07 & & 0.09 & & 0.08 & \\
\hline
\end{tabular}

Note: Because OU-C was a single operating unit mixed models would not be appropriate. To provide greater comparability mixed models are not used with the analysis with other operating units.

$* * *$ indicates $p<.001,{ }^{* *}$ indicates $p<.01,{ }^{*}$ indicates $p<.05$ 
Table 16

Percentage of Specific Personnel Actions Involving Women by Year and Type of Action

\begin{tabular}{lcccccc}
\hline & & \multicolumn{5}{c}{ Reassign- } \\
Year & Hiring & Separation & Conversion & Promotion & ment & Total \\
2000 & 30.0 & 23.7 & 28.4 & 26.1 & 22.0 & 19.5 \\
2005 & 24.4 & 23.5 & 24.2 & 30.8 & 24.6 & 19.5 \\
2010 & 23.5 & 25.5 & 26.8 & 27.8 & 25.7 & 22.9 \\
2015 & 26.6 & 25.7 & 22.4 & 28.0 & 26.2 & 23.9 \\
2019 & 28.2 & 26.6 & 21.0 & 27.1 & 29.3 & 24.8 \\
Total \% & 25.9 & 25.0 & 24.3 & 28.3 & 25.2 & 25.5 \\
Total N & 3391 & 3009 & 2341 & 1073 & 4454 & \\
chi- & 7.11, & 3.33, & 7.01, & $1.33, \mathrm{p}=$ & 5.71, & \\
square, & $\mathrm{p}=.13$ & $\mathrm{p}=.70$ & $\mathrm{p}=.14$ & .86 & $\mathrm{p}=.22$ & \\
prob. & & & & & &
\end{tabular}

Note: Chi-square values test the hypothesis that the percentage of women experiencing a given action varied across the years.

Table 17

Percentage of Specific Personnel Actions Regarding Under-Represented Minorities by Year and Type of Action

\begin{tabular}{lcccccc}
\hline & & & & Reassign- & \\
Year & Hiring & Separation & Conversion & Promotion & ment & Total \\
2000 & 9.2 & 5.9 & 7.8 & 8.2 & 3.2 & 4.9 \\
2005 & 5.6 & 7.8 & 5.9 & 5.6 & 5.2 & 5.2 \\
2010 & 6.8 & 7.0 & 4.8 & 7.2 & 5.4 & 4.8 \\
2015 & 7.6 & 8.0 & 5.5 & 6.3 & 4.8 & 5.3 \\
2019 & 7.9 & 8.4 & 5.8 & 6.5 & 5.6 & 5.7 \\
Total \% & 7.2 & 7.6 & 5.7 & 6.5 & 5.0 & 5.2 \\
Total N & 3391 & 3009 & 2341 & 1073 & 4454 & \\
chi- & 4.52, & 2.15, & $2.82, \mathrm{p}=.59$ & 1.21, & 3.48, & \\
square, & $\mathrm{p}=.34$ & $\mathrm{p}=.71$ & & $\mathrm{p}=.88$ & $\mathrm{p}=.48$ & \\
prob. & & & & & &
\end{tabular}

Note: Chi-square values test the hypothesis that the percentage of URM employees experiencing a given action varied across the years. 


\section{Report 2: Gender Differences in Salaries of NIST ZP Employees: Analysis of Personnel Data ${ }^{4}$}

This brief report is an addendum to the January 2020 analysis of the NIST HR data (Report 1 ) and examines gender differences in salaries. The analysis was prompted by comments in a meeting on April 22, 2020 with NIST employees involved in an in-house analysis of HR data. Some of those present suggested that women at NIST have lower salaries than men with similar employment characteristics, such as pay band, years of employment and operating unit, although no data were presented at that time. They also suggested that the gender differences first appeared at the time of hire and then became larger over time. This report examines those concerns using the data described in Report 1. The first section describes results from the "yearly" data set and limited to 2019; the second section describes results based on the "personnel action data set" and includes data from 2000 through 2019 grouped in the manner described in Report 1 . The final section provides brief reflections on the results. Analyses are limited to ZP employees at Bands III and higher, paralleling the sample used for Report 1.

\section{Gender Differences in Salaries, 2019}

Table 1 reports the average annual salaries of women and men NIST employees classified as ZP by pay band in the fall of 2019. At each band, men had higher salaries than women. The difference (shown in the next to last column) was equal to a little less than $\$ 1,000$ at Band III and $\$ 2,000$ at the higher bands. The analysis of variance results in the bottom rows of the table indicate that the difference between men and women was statistically significant. As would be expected, the difference between bands was also significant, but the interaction effect was not. In other words, the slight variation in gender differences from one pay band to another was not greater than would be expected by chance. The last column of the top rows report the effect size associated with the gender difference at each band. (Effect sizes translate the difference in dollars to standard deviation units and are thus comparable across the bands.) These data show that the difference at Band III translates to .07 of a standard deviation at Band III, slightly greater (.13) at Band IV, and higher (.23) at the highest bands.

The January analysis reported that men tended to be at band longer than women, and this greater seniority at band might help account for the salary advantage shown in Table 1. Table 2 shows the average years at band for men and women at each band, replicating the analysis given in the January report. The results indicate that there were significant differences by band, with longer years at band at the higher bands. There were also significant differences by gender, with men having more years at band. The interaction effect was not significant, although the

\footnotetext{
${ }^{4}$ This report was written by J. Stockard and completed May 8, 2020.
} 
actual difference ( $6^{\text {th }}$ column of data) and effect sizes (last column) indicate that the gender difference was larger at higher bands.

The participants in the April 22 meeting also suggested that the gender difference in salaries was greater in some operating units than in others. Table 3 reports the average salaries of men and women in each operating unit. The analysis of variance results indicate support for this suggestion, with a significant interaction between operating units and gender. Inspection of the means (first two columns of data), the difference of these values and the effect sizes (the last two columns), shows advantages for men in OU-C, and to a lesser extent in $E$ and $F$, but an advantage for women in OU-D.

Table 4 summarizes the results of mixed model regressions of salary (in 1000's) on gender and years at band. Results are presented separately for employees in Bands III, IV, and the higher bands. For the analysis for the higher bands a dummy variable was added to distinguish those at the ST band from those at Band V. Operating unit was a random variable. This analysis is important because it includes all of the variables in the analyses in Tables 1, 2, and 3 (band, years at band, and $\mathrm{OU}$ ). The Intraclass Correlation (ICC) values indicate that there was more variation in salaries between operating units at Band III than at the higher Bands. The Proportionate Reduction in Error (PRE) values comparing model results with baseline indicate that substantially more variation was explained in the analysis for the highest bands than for the lower bands. The coefficient associated with gender was positive in all the analyses, indicating that even with organizational unit and years at band controlled, men had higher salaries than women. The gap, once years at band and organizational unit were controlled, was smallest for the highest band (\$220) and largest at Band IV (about \$870). ${ }^{5}$ This difference was not, however, large enough to be considered statistically significant.

Those who attended the April 22 meeting also suggested that the discrepancy between men and women might occur at the point of hire and then increase over time. The data presented in Table 5 attempt to address this possibility by limiting the analysis to those who were relatively new to the NIST labor force: employees at Band III with five or fewer years of experience at NIST. The format of the table is similar to that used in others. Contrary to expectations, among those most newly hired (the top row of data), women had, on average, higher salaries than men (by about $\$ 4,700)$. Yet among those with longer periods of employment, men had higher salaries (about $\$ 1,000$ for those with 1 to 2 years of experience and $\$ 3,800$ for those with 3 to 5 years of experience). These differential patterns resulted in the significant interaction effect in the analysis of variance. It must be remembered, however, that these data are cross-sectional, rather

\footnotetext{
${ }^{5}$ It should be noted that very few women were at the Senior Scientist Band, and thus do not benefit from the increment associated with that rank. Because it was important to control for this distinction, it was included as a dummy variable in the regressions.
} 
than longitudinal. We do not know the starting salaries of the men and women in the groups with more experience and cannot trace the trajectory of their salaries over time. ${ }^{6}$

\section{Salaries at Time of Hire, 2000 to 2019}

Data in the "personnel action" data set allowed a more direct test of gender differences in salaries at the time of hire. Table 6 summarizes the results of this analysis for hires from 2000 to 2019. ${ }^{7}$ Results are given for employees at Band III and Band IV. (Band V data were omitted given the small number of new hires at that band.) The first line of data for each year reports the difference in salaries of men and women at the time of hiring, the second line gives the associated effect size, and the third line gives the t-ratio. Positive values indicate that men had higher salaries and negative values indicate that women had higher salaries. Two-tail tests of significance were used throughout.

The data indicate no clear pattern in gender differences in salary at the time of hire. In some years women earned more and in others men did, and the differences were rarely large enough to be statistically significant or substantively strong. Unfortunately, it was not possible to separate results by operating unit. However, from this, admittedly limited, analysis there appears to be little support for the suggestion that women routinely receive lower salaries at hire than do men.

\section{Summary Thoughts}

Taken together, this analysis of gender differences in salaries for NIST ZP employees does not appear to have produced clear-cut results. On average, women had lower salaries than men, but these differences were largely explained by years that employees had been at band. This can be seen most clearly by comparing results in Tables 1 and 4 . Table 1 reports the difference in average salaries of men and women at each band (.90, 2.01, and 2.03 (in 1000's) for Bands III, IV, and $\mathrm{V}$ and higher, respectively). The coefficients associated with gender in Table 4, where operating unit and years at band have been controlled, can be compared directly to these values. The net salary differences, as reported in Table 4 were .68, .87, and .22 for Bands III, IV, and V and higher. Comparing these two values it can be seen that the male advantage in salaries dropped by about $24 \%$ for Band III, $57 \%$ for Band IV and $89 \%$ for Band V and higher when years at rank and operating unit were controlled. While the gender differences in average salaries did not disappear, they were substantially smaller when the tendency for men to stay at band longer than women was controlled. In addition, the data in Table 5 could be used to question the suggestion that gender differences in salary first appear at the time of hire. This conclusion was bolstered by the analysis in Table 6 that used data from personnel files.

\footnotetext{
${ }^{6}$ This analysis could, of course, be done within NIST and might be one that should be routinely conducted as a check for potential inequities.

${ }^{7}$ Grouping of the data into year categories is explained in Report 1.
} 
At the same time, the data show that within NIST, on average, men have higher salaries than women, even if these differences were not strong enough to be statistically significant. In addition, discrepancies are greater in some operating units than others. The concerns expressed in the April 22 meeting were sincere and clearly deeply felt. One could suggest that these findings, when coupled with the expressed concerns, lend support to the calls that COACh has made for increasing communication and transparency, as well as for diligent oversight of areas in which inequities might appear. These efforts could help correct problems that might exist as well as allay fears or concerns that are not supported by data.

\section{Tables}

Table 1

\begin{tabular}{|c|c|c|c|c|c|c|c|}
\hline Band & $\underline{\text { Women }}$ & Men & $\underline{\text { Total }}$ & $\underline{\mathrm{SD}}$ & $\underline{N}$ & $\underline{\text { Difference }}$ & Cohen's d \\
\hline III & 86.9 & 87.8 & 87.6 & 13.2 & 474 & 0.90 & 0.07 \\
\hline IV & 138.0 & 140.1 & 139.5 & 15.6 & 997 & 2.01 & 0.13 \\
\hline V and Higher & 166.8 & 168.8 & 168.4 & 8.9 & 563 & 2.03 & 0.23 \\
\hline Total & 129.1 & 137.4 & 135.4 & 32.0 & 2,034 & 8.34 & 0.26 \\
\hline$N$ & 493 & 1,541 & 2,034 & & & & \\
\hline Anova & $\underline{F}$ & prob & & & & & \\
\hline Band & 3350.10 & $<.0001$ & & & & & \\
\hline Gender & 4.76 & 0.03 & & & & & \\
\hline Interaction & 0.24 & 0.78 & & & & & \\
\hline
\end{tabular}

Note: Bands V and higher were grouped together because so few women were in the ST category. 
Table 2

Average Years at Band, by Band and Gender

\begin{tabular}{lccccccc}
\hline Band & Women & Men & Total & SD & N & Difference & $\mathrm{d}$ \\
III & 4.7 & 4.9 & 4.8 & 5.5 & 474 & 0.2 & 0.04 \\
IV & 8.8 & 9.9 & 9.6 & 7.8 & 997 & 1.2 & 0.15 \\
V & 9.6 & 11.6 & 11.2 & 8.2 & 492 & 2.0 & 0.24 \\
ST & 6.2 & 10.3 & 9.9 & 6.4 & 71 & 4.1 & 0.65 \\
Total & 7.7 & 9.3 & 8.9 & 7.7 & 2,034 & 1.5 & 0.20 \\
Analysis of Variance & F & & $\underline{\text { Prob. }}$ & & & \\
Band & 44.2 & & $<.0001$ & & & \\
Gender & 5.41 & & 0.02 & & & \\
Interaction & 1.17 & & 0.32 & & & \\
\hline
\end{tabular}

Table 3

Average Salaries $(1,000)$ by Gender and Operating Unit

\begin{tabular}{|c|c|c|c|c|c|c|c|}
\hline$\underline{\mathrm{OU}}$ & $\underline{\text { Women }}$ & $\underline{\text { Men }}$ & $\underline{\text { Total }}$ & $\underline{\mathrm{SD}}$ & $\underline{N}$ & Difference & $\underline{\mathrm{d}}$ \\
\hline$A$ & 139.6 & 141.0 & 140.5 & 26.1 & 406 & 1.3 & 0.05 \\
\hline B & 128.4 & 134.5 & 133.6 & 32.9 & 95 & 6.1 & 0.19 \\
\hline C & 113.9 & 129.8 & 125.2 & 34.4 & 490 & 15.9 & 0.46 \\
\hline D & 141.4 & 131.2 & 133.2 & 26.9 & 77 & -10.2 & -0.38 \\
\hline$E$ & 129.4 & 138.6 & 137.0 & 34.0 & 456 & 9.1 & 0.27 \\
\hline $\mathrm{F}$ & 127.7 & 138.4 & 136.5 & 32.7 & 200 & 10.7 & 0.33 \\
\hline G & 137.9 & 144.8 & 143.1 & 28.6 & 310 & 6.9 & 0.24 \\
\hline Total & 129.1 & 137.4 & 135.4 & 32.0 & 2034 & 8.3 & 0.26 \\
\hline \multicolumn{2}{|c|}{ Analysis of Variance } & $\underline{F}$ & & prob & & & \\
\hline \multicolumn{2}{|l|}{ OU } & 14.75 & & $<.0001$ & & & \\
\hline \multicolumn{2}{|l|}{ Gender } & 6.55 & & 0.01 & & & \\
\hline \multicolumn{2}{|l|}{ Interaction } & 2.51 & & 0.02 & & & \\
\hline
\end{tabular}


Table 4

Mixed Models Regressing Salary (in 1000's) on Gender and Years at Band, by Band; Operating Unit as Random Variable

\begin{tabular}{lcccccc}
\hline & \multicolumn{2}{c}{$\underline{\text { Band III }}$} & \multicolumn{2}{c}{$\underline{\text { Band IV }}$} & \multicolumn{2}{c}{ Band V and Higher } \\
Ind. Variable & $\underline{\mathrm{b}}$ & $\underline{\text { s.e. }}$ & $\underline{\mathrm{b}}$ & $\underline{\text { s.e. }}$ & $\underline{\mathrm{b}}$ & $\underline{\text { s.e. }}$ \\
Male & 0.68 & 1.05 & 0.87 & 0.90 & 0.22 & 0.43 \\
Years at Band & $1.40^{* * *}$ & 0.09 & $1.20^{* * *}$ & 0.05 & $.15^{* * *}$ & 0.02 \\
Sen. Scientist & ----- & ---- & ----- & ---- & $24.02^{* * *}$ & 0.49 \\
Constant & $80.9 * * *$ & 1.47 & $127.07^{* * *}$ & 0.137 & $43.44 * * *$ & 2.52 \\
ICC & 0.07 & & 0.02 & & 0.04 & \\
PRE from baseline & 0.36 & 0.37 & & 0.81 & \\
$* * * *$ indicates $p<.001, * *$ indicates $p<.01, *$ indicates $p<.05$ &
\end{tabular}

Table 5

Average Salaries (1,000s) by Gender and Years Employed at NIST, Only Band III and Employed 5 Years or Less

\begin{tabular}{|c|c|c|c|c|c|c|c|}
\hline \multirow[b]{2}{*}{ Years at NIST } & \multicolumn{7}{|c|}{$\underline{\text { Total }}$} \\
\hline & Women & Men & $\underline{\text { Total }}$ & $\underline{\mathrm{SD}}$ & $\underline{N}$ & Difference & $\underline{\mathrm{d}}$ \\
\hline Lt 1 & 82.4 & 77.7 & 79.3 & 10.7 & 55 & -4.72 & -0.44 \\
\hline 1 to 2 & 76.0 & 77.0 & 76.7 & 8.2 & 123 & 1.06 & 0.13 \\
\hline 3 to 5 & 85.6 & 89.4 & 88.5 & 10.9 & 138 & 3.81 & 0.35 \\
\hline Total & 81.0 & 82.8 & 82.3 & 11.3 & 316 & 1.86 & 0.16 \\
\hline \multicolumn{2}{|c|}{ Analysis of Variance Results } & $\underline{F}$ & & \multicolumn{4}{|l|}{ Prob. } \\
\hline \multicolumn{2}{|l|}{ Gender } & 0 & & \multicolumn{4}{|l|}{0.97} \\
\hline \multicolumn{2}{|l|}{ Years at NIST } & 32.6 & & \multicolumn{4}{|l|}{$<.0001$} \\
\hline \multicolumn{2}{|l|}{ Interaction } & 3.12 & & \multicolumn{2}{|l|}{0.05} & & \\
\hline
\end{tabular}


Table 6

Average Difference of Salaries at Hire by Gender and Year, t-ratios and Effect Sizes

\begin{tabular}{lcc}
\hline 2000 & Band III & Band IV \\
\cline { 2 - 3 } Difference & $-\$ 116$ & $\$ 3,597$ \\
Cohen's d & -0.01 & 0.41 \\
t-ratio & 0.10 & 1.31 \\
2005 & & \\
\hline Difference & $\$ 427$ & $-\$ 5,091$ \\
Cohen's d & 0.06 & -0.39 \\
t-ratio & 0.48 & 1.50 \\
2010 & & \\
Difference & $-\$ 2,362$ & $\$ 6,864$ \\
Cohen's d & -0.26 & 0.48 \\
t-ratio & $2.10 *$ & $2.27 *$ \\
2015 & & \\
Difference & $\$ 1,500$ & $-\$ 1,445$ \\
Cohen's d & 0.15 & -0.10 \\
t-ratio & 1.55 & 0.73 \\
2019 & & $\$ 8,049$ \\
Difference & $-\$ 1,055$ & 0.49 \\
Cohen's d & -0.12 & 1.70 \\
t-ratio & 0.80 & \\
\hline
\end{tabular}

Note: Positive differences, t-ratios, and effect sizes indicate that men had higher salaries; negative values indicate that women had higher salaries. Differences are in dollars. Data obtained from NIST personnel actions 2000 to 2019. Years were grouped as defined in the January, 2020 report. ${ }^{*}=p<.05$. 


\section{Report 3: ZT and ZP I and II Employees at NIST: Analysis of Personnel Data8}

The report that inspired our contract only looked at permanent Federal STEM workforce ZP employees in Bands III and higher, and thus our original analyses of the HR data (Reports 1 and 2) only looked at that group. We were subsequently told that we needed to include ZT employees and ZPs who were at lower Bands in the analysis, and this report examines the HR data related to these employees. Two data sets were used: 1) a "yearly" set of data on all NIST employees in 2000, 2005, 2010, 2015, and 2019; and 2) a "personnel action" file that included reports of all personnel actions (e.g. hirings, separations, promotions) from 2000 to the fall of 2019. Additional details on the data sets are in Report 1. The first section of this report examines data related to the ZT employees, and the second examines data regarding ZPs at Bands I and II. The final section provides a bulleted list of issues arising from the analysis.

\section{ZT Employees}

From 2000 to 2019 ZT employees comprised from $8 \%$ to $10 \%$ of the scientific (ZP and ZT) work force, but their number declined over time. In 2000 there were 240 employees classified as ZT, but by 2019 there were only 191, a decline of $20 \%$. Over this time period the distribution of ZT employees across the pay bands altered, with substantially fewer being at Bands I and II, a change that was statistically significant. (See Table 1.)

$\underline{\text { Job Titles }}$

The personnel action file included the job title of employees, and Table 2 reports the titles by band of employee. The majority of those at Band I were described as "trainees," while somewhat fewer were described as "aides." The majority of those at the higher bands were described as "technicians," while a few were described as "operators," "draftsmen," or "repair" employees.

\section{$\underline{\text { Representation of Women and Underrepresented Minorities }}$}

Table 3 reports data on the representation of women and under-represented minorities among the ZT employees. In 2000 and 2005 women were slightly less than a fifth of all ZTs (18\%) and the percentage dropped slightly over time, to $16 \%$ in 2019 . The percentage of URMs among the ZT employees also declined over time, from 15\% in 2000 to 13\% in 2019. (See the lines labeled "total" in each panel of Table 3.) In most years the percentage of women in the higher bands was less than in the total group, but the comparison was statistically significant only in 2000 and 2015. The distribution of URM employees across the bands was not significantly different from what would be expected by chance in any year. (Compare the percentages for a given band with the percentage for the total group and see chi-square values in last lines of each panel of Table 3.)

Tables 4 and 5 provide another way of examining bivariate associations of gender and URM status with band by treating band as a continuous variable and comparing the average band

${ }^{8}$ This report was written by J. Stockard and completed on June 1, 2020. 
of men and women (Table 4), or URM and non-URM (Table 5), employees in each year. The top panels of each table give results for all ZT employees and the bottom panels restrict the analysis to those in Bands II to V, thus omitting employees who would most likely be students. For all comparisons t-tests and the associated effect sizes are reported. Positive signs indicate that men or URM employees were, on average, at higher bands. Results in Table 4 indicate that the average band for men was higher in all comparisons. But the discrepancies were much smaller and statistically insignificant in recent years. Non-URM employees had average bands that were higher than URM employees in almost all comparisons, but the differences were often smaller than those involving gender and none were statistically significant.

\section{$\underline{\text { Age Structure }}$}

Analyses of data for the ZP employees in Bands III and higher (Report 1) indicated that the age and seniority of employees was an important factor in understanding disparities in band placement. The top panel of Table 6 reports the mean, median, and $75^{\text {th }}$ and $95^{\text {th }}$ percentile of the age of ZT employees at each band. Band I employees were clearly much younger than those at higher bands, with a median age $\left(50^{\text {th }}\right.$ percentile) of only 19 . The average age within all other bands was greater than 40 , and the average values increase monotonically through the bands, with the oldest employees, on average, in Band V.

The second panel of Table 6 reports the percentage of employees eligible for retirement by year, gender and URM status. ${ }^{9}$ In 2000 and 2005, less than 5\% of ZT employees were eligible for retirement. The percentage was substantially higher in 2010 and 2015 (20 and 24, respectively), but declined to $11 \%$ in 2019 . Women and URM employees were slightly more likely to be eligible for retirement, but these differences were not statistically significant.

\section{Testing Hypotheses Regarding Differential Treatment}

Table 7 reports the average years that employees had been at band by gender (the first panel) and URM status (the second panel). Statistical significance of the differences were examined with analyses of variance (results in the bottom rows of each panel). If women or minorities were being held back in the promotion process one would expect that they would have been at rank for a longer period of time. Data were only available for 2010, 2015, and 2019. The average values in the top rows of the first panel indicate that the average years at rank was sometimes greater for women than men (e.g. Bands I to III in 2010; I, III and IV in 2015; and III in 2019); but just as frequently greater for men. Overall there was no significant gender difference in the average years at rank. With the comparisons related to URM status, those who identified as URMs had more years at rank in all comparisons for Bands I to IV, except for Band I in 2019. However, these differences were not large enough to be statistically significant.

Tables 8 to 12 present more sophisticated tests of the possibility of discrimination in promotions by gender and URM status. Tables 8 and 9 summarize the results of regressions of

\footnotetext{
${ }^{9}$ Retirement eligibility was determined by a combination of age and years of service as explained in Report 1.
} 
band on years at NIST and gender (Table 8 ) or URM status (Table 9). ${ }^{10}$ Data are presented for each year, thus controlling for changes over time. The top panel in each table presents results for employees at all bands, and the bottom panel presents results omitting employees at Band I, who are more often students or temporary employees. Results in Table 8 indicate that men ZT employees were at higher bands than women, even when years at NIST were controlled. However, the difference was smaller and not statistically significant in 2019. A similar pattern occurs with the analysis of data regarding URM employees, with URM employees being at lower ranks, even with years at NIST controlled. But again, the differences were smaller and not statistically significant in 2019.

Table 10 summarizes the results in Table 8 and 9 by converting the magnitude of the differences to effect sizes. Effect sizes are often used as an indicator of the magnitude of differences between two groups and are given in standard deviation units. ${ }^{11}$ Positive effects in Table 10 indicate advantages to male or non-URM employees. ${ }^{12}$ Results in the left two columns reflect differences when seniority (measured by years at NIST) was not controlled, while those in the right two columns are based on the regressions controlling for years of employment. All effects were positive, indicating higher bands for men and non-URM employees. In most instances the discrepancies were greater when years at NIST were controlled. They were also larger when the sample was restricted to those in Bands II to V, those who would be more likely to be part of the long-term NIST labor force. But, as with the analyses in Tables 8 and 9, differences were smaller in 2019. In that year, men employees were, on average, about .25 of a band higher than women with equivalent years of service; and non-URM employees were, on average about .21 of a band higher than URM employees with equivalent years of service.

Tables 11 and 12 provide yet another way of analyzing differences in promotion by gender and URM status by focusing on the transition from Band II to Band III (top panels) and from Band III to IV (bottom panels). These analyses used logistic regressions and compared employees within only two bands (II and III or III and IV), examining the probability that men or non-URM employees were overrepresented within the higher band when their years of employment at NIST was controlled. The coefficients are odds ratios and indicate the odds that a male (in Table 11) or a non-URM employee (in Table 12) would be at the higher band when they had years of employment that were equal to others. Thus, the values center around 1.0, which would indicate equal odds or probabilities.

The odds related to gender in Table 11 were consistently greater than 1.0, indicating that men had a greater odds, or probability, of being in the higher band than women with equivalent

\footnotetext{
${ }^{10}$ Extensive preliminary analyses indicated that there were no significant differences between OUs, so ordinary least squares (OLS) was used instead of mixed models. In addition, ZT's were not uniformly represented across OUs, making such an analysis even more problematic.

${ }^{11}$ Social scientists use a variety of "benchmarks" to classify effect sizes. Traditionally, psychologists have classified effects of .20 as small, .5 as medium, and .8 as large. Unlike probabilities, effect sizes are not influenced by sample size.

${ }^{12}$ The coding for this table was reversed from that used in Tables 8 and 9 to help aid interpretations.
} 
years at NIST. The differences were strong enough in the analysis of the transition from III to IV to be statistically significant. For instance, in 2019, a male employee had odds 2.5 times that of a woman with equal years at NIST of being at a Band IV rather than Band III. Results regarding URM status were more variable and rarely significant. In 2019 the odds of a URM employee being in Band III rather than II was .75 that of a non-URM employee with equal years of service. The odds of a URM employee being in Band IV rather than III was equal to that of a non-URM employee of equal years of service $(O R=1.02)$. Neither result was statistically significant. ${ }^{13}$

\section{Differential Hiring and Separation}

As noted in other reports, the issue of disparities in promotion should, logically, be considered in tandem with issues regarding hiring and retention, for employees cannot be promoted if they are not hired and retained. Table 13 presents data obtained from the file of personnel actions from 2000 through the fall of 2019, with the top panel presenting data regarding women employees and the bottom giving data regarding employees identifying as URM. As noted earlier the percentage of women and URM employees among all ZTs declined from 2000 to 2015, and the data in this table could provide insight into why this happened.

The first two columns of data report the percentage of all hires and separations that involved women or URM employees, and the third column reports the percentage of women or URM employees among all ZTs in each year. The next two columns (labeled ratios) compare the percentages for hiring and separations to the percentage for the total group. (Higher values indicate that the percentage of hires or separations was greater than the representation of a group in the workforce.) The final column reports the number of ZT employees in each year.

In all but the period around 2015, women were hired at a rate that was higher than their representation in the ZT workforce as a whole. However, at the same time the rate of separation was either greater than or equal to their representation in the total workforce. Thus, the overall representation did not increase. The picture for URM employees was, if anything, less positive. The rate of hiring was equal to or less than their representation within the labor force until the most recent time period. The rate of separations was greater than their representation in the NIST ZT workforce in the first two and the most recent time period.

\section{Comparison to National Labor Pool}

Table 14 reports data on the representation of women (first panel) and minorities (second panel) in the United States from 1993 to 2017 in a sample of STEM-related fields. The last panel reports data on the representation of women and URM among all ZT employees. While we have

\footnotetext{
${ }^{13}$ Readers are reminded that this analysis did not control for OU because of the limited sample size and distribution across OUs.
} 
not been able to obtain reliable information on the discipline of NIST employees, it would appear, from these data, that women are substantially less well represented among NIST employees than would be expected given their representation within STEM occupations as a whole. The disparities for URM employees appear to be less marked, but it should be remembered that these are national data rather than those associated with the geographic areas in which NIST facilities are located.

\section{ZP Employees at Bands I and II}

Table 15 reports the percentage of ZP employees by Band from 2000 to 2019. In all years those at Bands I and II were a small proportion of the total group. Moreover, their representation declined over time from $8.4 \%$ in 2000 to less than half that percentage (4.1) by 2019. The decline was more marked among those in Band I. In the fall of 2019 there were 49 ZP employees at Band I and 38 at Band II. Given these small numbers only bivariate statistical analyses were used.

The "personnel" data file included information on job titles. The vast majority (95\%) of those at Band I were described as "trainees," and the remainder were described with some type of professional title such as "engineer." Close to half (45\%) of those at Band II were listed as trainees, about a third (37\%) were described with some type of professional title, and the remainder (18\%) were described as "specialists."

Women and URM ZP Employees at Bands I and II

Table 16 reports the percentage of employees in each band who were women (top lines) or identified as URM (bottom rows) in each year. In all years women and URM employees were more often at Band II than Band I. The chi-square values in the table test the hypothesis that, within each year, the percentage of women or URM employees varied from one band to the other. These statistics were significant for the earlier years in the analysis, but not in later years as the representation of women and URM employees within the two bands became more similar. In addition, over time the percentage of women at Band II declined markedly, from 49\% in 2000 to $24 \%$ in 2019 . This change was statistically significant. ${ }^{14}$

\section{Hiring and Separation}

Table 17 presents data on hiring and separation of women and URM ZP employees, paralleling the structure of Table 13. Data on actions regarding women are in the top panel. From 2000 to 2015 women comprised a slightly smaller percentage of new hires than in the total pool of ZP employees, but a slightly larger percentage in 2019. From 2000 to 2015 women were less

\footnotetext{
${ }^{14}$ Chi-square values associated with the cross-tabulation of year and gender were $2.40(p=.66)$ for Band I and 9.42 $(p=.05)$ for Band II. Chi-square values for year and URM status were $4.76(p=.31)$ for Band I and $3.04(p=.55)$ for Band II.
} 
likely to separate than their overall representation would suggest, but substantially more likely to do so in 2019. Taken together, the relatively low rate of hiring women in earlier years and the recent higher rate of separation could be seen as contributing to their declining overall representation among ZP employees in Bands I and II.

Data for employees who were identified as URMs are in the second panel of Table 17. It is important to remember that the actual number of employees involved is small, but the pattern should be concerning. The ratios indicate that in most time periods employees identifying as URM were less likely to be hired but more likely to separate. Again, this would logically contribute to their declining representation among the ZP employees at Bands I and II.

\section{Promotions and Conversions}

Data in the personnel actions file provided the opportunity to examine the extent to which ZP employees in Bands I and II experienced promotions and other types of personnel actions. Over the 19 years of data there were 21 instances of an employee who had been at Band I being subsequently hired at a higher band, but only 4 instances of an employee in Band II later being hired at a higher band. Conversions were more common, with 61 instances for those at Band I and 51 for those at Band II. Promotions rarely occurred for those at Band I, but there were over 100 instances of promotions for those at Band II. In addition, one Band II employee was reassigned. (See Table 18.)

Because the information in Table 18 covered almost two decades it seemed important to estimate the yearly frequency of these actions, and Table 19 reports the estimated number of promotions or conversions that occurred within each year for the total group and for women and those identifying as URM. These numbers were quite small, ranging from 7 in 2000 to 14 in 2005 and 2015. Given the very small number of promotions and conversions, as well as the small number of employees, further statistical analyses are not advisable. However, the very low frequency of these actions should be noted.

\section{Summary Considerations}

\section{ZT Employees}

- From 2000 to 2019 the number of ZT employees declined.

- Over time proportionately more ZT's were at higher bands.

- The percentage of women and URM among ZTs declined over time.

- Net of years of employment at NIST, men and non-URM employees were at higher Bands, but there was less disparity in 2019 than in earlier years. Gender disparities were greater for the transition from III to IV than from II to III, paralleling results with the analyses of ZP employees at higher bands.

- Disparities in hiring and retention appear to have contributed to the declining representation of women and minorities over time. In addition, hiring has not kept pace with the national pool of STEM employees who are women or identify as URM. 
- Women and URM employees were slightly more likely than others to be eligible for retirement, a finding that differs from that with the ZP's and that could exacerbate issues of their representation in the future.

ZP Employees at Bands I and II

- In 2019 there were fewer than 100 ZP employees in these bands, and the majority were described as "trainees."

- Women and URM employees were more often at Band II than Band I and thus potentially more likely to be part of a "permanent" labor pool.

- Representation of women at Band II declined significantly from 2000 to 2019 (from 49\% to $24 \%)$.

- As with the ZT's women and minorities in Bands I and II appeared to be less often hired and more often separate from NIST than would be expected given their representation in the ZT Band I and II workforce.

- Promotions or conversion of positions occurred rarely over the 19 years of personnel data provided. The numbers were too small for reliable analysis of differences by gender or URM status. 


\section{Tables}

Table 1

ZT Employees by Band and Year

\begin{tabular}{lccccc} 
Band & $\underline{2000}$ & $\underline{2005}$ & $\underline{2010}$ & $\underline{2015}$ & $\underline{2019}$ \\
I & 19.2 & 20.9 & 8.6 & 6.3 & 2.1 \\
II & 11.2 & 10.7 & 9.5 & 7.3 & 6.8 \\
III & 26.7 & 23.3 & 28.1 & 31.1 & 30.4 \\
IV & 40.4 & 40 & 48.4 & 45.2 & 49.7 \\
V & 2.5 & 5.1 & 5.4 & 10.2 & 11.0 \\
Total \% & 100 & 100 & 100 & 100 & 100 \\
Total N & 240 & 215 & 221 & 206 & 191 \\
Chi-square $=75.81$, & $\mathrm{p}<.001$ & & & & \\
\hline
\end{tabular}

Table 2

Title of ZT Positions with Personnel Actions by Band

\begin{tabular}{|c|c|c|c|c|c|}
\hline$\underline{\text { Title }}$ & Band I & Band II & Band III & Band IV & Band V \\
\hline Aide & 24.2 & 0.7 & 0.0 & 0.0 & 0.0 \\
\hline Trainee & 70.5 & 4.6 & 0.0 & 0.0 & 0.0 \\
\hline Technician & 4.9 & 86.2 & 88.9 & 96.3 & 100.0 \\
\hline Operator & 0.1 & 2.0 & 0.9 & 0.0 & 0.0 \\
\hline Draftsman & 0.3 & 2.6 & 0.9 & 0.4 & 0.0 \\
\hline Repair & 0.0 & 4.0 & 9.4 & 3.3 & 0.0 \\
\hline Total (\%) & 100.0 & 100.0 & 100.0 & 100.0 & 100.0 \\
\hline $\mathrm{N}$ & 715 & 152 & 351 & 483 & 83 \\
\hline
\end{tabular}


Table 3

Percentage of ZT Employees Who Were Women or URMs by Band and Year

\begin{tabular}{|c|c|c|c|c|c|}
\hline \multicolumn{6}{|c|}{ Percentage Women } \\
\hline Band & $\underline{2000}$ & $\underline{2005}$ & $\underline{2010}$ & $\underline{2015}$ & $\underline{2019}$ \\
\hline I & 22 & 18 & 11 & 23 & 25 \\
\hline II & 26 & 35 & 19 & 7 & 8 \\
\hline III & 27 & 22 & 26 & 28 & 24 \\
\hline IV & 9 & 13 & 15 & 12 & 13 \\
\hline V & 0 & 0 & 0 & 5 & 14 \\
\hline Total & 18 & 18 & 17 & 17 & 16 \\
\hline N & 240 & 215 & 221 & 206 & 191 \\
\hline Chi-square & $11.12^{*}$ & 9.04 & 6.74 & $11.31^{*}$ & 4.55 \\
\hline \multicolumn{6}{|c|}{ Percentage URM } \\
\hline Band & $\underline{2000}$ & $\underline{2005}$ & $\underline{2010}$ & $\underline{2015}$ & $\underline{2019}$ \\
\hline 1 & 9 & 4 & 11 & 15 & 25 \\
\hline II & 26 & 13 & 5 & 13 & 15 \\
\hline III & 17 & 16 & 18 & 20 & 12 \\
\hline IV & 13 & 9 & 12 & 11 & 14 \\
\hline V & 0 & 0 & 0 & 5 & 5 \\
\hline Total \% & 15 & 10 & 12 & 14 & 13 \\
\hline Total N & 240 & 215 & 221 & 206 & 191 \\
\hline Chi-square & 5.55 & 5.14 & 4.30 & 4.53 & 1.94 \\
\hline
\end{tabular}

Note: Chi-square tests examined the hypothesis that distribution of employees by gender or URM status varied across the Bands. $\mathrm{df}=4$. *indicates $\mathrm{p}<.05, * *$ indicates $\mathrm{p}<.01, * * *$ indicates $\mathrm{p}<.001$. 
Table 4

Average Band by Gender, Year, and Sample

\begin{tabular}{|c|c|c|c|c|c|c|c|c|c|c|}
\hline \multicolumn{11}{|c|}{ All Employees } \\
\hline & \multicolumn{2}{|c|}{$\underline{2000}$} & \multicolumn{2}{|c|}{$\underline{2005}$} & \multicolumn{2}{|c|}{$\underline{2010}$} & \multicolumn{2}{|c|}{$\underline{2015}$} & \multicolumn{2}{|c|}{$\underline{2019}$} \\
\hline$\underline{\text { Statistic }}$ & Women & $\underline{\text { Men }}$ & Women & $\underline{\text { Men }}$ & Women & $\underline{\text { Men }}$ & Women & $\underline{\text { Men }}$ & Women & Men \\
\hline Mean & 2.6 & 3.0 & 2.7 & 3.1 & 3.2 & 3.4 & 3.2 & 3.5 & 3.5 & 3.6 \\
\hline SD & 1.1 & 1.2 & 1.1 & 1.3 & 0.8 & 1.1 & 0.9 & 1.0 & 0.9 & 0.9 \\
\hline t-ratio & $2.34^{*}$ & & 1.75 & & 0.77 & & 1.81 & & 0.88 & \\
\hline Ef. Size & 0.39 & & 0.31 & & 0.14 & & 0.33 & & 0.18 & \\
\hline \multicolumn{11}{|c|}{ Only Bands II to V } \\
\hline & \multicolumn{2}{|c|}{$\underline{2000}$} & \multicolumn{2}{|c|}{$\underline{2005}$} & \multicolumn{2}{|c|}{$\underline{2010}$} & \multicolumn{2}{|c|}{$\underline{2015}$} & \multicolumn{2}{|c|}{$\underline{2019}$} \\
\hline$\underline{\text { Statistic }}$ & Women & $\underline{\text { Men }}$ & Women & $\underline{\text { Men }}$ & Women & $\underline{\text { Men }}$ & Women & $\underline{\text { Men }}$ & Women & Men \\
\hline Mean & 3.1 & 3.5 & 3.1 & 3.6 & 3.3 & 3.6 & 3.4 & 3.7 & 3.6 & 3.7 \\
\hline SD & 0.7 & 0.8 & 0.8 & 0.2 & 0.7 & 0.8 & 0.6 & 0.8 & 0.7 & 0.8 \\
\hline t-ratio & $3.04^{* *}$ & & $3.06 * *$ & & 1.85 & & 1.84 & & 0.75 & \\
\hline Ef. Size & 0.57 & & 0.60 & & 0.34 & & 0.36 & & 0.14 & \\
\hline
\end{tabular}

Note: Probability levels are two-tail, $* p<.05, * * p<.01, * * * p<.001$. Effect sizes are Cohen's d.

Table 5

Average Band by URM Status, Year, and Sample

\begin{tabular}{|c|c|c|c|c|c|c|c|c|c|c|}
\hline \multicolumn{11}{|c|}{ All Employees } \\
\hline & \multicolumn{2}{|c|}{$\underline{2000}$} & \multicolumn{2}{|c|}{$\underline{2005}$} & \multicolumn{2}{|c|}{$\underline{2010}$} & \multicolumn{2}{|c|}{$\underline{2015}$} & \multicolumn{2}{|c|}{$\underline{2019}$} \\
\hline & $\underline{\text { Not }}$ & & $\underline{\text { Not }}$ & & $\underline{\text { Not }}$ & & $\underline{\text { Not }}$ & & $\underline{\text { Not }}$ & \\
\hline$\underline{\text { Statistic }}$ & $\underline{\text { URM }}$ & $\underline{\text { URM }}$ & $\underline{\text { URM }}$ & $\underline{\text { URM }}$ & $\underline{\mathrm{URM}}$ & $\underline{\text { URM }}$ & $\underline{\text { URM }}$ & $\underline{\text { URM }}$ & $\overline{\text { URM }}$ & $\underline{\text { URM }}$ \\
\hline Mean & 3.0 & 2.9 & 3.0 & 3.1 & 3.5 & 3.4 & 3.5 & 3.2 & 3.6 & 3.5 \\
\hline SD & 1.2 & 1.0 & 1.3 & 1.0 & 0.9 & 0.8 & 1.0 & 0.9 & 0.9 & 0.9 \\
\hline t-ratio & 0.08 & & -0.27 & & 0.27 & & 1.39 & & 0.92 & \\
\hline Ef. Size & 0.02 & & -0.06 & & 0.05 & & 0.28 & & 0.20 & \\
\hline \multicolumn{11}{|c|}{ Only Bands II to $\mathrm{V}$} \\
\hline & \multicolumn{2}{|c|}{$\underline{2000}$} & \multicolumn{2}{|c|}{$\underline{2005}$} & \multicolumn{2}{|c|}{$\underline{2010}$} & \multicolumn{2}{|c|}{2015} & \multicolumn{2}{|c|}{2019} \\
\hline & Not & & $\underline{\text { Not }}$ & & $\underline{\text { Not }}$ & & $\underline{\text { Not }}$ & & $\underline{\text { Not }}$ & \\
\hline$\underline{\text { Statistic }}$ & $\underline{\text { URM }}$ & $\underline{\text { URM }}$ & $\underline{\text { URM }}$ & $\underline{\text { URM }}$ & $\underline{\text { URM }}$ & $\underline{\text { URM }}$ & $\underline{\text { URM }}$ & $\underline{\text { URM }}$ & $\underline{\text { URM }}$ & $\underline{\text { URM }}$ \\
\hline Mean & 3.5 & 3.2 & 3.5 & 3.3 & 3.6 & 3.5 & 3.7 & 3.4 & 3.7 & 3.6 \\
\hline SD & 0.8 & 0.8 & 0.8 & 0.7 & 0.8 & 0.6 & 0.8 & 0.7 & 0.8 & 0.7 \\
\hline t-ratio & 1.83 & & 1.36 & & 0.4 & & 1.67 & & 0.65 & \\
\hline Ef. Size & 0.36 & & 0.33 & & 0.09 & & 0.36 & & 0.14 & \\
\hline
\end{tabular}

Note: Probability levels are two-tail, ${ }^{*}=p<.05,{ }^{*}=p<.01, * * *=p<.001$. Effect sizes are Cohen's d. 
Table 6

Age and Retirement Eligibility of ZT Employees

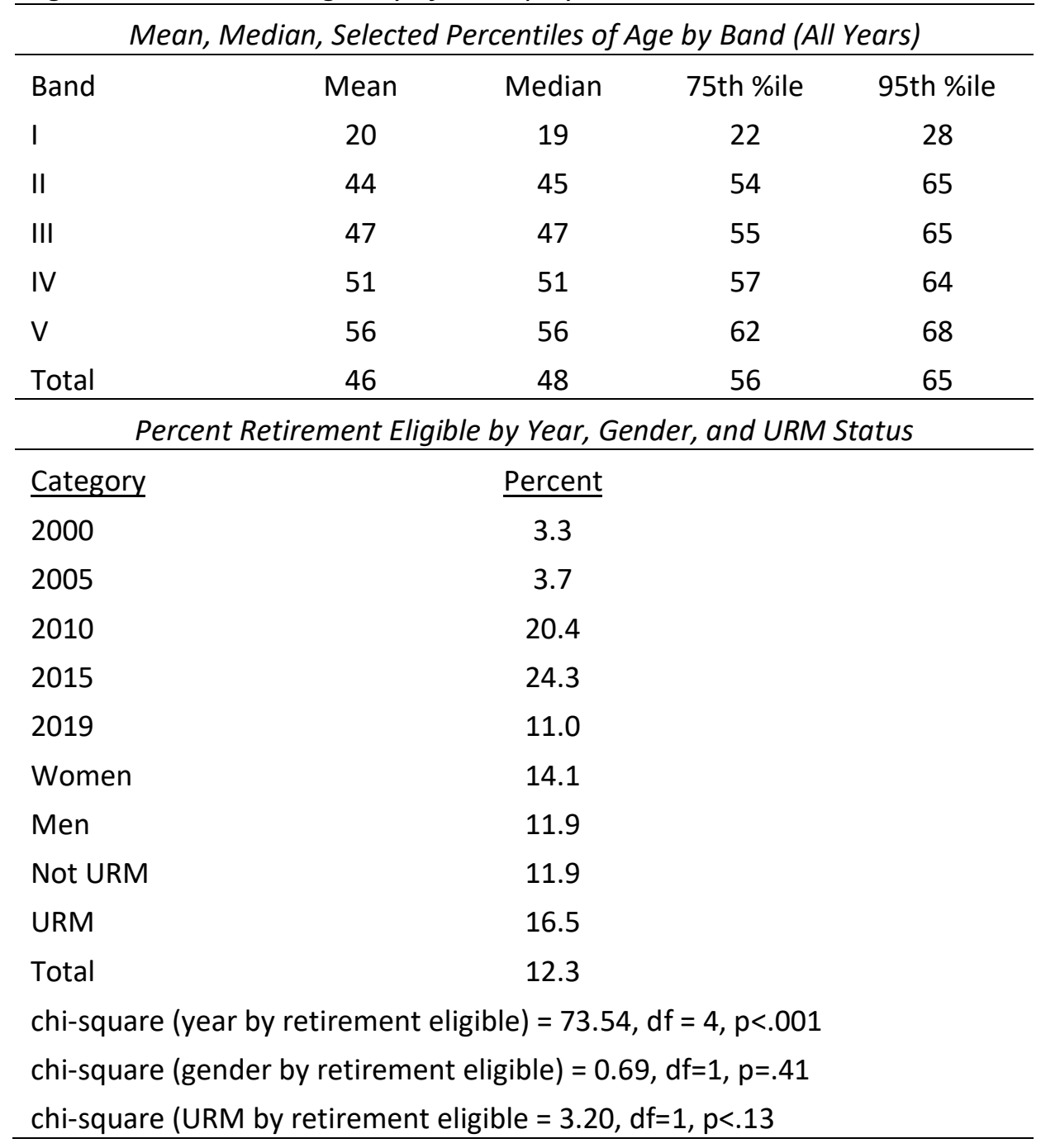


Table 7

Average Years at Band by Band, Year, Gender, and URM Status

\begin{tabular}{|c|c|c|c|c|c|c|}
\hline \multicolumn{7}{|c|}{ Average Years at Band by Band, Gender, and Year } \\
\hline & \multicolumn{2}{|c|}{$\underline{2010}$} & \multicolumn{2}{|c|}{$\underline{2015}$} & \multicolumn{2}{|c|}{$\underline{2019}$} \\
\hline Band & Women & $\underline{\text { Men }}$ & Women & $\underline{\text { Men }}$ & $\underline{\text { Women }}$ & Men \\
\hline I & 3.1 & 1.6 & 4.6 & 1.7 & 1.4 & 4.5 \\
\hline II & 10.8 & 5.6 & 2.6 & 6.2 & 3.7 & 6.9 \\
\hline III & 7.9 & 5.2 & 9.4 & 7.0 & 8.9 & 4.4 \\
\hline IV & 7.5 & 8.4 & 9.6 & 7.6 & 4.9 & 7.1 \\
\hline V & ---- & 8.8 & 1.6 & 6 & 4 & 5.1 \\
\hline Total & 7.8 & 6.8 & 8.6 & 6.8 & 6.5 & 6.1 \\
\hline \multicolumn{7}{|c|}{ Analysis of Variance } \\
\hline & \multicolumn{2}{|c|}{$\underline{2010}$} & \multicolumn{2}{|c|}{$\underline{2015}$} & \multicolumn{2}{|c|}{$\underline{2019}$} \\
\hline Effect & $\underline{F}$ & $\underline{\text { Prob }}$ & $\underline{F}$ & prob & $\underline{F}$ & prob \\
\hline Band & 2.52 & 0.04 & 1.39 & 0.24 & 0.45 & 0.77 \\
\hline Gender & 1.93 & 0.17 & 0.00 & 0.96 & 0.23 & 0.63 \\
\hline Interaction & 1.28 & 0.28 & 0.29 & 0.88 & 1.76 & 0.14 \\
\hline \multicolumn{7}{|c|}{ Average Years at Band by Band, URM Status, and Year } \\
\hline & \multicolumn{2}{|c|}{$\underline{2010}$} & \multicolumn{2}{|c|}{$\underline{2015}$} & \multicolumn{2}{|c|}{$\underline{2019}$} \\
\hline Band & $\underline{\text { Not URM }}$ & $\underline{\text { URM }}$ & Not URM & $\underline{\text { URM }}$ & $\underline{\text { Not URM }}$ & $\underline{\text { URM }}$ \\
\hline I & 2.9 & 3.5 & 2.4 & 2.0 & 4.5 & 1.4 \\
\hline II & 6.3 & 11.8 & 5.6 & 8.8 & 5.9 & 10.8 \\
\hline III & 5.8 & 8.4 & 7.6 & 7.9 & 5.2 & 7.4 \\
\hline IV & 8.3 & 8.5 & 7.6 & 10.3 & 6.7 & 7.3 \\
\hline V & 8.8 & --- & 6.0 & 1.4 & 5.1 & 3.2 \\
\hline Total & 7.2 & 8.4 & 7.0 & 8.2 & 6 & 7.2 \\
\hline \multicolumn{7}{|c|}{ Analysis of Variance } \\
\hline & \multicolumn{2}{|c|}{$\underline{2010}$} & \multicolumn{2}{|c|}{$\underline{2015}$} & \multicolumn{2}{|c|}{$\underline{2019}$} \\
\hline$\underline{\text { Effect }}$ & $\underline{F}$ & Prob & $\underline{F}$ & prob & $\underline{F}$ & prob \\
\hline Band & 1.24 & 0.30 & 1.32 & 0.26 & 0.59 & 0.67 \\
\hline URM & 0.84 & 0.36 & 0.01 & 0.92 & 0.06 & 0.81 \\
\hline Interaction & 0.36 & 0.78 & 0.3 & 0.88 & 0.35 & 0.84 \\
\hline
\end{tabular}


Table 8

Employee Band Regressed on Years at NIST and Gender, by Year and Sample

\begin{tabular}{|c|c|c|c|c|c|c|c|c|c|c|}
\hline \multicolumn{11}{|c|}{ All Employees } \\
\hline & 2000 & & 2005 & & 2010 & & 2015 & & 2019 & \\
\hline Ind. Var. & B & s.e. & B & s.e. & $b$ & s.e. & $b$ & s.e. & B & s.e. \\
\hline Yrs NIST & $.07 * * *$ & 0.005 & $.07 * * *$ & 0.005 & $.05 * * *$ & 0.005 & $.04 * * *$ & 0.005 & $.03 * * *$ & 0.005 \\
\hline Male & $.36^{*}$ & 0.15 & .31 & 0.16 & .29 & 0.16 & $.47 * * *$ & 0.16 & 0.22 & 0.15 \\
\hline Constant & $1.66 * * *$ & 0.15 & $1.68 * * *$ & 0.16 & $2.40 * * *$ & 0.17 & $2.49 * * *$ & 0.18 & $2.99 * * *$ & 0.16 \\
\hline $\mathrm{R}^{2}$ & $.44 * * *$ & & $.47 * * *$ & & $.26 * * *$ & & $.23 * * *$ & & $.16 * * *$ & \\
\hline \multicolumn{11}{|c|}{ Only Bands II to V } \\
\hline & \multicolumn{2}{|c|}{$\underline{2000}$} & \multicolumn{2}{|c|}{$\underline{2005}$} & \multicolumn{2}{|c|}{$\underline{2010}$} & \multicolumn{2}{|c|}{$\underline{2015}$} & \multicolumn{2}{|c|}{$\underline{2019}$} \\
\hline$\underline{\text { Statistic }}$ & $\underline{b}$ & $\underline{\text { s.e. }}$ & $\underline{B}$ & $\underline{\text { s.e. }}$ & $\underline{B}$ & $\underline{\text { s.e. }}$ & $\underline{b}$ & $\underline{\text { s.e. }}$ & $\underline{B}$ & $\underline{\text { s.e. }}$ \\
\hline Yrs NIST & $.02 * * *$ & 0.005 & $.03 * * *$ & 0.005 & $.03 * * *$ & 0.005 & $.03 * * *$ & 0.005 & $.03 * * *$ & 0.005 \\
\hline Male & $.42 * *$ & 0.14 & $.45^{* *}$ & 0.14 & $.33 * *$ & 0.13 & $.38 * *$ & 0.14 & 0.19 & 0.14 \\
\hline Constant & $2.61 * * *$ & 0.15 & $2.54 * * *$ & 0.15 & $2.85^{* * *}$ & 0.14 & $2.90 * * *$ & 0.15 & $3.13 * * *$ & 0.15 \\
\hline$R^{2}$ & $.16 * * *$ & & $.25 * * *$ & & $.16^{* * *}$ & & $.17^{* * *}$ & & $.14^{* * *}$ & \\
\hline
\end{tabular}

Note: Probability levels are two-tail, ${ }^{*}=\mathrm{p}<.05,{ }^{*}=\mathrm{p}<.01,{ }^{* * *}=\mathrm{p}<.001$. Tests of the interaction of gender and years at NIST were not significant.

Table 9

Band Regressed on Years at NIST and URM Status, by Year and Sample

\begin{tabular}{|c|c|c|c|c|c|c|c|c|c|c|}
\hline \multicolumn{11}{|c|}{ All Employees } \\
\hline & \multicolumn{2}{|c|}{$\underline{2000}$} & \multicolumn{2}{|c|}{$\underline{2005}$} & \multicolumn{2}{|c|}{$\underline{2010}$} & \multicolumn{2}{|c|}{$\underline{2015}$} & \multicolumn{2}{|c|}{2019} \\
\hline Ind. Var. & $\underline{b}$ & s.e. & $\underline{b}$ & s.e. & $\underline{b}$ & s.e. & $\underline{b}$ & s.e. & $\underline{B}$ & s.e. \\
\hline Yrs NIST & $.07 * * *$ & 0.005 & $.07 * * *$ & 0.005 & $.04^{* * *}$ & 0.005 & $.04^{* * *}$ & 0.006 & $.03 * * *$ & 0.005 \\
\hline URM & -0.20 & 0.16 & -0.20 & 0.21 & -0.23 & 0.18 & $-.40 *$ & 0.18 & -0.22 & 0.17 \\
\hline Constant & $1.97 * * *$ & 0.10 & $1.94 * * *$ & 0.10 & $2.90 * * *$ & 0.10 & $2.94 * * *$ & 0.10 & $3.21 * * *$ & 0.09 \\
\hline $\mathrm{R}^{2}$ & $.43 * * *$ & & $.47 * * *$ & & $.19 * * *$ & & $.22 * * *$ & & $.16 * * *$ & \\
\hline \multicolumn{11}{|c|}{ Only Bands II to V } \\
\hline & \multicolumn{2}{|c|}{$\underline{2000}$} & \multicolumn{2}{|c|}{$\underline{2005}$} & \multicolumn{2}{|c|}{2010} & \multicolumn{2}{|c|}{$\underline{2015}$} & \multicolumn{2}{|c|}{$\underline{2019}$} \\
\hline$\underline{\text { Statistic }}$ & $\underline{b}$ & s.e. & $\underline{b}$ & s.e. & $\underline{b}$ & s.e. & $\underline{b}$ & s.e. & $\underline{\mathrm{B}}$ & s.e. \\
\hline Yrs NIST & $.03 * * *$ & 0.005 & $.03 * * *$ & 0.005 & $.03 * * *$ & 0.005 & $.03 * * *$ & 0.005 & $.03 * * *$ & 0.005 \\
\hline URM & $-.31 *$ & 0.14 & $-.34^{a}$ & 0.18 & -0.2 & 0.16 & $-.37^{*}$ & 0.15 & -0.16 & 0.16 \\
\hline Constant & 2.99 & 0.11 & $2.92 * * *$ & 0.11 & $3.16 * * *$ & 0.09 & $3.27 * * *$ & 0.09 & $3.31 * * *$ & 0.09 \\
\hline$R^{2}$ & $.14 * * *$ & & $.22 * * *$ & & $.13 * * *$ & & $.16^{* * *}$ & & $.14 * * *$ & \\
\hline
\end{tabular}

Note: Probability levels are two-tail, ${ }^{*}=p<.05, * *=p<.01, * * *=p<.001$. Tests of the interaction of URM status and years at NIST were not significant. 
Table 10

Summary of Effect Sizes by Type of Analysis and Sample, Gender and URM Analyses

Gender Differences

\begin{tabular}{|c|c|c|c|c|}
\hline \multirow[b]{2}{*}{ Year } & \multicolumn{2}{|c|}{ Without Controls } & \multicolumn{2}{|c|}{ Controlling for Years at NIST } \\
\hline & All Bands & Bands II-V & All Bands & Bands II-V \\
\hline 2000 & 0.39 & 0.57 & 0.31 & 0.55 \\
\hline 2005 & 0.31 & 0.60 & 0.25 & 0.56 \\
\hline 2010 & 0.14 & 0.34 & 0.28 & 0.43 \\
\hline 2015 & 0.33 & 0.36 & 0.47 & 0.49 \\
\hline 2019 & 0.18 & 0.14 & 0.26 & 0.25 \\
\hline \multicolumn{5}{|c|}{ Differences Related to URM Status } \\
\hline & \multicolumn{2}{|c|}{ Without Controls } & \multicolumn{2}{|c|}{ Controlling for Years at NIST } \\
\hline Year & All Bands & Bands II-V & $\underline{\text { All Bands }}$ & Bands II-V \\
\hline 2000 & 0.02 & 0.36 & 0.17 & 0.40 \\
\hline 2005 & -0.06 & 0.33 & 0.16 & 0.42 \\
\hline 2010 & 0.05 & 0.09 & 0.23 & 0.26 \\
\hline 2015 & 0.28 & 0.36 & 0.18 & 0.47 \\
\hline 2019 & 0.20 & 0.14 & 0.26 & 0.21 \\
\hline
\end{tabular}

Note: Positive effects indicate advantage to male or non-URM employees. Data labeled "without controls" are results from bivariate analyses in Tables 3. Effects for regressions, in the last two columns, calculated by dividing the unstandardized regression coefficient by the standard deviation of the dependent measure for a given year. 
Table 11

Logistic Regression of Band III versus Band II and Band IV versus III on Gender and Years at NIST by Year

\begin{tabular}{|c|c|c|c|c|c|c|c|c|c|c|}
\hline \multicolumn{11}{|c|}{ Band III Versus Band II } \\
\hline & \multicolumn{2}{|c|}{$\underline{2000}$} & \multicolumn{2}{|c|}{$\underline{2005}$} & \multicolumn{2}{|c|}{$\underline{2010}$} & \multicolumn{2}{|c|}{$\underline{2015}$} & \multicolumn{2}{|c|}{$\underline{2019}$} \\
\hline Ind. Var. & $\underline{\mathrm{OR}}$ & $\underline{Z}$ & $\underline{\mathrm{OR}}$ & $\underline{Z}$ & $\underline{\mathrm{OR}}$ & $\underline{Z}$ & $\underline{\mathrm{OR}}$ & $\underline{Z}$ & $\underline{\mathrm{OR}}$ & $\underline{z}$ \\
\hline Yrs NIST & 1.02 & 0.78 & $1.12 * *$ & 3.12 & 1.03 & 1.12 & 1.04 & 0.96 & 0.99 & -0.19 \\
\hline Male & 1.02 & 0.03 & 2.57 & 1.48 & 0.78 & -0.39 & 0.21 & -1.42 & 0.26 & -1.25 \\
\hline Constant & 1.75 & 0.91 & $.28 a$ & -1.79 & 2.56 & 1.39 & $11.17^{*}$ & 2.16 & 15.34 & 2.37 \\
\hline Pseud $\mathrm{R}^{2}$ & 0.006 & & 0.17 & & 0.02 & & 0.06 & & 0.03 & \\
\hline $\mathrm{N}$ & 91 & & 73 & & 83 & & 79 & & 71 & \\
\hline \multicolumn{11}{|c|}{ Band IV Versus Band III } \\
\hline & \multicolumn{2}{|c|}{$\underline{2000}$} & \multicolumn{2}{|c|}{$\underline{2005}$} & \multicolumn{2}{|c|}{$\underline{2010}$} & \multicolumn{2}{|c|}{$\underline{2015}$} & \multicolumn{2}{|c|}{$\underline{2019}$} \\
\hline Ind. Var. & $\underline{\mathrm{OR}}$ & $\underline{Z}$ & $\underline{\mathrm{OR}}$ & $\underline{Z}$ & $\underline{\mathrm{OR}}$ & $\underline{Z}$ & $\underline{\mathrm{OR}}$ & $\underline{Z}$ & $\underline{\mathrm{OR}}$ & $\underline{z}$ \\
\hline Yrs NIST & $1.06 * * *$ & 3.21 & $1.04^{*}$ & 2.09 & $1.07 * * *$ & 3.79 & $1.06^{* *}$ & 3.16 & $1.06 * * *$ & 3.22 \\
\hline Male & $3.99 * *$ & 2.98 & 2.19 & 1.63 & $2.47^{*}$ & 2.11 & $4.07^{* *}$ & 3.03 & $2.52^{*}$ & 1.99 \\
\hline Constant & $.16^{* * *}$ & -3.22 & 0.44 & -1.41 & $.31 *$ & -2.39 & $.22 * *$ & -2.91 & $.35^{*}$ & -2.07 \\
\hline Pseud $R^{2}$ & 0.09 & & 0.04 & & 0.09 & & 0.08 & & 0.07 & \\
\hline $\mathrm{N}$ & 161 & & 136 & & 169 & & 157 & & 153 & \\
\hline
\end{tabular}

Note: OR refers to odds ratio. ${ }^{*}$ indicates $p<.05,{ }^{* *} p<.01,{ }^{* * *} p<.001$. 
Table 12

Logistic Regression of Band III versus Band II and Band IV versus III on URM Status and Years at NIST by Year

\begin{tabular}{|c|c|c|c|c|c|c|c|c|c|c|}
\hline \multicolumn{11}{|c|}{ Band III Versus Band II } \\
\hline & \multicolumn{2}{|c|}{$\underline{2000}$} & \multicolumn{2}{|c|}{2005} & \multicolumn{2}{|c|}{$\underline{2010}$} & \multicolumn{2}{|c|}{$\underline{2015}$} & \multicolumn{2}{|c|}{2019} \\
\hline Ind. Var. & $\underline{\mathrm{OR}}$ & $\underline{Z}$ & $\underline{\mathrm{OR}}$ & $\underline{Z}$ & $\underline{\mathrm{OR}}$ & $\underline{z}$ & $\underline{\mathrm{OR}}$ & $\underline{z}$ & $\underline{\mathrm{OR}}$ & $\underline{Z}$ \\
\hline Yrs NIST & 1.03 & 1.00 & $1.11^{* *}$ & 0.04 & 1.04 & 1.36 & 1.05 & 1.25 & 1.00 & 0.03 \\
\hline URM & 0.52 & -1.15 & 0.9 & 0.72 & 3.56 & 1.16 & 1.55 & 0.53 & 0.75 & -0.32 \\
\hline Constant & 1.85 & 1.42 & 0.61 & 0.27 & 1.54 & 1.09 & $2.56^{*}$ & 2.16 & $4.59 * * *$ & 3.28 \\
\hline Pseud $R^{2}$ & 0.02 & & 0.14 & & 0.05 & & 0.03 & & 0.002 & \\
\hline $\mathrm{N}$ & 91 & & 73 & & 78 & & 79 & & 71 & \\
\hline \multicolumn{11}{|c|}{ Band IV Versus Band III } \\
\hline & \multicolumn{2}{|c|}{$\underline{2000}$} & \multicolumn{2}{|c|}{$\underline{2005}$} & \multicolumn{2}{|c|}{$\underline{2010}$} & \multicolumn{2}{|c|}{$\underline{2015}$} & \multicolumn{2}{|c|}{$\underline{2019}$} \\
\hline Ind. Var. & $\underline{O R}$ & $\underline{z}$ & $\underline{\mathrm{OR}}$ & $\underline{z}$ & $\underline{\mathrm{OR}}$ & $\underline{z}$ & $\underline{\mathrm{OR}}$ & $\underline{z}$ & $\underline{\mathrm{OR}}$ & $\underline{z}$ \\
\hline Yrs NIST & $1.06 * *$ & 3.14 & $1.04 *$ & 2.08 & $1.06 * * *$ & 3.27 & $1.05^{* *}$ & 3.00 & $1.06^{* *}$ & 3.11 \\
\hline URM & 0.64 & -0.96 & 0.46 & -1.42 & 0.48 & -1.51 & $.35^{*}$ & -2.11 & 1.02 & 0.03 \\
\hline Constant & 0.58 & -1.53 & 0.94 & -0.18 & 0.86 & -0.48 & 0.85 & -0.60 & 0.78 & -0.86 \\
\hline Pseud $R^{2}$ & 0.05 & & 0.04 & & 0.06 & & 0.06 & & 0.05 & \\
\hline $\mathrm{N}$ & 161 & & 136 & & 164 & & 157 & & 153 & \\
\hline
\end{tabular}

Note: OR refers to odds ratio. ${ }^{*}$ indicates $p<.05,{ }^{* *} p<.01,{ }^{* * *} p<.001$. 
Table 13

Women and URM Employees as a Percent of ZT Hires, Separations, and Current Employees by Year

\begin{tabular}{|c|c|c|c|c|c|c|}
\hline \multicolumn{7}{|c|}{ Women Employees } \\
\hline \multirow[b]{2}{*}{ Year } & \multirow[b]{2}{*}{$\underline{\text { Hires }}$} & \multicolumn{2}{|l|}{ Percentages } & \multicolumn{2}{|c|}{$\underline{\text { Ratios to Total }}$} & \multirow[b]{2}{*}{$\underline{\mathrm{N} \text { (total) }}$} \\
\hline & & $\underline{\text { Separations }}$ & All ZT & $\underline{\text { Hiring }}$ & $\underline{\text { Separation }}$ & \\
\hline 2000 & 34 & 23 & 18 & 1.9 & 1.3 & 240 \\
\hline 2005 & 22 & 26 & 18 & 1.2 & 1.5 & 215 \\
\hline 2010 & 22 & 24 & 17 & 1.3 & 1.4 & 221 \\
\hline 2015 & 14 & 17 & 17 & 0.8 & 1.0 & 206 \\
\hline 2019 & 29 & 16 & 16 & 1.8 & 1.0 & 191 \\
\hline \multicolumn{7}{|c|}{ URM Employees } \\
\hline & \multicolumn{3}{|c|}{ Percentages } & \multicolumn{2}{|c|}{ Ratios to Total } & \\
\hline Year & $\underline{\text { Hires }}$ & $\underline{\text { Separations }}$ & All ZT & $\underline{\text { Hiring }}$ & $\underline{\text { Separation }}$ & $\underline{\mathrm{N} \text { (total) }}$ \\
\hline 2000 & 16 & 19 & 15 & 1.1 & 1.3 & 240 \\
\hline 2005 & 10 & 14 & 10 & 1.0 & 1.4 & 215 \\
\hline 2010 & 6 & 5 & 12 & 0.5 & 0.4 & 221 \\
\hline 2015 & 10 & 12 & 14 & 0.8 & 0.9 & 206 \\
\hline 2019 & 21 & 16 & 13 & 1.7 & 1.3 & 191 \\
\hline
\end{tabular}

Note: Data on hirings and separations obtained from the "personnel action" file. Data on percentage of ZT's of all employees obtained from the "yearly" data file. Data from the personnel file were grouped into years as explained in the January document. 
Table 14

Women and URMs in U.S. STEM Labor Force and NIST ZT Employee Group

\begin{tabular}{lccccc}
\hline \multicolumn{7}{c}{ Women Employees in STEM } & & & \\
\hline Field & 1993 & $\underline{1999}$ & $\underline{2006}$ & $\underline{2013}$ & $\underline{2017}$ \\
Life and Related Sciences & 34 & 36 & 44 & 48 & 48 \\
Math and Computer Sciences & 31 & 27 & 27 & 25 & 27 \\
Physical Sciences & 21 & 23 & 28 & 31 & 29 \\
Social Sciences & 51 & 54 & 54 & 62 & 59 \\
Engineering & 9 & 9 & 12 & 15 & 16 \\
\hline \multicolumn{7}{c}{ URM Employees in STEM } & & & \\
\hline Field & 1993 & 1999 & 2006 & 2013 & 2017 \\
Life and Related Sciences & 7 & 6 & 8 & 10 & 11 \\
Math and Computer Sciences & 7 & 8 & 9 & 12 & 14 \\
Physical Sciences & 6 & 6 & 7 & 8 & 13 \\
Social Sciences & 9 & 9 & 11 & 12 & 24 \\
Engineering & 6 & 7 & 9 & 11 & 14 \\
\hline \multicolumn{7}{c}{ Women } & and URM ZT Employees in NIST & & \\
\hline & 2000 & 2005 & 2010 & 2015 & 2019 \\
Women & 18 & 18 & 17 & 17 & 16 \\
URM & 15 & 10 & 12 & 14 & 13 \\
\hline
\end{tabular}

Note: Data obtained from NSF Digests of Data on Women and Minorities in Science and Engineering

Table 15

ZP Employees by Band and Year

\begin{tabular}{lccccc} 
Band & 2000 & 2005 & 2010 & 2015 & 2019 \\
I & 5.4 & 4.9 & 4.5 & 2.2 & 2.3 \\
II & 3.0 & 4.2 & 2.8 & 2.4 & 1.8 \\
III & 22.2 & 18.7 & 23.1 & 24.3 & 22.6 \\
IV & 44.0 & 44.8 & 43.1 & 45.2 & 47.6 \\
V & 23.9 & 25.5 & 24.8 & 23.8 & 23.5 \\
ST & 1.5 & 2.0 & 1.7 & 2.2 & 2.1 \\
Total \% & 100 & 100 & 100 & 100 & 100 \\
Total N & 1,718 & 1,646 & 1,798 & 2,031 & 2,094 \\
\hline
\end{tabular}


Table 16

\begin{tabular}{cccccc}
\multicolumn{5}{c}{ Percent of ZP I and II Employees who were Women or Identified as URM by } & Band and Year \\
\hline \% Women & $\underline{2000}$ & $\underline{2005}$ & $\underline{2010}$ & $\underline{2015}$ & $\underline{2019}$ \\
Gr I & 23.9 & 20.0 & 20.0 & 29.6 & 18.4 \\
Gr II & 49.0 & 52.2 & 49.0 & 40.8 & 23.7 \\
Total & 32.9 & 34.9 & 31.3 & 35.5 & 20.7 \\
Chi-Square & $9.38^{* *}$ & $16.88^{* * *}$ & $12.20^{* * *}$ & 1.29 & 0.37 \\
\% URM & & & & & \\
Gr I & 4.4 & 6.2 & 0.0 & 11.4 & 6.1 \\
Gr II & 19.6 & 18.8 & 7.7 & 14.3 & 15.8 \\
Total & 9.8 & 12.1 & 4.4 & 12.9 & 10.3 \\
Chi-Square & $8.65^{* *}$ & $5.53^{*}$ & 2.41 & 1.8 & 2.16 \\
$\mathrm{~N}$ & 143 & 149 & 69 & 93 & 87 \\
\hline
\end{tabular}

* indicates $p<.05, * * p<.01, * * * p<.001$.

Table 17

Women and URM Employees as a Percent of ZP I and II Hires, Separations, and Current Employees by Year

\begin{tabular}{|c|c|c|c|c|c|c|}
\hline \multicolumn{7}{|c|}{ Women Employees } \\
\hline \multirow[b]{2}{*}{ Year } & \multirow[b]{2}{*}{$\underline{\text { Hires }}$} & \multirow{2}{*}{$\begin{array}{l}\text { Percentages } \\
\text { Separations }\end{array}$} & \multicolumn{4}{|c|}{ Ratios to Total } \\
\hline & & & $\underline{\text { All ZT }}$ & $\underline{\text { Hiring }}$ & Separation & $\underline{N}$ (total) \\
\hline 2000 & 33 & 23 & 32.9 & 1.0 & 0.7 & 143 \\
\hline 2005 & 31 & 28 & 34.9 & 0.9 & 0.8 & 149 \\
\hline 2010 & 21 & 27 & 31.3 & 0.7 & 0.8 & 69 \\
\hline 2015 & 31 & 28 & 35.5 & 0.9 & 0.8 & 93 \\
\hline 2019 & 25 & 33 & 20.7 & 1.2 & 1.6 & 87 \\
\hline \multicolumn{7}{|c|}{ URM Employees } \\
\hline & & \multicolumn{2}{|l|}{ Percentages } & \multicolumn{2}{|c|}{$\underline{\text { Ratios to Total }}$} & \\
\hline Year & $\underline{\text { Hires }}$ & $\underline{\text { Separations }}$ & $\underline{\text { All ZT }}$ & $\underline{\text { Hiring }}$ & Separation & $\underline{\mathrm{N} \text { (total) }}$ \\
\hline 2000 & 6 & 7 & 9.8 & 0.6 & 0.7 & 143 \\
\hline 2005 & 8 & 9 & 12.1 & 0.7 & 0.8 & 149 \\
\hline 2010 & 9 & 6 & 4.4 & 2.1 & 1.3 & 69 \\
\hline 2015 & 11 & 14 & 12.9 & 0.9 & 1.1 & 93 \\
\hline 2019 & 13 & 14 & 10.3 & 1.2 & 1.3 & 87 \\
\hline
\end{tabular}

Note: Data on hirings and separations obtained from the "personnel action" file. Data on percentage of ZP employees at Bands I and II obtained from the "yearly" data file. Data from the personnel file were grouped into years as explained in the January document. 
Table 18

Number of Personnel Actions, ZP I and II, 2000 to 2019, Involving Changes from Band I or II to other Bands, by Type of Action and Starting Band

\begin{tabular}{lccc}
\hline Action & Band I & Band II & Total \\
Hiring & 21 & 4 & 25 \\
Conversion & 61 & 51 & 112 \\
Promotion & 5 & 119 & 124 \\
Reassignment & ---- & 1 & 1 \\
Total & 87 & 175 & 262 \\
\hline
\end{tabular}

Table 19

Estimated Number of Conversion or Promotion Actions for ZP Employees at Bands I or II, by Year

$\underline{\text { Statistic }}$

$\underline{\text { Year }}$

N Promotions or

Conversions

Women

$\underline{2000}$

2005

$\underline{2010}$

$\underline{2015}$

$\underline{2019}$

URM

3

5

4

4

Total

2

1

1

1

1

14

10

14

12

Note: Numbers of personnel actions for each year were averaged across the span of years that corresponded to the data from the yearly data set. . 


\section{Report 4: Federal Employee Viewpoint Survey: Comparison of Views within NIST Labs $^{15}$}

This short report summarizes data on 71 questions regarding workplace climate from the Federal Employment Viewpoint Survey (FEVS) in laboratory operating units (OUs) at NIST. The FEVS survey involved series of questions concerning employees' work experiences, work unit, agency, supervisor, and satisfaction. Aggregate data were obtained from spreadsheets associated with the $4^{\text {th }}$ Level Sub agency Reports. The focus of analysis was the percentage of employees in each OU who gave positive responses to each question. These percentages were compared to responses of all NIST lab employees.

To facilitate the comparisons, two statistics were calculated. The first was a z-score testing the hypothesis that the proportion of employees expressing positive views within a given OU was equal to the proportion within NIST lab employees as a whole. The second was the effect size associated with this difference (Cohen's d). Z-scores and effect sizes were calculated for each question and then, for summary purposes, aggregated across each area of questions. Calculations were done in Excel and the equations used are in an appendix. The identifiers for OUs are correspond to those used in reports in Part I.

Table 1 reports average values associated with each set of questions for each OU. The top panel reports the average percentage of employees giving positive responses to questions in each area. Data for each area of the questionnaire are in rows and results for each $\mathrm{OU}$ are in the columns. For instance, data in the first row of the top panel indicate that, on average, $79 \%$ of employees in OU-D and OU-F gave positive responses to the questions regarding work experiences, while $81 \%$ of OU-G employees gave positive responses, etc. The bottom row of the panel gives the average percent of positive responses across each area for each $\mathrm{OU}$.

The second panel of Table 1 reports the average z-score for each area for each OU. Again, average values for each survey area are in the rows and results for each OU are in the columns. Z-scores greater than zero indicate that employees in an OU were more likely than NIST lab employees in general to express positive views. The bottom row of the panel reports the average z-score over all the areas examined. The third panel of Table 1 reports the effect sizes associated with the difference between the average for an OU and the total set of NIST lab employees, and the bottom row of the panel reports the average effect size for a unit across all the areas. While $z$-scores are affected by the number of cases in a comparison, effect sizes are not and thus can be more helpful in comparing results across the OUs. However, as would be expected, the pattern of results with the two measures was identical.

The results from OUs B and $E$ were very similar to the total group. Those from $D$ and $F$ were also similar to the total group with one exception. The percentage of OU-D employees having positive views related to the agency was less than that for all NIST lab employees, and the

\footnotetext{
15 This report was written by J. Stockard and completed February 2, 2020.
} 
percentage of OU-F employees having positive views regarding their work unit was less than that for all. Perhaps the most interesting comparison involves results for OUs $\mathrm{C}$ and $\mathrm{G}$. Employees in OU-G had consistently more positive views than other NIST lab employees, while those in OU-C had consistently more negative views. Differences in responses to the questions regarding supervisors and overall satisfaction were especially marked.

Tables 2, 3, and 4 give information for each of the individual questions. Table 2 reports the percentage of employees in each OU who gave positive responses. Table 3 reports the zscores comparing these percentages to those for the total group of NIST lab employees, and Table 4 gives the associated effect sizes. (Z-scores greater than 1.96 in absolute value would be considered significant at the .05 level; i.e. likely to have occurred by chance only $5 \%$ of the time or less.) From these tables it can be seen that the most troublesome areas for OU-C employees (the areas with the fewest employees giving positive responses relative to the total) involved a number of items related to promotion, evaluation, and support from supervisors (e.g. questions $15-19,22-23,33,37,43$ ), the quality of management practices (q47, 53, 54, 56 to 62) as well as concerns with having needed resources (q 9), and commitment to diversity (q35). They were much less likely than employees in other divisions to express satisfaction with various aspects of their job (q 63 to 70). Finally, employees in OU-C were significantly less likely than those in other areas to believe that the findings of the survey would be used to make the agency a better place (q41). 


\section{Tables}

Table 1

Summary of Positive Responses to FEVS and Comparisons to All NIST Lab Employees, by OU and Category of Questions

\begin{tabular}{lcccccc}
\hline \multicolumn{7}{c}{ Percentage Positive } \\
\hline Question Categories & $\underline{\mathrm{D}}$ & $\underline{\mathrm{F}}$ & $\underline{\mathrm{G}}$ & $\underline{\mathrm{C}}$ & $\underline{\mathrm{B}}$ & $\underline{\mathrm{E}}$ \\
Work Experience & $79 \%$ & $79 \%$ & $81 \%$ & $76 \%$ & $78 \%$ & $77 \%$ \\
Work Unit & $67 \%$ & $60 \%$ & $69 \%$ & $62 \%$ & $63 \%$ & $65 \%$ \\
Agency & $68 \%$ & $74 \%$ & $77 \%$ & $70 \%$ & $69 \%$ & $72 \%$ \\
Supervisor & $78 \%$ & $75 \%$ & $80 \%$ & $71 \%$ & $79 \%$ & $75 \%$ \\
Satisfaction & $67 \%$ & $64 \%$ & $69 \%$ & $57 \%$ & $64 \%$ & $62 \%$ \\
Average & $72 \%$ & $70 \%$ & $75 \%$ & $67 \%$ & $71 \%$ & $70 \%$ \\
\hline \multicolumn{1}{c}{ Z-Scores Comparing } & Average for & Each OU to & Overall Average for NIST Lab Employees \\
\hline Question Categories & $\underline{\mathrm{D}}$ & $\underline{\mathrm{F}}$ & $\underline{\mathrm{G}}$ & $\underline{\mathrm{C}}$ & $\underline{\mathrm{B}}$ & $\underline{\mathrm{E}}$ \\
Work Experience & 0.31 & -0.01 & 0.76 & -0.75 & -0.16 & -0.17 \\
Work Unit & 0.42 & -1.16 & 1.33 & -0.58 & 0.11 & 0.45 \\
Agency & -0.75 & 0.57 & 1.33 & -0.61 & 0.51 & -0.21 \\
Supervisor & 0.40 & 0.02 & 1.39 & -1.46 & -0.48 & -0.03 \\
Satisfaction & 0.52 & 0.41 & 1.52 & -1.84 & -0.20 & -0.34 \\
Average & 0.18 & -0.03 & 1.27 & -1.05 & -0.05 & -0.06 \\
\hline \multicolumn{1}{c}{ Effect Sizes (Cohen's d) Comparing Average for Each OU to Overall Average for NIST Lab Employees } \\
\hline Question Categories & $\underline{\mathrm{D}}$ & $\underline{\mathrm{F}}$ & $\underline{\mathrm{G}}$ & $\underline{\mathrm{C}}$ & $\underline{\mathrm{B}}$ & $\underline{\mathrm{E}}$ \\
Work Experience & 0.05 & 0.00 & 0.06 & -0.05 & -0.02 & -0.01 \\
Work Unit & 0.07 & -0.09 & 0.11 & -0.04 & 0.02 & 0.03 \\
Agency & -0.11 & 0.05 & 0.11 & -0.04 & 0.08 & -0.01 \\
Supervisor & 0.06 & 0.00 & 0.12 & -0.10 & -0.07 & 0.00 \\
Satisfaction & 0.08 & 0.03 & 0.13 & -0.12 & -0.03 & -0.02 \\
Average & 0.03 & 0.00 & 0.11 & -0.07 & -0.01 & 0.00 \\
\hline
\end{tabular}

There is no significance in ordering of OUs. OU-A does is not a research lab so not included. 
Table 2

Percentage of Positive Responses to All FEVS Questions by Lab, by Area of Survey

\begin{tabular}{|c|c|c|c|c|c|c|c|}
\hline \multicolumn{8}{|c|}{ Work Experience } \\
\hline & & $\underline{\mathrm{D}}$ & $\underline{F}$ & $\underline{\mathrm{G}}$ & $\underline{\mathrm{C}}$ & $\underline{B}$ & $\underline{E}$ \\
\hline 1) & $\begin{array}{l}\text { I am given a real opportunity to improve my } \\
\text { skills in my organization. }\end{array}$ & $89 \%$ & $83 \%$ & $90 \%$ & $81 \%$ & $83 \%$ & $81 \%$ \\
\hline 2) & I have enough information to do my job well. & $85 \%$ & $81 \%$ & $90 \%$ & $79 \%$ & $79 \%$ & $80 \%$ \\
\hline 3) & $\begin{array}{l}\text { I feel encouraged to come up with new and } \\
\text { better ways of doing things. }\end{array}$ & $86 \%$ & $76 \%$ & $81 \%$ & $76 \%$ & $82 \%$ & $79 \%$ \\
\hline 4) & $\begin{array}{l}\text { My work gives me a feeling of personal } \\
\text { accomplishment. }\end{array}$ & $88 \%$ & $86 \%$ & $83 \%$ & $84 \%$ & $86 \%$ & $85 \%$ \\
\hline 5) & I like the kind of work I do. & $96 \%$ & $89 \%$ & $91 \%$ & $93 \%$ & $88 \%$ & $88 \%$ \\
\hline 6) & I know what is expected of me on the job. & $77 \%$ & $81 \%$ & $80 \%$ & $77 \%$ & $74 \%$ & $82 \%$ \\
\hline 7) & $\begin{array}{l}\text { When needed I am willing to put in the extra } \\
\text { effort to get a job done. }\end{array}$ & $98 \%$ & $96 \%$ & $98 \%$ & $98 \%$ & $100 \%$ & $100 \%$ \\
\hline 8) & $\begin{array}{l}\text { I am constantly looking for ways to do my job } \\
\text { better. }\end{array}$ & $95 \%$ & $92 \%$ & $93 \%$ & $95 \%$ & $98 \%$ & $96 \%$ \\
\hline 9) & I have sufficient resources to get my job done. & $60 \%$ & $56 \%$ & $64 \%$ & $45 \%$ & $64 \%$ & $42 \%$ \\
\hline 10) & My workload is reasonable. & $56 \%$ & $61 \%$ & $73 \%$ & $59 \%$ & $71 \%$ & $51 \%$ \\
\hline 11) & My talents are used well in the workplace. & $69 \%$ & $62 \%$ & $76 \%$ & $67 \%$ & $66 \%$ & $72 \%$ \\
\hline 12) & $\begin{array}{l}\text { I know how my work relates to the agency's } \\
\text { goals. }\end{array}$ & $98 \%$ & $87 \%$ & $85 \%$ & $86 \%$ & $94 \%$ & $85 \%$ \\
\hline 13) & The work I do is important. & $98 \%$ & $89 \%$ & $88 \%$ & $93 \%$ & $100 \%$ & $92 \%$ \\
\hline 14) & $\begin{array}{l}\text { Physical conditions allow employees to } \\
\text { perform their jobs well. }\end{array}$ & $81 \%$ & $75 \%$ & $71 \%$ & $71 \%$ & $66 \%$ & $68 \%$ \\
\hline 15) & $\begin{array}{l}\text { My performance appraisal is a fair reflection of } \\
\text { my performance. }\end{array}$ & $70 \%$ & $75 \%$ & $76 \%$ & $67 \%$ & $58 \%$ & $76 \%$ \\
\hline 16) & I am held accountable for achieving results. & $81 \%$ & $88 \%$ & $85 \%$ & $82 \%$ & $87 \%$ & $88 \%$ \\
\hline 17) & $\begin{array}{l}\text { I can disclose a suspected violation of any law, } \\
\text { rule or regulation without fear of } \\
\text { reprisal. }\end{array}$ & $76 \%$ & $79 \%$ & $74 \%$ & $70 \%$ & $80 \%$ & $74 \%$ \\
\hline 18) & My training needs are assessed. & $51 \%$ & $63 \%$ & $65 \%$ & $51 \%$ & $61 \%$ & $57 \%$ \\
\hline 19) & $\begin{array}{l}\text { In my most recent performance appraisal, I } \\
\text { understood what I had to do to be rated at } \\
\text { different performance levels }\end{array}$ & $54 \%$ & $73 \%$ & $77 \%$ & $65 \%$ & $54 \%$ & $72 \%$ \\
\hline Ave & rage & $79 \%$ & $79 \%$ & $81 \%$ & $76 \%$ & $78 \%$ & $77 \%$ \\
\hline
\end{tabular}




\section{Work Unit}

\begin{tabular}{|c|c|c|c|c|c|c|c|}
\hline & & $\underline{\mathrm{D}}$ & $\underline{F}$ & $\underline{\mathrm{G}}$ & $\underline{\mathrm{C}}$ & $\underline{B}$ & $\underline{E}$ \\
\hline 20) & $\begin{array}{l}\text { The people I work with cooperate to get the job } \\
\text { done. }\end{array}$ & $83 \%$ & $83 \%$ & $86 \%$ & $83 \%$ & $77 \%$ & $83 \%$ \\
\hline 21) & $\begin{array}{l}\text { My work unit is able to recruit people with the } \\
\text { right skills. }\end{array}$ & $45 \%$ & $40 \%$ & $49 \%$ & $48 \%$ & $59 \%$ & $48 \%$ \\
\hline 22) & Promotions in my work unit are based on merit. & $55 \%$ & $53 \%$ & $64 \%$ & $51 \%$ & $52 \%$ & $56 \%$ \\
\hline 23) & $\begin{array}{l}\text { In my work unit, steps are taken to deal with a } \\
\text { poor performer who cannot or will not improve. }\end{array}$ & $54 \%$ & $35 \%$ & $44 \%$ & $32 \%$ & $40 \%$ & $46 \%$ \\
\hline 24) & $\begin{array}{l}\text { In my work unit, differences in performance are } \\
\text { recognized in a meaningful way. }\end{array}$ & $49 \%$ & $43 \%$ & $57 \%$ & $44 \%$ & $37 \%$ & $42 \%$ \\
\hline 25) & $\begin{array}{l}\text { Awards in my work unit depend on how well } \\
\text { employees perform their jobs. }\end{array}$ & $54 \%$ & $52 \%$ & $61 \%$ & $51 \%$ & $40 \%$ & $59 \%$ \\
\hline 26) & $\begin{array}{l}\text { Employees in my work unit share job knowledge } \\
\text { with each other. }\end{array}$ & $89 \%$ & $75 \%$ & $80 \%$ & $81 \%$ & $83 \%$ & $84 \%$ \\
\hline 27) & $\begin{array}{l}\text { The skill Band in my work unit has improved in } \\
\text { the past year. }\end{array}$ & $72 \%$ & $55 \%$ & $65 \%$ & $57 \%$ & $47 \%$ & $50 \%$ \\
\hline 28) & $\begin{array}{l}\text { How would you rate the overall quality of work } \\
\text { done by your work unit? }\end{array}$ & $86 \%$ & $86 \%$ & $95 \%$ & $90 \%$ & $96 \%$ & $93 \%$ \\
\hline 29) & $\begin{array}{l}\text { My work unit has the job-relevant knowledge } \\
\text { and skills necessary to accomplish organizational } \\
\text { goals. }\end{array}$ & $87 \%$ & $81 \%$ & $91 \%$ & $87 \%$ & $96 \%$ & $89 \%$ \\
\hline \multicolumn{2}{|r|}{ Average } & $67 \%$ & $60 \%$ & $69 \%$ & $62 \%$ & $63 \%$ & $65 \%$ \\
\hline \multicolumn{8}{|c|}{ Agency } \\
\hline 30) & $\begin{array}{l}\text { Employees have a feeling of personal } \\
\text { empowerment with respect to work processes. }\end{array}$ & $57 \%$ & $61 \%$ & $68 \%$ & $59 \%$ & $64 \%$ & $60 \%$ \\
\hline 31) & $\begin{array}{l}\text { Employees are recognized for providing high } \\
\text { quality products and services. }\end{array}$ & $65 \%$ & $69 \%$ & $74 \%$ & $67 \%$ & $70 \%$ & $71 \%$ \\
\hline 32) & Creativity and innovation are rewarded. & $59 \%$ & $64 \%$ & $70 \%$ & $62 \%$ & $54 \%$ & $67 \%$ \\
\hline 33) & $\begin{array}{l}\text { Pay raises depend on how well employees } \\
\text { perform their jobs. }\end{array}$ & $42 \%$ & $56 \%$ & $57 \%$ & $49 \%$ & $39 \%$ & $57 \%$ \\
\hline 34) & $\begin{array}{l}\text { Policies and programs promote diversity in the } \\
\text { workplace. }\end{array}$ & $64 \%$ & $68 \%$ & $81 \%$ & $59 \%$ & $60 \%$ & $59 \%$ \\
\hline 35) & $\begin{array}{l}\text { Employees are protected from health and safety } \\
\text { hazards on the job. }\end{array}$ & $88 \%$ & $94 \%$ & $95 \%$ & $97 \%$ & $87 \%$ & $92 \%$ \\
\hline 36) & $\begin{array}{l}\text { My organization has prepared employees for } \\
\text { potential security threats. }\end{array}$ & $85 \%$ & $87 \%$ & $94 \%$ & $89 \%$ & $84 \%$ & $87 \%$ \\
\hline
\end{tabular}




\begin{tabular}{|c|c|c|c|c|c|c|c|}
\hline & & $\underline{\mathrm{D}}$ & $\underline{F}$ & $\underline{G}$ & $\underline{C}$ & $\underline{B}$ & $\underline{E}$ \\
\hline 37) & $\begin{array}{l}\text { Arbitrary action, personal favoritism and } \\
\text { coercion for partisan political purposes are } \\
\text { not tolerated. }\end{array}$ & $75 \%$ & $80 \%$ & $73 \%$ & $67 \%$ & $67 \%$ & $74 \%$ \\
\hline 38) & $\begin{array}{l}\text { Prohibited Personnel Practices are not } \\
\text { tolerated. }\end{array}$ & $84 \%$ & $88 \%$ & $81 \%$ & $82 \%$ & $86 \%$ & $85 \%$ \\
\hline 39) & $\begin{array}{l}\text { My agency is successful at accomplishing its } \\
\text { mission. }\end{array}$ & $76 \%$ & $90 \%$ & $91 \%$ & $89 \%$ & $90 \%$ & $90 \%$ \\
\hline 40) & $\begin{array}{l}\text { I recommend my organization as a good } \\
\text { place to work. }\end{array}$ & $76 \%$ & $83 \%$ & $88 \%$ & $83 \%$ & $83 \%$ & $79 \%$ \\
\hline 41) & $\begin{array}{l}\text { I believe the results of this survey will be } \\
\text { used to make my agency a better place to } \\
\text { work. }\end{array}$ & $46 \%$ & $51 \%$ & $55 \%$ & $36 \%$ & $43 \%$ & $42 \%$ \\
\hline \multicolumn{2}{|c|}{ Average } & $68 \%$ & $74 \%$ & $77 \%$ & $70 \%$ & $69 \%$ & $72 \%$ \\
\hline \multicolumn{8}{|c|}{ Supervisor } \\
\hline 42) & $\begin{array}{l}\text { My supervisor supports my need to balance } \\
\text { work and other life issues. }\end{array}$ & $91 \%$ & $89 \%$ & $95 \%$ & $91 \%$ & $88 \%$ & $89 \%$ \\
\hline 43) & $\begin{array}{l}\text { My supervisor provides me with } \\
\text { opportunities to demonstrate my } \\
\text { leadership skills. }\end{array}$ & $78 \%$ & $80 \%$ & $81 \%$ & $71 \%$ & $67 \%$ & $79 \%$ \\
\hline 44) & $\begin{array}{l}\text { Discussions with my supervisor about my } \\
\text { performance are worthwhile. }\end{array}$ & $73 \%$ & $74 \%$ & $76 \%$ & $73 \%$ & $74 \%$ & $75 \%$ \\
\hline 45) & $\begin{array}{l}\text { My supervisor is committed to a workforce } \\
\text { representative of all segments of society. }\end{array}$ & $87 \%$ & $78 \%$ & $83 \%$ & $81 \%$ & $86 \%$ & $77 \%$ \\
\hline 46) & $\begin{array}{l}\text { My supervisor provides me with } \\
\text { constructive suggestions to improve my job } \\
\text { performance. }\end{array}$ & $75 \%$ & $73 \%$ & $75 \%$ & $71 \%$ & $70 \%$ & $73 \%$ \\
\hline 47) & $\begin{array}{l}\text { Supervisors in my work unit support } \\
\text { employee development. }\end{array}$ & $78 \%$ & $79 \%$ & $86 \%$ & $76 \%$ & $76 \%$ & $81 \%$ \\
\hline 48) & My supervisor listens to what I have to say. & $89 \%$ & $86 \%$ & $87 \%$ & $85 \%$ & $88 \%$ & $88 \%$ \\
\hline 49) & My supervisor treats me with respect. & $89 \%$ & $85 \%$ & $88 \%$ & $91 \%$ & $86 \%$ & $90 \%$ \\
\hline 50) & $\begin{array}{l}\text { In the last six months, my supervisor has } \\
\text { talked with me about my performance. }\end{array}$ & $94 \%$ & $93 \%$ & $90 \%$ & $89 \%$ & $75 \%$ & $89 \%$ \\
\hline 51) & $\begin{array}{l}\text { I have trust and confidence in my } \\
\text { supervisor. }\end{array}$ & $82 \%$ & $80 \%$ & $79 \%$ & $78 \%$ & $82 \%$ & $82 \%$ \\
\hline 52) & $\begin{array}{l}\text { Overall, how good a job do you feel is being } \\
\text { done by your immediate supervisor? }\end{array}$ & $80 \%$ & $75 \%$ & $81 \%$ & $78 \%$ & $80 \%$ & $86 \%$ \\
\hline 53) & $\begin{array}{l}\text { In my organization, senior leaders generate } \\
\text { high Bands of motivation and commitment } \\
\text { in the workforce. }\end{array}$ & $59 \%$ & $53 \%$ & $66 \%$ & $43 \%$ & $73 \%$ & $51 \%$ \\
\hline
\end{tabular}




\begin{tabular}{|c|c|c|c|c|c|c|c|}
\hline 54) & $\begin{array}{l}\text { My organization's senior leaders maintain } \\
\text { high standards of honesty and integrity. }\end{array}$ & $76 \%$ & $78 \%$ & $80 \%$ & $65 \%$ & $88 \%$ & $71 \%$ \\
\hline 55) & $\begin{array}{l}\text { Supervisors work well with employees of } \\
\text { different backgrounds. }\end{array}$ & $72 \%$ & $77 \%$ & $85 \%$ & $74 \%$ & $87 \%$ & $73 \%$ \\
\hline 56) & $\begin{array}{l}\text { Managers communicate the goals of the } \\
\text { organization. }\end{array}$ & $70 \%$ & $65 \%$ & $76 \%$ & $55 \%$ & $72 \%$ & $67 \%$ \\
\hline 57) & $\begin{array}{l}\text { Managers review and evaluate the } \\
\text { organization's progress toward meeting its } \\
\text { goals and objectives. }\end{array}$ & $66 \%$ & $71 \%$ & $72 \%$ & $56 \%$ & $73 \%$ & $65 \%$ \\
\hline 58) & $\begin{array}{l}\text { Managers promote communication among } \\
\text { different work units. }\end{array}$ & $68 \%$ & $59 \%$ & $68 \%$ & $53 \%$ & $69 \%$ & $61 \%$ \\
\hline 59) & $\begin{array}{l}\text { Managers support collaboration across } \\
\text { work units to accomplish work objectives. }\end{array}$ & $81 \%$ & $68 \%$ & $78 \%$ & $63 \%$ & $78 \%$ & $73 \%$ \\
\hline 60) & $\begin{array}{l}\text { Overall, how good a job do you feel is being } \\
\text { done by the manager directly above your } \\
\text { immediate supervisor? }\end{array}$ & $66 \%$ & $66 \%$ & $79 \%$ & $62 \%$ & $78 \%$ & $74 \%$ \\
\hline 61) & $\begin{array}{l}\text { I have a high Band of respect for my } \\
\text { organization's senior leaders. }\end{array}$ & $66 \%$ & $72 \%$ & $75 \%$ & $58 \%$ & $81 \%$ & $63 \%$ \\
\hline 62) & $\begin{array}{l}\text { Senior leaders demonstrate support for } \\
\text { Work-Life programs. }\end{array}$ & $92 \%$ & $78 \%$ & $84 \%$ & $69 \%$ & $84 \%$ & $64 \%$ \\
\hline \multicolumn{2}{|c|}{ Average } & $78 \%$ & $75 \%$ & $80 \%$ & $71 \%$ & 79\% & $75 \%$ \\
\hline
\end{tabular}

\section{Satisfaction}

\begin{tabular}{|c|c|c|c|c|c|c|c|}
\hline 63) & $\begin{array}{l}\text { How satisfied are you with your involvement in } \\
\text { decisions that affect your work? }\end{array}$ & $60 \%$ & $63 \%$ & $68 \%$ & $59 \%$ & $58 \%$ & $65 \%$ \\
\hline 64) & $\begin{array}{l}\text { How satisfied are you with the information you } \\
\text { receive from management on what's going on in } \\
\text { your organization? }\end{array}$ & $65 \%$ & $55 \%$ & $70 \%$ & $47 \%$ & $56 \%$ & $58 \%$ \\
\hline 65) & $\begin{array}{l}\text { How satisfied are you with the recognition you } \\
\text { receive for doing a good job? }\end{array}$ & $66 \%$ & $66 \%$ & $70 \%$ & $58 \%$ & $59 \%$ & $61 \%$ \\
\hline 66) & $\begin{array}{l}\text { How satisfied are you with the policies and practices } \\
\text { of your senior leaders? }\end{array}$ & $65 \%$ & $59 \%$ & $65 \%$ & $47 \%$ & $72 \%$ & $54 \%$ \\
\hline 67) & $\begin{array}{l}\text { How satisfied are you with your opportunity to get a } \\
\text { better job in your organization? }\end{array}$ & $51 \%$ & $44 \%$ & $49 \%$ & $39 \%$ & $43 \%$ & $44 \%$ \\
\hline 68) & $\begin{array}{l}\text { How satisfied are you with the training you receive } \\
\text { for your present job? }\end{array}$ & $71 \%$ & $73 \%$ & $74 \%$ & $59 \%$ & $72 \%$ & $64 \%$ \\
\hline 69) & $\begin{array}{l}\text { Considering everything, how satisfied are you with } \\
\text { your job? }\end{array}$ & $74 \%$ & $78 \%$ & $81 \%$ & $74 \%$ & $76 \%$ & $76 \%$ \\
\hline 70) & $\begin{array}{l}\text { Considering everything, how satisfied are you with } \\
\text { your pay? }\end{array}$ & $79 \%$ & $66 \%$ & $64 \%$ & $57 \%$ & $66 \%$ & $62 \%$ \\
\hline 71) & $\begin{array}{l}\text { Considering everything, how satisfied are you with } \\
\text { your organization? }\end{array}$ & $71 \%$ & $74 \%$ & $79 \%$ & $73 \%$ & $75 \%$ & $72 \%$ \\
\hline \multicolumn{2}{|c|}{ Average } & $67 \%$ & $64 \%$ & $69 \%$ & $57 \%$ & $64 \%$ & $62 \%$ \\
\hline
\end{tabular}


Table 3

Z-scores Comparing Percent Positive in Labs to Overall Lab Percentage by Lab and Question Number

\begin{tabular}{|c|c|c|c|c|c|c|}
\hline \multicolumn{7}{|c|}{ Work Experience } \\
\hline Item & $\underline{\mathrm{D}}$ & $\underline{F}$ & $\underline{G}$ & $\underline{\mathrm{C}}$ & $\underline{B}$ & $\underline{E}$ \\
\hline Q1 & 1.01 & -0.15 & 2.19 & -0.99 & 0.16 & -1.15 \\
\hline Q2 & 0.59 & -0.11 & 2.70 & -1.23 & 0.43 & -0.67 \\
\hline Q3 & 1.14 & -0.84 & 0.76 & -1.01 & -0.53 & -0.04 \\
\hline Q4 & 0.46 & 0.41 & -0.56 & -0.41 & -0.18 & -0.06 \\
\hline Q5 & 1.25 & -0.59 & 0.16 & 1.15 & 0.63 & -1.23 \\
\hline Q6 & -0.38 & 0.31 & 0.11 & -1.02 & 0.97 & 0.86 \\
\hline Q7 & -0.19 & -2.36 & -0.74 & 0.13 & -0.91 & 1.69 \\
\hline Q8 & 0.24 & -1.18 & -0.68 & 0.59 & -1.02 & 1.21 \\
\hline Q9 & 1.12 & 1.18 & 2.95 & -2.01 & -1.61 & -3.22 \\
\hline Q10 & -0.57 & 0.18 & 3.20 & -0.21 & -1.57 & -3.03 \\
\hline Q11 & -0.09 & -2.09 & 1.72 & -0.99 & 0.53 & 0.95 \\
\hline Q12 & 2.19 & -0.08 & -0.61 & -0.39 & -1.44 & -0.83 \\
\hline Q13 & 1.48 & -1.35 & -1.67 & 0.44 & -2.05 & 0.04 \\
\hline Q14 & 1.49 & 1.29 & 0.26 & 0.39 & 0.71 & -0.99 \\
\hline Q15 & -0.35 & 0.78 & 1.04 & -1.79 & 2.18 & 1.28 \\
\hline Q16 & -0.89 & 0.88 & -0.09 & -1.60 & -0.32 & 1.21 \\
\hline Q17 & 0.37 & 1.46 & 0.02 & -1.45 & -0.92 & 0.01 \\
\hline Q18 & -0.89 & 1.32 & 1.80 & -2.26 & -0.42 & -0.14 \\
\hline Q19 & -2.12 & 0.84 & 1.97 & -1.54 & 2.32 & 0.95 \\
\hline Average & 0.31 & -0.01 & 0.76 & -0.75 & -0.16 & -0.17 \\
\hline \multicolumn{7}{|c|}{ Work Unit } \\
\hline Q20 & 0.07 & 0.12 & 0.93 & 0.02 & 1.06 & -0.05 \\
\hline Q21 & -0.34 & -1.93 & 0.32 & 0.05 & -1.52 & 0.24 \\
\hline Q22 & 0.02 & -0.51 & 2.10 & -1.43 & 0.45 & 0.41 \\
\hline Q23 & 1.76 & -1.19 & 0.89 & -2.44 & 0.03 & 1.82 \\
\hline Q24 & 0.55 & -0.57 & 2.79 & -0.34 & 1.11 & -0.98 \\
\hline Q25 & -0.08 & -0.60 & 1.49 & -1.15 & 2.02 & 1.48 \\
\hline Q26 & 1.35 & -1.75 & -0.12 & 0.14 & -0.34 & 1.26 \\
\hline Q27 & 2.04 & -0.34 & 2.07 & 0.45 & 1.23 & -1.79 \\
\hline Q28 & -1.07 & -2.38 & 1.59 & -0.82 & -1.16 & 1.40 \\
\hline Q29 & -0.07 & -2.42 & 1.21 & -0.26 & -1.82 & 0.66 \\
\hline Average & 0.42 & -1.16 & 1.33 & -0.58 & 0.11 & 0.45 \\
\hline \multicolumn{7}{|c|}{ Agency } \\
\hline Q30 & -0.51 & -0.16 & 1.63 & -0.77 & -0.44 & -0.52 \\
\hline Q31 & -0.70 & -0.08 & 1.04 & -0.99 & -0.09 & 0.44 \\
\hline Q32 & -0.75 & -0.26 & 1.36 & -0.74 & 1.49 & 0.74 \\
\hline Q33 & -1.42 & 0.75 & 0.89 & -1.19 & 1.82 & 1.20 \\
\hline Q34 & 0.01 & 1.02 & 4.04 & -1.63 & 0.58 & -1.77 \\
\hline
\end{tabular}




\begin{tabular}{|c|c|c|c|c|c|c|}
\hline Q35 & -1.53 & 0.37 & 0.64 & 2.01 & 1.73 & -1.06 \\
\hline Q36 & -0.63 & -0.53 & 2.35 & 0.68 & 0.81 & -0.51 \\
\hline Q37 & 0.30 & 1.95 & 0.13 & -1.96 & 0.76 & 0.35 \\
\hline Q38 & 0.06 & 1.49 & -0.72 & -0.59 & -0.42 & 0.59 \\
\hline Q39 & -2.80 & 0.44 & 0.55 & 0.04 & -0.20 & 0.28 \\
\hline Q40 & -1.16 & 0.17 & 1.54 & 0.20 & -0.10 & -1.54 \\
\hline Q41 & 0.19 & 1.71 & 2.51 & -2.44 & 0.17 & -0.73 \\
\hline Average & -0.75 & 0.57 & 1.33 & -0.61 & 0.51 & -0.21 \\
\hline \multicolumn{7}{|c|}{ Supervisor } \\
\hline Q42 & 0.14 & -0.90 & 1.66 & -0.08 & 0.73 & -0.80 \\
\hline Q43 & 0.14 & 0.79 & 1.30 & -2.16 & 1.68 & 0.96 \\
\hline Q44 & -0.30 & -0.15 & 0.47 & -0.54 & 0.15 & 0.09 \\
\hline Q45 & 1.05 & -0.67 & 0.83 & 0.17 & -0.87 & -1.12 \\
\hline Q46 & 0.34 & -0.07 & 0.52 & -0.52 & 0.44 & -0.03 \\
\hline Q47 & -0.24 & -0.29 & 1.71 & -1.60 & 0.62 & 0.59 \\
\hline Q48 & 0.38 & -0.46 & 0.11 & -0.69 & -0.21 & 0.33 \\
\hline Q49 & -0.03 & -1.43 & -0.41 & 1.17 & 0.54 & 0.27 \\
\hline Q50 & 0.90 & 1.47 & 0.10 & -0.31 & 3.13 & -0.39 \\
\hline Q51 & 0.35 & 0.09 & -0.29 & -0.93 & -0.40 & 0.78 \\
\hline Q52 & -0.13 & -1.81 & 0.20 & -1.18 & 0.11 & 2.28 \\
\hline Q53 & 0.80 & 0.09 & 3.27 & -2.99 & -2.81 & -0.57 \\
\hline Q54 & 0.44 & 1.41 & 1.92 & -2.46 & -2.33 & -0.73 \\
\hline Q55 & -0.60 & 0.17 & 2.42 & -0.80 & -1.71 & -1.10 \\
\hline Q56 & 0.62 & 0.01 & 2.84 & -3.25 & -0.95 & 0.66 \\
\hline Q57 & 0.13 & 1.39 & 1.70 & -2.97 & -1.06 & -0.14 \\
\hline Q58 & 1.08 & -0.26 & 2.01 & -2.27 & -1.28 & 0.28 \\
\hline Q59 & 1.46 & -0.81 & 1.86 & -2.55 & -1.08 & 0.99 \\
\hline Q60 & -0.56 & -0.96 & 2.31 & -2.39 & -1.21 & 1.45 \\
\hline Q61 & -0.05 & 1.64 & 2.17 & -2.74 & -2.14 & -0.99 \\
\hline Q62 & 2.45 & 1.19 & 2.61 & -1.50 & -1.50 & -3.42 \\
\hline Average & 0.40 & 0.02 & 1.39 & -1.46 & -0.48 & -0.03 \\
\hline \multicolumn{7}{|c|}{ Satisfaction } \\
\hline Q63 & -0.50 & 0.01 & 1.09 & -1.34 & 0.72 & 0.40 \\
\hline Q64 & 1.08 & -0.41 & 3.15 & -3.07 & 0.04 & 0.46 \\
\hline Q65 & 0.38 & 0.78 & 1.70 & -1.68 & 0.49 & -0.67 \\
\hline Q66 & 1.16 & 0.84 & 2.13 & -2.79 & -2.15 & -0.81 \\
\hline Q67 & 0.90 & 0.00 & 1.37 & -1.52 & 0.05 & 0.07 \\
\hline Q68 & 0.60 & 1.66 & 1.75 & -2.54 & -0.75 & -1.04 \\
\hline Q69 & -0.55 & 0.29 & 1.17 & -1.27 & 0.18 & -0.29 \\
\hline Q70 & 2.12 & 0.68 & 0.09 & -1.98 & -0.33 & -0.41 \\
\hline Q71 & -0.55 & -0.19 & 1.22 & -0.37 & -0.09 & -0.76 \\
\hline
\end{tabular}


Table 4

Effect Sizes Comparing Percent Positive in Labs to Overall Lab Percentage by Lab and Question Number

\begin{tabular}{|c|c|c|c|c|c|c|}
\hline Item & $\underline{D}$ & $\underline{F}$ & $\underline{\mathrm{G}}$ & $\underline{\mathrm{C}}$ & $\underline{B}$ & $\underline{E}$ \\
\hline \multicolumn{7}{|c|}{ Work Experiences } \\
\hline Q1 & 0.15 & -0.01 & 0.18 & -0.06 & 0.02 & -0.07 \\
\hline Q2 & 0.09 & -0.01 & 0.22 & -0.08 & 0.06 & -0.04 \\
\hline Q3 & 0.17 & -0.07 & 0.06 & -0.06 & -0.08 & 0.00 \\
\hline Q4 & 0.07 & 0.03 & -0.05 & -0.03 & -0.03 & 0.00 \\
\hline Q5 & 0.19 & -0.05 & 0.01 & 0.07 & 0.09 & -0.07 \\
\hline Q6 & -0.06 & 0.02 & 0.01 & -0.06 & 0.14 & 0.05 \\
\hline Q7 & -0.03 & -0.18 & -0.06 & 0.01 & -0.13 & 0.10 \\
\hline Q8 & 0.04 & -0.09 & -0.06 & 0.04 & -0.15 & 0.07 \\
\hline Q9 & 0.17 & 0.09 & 0.24 & -0.13 & -0.24 & -0.19 \\
\hline Q10 & -0.08 & 0.01 & 0.26 & -0.01 & -0.23 & -0.18 \\
\hline Q11 & -0.01 & -0.17 & 0.14 & -0.06 & 0.08 & 0.06 \\
\hline Q12 & 0.33 & -0.01 & -0.05 & -0.02 & -0.21 & -0.05 \\
\hline Q13 & 0.22 & -0.11 & -0.14 & 0.03 & -0.30 & 0.00 \\
\hline Q14 & 0.22 & 0.10 & 0.02 & 0.02 & 0.10 & -0.06 \\
\hline Q15 & -0.05 & 0.06 & 0.09 & -0.11 & 0.31 & 0.08 \\
\hline Q16 & -0.13 & 0.07 & -0.01 & -0.10 & -0.05 & 0.07 \\
\hline Q17 & 0.06 & 0.12 & 0.00 & -0.09 & -0.14 & 0.00 \\
\hline Q18 & -0.13 & 0.11 & 0.15 & -0.14 & -0.06 & -0.01 \\
\hline Q19 & -0.33 & 0.07 & 0.16 & -0.10 & 0.33 & 0.06 \\
\hline Average & 0.05 & 0.00 & 0.06 & -0.05 & -0.02 & -0.01 \\
\hline \multicolumn{7}{|c|}{ Work Unit } \\
\hline Q20 & 0.01 & 0.01 & 0.08 & 0.00 & 0.15 & 0.00 \\
\hline Q21 & -0.05 & -0.15 & 0.03 & 0.00 & -0.22 & 0.01 \\
\hline Q22 & 0.00 & -0.04 & 0.18 & -0.09 & 0.07 & 0.03 \\
\hline Q23 & 0.28 & -0.10 & 0.08 & -0.17 & 0.01 & 0.12 \\
\hline Q24 & 0.09 & -0.05 & 0.25 & -0.02 & 0.16 & -0.06 \\
\hline Q25 & -0.01 & -0.05 & 0.13 & -0.08 & 0.30 & 0.09 \\
\hline Q26 & 0.20 & -0.14 & -0.01 & 0.01 & -0.05 & 0.08 \\
\hline Q27 & 0.32 & -0.03 & 0.18 & 0.03 & 0.18 & -0.11 \\
\hline Q28 & -0.16 & -0.19 & 0.13 & -0.05 & -0.17 & 0.08 \\
\hline Q29 & -0.01 & -0.19 & 0.10 & -0.02 & -0.27 & 0.04 \\
\hline Average & 0.07 & -0.09 & 0.11 & -0.04 & 0.02 & 0.03 \\
\hline \multicolumn{7}{|c|}{ Agency } \\
\hline Q30 & -0.08 & -0.01 & 0.14 & -0.05 & -0.07 & -0.03 \\
\hline Q31 & -0.11 & -0.01 & 0.09 & -0.06 & -0.01 & 0.03 \\
\hline Q32 & -0.11 & -0.02 & 0.12 & -0.05 & 0.22 & 0.05 \\
\hline Q33 & -0.23 & 0.06 & 0.08 & -0.08 & 0.28 & 0.08 \\
\hline
\end{tabular}




\begin{tabular}{|c|c|c|c|c|c|c|}
\hline Q34 & 0.00 & 0.09 & 0.34 & -0.11 & 0.09 & -0.11 \\
\hline Q35 & -0.23 & 0.03 & 0.05 & 0.13 & 0.26 & -0.06 \\
\hline Q36 & -0.10 & -0.04 & 0.19 & 0.04 & 0.12 & -0.03 \\
\hline Q37 & 0.05 & 0.16 & 0.01 & -0.13 & 0.12 & 0.02 \\
\hline Q38 & 0.01 & 0.12 & -0.06 & -0.04 & -0.07 & 0.04 \\
\hline Q39 & -0.43 & 0.04 & 0.05 & 0.00 & -0.03 & 0.02 \\
\hline Q40 & -0.18 & 0.01 & 0.13 & 0.01 & -0.01 & -0.09 \\
\hline Q41 & 0.03 & 0.14 & 0.21 & -0.16 & 0.03 & -0.05 \\
\hline Average & -0.11 & 0.05 & 0.11 & -0.04 & 0.08 & -0.01 \\
\hline \multicolumn{7}{|c|}{ Supervisor } \\
\hline Q42 & 0.02 & -0.07 & 0.14 & -0.01 & 0.11 & -0.05 \\
\hline Q43 & 0.02 & 0.06 & 0.11 & -0.14 & 0.25 & 0.06 \\
\hline Q44 & -0.05 & -0.01 & 0.04 & -0.03 & 0.02 & 0.01 \\
\hline Q45 & 0.16 & -0.06 & 0.07 & 0.01 & -0.14 & -0.07 \\
\hline Q46 & 0.05 & -0.01 & 0.04 & -0.03 & 0.07 & 0.00 \\
\hline Q47 & -0.04 & -0.02 & 0.14 & -0.10 & 0.09 & 0.04 \\
\hline Q48 & 0.06 & -0.04 & 0.01 & -0.04 & -0.03 & 0.02 \\
\hline Q49 & -0.01 & -0.12 & -0.03 & 0.07 & 0.08 & 0.02 \\
\hline Q50 & 0.14 & 0.12 & 0.01 & -0.02 & 0.46 & -0.02 \\
\hline Q51 & 0.05 & 0.01 & -0.02 & -0.06 & -0.06 & 0.05 \\
\hline Q52 & -0.02 & -0.15 & 0.02 & -0.08 & 0.02 & 0.14 \\
\hline Q53 & 0.12 & 0.01 & 0.28 & -0.19 & -0.41 & -0.04 \\
\hline Q54 & 0.07 & 0.12 & 0.17 & -0.17 & -0.36 & -0.05 \\
\hline Q55 & -0.09 & 0.01 & 0.21 & -0.05 & -0.26 & -0.07 \\
\hline Q56 & 0.09 & 0.00 & 0.24 & -0.21 & -0.14 & 0.04 \\
\hline Q57 & 0.02 & 0.11 & 0.14 & -0.20 & -0.16 & -0.01 \\
\hline Q58 & 0.17 & -0.02 & 0.17 & -0.15 & -0.19 & 0.02 \\
\hline Q59 & 0.22 & -0.07 & 0.16 & -0.16 & -0.16 & 0.06 \\
\hline Q60 & -0.09 & -0.08 & 0.20 & -0.16 & -0.18 & 0.09 \\
\hline Q61 & -0.01 & 0.13 & 0.18 & -0.18 & -0.32 & -0.06 \\
\hline Q62 & 0.40 & 0.10 & 0.23 & -0.10 & -0.22 & -0.22 \\
\hline Average & 0.06 & 0.00 & 0.12 & -0.10 & -0.07 & 0.00 \\
\hline \multicolumn{7}{|c|}{ Satisfaction } \\
\hline Q63 & -0.08 & 0.00 & 0.09 & -0.09 & 0.11 & 0.02 \\
\hline Q64 & 0.17 & -0.03 & 0.26 & -0.20 & 0.01 & 0.03 \\
\hline Q65 & 0.06 & 0.06 & 0.14 & -0.11 & 0.07 & -0.04 \\
\hline Q66 & 0.18 & 0.07 & 0.18 & -0.18 & -0.32 & -0.05 \\
\hline Q67 & 0.14 & 0.00 & 0.11 & -0.10 & 0.01 & 0.00 \\
\hline Q68 & 0.09 & 0.13 & 0.15 & -0.16 & -0.11 & -0.06 \\
\hline Q69 & -0.08 & 0.02 & 0.10 & -0.08 & 0.03 & -0.02 \\
\hline Q70 & 0.32 & 0.06 & 0.01 & -0.13 & -0.05 & -0.02 \\
\hline Q71 & -0.08 & -0.02 & 0.10 & -0.02 & -0.01 & -0.05 \\
\hline Average & 0.08 & 0.03 & 0.13 & -0.12 & -0.03 & -0.02 \\
\hline
\end{tabular}




\section{Appendix}

\section{Formulas Used for Computations}

The comparison of proportions in the organizational units to the proportions in the total sample of NIST labs is an example of testing the difference between a sample statistic (Ps, the proportion in a given organizational unit) and the population parameter ( $\mathrm{Pu}$, or the proportion for all NIST lab employees). The standard deviation of the population is defined as

$s d=\operatorname{sqrt}\left(P u^{*} Q u\right)$, where $Q u=1-P u$.

The standard error for a given organizational unit $\mathrm{i}$ is defined as

s.e. $i=s d /\left(s q r t(n\right.$,$) , where n_{i}$ refers to the number of respondents in organizational unit $i$ and $s d$ is the standard deviation of the population (the total group of NIST lab employees).

The formulas for the z-ratio and the effect size (Cohen's d) differ only in the denominator:

$Z_{i}=(P s-P u) / s \cdot e \cdot i$ and

$d=(P s=P u) / s d$.

Probabilities associated with the $z$ value can be obtained from a normal curve table. As a point of reference, $z$ values of 1.96 or larger in absolute value would occur by chance less than $5 \%$ of the time. 


\section{Part II \\ Survey of ZP Employees in Bands III and Higher}

An on-line survey of NIST ZP employees in Bands III and higher was distributed in March, 2020, and over 600 employees (about a third of all who were contacted) responded. Three reports were written regarding these data: 1 ) a relatively short, summary analysis of the results (Report 5); 2) a longer, largely quantitative, analysis with extensive explanations (Report 6); and 3) an analysis of characteristics of those who provided open-ended comments regarding the promotion process and all of these comments (Report 7). Respondents' comments have been edited to remove information that might be used to identify individuals. Note that Report 6 is relatively long. Thus, to help guide the reader, it begins with an outline of the contents and a list of tables. References to tables in this introductory material are to the tables in Report 6.

Comparisons to available data on all employees indicated that, while respondents were relatively representative of the population, women, younger employees and those in certain OUs were more likely to respond. Thus, frequency distributions were weighted to reflect the population more closely (Tables 1, 2, and A-1). Responses regarding employees' experiences with promotion, including time at band and before their last promotion, paralleled analyses of data obtained from NIST HR (Tables 3, A-2, and A-3), providing further evidence that the sample was relatively representative of the population.

Separate sets of questions dealt with the criteria for promotion from III to IV, IV to V, V to Senior Scientist, and employees' own experiences with the process. Questions regarding promotion criteria involved the extent to which employees understood the criteria, the extent to which others understood the criteria, whether they were fairly applied, appropriate for people in their OU, and reflected NIST's stated mission. Questions regarding employees' experiences involved confidence that their accomplishments would be recognized and rewarded, whether they had productive conversations with their supervisor about career progress, and the extent to which their own experiences with the promotion process, as well as the experiences of others, had been productive.

Respondents seemed careful to indicate when they didn't know enough to give a valid answer. Bivariate and multivariate analyses were used to examine factors related to giving responses. Seniority was the most consistent predictor of whether or not individuals felt they knew enough to give a response. Those who had been at NIST for a longer period of time were more likely to respond to questions (in Report 6 :Tables 8, A-6, A-7, A-9, A-10, A-12, A-13, A-14, A-17, A-24).

On average, employees' views regarding NIST promotion policies were neutral to relatively negative. Views were more positive about the III-IV transition than from IV to V, views regarding IV-V were more positive than those regarding $\mathrm{V}$ to $\mathrm{ST}$, and these differences were highly significant. Reports of their own experiences also were, on average, neutral to relatively negative (in Report 6: Tables 4, 6, 9, 11). There were also differences between employees in their 
perceptions of promotion, with some having more favorable views than others. To understand these variations bivariate and multivariate techniques were used to systematically look at the association of perceptions with socio-demographic variables (gender, identification as an underrepresented minority, highest degree, field of highest degree, having held a leadership position at NIST, current band, years at NIST, and age) and employment-related variables (years employed at NIST, other experiences in the federal government or at NIST, previous promotion experiences, and operating unit) (in Report 6: Tables 5, 7, 10, 12, 16, A-8, A-11, A-15, A-16, A-18, A-19).

A number of factors were not related to employees' views about promotion including their highest degree, the discipline of this degree, previous types of federal employment, and operating unit. Employees who identified as under-represented minorities had significantly more negative views of the promotion process and their own experiences but, unfortunately, there were too few cases within this group to allow valid multivariate analyses. Women had more negative views than men, but these differences were often not statistically significant when factors such as seniority were controlled or in analyses within various subgroups. Respondents' with more timely promotion experiences were more likely to have positive views, although this result did not appear in all analyses or with all subgroups. The most consistent correlate of positive views was employees' seniority at NIST. Those who were older, had held leadership posts, had been employed at NIST for a longer period of time and were at higher bands had more positive views of the transition from III to IV, IV to V, and their own experiences. Results were more complex with views regarding the $V$ to ST transition. In this analysis the years employees had been at NIST was not related to views and the impact of band was curvilinear with those at the highest band (i.e. ST) having the most positive views.

Open-ended comments provided greater insight into employees' views about the promotion process. Report 6 includes discusses these comments and provides examples, and Report 7 includes all of the comments that were provided.

Substantial proportions of the respondents reported that they had taken or planned to engage in courses or training related to leadership skills, communication, and conflict resolution. Only a minority indicated they weren't aware of such opportunities. Respondents with more seniority, those outside of physics, and women were more likely to have taken the trainings listed in the survey, while men, those in physics, as well as those not in leadership roles were more likely to say they did not want to do so (Tables 13, 14, 15, and A-20, A-21, A-22, A-23). Openended comments regarding the types of professional training employees had experienced or would like to experience are included in Report 6 (Appendices B and C). A list of professional development opportunities that were desired by employees is in Appendix $A$ of this full report (following Report 11). 


\section{Report 5: Survey of NIST ZP Employees: Summary of Findings ${ }^{16}$}

In 2019 NIST contracted with COACh "to implement a data-driven study to examine the causes of inequity in promotions at NIST, and to develop draft recommendations." As part of that work COACh initially examined data on the NIST work force and personnel actions supplied by the HR office, focusing on Federal STEM Workforce ZP employees in Bands III and higher. The analysis indicated that the percentage of women at Band IV increased over time and, by 2019, essentially matched the percentage of women in the total group of employees. However, women were still under-represented at Band $\mathrm{V}$, and one operating unit appeared to have more inequities than others. There was little evidence from the available data that women remained in band for significantly longer periods than men, that they were significantly less likely to hold supervisory positions, or that they had lower salaries at the time of hire. The number of under-represented minorities was too small to allow similar analyses. There appeared to be little change over time in the numbers of women and minorities who were hired and also some indications that retention of women and minorities might be problematic. Data suggested that the older age composition of NIST employees was related to the probability that employees could advance to higher bands. We also reviewed summaries of responses to questions regarding workplace climate in the Federal Employee Viewpoint Survey. This analysis indicated that views were more negative in some operating units than in others and that these differences paralleled those found in the analysis of the HR data.

Data summarized in this short report were obtained from an on-line survey of NIST ZP employees in Bands III and higher that was distributed in March, 2020. ${ }^{17}$ Over 600 employees responded, representing about a third of those who received the invitation to participate. Data indicated that those who returned the survey were more often women, younger employees, and in certain operating units than would be expected given the characteristics of those invited to participate. The univariate results below adjust for those differences.

Analysis of respondents' reports of their time at band, years before obtaining promotion, and being hired at rank were similar to the results from the HR data. Men had been at band longer than women at each band examined (III, IV, and V and higher). Women reported slightly more time before promotion to IV, while men reported slightly more time before promotion to V. Men were slightly more likely to be hired at Band IV, while women were more likely to be hired at $\mathrm{V}$. None of the comparisons was large enough to be considered statistically significant. (See

\footnotetext{
16 This report was written by J. Stockard and completed May 12, 2020.

${ }^{17}$ Full statistical analyses of the data provided by HR and the FEV Survey, as well as an extensive analysis of the survey data summarized in this document, are in companion reports (Reports 1 to 4 ). The information in this document is only a summary of the findings.
} 
Table 1.) In contrast to results obtained in analysis of the HR data, there were no differences among operating units in employees' reports of time at band or before the last promotion. ${ }^{18}$

Employees were asked a series of five questions about the criteria for promotion from III to IV, IV to V, and V to Senior Scientist (ST). These questions involved their own understanding, understanding of others, application of the criteria, and the extent to which they were appropriate for their operating unit and for the mission of NIST. Their answers are summarized in Table 2, with the percentage of respondents disagreeing or strongly disagreeing in the three left-hand columns of data and the percentage agreeing or strongly agreeing in the right-hand columns. Within each set of responses, the first column of data refers to promotion from III to IV, the second to promotion from IV to V, and the third from V to Senior Scientist. The data indicate that fewer than half of the respondents agreed with any of the statements. Views of the process from III to IV were more positive than those from IV to V, and views of the process from $\checkmark$ to ST were the least positive. Respondents were more likely to agree that promotion criteria were appropriate for their OU and reflected NIST's mission than to agree that most ZP employees understood the criteria or that they were fairly applied.

Extensive statistical analyses, fully documented in the companion document, were used to understand factors that might explain why some employees had more favorable views of the promotion process. Employees' seniority within NIST was the most powerful predictor, and the timely nature of respondents' own promotion experience was also generally important. Bivariate analyses indicated that women had less favorable views than men, but multivariate analyses revealed that, in a majority of the analyses, men and women at the same band had views of the promotion process that were statistically indistinguishable. There were no differences in views among operating units, employees from different disciplines, with different terminal degrees, or with other employment experiences in the government.

Table 3 presents data that illustrate these relationships, showing the average views across the questions regarding the promotion process for each band of promotion by gender, promotion experiences, and band. (Scale values ranged from 1 to 5 with 5 indicating strong agreement. Values that can be rounded to 4.0 would indicate agreement, on average, with the statements.) Results show that, on average, only employees currently at Band $\mathrm{V}$ or higher expressed agreement with the statements regarding promotion from III to IV; and only men at the highest bands expressed agreement with the statements regarding promotion from IV to V. No subgroup of employees - regardless of their gender, individual experiences with promotion, or current band - agreed, on average, that the process for promotion from V to ST was understood, fair, appropriate for their OU, or reflected NIST's mission. Bivariate analyses showed that employees who identified as URM expressed significantly less positive views.

\footnotetext{
${ }^{18}$ Given the very small number of employees from under-represented minority groups we were usually not able to conduct valid statistical comparisons of members of these groups to others. This should not indicate a lack of concern with this population but, instead the extent of potential issues with hiring and retention.
} 
After answering questions about the promotion process, respondents were asked a series of questions about their own experiences. Table 4 shows the percentage of respondents who marked each possible answer to these questions. As with views of the promotion process, there was substantial variability in employees' views. Slightly more than four-fifths reported that they had productive, annual conversations with their supervisor regarding their career progress. Slightly fewer indicated that they had or expected to have positive experiences with the promotion process. Only about a third indicated that they and/or people that they knew had had positive experiences. Extensive statistical analyses revealed that men, those in the highest bands, and those who had experienced timely promotions had more positive views. However, among those at Bands III and IV gender differences were not strong enough to be statistically significant. In addition, as with views of the general promotion process, there were no differences in respondents' reports between operating units, employees with degrees in different disciplines, with different terminal degrees, other employment experiences in the government, or when they returned the survey.

Table 5 shows average scores across the questions regarding respondents' promotion experiences and parallels the construction of Table 3. As with the data in Table 3, average values that can be rounded to 4.0 indicate agreement to the questions and thus a positive view of their experiences. Average values across the sub-groups ranged from 2.7 for women in Band III with less than timely experiences to 3.9 for men in Band $V$ and higher. The only sub-groups in which the average response would indicate agreement are those in Band $V$ and higher. In all other categories, average values indicate a neutral depiction of their promotion experiences.

Respondents were invited to provide additional comments on the NIST promotion process, and slightly over two-fifths of the respondents $(n=263)$ did so. Those who provided comments had more negative perceptions of the promotion process in general and more negative reports of their own experiences. Women employees and those at Band IV were more likely to provide responses. Half of the responses $(n=132)$ involved the promotion process, and a slightly smaller number (112) reflected concerns with transparency of standards and the process of making decisions.

The final set of substantive questions asked the employees about professional development opportunities that they had experienced or wished to have. Over half of the respondents indicated that they had taken courses related to leadership skills and communication, and slightly fewer reported taking courses related to conflict resolution. About a fourth reported instruction in federal regulations, and a tenth indicated that they had received instruction in budget skills. About a fifth of respondents indicated that they planned to take courses related to leadership skills, communication skills, and conflict resolution; and many were interested in learning more about "detail" assignments, often suggesting this would help chances for promotion. Respondents who were more senior in their careers were more likely to have taken classes, and those with less seniority were more likely to plan to take courses in the future. 


\section{Tables}

Table 1

Time at Band, Time Before Promotion, and Hired at Band by Gender and Band

\begin{tabular}{|c|c|c|c|}
\hline \multicolumn{4}{|c|}{$\%$ At Band for 6 or More years } \\
\hline Band & Women & Men & Chi-square \\
\hline III & 19.7 & 27.8 & $1.28, p=.26$ \\
\hline IV & 45.8 & 52.2 & $.96, p=.33$ \\
\hline V or Higher & 55.8 & 63.8 & $.88, p=.35$ \\
\hline \multicolumn{4}{|c|}{$\%$ At Band 6 or More Years Before Last Promotion } \\
\hline Band & Women & Men & $\underline{\text { Chi-square }}$ \\
\hline IV & 58.8 & 45.0 & $3.20, p=.07$ \\
\hline V or Higher & 63.9 & 75.4 & $1.83, p=.18$ \\
\hline \multicolumn{4}{|c|}{$\%$ Hired at Band } \\
\hline Band & Women & Men & Chi-square \\
\hline IV & 28.4 & 31.9 & $.34, p=.56$ \\
\hline V or Higher & 14.3 & 7.6 & $1.66, p=.20$ \\
\hline
\end{tabular}


Table 2

Percent of Respondents Agreeing or Disagreeing with Characteristics of the Promotion Process by Type of Transition

\begin{tabular}{|c|c|c|c|c|c|c|}
\hline \multirow[b]{2}{*}{ Question } & \multicolumn{3}{|c|}{$\frac{\text { Disagree or Strongly }}{\text { Disagree }}$} & \multicolumn{3}{|c|}{ Agree or Strongly Agree } \\
\hline & III to IV & IV to $\mathrm{V}$ & V to ST & III to IV & IV to $\mathrm{V}$ & $\underline{V}$ to $S T$ \\
\hline $\begin{array}{l}\text { I understand what is needed to gain } \\
\text { promotion from.... }\end{array}$ & 38 & 42 & 65 & 45 & 43 & 22 \\
\hline $\begin{array}{l}\text { Most NIST ZP employees understand } \\
\text { what is needed to gain promotion from } \\
\text {... }\end{array}$ & 45 & 53 & 76 & 30 & 26 & 10 \\
\hline $\begin{array}{l}\text { The promotion criteria for promotion } \\
\text { from ... are fairly applied. }\end{array}$ & 38 & 46 & 45 & 36 & 30 & 23 \\
\hline $\begin{array}{l}\text { The promotion criteria from ... are } \\
\text { appropriate for people in my operating } \\
\text { unit. }\end{array}$ & 26 & 34 & 36 & 47 & 42 & 32 \\
\hline $\begin{array}{l}\text { The promotion criteria from ... reflect } \\
\text { the stated mission of NIST. }\end{array}$ & 30 & 33 & 34 & 41 & 39 & 32 \\
\hline
\end{tabular}

Note: All results are based on data weighted to more accurately reflect the population. Respondents who did not answer a question or who marked "don't know" or neutral are omitted. See the full report for complete details including results with other measures and both bivariate and multivariate analyses. 
Table 3

Average Score, Perceptions of Promotion Process by Promotion Experiences, Gender, Band, and Band of Promotions

\begin{tabular}{|c|c|c|c|c|c|c|}
\hline \multicolumn{7}{|c|}{ Band III to IV } \\
\hline & \multicolumn{2}{|c|}{ Band III } & \multicolumn{2}{|c|}{ Band IV } & \multicolumn{2}{|c|}{ Band $V$ and Higher } \\
\hline Promotion Exper. & Women & $\underline{\text { Men }}$ & Women & $\underline{\text { Men }}$ & Women & Men \\
\hline Less than Timely & 2.4 & 2.5 & 2.9 & 3.3 & 3.5 & 3.6 \\
\hline Timely & 2.6 & 2.8 & 3.1 & 3.2 & 3.5 & 3.8 \\
\hline \multicolumn{7}{|c|}{ Band IV to V } \\
\hline & \multicolumn{2}{|c|}{ Band III } & \multicolumn{2}{|c|}{ Band IV } & \multicolumn{2}{|c|}{ Band $V$ and Higher } \\
\hline Promotion Exper. & $\underline{\text { Women }}$ & Men & Women & $\underline{\text { Men }}$ & Women & $\underline{\text { Men }}$ \\
\hline Less than Timely & 2.2 & 2.5 & 2.5 & 2.9 & 3.1 & 3.6 \\
\hline Timely & 2.2 & 2.6 & 3.1 & 2.9 & 3.4 & 3.9 \\
\hline \multicolumn{7}{|c|}{ Band V to ST } \\
\hline & \multicolumn{2}{|c|}{ Band III } & \multicolumn{2}{|c|}{ Band IV } & \multicolumn{2}{|c|}{ Band $V$ and Higher } \\
\hline Promotion Exper. & $\underline{\text { Women }}$ & Men & Women & Men & $\underline{\text { Women }}$ & Men \\
\hline Less than Timely & 1.7 & 2.0 & 2.2 & 2.3 & 2.1 & 2.6 \\
\hline Timely & 2.1 & 2.3 & 2.3 & 2.4 & 2.4 & 2.8 \\
\hline \multicolumn{7}{|c|}{$\begin{array}{l}\text { Note: Higher values indicate more positive views and reflect the average response across all items } \\
\text { related to each transition. Responses could range from } 1 \text { to } 5 \text { with } 1 \text { indicating, "strongly disagree" and } \\
5 \text { indicating "strongly agree." Timely promotion experiences were defined as follows: for those at Band } \\
\text { III, being at rank for less than } 6 \text { years; for those at Bands IV and V, having been promoted after less than } \\
6 \text { years at the previous rank or being hired at rank. }\end{array}$} \\
\hline
\end{tabular}


Table 4

Respondents' Perceptions of Their Experiences with Promotion

$\underline{\text { Item }} \quad \underline{\text { Str. Dis }} \underline{\text { Disagree }} \underline{\text { Neutral }} \underline{\text { Agree }} \underline{\text { Str. Agr. }}$

I am confident that my

accomplishments will be recognized

and rewarded in the promotion

16.7

$22.4 \quad 24.0$

17.6

19.4

process in the future.

I have productive conversations

with my supervisor about my career

13.3

21.3

21.6

21.9

21.9

progress on an annual basis.

Other employees at NIST who I

know have had positive experiences

17.0

23.5

25.9

17.2

16.5

with the NIST promotion process.

I have had positive experiences with the NIST promotion process.

19.8

20.5

23.8

14.5

23.4

Responses are weighted to more accurately reflect population of NIST ZP employees. Number of respondents varied from 553 (regarding other employees' experiences) to 616 (productive conversations). Those who marked "don't know" were omitted.

Table 5

Average Score, Perceptions of Promotion Experiences by Previous Experiences, Gender, and Band

\begin{tabular}{|c|c|c|c|c|c|c|}
\hline \multirow[b]{2}{*}{ Promotion Exper. } & \multicolumn{2}{|c|}{ Band III } & \multicolumn{2}{|c|}{$\underline{\text { Band IV }}$} & \multicolumn{2}{|c|}{ Band $V$ and Higher } \\
\hline & Women & Men & Women & Men & Women & Men \\
\hline Less than Timely & 2.7 & 2.9 & 3.0 & 3.2 & 3.2 & 3.6 \\
\hline Timely & 3.3 & 3.4 & 3.2 & 3.3 & 3.6 & 3.9 \\
\hline Total & 3.2 & 3.3 & 3.1 & 3.3 & 3.4 & 3.7 \\
\hline
\end{tabular}

Note: Higher values indicate more positive views and reflect the average response across all items related to each transition. Responses could range from 1 to 5 with 1 indicating, "strongly disagree" and 5 indicating "strongly agree." Timely promotion experiences were defined as follows: for those at Band III, being at rank for less than 6 years; for those at Bands IV and V, having been promoted after less than 6 years at the previous rank or being hired at rank. 


\section{Report 6: Analysis of a COACh-Sponsored Survey to NIST ZP Employees Distributed in March, 2020 ${ }^{19}$}

This report is substantially longer than others in this document and includes tables in both the text and in an appendix. To help readers, an outline of the contents and a list of tables is given below.

\section{Outline}

Sample

Socio-Demographic and Employment-Related Characteristics

Time at Band

Independent Variables in the Analysis

Analysis Plan

Views of the Promotion Process

Promotion from Band III to IV

Promotion from Band IV to $\mathrm{V}$

Promotion from $\mathrm{V}$ to ST

Respondents' Promotion Experiences

Open-Ended Comments

Professional Development Opportunities

Summary

Text Tables

1 - Demographic and Employment-Related Variables, Survey Sample and Total Population, ZRatios and Effect Sizes

2 - Highest Degree, Discipline, and Previous Federal Experience

3 - Time at Band and Time to Promotion by Band

4 - Views of Promotion Process from III to IV, Univariate Statistics

5 - Mixed Model Regressions of Perceptions of Promotion, III to IV, on Gender, Timely

Promotion Experience, and Seniority, Total Group and By Band and Retirement Status

6 - Views of Promotion Process from IV to V, Univariate Statistics

7 - Mixed-Model Regressions, Promotion IV to V on Gender, Physics, and Seniority, Total

Group, and by Band and Retirement Status

8 - Mixed-Model Logistic Regression of Awareness of ST Band on Gender, PhD, Postdoc at NIST, Physics, and Seniority

9 - Views of Promotion Process from V to ST, Univariate Statistics

19 This report was written by J. Stockard and completed May 20, 2020. 
10 - Mixed Model Regressions of Scale Score Regarding Perceptions of Promotion from V to ST on Gender, Band, and Age, Total Group and by Retirement Eligibility and Band

11 - Respondents' Perceptions of Promotion-Related Experiences, Univariate Statistics

12 - Mixed Model Regressions of Scale Score Regarding Own Promotion Experiences, Total Group and by Retirement Eligibility and Band

13 - Professional Development Experiences and Interest by Type of Experience

14 - Regressions of Professional Development Experiences and Desires on Socio-Demographic Characteristics, Employment-Related Variables, and Promotion Related Views, Final Reduced Models

15 - Regressions of Other Professional Development Experiences on Socio-Demographic Characteristics, Employment-Related Variables, and Promotion Related Views, Final Reduced Models

16 - Summary of Significant Correlations and Fixed Effects from Regressions of Scales Scores Related to Promotion by Band of Promotion

\section{Appendix A - Additional Statistical Tables}

A-1 - Weights Assigned by Age, Gender, and Operating Unit

A-2 - Years at Current Band and Years at Rank Before Promotion by Gender and Band A-3 - Years at Current Band and Years at Rank Before Promotion by Gender and Operating Unit A-4 - Descriptive Statistics (Means, Standard Deviations, N), Independent Variables

A-5 - Inter-correlations (Pearson's $r$ ) of Independent Variables

A-6 - Average Count of Don't Know (DK) Responses Regarding Promotion Band III to IV by Demographic and Employment Related Variables

A-7 - Mixed Model Poisson Regressions of Count of Don't Know Responses to Questions Regarding Promotion III to IV on Variables Significant in Bivariate Analysis, Total Sample and by Band and Retirement Eligibility

A-8 - Average Values of Scale Score of Perceptions Regarding Promotion Band III to IV by Demographic and Employment Related Variables

A-9 - Average Count of Don't Know (DK) Responses Regarding Promotion Band IV to V by Demographic and Employment Related Variables

A-10 - Mixed Model Poisson Regressions, Count of Don't Know Responses Regarding Promotion IV to $\mathrm{V}$

A-11 - Average Values of Scale Score of Perceptions Regarding Promotion Band IV to V by Demographic and Employment Related Variables

A-12 - Proportion Aware of ST Rank by Demographic and Employment Related Variables

A-13 - Average Count of Don't Know (DK) Responses Regarding Promotion Band V to ST by Demographic and Employment Related Variables

A-14 - Mixed Model Poisson Regressions, Count of Don't Know Responses Regarding Promotion $\mathrm{V}$ to $\mathrm{ST}$

A-15 - Average Scale Scores, Perceptions of Promotion from Band V to ST by Demographic and Employment-Related Variables 
A-16 - Model Fit Statistics, Mixed Model Regressions of Perceptions of Promotion from V to ST by Gender, Seniority Scale, Band, Leadership and Age

A-17 - Average Count of Don't Know (DK) Respondents Regarding Respondents' Perceptions of their Promotion-Related Experiences by Demographic and Employment-Related Variables

A-18 - Average Scale Scores, Respondents' Perceptions of their Promotion-Related Experiences by Demographic and Employment-Related Variables

A-19 - Model Fit Statistics, Mixed Model Regressions of Respondents' Perceptions of their Promotion-Related Experiences by Gender, Timely Promotion, Leadership, and Band

A-20 - Correlations of Measures of Professional Development Experiences with SocioDemographic and Employment-Related Variables and Views and Experiences of Promotion

A-21 - Regressions of Experiences and Plans Related to Professional Development on SocioDemographic Characteristics, Employment-Related Variables, and Promotion-Related Views and Experiences, Full and Reduced Models

A-22 - Correlations of Measures of Other Professional Development Experiences with SocioDemographic and Employment-Related Variables and Views and Experiences of Promotion

A-23 - Regressions of Other Professional Development Experiences on Socio-Demographic Characteristics, Employment-Related Variables, and Promotion-Related Views and Experiences, Full and Reduced Models

A-24 - Summary of Significant Correlations or Fixed Effects Related to DK Responses by Dependent Measure

Appendix B - Open-Ended Responses Regarding Additional Professional Development Experiences

Appendix C - Open-Ended Responses Regarding Professional Development Experiences Would Like to Have 
This document reports an analysis of data obtained from a survey of NIST Permanent Federal STEM ZP employees in Bands III and higher regarding their views of the NIST promotion process. A link to the survey was sent to all targeted employees early in March 2020, and the survey remained open for four weeks. The NIST liaison for COACh sent emails to targeted employees at regular intervals during that period thanking them for their participation and encouraging those who had not yet responded to do so. The survey was approved by appropriate bodies at the University of Oregon and NIST. It was totally anonymous and respondents were assured that raw data would not be shared with NIST. In addition, respondents were free to skip any questions they did not wish to answer. Sections below summarize information respondents provided related to their demographic and employment characteristics, their views and experiences with the promotion process, and their professional development opportunities. Statistical analyses were used to identify factors related to these views. Open-ended comments were also examined.

The report includes several extensive appendices. Appendix A has statistical tables that include important information but were judged too long to be included with the body of the report. Results of these analyses are briefly summarized in the text. (Tables in this appendix are numbered A-1, A-2, etc.) Appendices $B$ and $C$ include the open-ended comments regarding professional development provided by respondents. Open-ended comments regarding the promotion process are in Report 7. All comments were edited to remove information that might potentially be linked to individuals.

\section{Sample}

A total of 633 employees replied to the survey. About half of the responses (48\%) were received in the first week after distribution. Data received from NIST Human Resources office in Fall 2019 indicated that there were 2,034 employees at NIST in the pay bands targeted for the survey. Thus, the responses represent approximately $31 \%$ of the total population. ${ }^{20}$

\section{Socio-Demographic and Employment-Related Characteristics}

Table 1 reports data on demographic and employment related characteristics of the sample (first column of data and labeled "survey") for which we had comparable data for all employees in Fall 2019 (second column of data and labeled "population"): age, years employed at NIST, race-ethnicity, gender, operating unit, and band. Two comparative statistics are reported: the z-ratio testing the hypothesis that the proportion within the sample equals that within the population, and the effect size associated with this difference (third and fourth columns). ${ }^{21}$ The sample included respondents with a wide range of ages and years of employment at NIST. They also varied in gender and race-ethnicity, represented all operating units and all of

\footnotetext{
20 The tests of statistical significance in this report have not been adjusted for this sampling fraction, and thus the results reported are conservative in nature.

21 The z-ratio is the difference of the two proportions divided by the standard error. The effect size is the difference divided by the standard deviation of the population.
} 
the targeted bands. While the comparisons in Table One indicate that the composition of the sample was generally similar to the total population of NIST ZP employees, three exceptions were noteworthy. Younger employees (defined as 44 years of age or younger), women, and those in OU-C responded significantly more often than would be expected given their representation in the population. Those in UO-B and administrative or other ancillary units responded less often. To help ensure that these discrepancies did not unduly affect our report, we weighted responses for univariate descriptive statistics by age, gender and operating unit. ${ }^{22}$ The weights for each possible combination of categories are in Appendix A (Table A-1).

Table 2 reports additional information on the sample: respondents' highest degrees, discipline of study, and work with the government other than as a "fed" at NIST. (We did not have comparable information for the population for these variables.) Slightly more than two-thirds of the respondents had PhD's and about 20\% had a Master's degree. For analysis we distinguished between respondents with a PhD and others. The respondents reported having terminal degrees in a wide range of disciplines. Some type of engineering was most common, followed by physics and chemistry. Together, these three areas represented about two-thirds of the total group, and in the analyses we used a set of three dummy variables to distinguish these three disciplines from all others. About a third of the respondents had been a Postdoc at NIST, a tenth had been contract employees before becoming a "fed," and slightly more (13\%) had worked at another federal agency. Most employees were in these positions for five years or less.

A few respondents ( $2 \%$ of the total) did not provide information on demographic and/or employment related variables. Thus, their responses were not included in the bivariate and multivariate analyses reported below. However, to assess the extent to which their absence produced any bias in the results we examined differences in their responses from those of other respondents, and these results are included in the bivariate analyses. We also examined the possibility that responses given by employees who answered the survey early or late in the process differed.

\section{$\underline{\text { Time at Band }}$}

Table 3 gives data regarding respondents' reports of the time they had spent at their current band and, when applicable, before promotion to their current band. Results in the first panel indicate that half of the respondents had been at their current band for five or fewer years. However, data within the columns show that a shorter time at band was more common for those at Band III than at the higher bands, with about three-fourths of the Band III respondents at that band for five or fewer years. In contrast, slightly less than two-fifths of those at Band $\mathrm{V}$ or higher

\footnotetext{
${ }^{22}$ Results in Table 1 indicate that Asians were under-represented, but we chose not to weight on race-ethnicity given the highly skewed distribution of this variable. We did not weight on both years at NIST and age because the two variables were very highly associated. To calculate weights the three youngest age categories and the three oldest ones were grouped. Following standard procedures in the social sciences weighted data were not used in multivariate analyses, which included variables used in the weighting. If a respondent did not provide data on all variables used in the weighting, the data that were available were used, as can be seen in Table A-1.
} 
had been at that band five years or less. Twenty percent of respondents at Band $\mathrm{V}$ or higher had been at that band for at least 16 years. ${ }^{23}$

The second panel of Table 3 reports data regarding the time that respondents spent at their previous band before promotion, and the third panel reports the percentage of respondents who were hired at their current band. Data are presented separately for those in Band IV and Band V and higher. Close to a third of the respondents at Band IV had been hired at that band, but less than a tenth of those at the highest band had been hired directly at that band (chisquare $=27.79, \mathrm{df}=1, \mathrm{p}<.001$ ). Among those at Band IV who were promoted within NIST, half gained promotion after five years or less at Band III. Employees at Band V reported waiting longer for promotion from IV, with about a quarter waiting five years or less and more than a third waiting 6 to 10 years (chi-square $=33.41, d f=3, p<.001$ ). There were no significant differences by gender or operating unit in the years that respondents spent at band before their last promotion. ${ }^{24}$ (See Tables A-2 and A-3 for details.)

The data regarding the two variables described in Table 3 were combined to create an indicator of respondents' experiences with promotion. We used a criterion of "at band" for 6 years or more as the cut-off for "timely" promotions and compared respondents with a more timely promotion experience and those with a longer "wait period." For those at Band III, respondents were classified as potentially having a timely experience if they had been at band for less than 6 years. For those at the higher bands they were classified as having a timely experience if they had been promoted from their previous band after 6 years or less or if they had been hired directly into that band. Data in the last panel of Table 3 indicate that close to three-fifths of the respondents were classified as having a timely promotion experience, but that this was much more common for those at Bands III and IV (chi-square $=64.04, \mathrm{df}=2, \mathrm{p}<.001) .{ }^{25}$

Because the definition of timely promotion differs by band we conducted multivariate analyses for both the total group and by Band. ${ }^{26}$ In addition, because a substantial proportion of the survey respondents had been employed at NIST for a number of years and were nearing retirement age, we conducted multivariate analyses separately for those who were technically

\footnotetext{
${ }^{23}$ Chi-square related to the association between band and years at band $=63.57, \mathrm{df}=8, \mathrm{p}<.001$. There was no significant association between gender and years at band when band was controlled: for Band III chi-square $=3.37$, $\mathrm{df}-4, \mathrm{p}=.50$; for Band IV, chi-square $=4.52, \mathrm{df}=4, \mathrm{p}=.34$; and for Band V, chi-square $=2.11, \mathrm{df}=4, \mathrm{p}=.72$. See Tables A2 and $A-3$ for additional details.

${ }^{24}$ On average, in the majority of comparisons men had more years at band and more time at band before promotion than women, although none of the differences were large enough to be statistically significant.

25 There were very few respondents at the higher bands who had been at their new band for less than six years and also experienced a timely promotion from their previous band. Thus, a more restrictive definition that included both of these elements was not used.

${ }^{26}$ As would be expected given the results with the component measures, women were slightly more likely to have a timely promotion process than men (63\% timely for women, and $57 \%$ for men), but this difference was not strong enough to be statistically significant (chi-square $=2.08, p=.15$ ).
} 
eligible for retirement ( $28 \%$ of the respondents) and those who were not. Eligibility was defined as age 65 and older and/or working at NIST for more than 20 years.

\section{$\underline{\text { Independent Variables in the Analyses }}$}

We examined associations of perceptions of promotion with five socio-demographic variables - gender, minority status, age, highest degree, and discipline; six employment related variables - operating unit, band, years at NIST, holding a leadership position, other federal employment, and timely experience with promotion; as well as patterns of missing data and the week in which respondents returned the survey. When appropriate the categorical variables were translated into dummy variables. Table A-4 gives descriptive statistics on these variables. Results indicated that some variables were so highly skewed that it would not be appropriate to include them in multivariate analyses. Thus, these variables were only included in bivariate analyses or, when possible, combined with other groups to provide an adequate distribution. ${ }^{27}$

Table A-5 gives a correlation matrix of the variables shown in Table A-4. As would be expected there were a number of significant associations between the socio-demographic and employment related variables. For instance, when compared to women, men respondents were older, more often had their PhD, had been at NIST longer, were more likely to have done a postdoc at NIST, and more often had degrees in engineering or physics. Respondents' terminal degrees and areas of specialty varied from one operating unit to another. The most striking intercorrelations involved age, years of employment at NIST, band, and having held leadership positions. The correlations between these variables ranged from .36 to .63. Given the strong correlations we combined these variables into a summative scale using standardized scores to control for the different metrics of each variable. Higher values on the scale indicate more seniority, and the scale had high reliability (Cronbach's alpha $=.82$ ).

\section{Analysis Plan}

The body of the survey asked employees about their perceptions of the promotion process, their own promotion-related experiences and their professional development opportunities. We began the analysis by examining the univariate distributions of survey responses. With the dependent measures regarding views of promotion, both weighted and unweighted data were examined. In addition, several of the survey questions allowed respondents to indicate that they "did not know." We used two different ways of handling these data: 1 ) recoding the "don't know" (DK) responses to the neutral category and 2) omitting these respondents from the analysis. Results with the two methods were substantively identical, and we used measures that omitted the "don't know" responses from the multivariate analyses. However, we separately analyzed factors that were related to the probability that individuals

\footnotetext{
${ }^{27}$ Variables with extreme skew included the following dummy variables: URM, OU-D, OU-B, missing demographics, and having been a contract employee. URM was not included in the multivariate analyses. When bivariate results indicated that other variables were significant, they were combined with substantively similar groups to include in multivariate analyses as shown in associated tables.
} 
gave a DK answer, using both bivariate and multivariate techniques. This was important to understand characteristics of the group that answered the questions. (All analyses were done with STATA.)

Bivariate results were then examined, exploring the extent to which responses varied among respondents with different demographic and employment-related characteristics. For dichotomous independent variables, t-tests and effect sizes were calculated; and for categorical variables, analysis of variance was used.

As a third step, we used mixed model regressions to calculate the independent (or net) association of independent variables with the dependent measures, using organizational unit (OU) as the random, or grouping, variable. Variables that were determined to be significantly related to the dependent measures, based on the bivariate analysis, were systematically added to a baseline, intercept-only model. ${ }^{28}$ Logistic regressions were used for dichotomous dependent variables and Poisson regressions for counts. Two statistics were used to examine the fit of relatively more complex models: the change in the -2 Log Likelihood statistic, which is distributed as chi-square; and a Proportionate Reduction in Error (PRE) measure calculated from the change in residual variance from one model to another. ${ }^{29} \mathrm{PRE}$ values can range from 0 to 1.0 and indicate the percentage of variation in the dependent variable that is explained by a more complex model. The Intraclass Correlation (ICC) was used to examine the extent to which results differed between OUs. ${ }^{30}$ Fixed effect coefficients and associated z-scores and probability levels were used to determine the statistical significance of explanatory variables. For analyses of dependent variables that were continuous or counts the coefficients and standard errors are reported, representing the scale of the measures. ${ }^{31}$ For the logistic results, to facilitate interpretations, odds ratios and z-values are reported. As noted above, to check the accuracy of our conclusions we conducted most analyses with the total group, separately by those in different bands, and also for those who were or were not eligible for retirement.

To analyze the qualitative data, COACh team members carefully read each response, searching for key themes, and gradually developing categories to capture the content. All responses were assigned to at least one category, but a response could be coded as falling into more than one category. We then compared patterns of responses across the socio-demographic and employment-related variables used in the quantitative analyses. All comments are in the

\footnotetext{
${ }^{28}$ For the analyses of professional development measures an initial "full model" was first examined and then was reduced based on significant associations. This method was chosen because the correlation matrices revealed that there were relatively few significant associations with these variables.

${ }^{29}$ The PRE measure could not be calculated for the Poisson analyses (the counts of don't know responses) or the logistic analyses (the measure of respondents' awareness of the ST category and some measures related to professional development) because the techniques do not, by definition, provide a measure of residual variance. ${ }^{30}$ In the original proposal for the contract we anticipated using variables related to OUs to explain differences between the groups. However, as will be seen below, differences between the OU's (as indicated by the variance of the constant or intercept) were equal to or very near zero in all analyses, thus obviating the need for this step. The ICC could not be calculated for the Poisson or logistic analyses.

${ }^{31}$ Throughout the analysis, all dichotomous variables are coded as 0,1 to facilitate interpretations.
} 
appendices to this report or Report 7. The COACh team will continue to examine these comments and their association with the quantitative results in developing recommendations for change (See Reports 7 and 11 in this volume.). Thus, the discussions of qualitative comments in this report should be seen as simply an initial step.

Views of the Promotion Process

The first questions on the survey asked employees their perceptions of the promotion process with specific questions regarding their understanding, the understanding of others, and the extent to which they believed the criteria and process were fair, appropriate for their operating unit, and matched the mission of NIST. Separate questions were given regarding promotion from III to IV, IV to V, and V to Senior Scientist (ST). These questions were followed by specific questions about their own promotion experiences. Responses were given on a Likerttype scale, ranging from 1 to 5, with higher values indicating more positive perceptions. Subsections below report results regarding each set of questions.

Promotion from Band III to IV

Table 4 summarizes respondents' answers to the questions regarding promotion from III to IV. The top panel reports the percentage distribution, using weighted data and omitting those who marked "DK." Close to half of the respondents agreed that they understood the criteria (45\%) and that they were appropriate for their operating unit (47\%), while slightly fewer (41\%) agreed that they reflect NIST's mission. Only around one-third of the respondents agreed that the criteria were fairly applied (36\%) or that most employees understood the criteria (31\%).

The first six columns of data in the second panel of Table 4 report the means and standard deviations for each of the measures that we used: unweighted results, omitting the don't know responses; weighted results, omitting the don't know responses; and unweighted responses with the don't know responses coded in the neutral category. The differences between the three measures reflect the nature of the calculations. Means were slightly smaller when the "don't knows" were coded as neutral simply because the neutral value lies between the two extremes. Means were slightly larger for the weighted results because, as discussed later in this report, those who were less likely to respond to the survey (and thus had higher weights), tended to provide more positive responses.

The final column of the second panel of Table 4 reports the percentage of respondents who indicated they did not know. While only $6 \%$ gave this response to the query about their understanding, a quarter or more gave this response to the questions regarding whether the criteria were fair, appropriate to their OU or reflected NIST's mission. We calculated a summative variable, ranging from zero to five, indicating the number of questions to which a reply of "don't know" was given. Three-fifths of the respondents (59\%) answered each of the questions, another $11 \%$ answered all but one, and only $5 \%$ replied "don't know" to each of the five queries. 
We then looked at associations of the number of don't know responses to the various socio-demographic and employment-related variables using both bivariate and multivariate analyses, as described in the previous section. This analysis was important to provide a greater understanding of the employees who provided information about the promotion process at this band. Results for the total group and those not yet eligible for retirement indicated that employees with less seniority, as well as those who had no federal employment experience other than as a NIST, were more likely to reply DK. For those at Band IV, those who had only been a NIST "fed" and those who had experienced timely promotions (including being hired at band), more often marked DK. For those who were eligible to retire those who had only been a NIST "fed" and those with lower scores on the "seniority" measure more often marked DK. For employees at Bands III and V, those who answered DK were not significantly different from other employees at their band. There were no significant differences between OUs in the number of don't know responses. (See Tables A-6 and A-7.)

Respondents' answers to the five questions regarding promotion from III to IV were highly correlated, with individual pair-wise correlations ranging from .54 to $.78 .^{32}$ Given these high correlations a summative scale was created from the five individual variables. The scale had high internal reliability (Cronbach's alpha $=.88$ ). Scale values paralleled the values of the component items and could range from 1 to 5 . The overall average was 3.17, slightly higher than the neutral point; and the standard deviation was 1.02, indicating a fair amount of variability. Scale scores for respondents who indicated they did not know or did not answer one of the five items were based on the items for which they gave valid scores. Valid data were available for 600 respondents (omitting the $5 \%$ of the respondents who replied "don't know" to all of the questions in the scale).

We then examined differences in scale scores related to the demographic and employment-related variables described in the first section. Bivariate results indicated that there were no significant differences between operating units, whether or not respondents had a PhD, field of highest degree, when the survey was returned or the extent of missing data on demographic and employment-related variables. Women, under-represented minorities, and those with less seniority expressed significantly less positive views. In addition, there was a trend $(p=.09)$ for those with more timely promotion experiences to have less positive views, and this measure was also included in the multivariate analyses. (See full results of the bivariate analysis in Table A-8.)

\footnotetext{
32 These correlations and summative scale were calculated using measures when the DK responses were omitted. When the DK responses were coded as neutral, correlations ranged from .47 to .74 and the alpha value for the scale was virtually identical. Correlations were markedly higher when the weighted variables were used (.86 to .96), but that result simply reflects the impact of the weighting variables and thus those variables were not used in calculating the scale.
} 
The multivariate results are in Table $5 .{ }^{33}$ The top panel of Table 5 gives results for the total set of respondents, showing findings with incrementally more complex models. Model 1 included gender as a predictor, Model 2 added the indicator of timely promotion, and Model 3 added the composite measure of seniority. The coefficients in the final model indicate the association of a given independent variable with perceptions once other variables in the model are controlled. They indicate more positive perceptions were expressed by men, those who were more senior in their careers and those who had more timely promotion experiences. ${ }^{34}$ There were no differences between operating units, as indicated by the zero-value associated with the variance for the constant term.

The second panel of Table 5 presents results for Model 3 for each band, and the third panel gives results separately by for those who were or were not eligible for retirement. Results for those not yet eligible for retirement mirrored those for the total group with significantly more positive views expressed by men, those who were more senior, and who had more timely promotion experiences. For those in the highest bands (V and ST) and employees who were eligible for retirement, the only significant predictor of more positive views was greater seniority. For those in Bands III and IV, none of the independent variables were significantly related to views of the III to IV promotion process. ${ }^{35}$ Notably, when data were separated by band, gender was not significantly associated with views, although men continued to express slightly more positive views (around .2 of a point on the five-point scale). In other words, within each band men and women expressed views of the process of promotion from III to IV that were statistically indistinguishable. (Table 3 in the companion summary report (Report 5) provides descriptive data that illustrate this result.)

ICC values were virtually zero in all analyses, indicating that there were no differences between OUs in respondents' views. As explained in the previous section, the change in - 2 Log Likelihood values indicate the fit of the data to the model, and all results were highly significant. The PRE values indicate that relatively little variation was explained for the analyses involving Bands III and IV, while over $10 \%$ of the variation was explained in the analyses for the total sample and within the two retirement-eligible groups. ${ }^{36}$

\footnotetext{
${ }^{33}$ Recall that URM status was not included in the multivariate analyses because of the high degree of skew in the variable.

${ }^{34}$ Careful readers may note the change in sign associated with timely promotion from Model 2 to Model 3 with results in Model 2 replicating the bivariate results, but those in Model 3 having the opposite sign. This reflects the association of timely promotion with seniority as shown in the correlation matrix in Table A-5.

${ }^{35}$ The $z$-values used to determine statistical significance can be calculated by dividing the coefficient (b) by the standard error (s.e.).

${ }^{36}$ We suggest that the differences in the PRE values indicate the importance of seniority in explaining perceptions, for that variable was not a significant influence on perceptions for Band III and IV, where there was less variability.
} 


\section{Promotion from Band IV to $\mathrm{V}$}

Table 6 presents data on respondents' perceptions of promotion from Band IV to $\mathrm{V}$, with a format identical to that used in Table 4. The employees expressed less positive views of promotions at this band than they expressed regarding the move from III to IV. Less than half of the employees agreed or strongly agreed with any of the statements. Less than a third agreed that the criteria were fairly applied or that most employees understood what was needed to gain promotion at this band. The average values shown in the bottom panel of Table 6 were substantially smaller (more negative) than those regarding the promotion from III to IV. Statistical comparisons of individuals' scores regarding the promotion process from III to IV and IV to V were highly significant. ${ }^{37}$

A summary of the bivariate analysis of the count of don't know responses is in Table A-9 and the multivariate analysis of the count is in Table A-10. While the bivariate analyses indicated a number of significant relationships, the multivariate Poisson regressions indicated that most of these associations were spurious. Once other variables were controlled the only significant association with the number of DK responses was seniority and other work experiences. Employees with less seniority or who had no "fed" experience other than as a contractor or "fed" employee at NIST more often marked DK. There were no differences between OUs. The only analysis for which women gave significantly more DK responses involved the subgroup of employees eligible for retirement.

As with the responses regarding promotion from III to IV, the responses regarding promotions from IV to $V$ were highly correlated, and a summative score was created (Cronbach's alpha $=.89) .{ }^{38} \mathrm{~A}$ summary of the bivariate analysis of associations of the summative score with the socio-demographic and employment related variables is in Table A-11. Results indicated no significant differences between employees with or without a $\mathrm{PhD}$, those in different operational units, those with different types of previous federal employment, and those with or without timely promotion experiences. As with perceptions regarding promotions from III to IV, women and under-represented minorities had less positive views and those with higher values on the variables related to seniority had more positive views. In addition, there was a significant difference across disciplines, with physicists having more positive perceptions than those in other areas.

Results with the multivariate analyses are in Table 7. In each of the analyses the tendency for physicists to have more positive views disappeared when seniority was controlled, suggesting that the bivariate association was spurious. This result reflected the tendency for physicists to have been employed at NIST for more years, to be older, at higher bands and more often holding

\footnotetext{
${ }^{37}$ Paired t-tests comparing scale scores and values on each of the individual items were all highly significant with probability values less than .0001.

38 Inter-item correlations ranged from .57 to .77 with the individual measures that omitted DK responses and from .46 to .72 for the measures in which DK responses were recoded to neutral.
} 
leadership posts (the component elements of the measure of seniority). Seniority was highly significant for the analysis for the total group and for both those who were or were not eligible for retirement. In contrast to the results regarding promotion from III to IV, the association of gender remained significant when seniority was controlled, with women having significantly less positive views than men for the total group and analyses restricted to those in Band III or Band V and higher. Interestingly the gender difference for those in Band IV, the group potentially most affected by the transition, was quite small (equal to .04 on the five-point scale) and far from significant. In other words, the relatively negative view of the promotion process from IV to $\mathrm{V}$ (averaging 2.8, or just below the neutral mark on the 5-point scale) was shared by both men and women at Band IV.

As with the analysis of perceptions of the III to IV promotion, there were no significant differences between operational units, and the changes in -2 LL values from baseline were highly significant. In addition, apart from the analyses within each band, the PRE measures from baseline were not insubstantial, equaling .15 for total group and those not eligible for retirement and .19 for those who were eligible for retirement.

\section{Promotion from V to ST}

Two thirds of the employees $(n=425)$ said that they were aware of the ST (Fellows and Senior Research Scientists) category of employment. Because a relatively large proportion of employees indicated that they were not aware of this group, we examined the relationship of this awareness to the various socio-demographic and employment-related variables. Table A-12 gives the results of the bivariate analyses, and Table 8 gives the results of the multivariate analysis. The bivariate results indicated that men, those with a $\mathrm{PhD}$, who had completed a Postdoc at NIST, who had more timely promotion experiences, who were physicists, and who had greater seniority were more likely to be aware of the category, while those who had more timely promotion experiences were less likely to be aware. The multivariate analyses indicated that the associations of awareness with gender and experiences with promotion were spurious, dropping to insignificance when the other variables were controlled. ${ }^{39,40}$ However, employees with a PhD, physicists, those who had done a Postdoc at NIST and who had more seniority were significantly more likely to be aware of the category, even when the other variables were controlled.

Only the respondents who indicated that they were aware of the ST category were asked about the promotion process from $\mathrm{V}$ to ST. Descriptive statistics related to their answers are in

\footnotetext{
${ }^{39}$ Because the dependent variable was a dichotomy, logistic mixed model regressions were used, as noted in the explanation of analysis procedures in an earlier section. To facilitate interpretations the coefficients are odds ratios and z-ratios are given rather than standard errors as in other text tables. An odds ratio less than 1.0 would correspond to a negative regression coefficient, while an odds ratio greater than 1.0 would correspond to a positive coefficient.

${ }^{40}$ In fact, when seniority was controlled, women and those with more timely promotions were more likely to be aware of the category, although these differences were not statistically significant. The change in sign can be attributed to the fact that those who were more senior were more often men and less likely to have timely promotions.
} 
Table 9, which parallels Tables 4 and 6 in construction. The perceptions regarding promotions at this band were less positive than those regarding IV to V. About a third of the respondents agreed that the criteria were appropriate for their operating unit and reflected NIST's mission. Slightly less than a fourth indicated they understood what was needed for promotion to this band and that the criteria were fairly applied. Only ten percent believed that most NIST employees understood what was needed for promotion to ST.

Substantially more employees gave a response of DK to this set of questions than to those regarding lower bands. The number of such responses ranged from 0 to 5 , with an average of 1.60 (s.d. = 1.74). Over two-fifths gave a DK response to the questions about the extent to which the criteria were fair, appropriate for their OU and reflected NIST's mission. Over a fifth said they did not know how much other NIST employees understood the criteria. Because these questions were only asked of those who indicated that they were aware of the band, the actual number of respondents who did not express an opinion is greater than reflected in this analysis of DK responses.

As in the other analyses, we examined the extent to which socio-demographic and employment-related variables were related to the count of DK responses. Bivariate analyses (in Table A-13) indicated that employees who had a PhD and who had greater seniority marked DK significantly less often, while those with more timely promotion experiences marked DK more often. Multivariate analyses (Table A-14) indicated that the association of timely promotion experiences with DK responses was spurious. For the total group, those with PhD's and greater seniority were less likely to mark DK. While the effect associated with having a PhD was not significant in analyses with the various sub-groups, the effect of seniority remained. Thus, the responses to questions regarding promotion from $\mathrm{V}$ to ST are significantly more likely to reflect the views of those with greater seniority. This pattern results both from less senior employees not being aware of the category or replying DK to relatively more questions.

As with questions regarding promotions at other bands, responses regarding promotions from $\mathrm{V}$ to ST were highly correlated and combined into an additive scale (Cronbach's alpha = .88). ${ }^{41}$ The average value of the scale was $2.41(.94)$, between disagree and neutral on the fivepoint scale and indicating that views were markedly more negative regarding this transition. Table A-15 reports the results of the bivariate analysis of the associations of the sociodemographic and employment related variables with the scale score. Bivariate results indicated that men, those who did not identify as URM, employees who were older, had held leadership positions, and were in the highest band had more positive views. Notably, views did not differ among those with different years of employment at NIST, suggesting that the global measure of seniority, which included years of employment, as well as age, leadership posts, and band, might be inappropriate to use in further analyses of the measure. In addition, the association of current band with views regarding promotion to ST was curvilinear, with a rather dramatic difference

\footnotetext{
${ }^{41}$ Correlations among items when the DK responses were omitted ranged from .41 to .81, and when the DK responses were recoded as neutral ranged from .34 to .74 .
} 
between those at that band (average=3.45) and those at lower bands (with average values ranging from 2.12 to 2.45 , a full point lower). Thus, in the multivariate analyses we explored the association of perceptions with gender and seniority as well as with the separate elements of the seniority scale. We also included curvilinear terms in the models. Results of tests of model fit, which are summarized in Table A-16, indicated that the best model included gender, age, band, and band squared (to capture the nonlinear association with band).

Table 10 summarizes the results of the multivariate analysis with this best model. Results with the total group and employees who were eligible for retirement largely confirmed those found with the bivariate analysis. Men, older employees, and those already at the highest Band had significantly more positive views, even when other variables were controlled. Differences by gender were smaller and statistically insignificant for analyses of employees in Bands III and IV, but larger for those in the highest bands. Note that this pattern of gender differences differs from the pattern associated with views of promotion from IV to V. Men and women currently at Band IV expressed, on average, very similar views of the promotion process to Band $\mathrm{V}$ (a net difference of .04 on the five-point scale). But when asked about the process of promotion from $V$ to ST, men at Band $V$ and higher had markedly more positive views (a net difference of .40), even when the distinction between being at Band V and at ST was controlled. ${ }^{42}$

As with other analyses, there were no differences across operating units in responses. In all analyses, changes in model fit from baseline were highly significant. Paralleling results with analyses of views of promotions at other bands, PRE values were smaller than .10 for the analyses by band, but ranged from .11 to .16 for other analyses.

\section{$\underline{\text { Respondents' Promotion Experiences }}$}

After answering questions about promotion from one band to another, employees were asked a series of four questions regarding their own promotion experiences. The questions asked and descriptive statistics are in Table 11. Close to half of the respondents indicated that they had productive conversations with their supervisor about career progress. But less than two-fifths (37\%) were confident that their accomplishments would be recognized or rewarded in the promotion process, and an equivalent percentage reported that they had had positive experiences with the NIST promotion process. Slightly fewer (33\%) reported that other employees had positive experiences. While close to a fourth of the respondents marked "neutral" on each item, a third to two fifths of the respondents had negative views related to each item.

The percentage of respondents who gave a DK response was markedly lower for this set of questions, ranging from $1 \%$ for the question regarding productive conversations with the supervisor to $11 \%$ for experiences of other employees. The average number of DK responses was only .22 ( $s d=.53$ ). Over four-fifths (83\%) of the respondents answered all four questions, $12 \%$ answered all but one, and $4 \%$ answered two of the four questions. Bivariate analyses indicated

\footnotetext{
42 Significant gender differences in views regarding promotions from IV to $\mathrm{V}$ also appeared for respondents at the highest Bands and at Band III.
} 
that factors related to seniority were the best predictor of providing this answer. Respondents who more often marked DK tended to have been at NIST for shorter period of time, were younger, at lower bands, and had not held leadership posts. ${ }^{43}$

As with the other sets of questions, responses to the questions regarding employees' own promotion experiences were highly inter-correlated, and we constructed a summative scale (Cronbach's alpha $=.82$ ) for analysis. ${ }^{44}$ The average value on the scale was 3.33 , slightly above the neutral point $(s d=.92)$. Bivariate analyses indicated that more positive responses were reported by men, those who were not members of under-represented minority groups, who had held leadership posts, who were in higher bands, and who had more timely promotion experiences. (See Table A-18.) Neither respondents' age nor their years employed at NIST were significantly related to reports of their own experiences. And, as with the analysis of views of the promotion process from $\mathrm{V}$ to ST, the association with band appeared to be curvilinear, with sharp differences between those at the highest band (average scale score $=4.36$ ), those at Band $V$ (average $=3.55$ ), and those at Bands III and IV (average $=3.21$ for both groups).

Given these results we examined the relative fit of a variety of models including gender, timely promotion experiences, leadership posts, band and band squared. Results indicated that the best fitting model included each of these variables. (See Table A-19.) Findings using this model for the total sample, by eligibility for retirement, and by band are in Table 12. Results for the total group and those not yet eligible for retirement were similar, indicating significantly more positive perceptions for men, those in the highest bands, and those who had timely promotion processes. However, the coefficient associated with gender declined in statistical significance when the sample was limited to those not eligible for retirement. Among those eligible for retirement none of these variables were statistically significant. For employees in Bands III and IV, the most important influence on positive reports was having experienced timely promotions, and the impact of gender was markedly smaller and statistically insignificant. For employees in the highest bands ( $V$ and higher), men had significantly more positive views, as did those with timely promotion experiences and those who were at the ST rank. As with other analyses there were no differences between operating units. In addition, holding a leadership position had no significant associations in any of the analyses, once other variables were controlled.

\section{Open-Ended Comments}

At the end of the questions about promotion, respondents were asked to provide additional comments: "Please feel free to add any other comments or information that you

\footnotetext{
${ }^{43}$ We did not conduct Poisson regressions of the count of don't know responses because the distribution was so highly skewed and because zero-order correlations revealed that seniority was the only variable with a significant association. The correlation of seniority and the count of DK responses was $-.16(p<.001)$.

${ }^{44}$ Inter-item correlations using the measures omitting DK responses ranged from .34 to .68; correlations when DK responses were recoded to neutral ranged from .42 to .65 . As in other analyses the responses with DK omitted were used in scale construction.
} 
believe will help COACh understand more about promotion processes at NIST." A total of 263 employees provided additional comments (41.5\% of all respondents). Members of the COACh team carefully read and categorized each of the statements as explained in an earlier section. Statements could be placed in more than one category. The most common themes involved the nature of the promotion process, mentioned in half of the comments, as well as transparency, mentioned by over two-fifths (43\%). About a third (34\%) had comments that dealt with standards associated with promotion. Slightly fewer explicitly commented on issues involving inequities (26\%) or talked about their individual experiences (18\%). A few respondents (5\%) noted ways in which promotion procedures and policies promoted equity in some way. Women, those whose promotion experiences had been less timely, and employees with less positive views of the promotion process were more likely to provide comments. (See Table A-18.)

All comments are in the Appendix to Report 7. Among other aspects, the comments appear to provide illustrations of employees' concerns with the clarity of promotion criteria, the extent to which they are appropriate, the consistency and fairness of the process, and ways in which they or other individuals have experienced the process. Following are examples of comments related to promotion criteria and process:

- The criteria for promotion from III to IV are not clearly communicated. There are OUspecific guidelines posted on the website for promotion criteria; however, the promotion process is dependent upon the group leader and division leader approval...the promotion process is biased because it is solely based on the group leader advocating for the staff.

- Band V promotions are not handled uniformly...The requirements seemingly change every few years. It's also very dependent on your management. I lucked out both in my timing and in having a strong advocate. But I see people now who are better than me who aren't even being put up for promotion.

- Leaving the III to IV promotions at the Division-level leads to uneven application of promotion criteria across Divisions and within a Division. This promotion is the least transparent of all promotions, yet is the most important to most careers and the most common promotion."

- ...Too many times people are promoted because of their managerial duties instead of technical merits. This is fine if the selection of managers is transparent. Unfortunately, the leadership is very homogeneous and does not reflect the diversity of the NIST workforce.

- ...The system is broken and needs to be revamped. Not fixed because that will mean only minor changes around the edges. The lack of diversity in NIST leadership is another factor that I believe is a strong contributor to the disparity in promotions.

- Some of my colleagues perceive the promotion criteria as moving targets...It is clear that there should not be a strict rubric that applies to everyone...However, it seems that supervisors should work with each other and coordinate with each employee to develop different performance metrics and pathways to promotion. The paths should be documented but can evolve as the needs of the OU change... 
A number of the comments described individuals' experiences with the promotion process. They often highlighted the important role of immediate supervisors, the way in which the process can vary from one individual to another as well as, as highlighted immediately above, from one OU to another. Some examples follow:

- My career benefited the most from the informal guidance that I received from managers, fellows, etc. across NIST. Flexibility and removal of barriers to access was important for my own career.

- In my experience, promotion at NIST strongly depends on one's immediate group leader.... The largest improvements in the promotion process at NIST can be realized by focusing on Group Leaders...impartiality, equity and rebalancing their work for more group interaction and career advancement.

- Personally, I've had a positive experience with the promotion process. However, talking with colleagues, I've found my experience is exceptional and have yet to find anyone who has had a similar experience. I credit this to my direct management, a bit of luck and my being forward with my management about my goals.

- I have been incredibly fortunate in my supervisors. They have advocated for me and have made it clear what I needed to get done to advance within NIST. However, based on anecdotal data from my peers, my perception is that it is all too easy to have a supervisor who does not advocate, does not clearly communicate requirements, or worse actively discriminates....

Several other examples appeared to provide a relatively favorable view of the current promotion process or standards:

- To attract the best...the focus should be on the quality of the hiring process and career development, not promotion of internal staff.

- I have been involved in many promotion discussions ... and I believe the process is fair and that those involved in the process are trying to rectify past wrongs."

- ...I have been fortunate in my research success...the metric that matters is "status in my field...

\section{Professional Development Opportunities}

After the questions regarding the promotion process, respondents were posed the following question:

The federal government offers a number of courses to help those in supervisory positions or thinking about becoming supervisors. Please indicate courses that you have taken or plan to take in the future related to the following areas: leadership 
skills, conflict resolution, communication skills, budget execution, and federal regulations.

Employees could mark four possible responses: have taken this or similar courses, plan to take in the future, do not plan to take, and did not know about these courses.

Table 13 summarizes responses to this item. About three-fourths of the respondents had either experienced or planned to seek experiences related to leadership skills, communication skills and conflict resolution. About a third reported interest or plans in work related to federal regulations. The least experience and interest was voiced regarding development experiences related to budgets. The majority of respondents indicated that they knew about the courses related to each of the areas, but they were least likely to be aware of professional development opportunities related to federal regulations and budgeting.

Respondents' answers to questions about different types of professional development opportunities were highly correlated. That is, respondents who had taken one type of course were likely to have taken other classes; those who did not plan to take one type of course did not plan to take another, etc. ${ }^{45}$ Given these high correlations we constructed additive scales that captured the extent to which respondents had taken courses, planned to take them in the future, did not plan to take, or did not know about them. (Cronbach alpha values were, respectively, .81, .78, .84, and .80.) We examined the bivariate relationships between these scales and the sociodemographic and employment-related variables used in previous analyses and views and experiences of the promotion process. The correlation coefficients associated with this analysis are in Table A-20. We then used mixed-model regressions to develop a more parsimonious understanding of employees' experiences and desires for professional development experiences, starting with models that included all variables that were significant in the bivariate analyses and then reducing these models to include only those that had significant effects net of other variables. The full set of models tested for each dependent variable are in Table A-21, and the final models are in Table 14.

Results differed for each professional development-related measure. Respondents who reported taking more courses tended to be women, to have more seniority (older, at NIST for a longer time, at higher bands, and having leadership posts), and in fields other than physics. In contrast, those who did not plan to engage in professional development were also older, but, in contrast to those who had taken the courses, were more often men and in physics, and less likely to have held formal leadership positions. There were no significant gender differences related to the other measures (planning to take or did not know of). Employees who were more junior, who had employment experiences other than as a NIST fed, and who returned their surveys later were more likely to indicate that they planned to engage in these activities in the future. Employees

\footnotetext{
45 Pair-wise correlations between items ranged from .28 to .67 for reports of having taken, .27 to .66 for planning to take in the future, .37 to .67 for not planning, and .29 to .68 for did not know.
} 
who were less senior and had less positive views of the promotion process more often indicated that they did not know of the opportunities.

Over two-thirds (70\%) of the respondents indicated that they had experienced other types of professional development opportunities while at NIST and those who had experienced a more timely promotion were more likely to report such opportunities. (See Tables A-20, A-21, and last two columns of Table 14). Of the 436 respondents who indicated that they had other types of professional development experiences, close to $90 \%(n=388)$ described the nature of that work.

The nature of the experiences varied greatly. About two-fifths (41\%) mentioned some type of leadership experience, such as being a program or group leader, supervising other researchers, and mentoring others. An equivalent percentage mentioned specific training or course work, both internal to NIST and externally. Twenty percent of the respondents mentioned having detail assignments outside their official appointment and an equivalent percentage mentioned work on committees within NIST or with professional organizations.

It is important to remember that the responses were open-ended in nature and reflected their personal definitions of what had contributed to their professional development. Thus, the responses might be less reliable and inclusive than a more closed-ended query. We subjected the data to further statistical analysis, but the results should be interpreted cautiously. Table A-22 reports zero-order correlations of reporting each of these general type of experiences with the socio-demographic and employment-related variables and views of promotion. Table A-23 reports full and reduced regression models, and Table 15 reports findings from the reduced models. (These tables parallel the format of Tables A-20, A-21, and 14. But because the dependent variables are dichotomies and logistic regression was used, the coefficients are odds ratios.) Results of the multivariate analyses indicated that employees who had PhDs, but who had not held official leadership roles were more likely to report having leadership and supervisory experiences that they felt helped their professional development. Employees who had held Postdocs at NIST more often reported committee appointments and experience. Employees who had all of their NIST experience within a "fed" role more often reported coursework or training, while employees with more seniority were less likely to report such training. In contrast, those with more seniority more often reported being detailed to another work role. Note that there was no significant association of these reports with employees' gender, disciplinary specialty, OU, perceptions of the promotion process, experiencing a more timely promotion, or reporting a more or less positive promotion experience.

In the process of examining the open-ended comments a number of observations were developed regarding their implications for understanding issues at NIST and potential recommendations for change. As noted earlier in this report, these comments and observations will be examined much more thoroughly as recommendations are considered. All reports of previous experiences are listed in Appendix B of this report. 
Finally, respondents were asked, "What type of professional development opportunities or courses would be helpful in your NIST career?" Almost 400 employees $(n=383)$ responded to this question. Their responses are listed in Appendix $C$ of this report, and Appendix $A$ of the full document provides a list of specific professional development opportunities and coursework requested.

\section{Summary of Findings}

The rate of responding to the survey was higher than often occurs in general surveys. Comparisons to available data on all employees indicated that respondents were relatively representative of the population, although women, younger employees, and those in certain OUs were more likely to respond. Thus, frequency distributions were weighted to reflect the population more closely. Responses regarding employees' experiences with promotion, including time at band and before their last promotion, replicated analyses of data obtained from NIST HR, providing further indication that the sample was relatively representative of the population.

Separate sets of questions dealt with the criteria for promotion from III to IV, IV to V, V to Senior Scientist, and employees' own experiences with the process. Respondents seemed careful to indicate when they didn't know (DK) enough to give a valid answer. Bivariate and multivariate analyses were used to examine factors related to whether or not respondents marked DK. Seniority was the most consistent predictor of whether or not individuals gave this response. This association was significant for views of all transitions from one rank to another as well as knowing about the ST rank.

Questions regarding promotion criteria involved the extent to which employees understood the criteria, the extent to which they thought others understood the criteria, whether they were fairly applied, appropriate for people in their OU, and reflected NIST's stated mission. On average, views of both the promotion criteria and reports of their own experiences were neutral to relatively negative. Views were more positive about the III-IV transition than from IV to $\mathrm{V}$, and views regarding IV-V were more positive than those regarding $\mathrm{V}$ to ST. These differences were highly significant statistically.

Questions regarding employees' own experiences asked about confidence that their accomplishments would be recognized and rewarded in the promotion process, whether they had productive conversations with their supervisors about career progress, and the extent to which their own experiences with the promotion process, as well as the experiences of others, had been productive. Respondents' reports of their own experiences with promotion were, on average, neutral to negative in nature.

There were differences between employees in their perceptions of promotion, with some having more favorable views than others. Bivariate and multivariate statistical techniques were used to systematically examine the association of perceptions with socio-demographic variables and employment-related variables (gender, identification as an under-represented minority, highest degree, field of highest degree, having held a leadership position at NIST, current band, 
years at NIST, age, years employed at NIST, other experiences in the federal government or at NIST, previous promotion experiences, and operating unit). Table 16 summarizes significant relationships in these analyses. The first panel summarizes findings regarding promotion from III to IV, the second regarding promotion to IV to V, etc., following the order of discussion in earlier sections of this document. The first column lists the socio-demographic and the employment related variables that were examined, and the second column reports whether bivariate analyses indicated a significant relationship. For instance, for views regarding promotion to III to IV there were positive associations with gender (a dummy variable with code $1=$ male), but negative associations with identification as URM (a dummy variable with code $1=U R M$ ). The remaining columns in each panel summarize results within the regression analyses for both the total group and for each of the sub-samples that were examined. ${ }^{46}$ (Table A-24 summarizes relationships with the count of Don't Know responses using a similar format.)

A number of factors were not related to employees' views about promotion including their highest degree, the discipline of this degree, previous types of federal employment, and operating unit. Bivariate analysis indicated that physicists had more positive views of the promotion process from IV to $\mathrm{V}$, but this relationship was spurious and disappeared in multivariate analyses when band of seniority was controlled. The lack of differences by operating unit is also noteworthy because it contrasts with analyses of HR and FEVS data. Notably, those data reflected situations of well over 6 months before the survey was administered.

Employees who identified as under-represented minorities had significantly more negative views of the promotion process and their own experiences but, unfortunately, there were too few cases within this group to allow valid multivariate analyses. Women had more negative views than men, but these differences were often not statistically significant when factors such as seniority were controlled or in analyses within various subgroups. Respondents' with more timely promotion experiences were more likely to have positive views, although this result did not appear in all analyses or with all subgroups. ${ }^{47}$ The most consistent correlate of positive views was employees' seniority at NIST. Those who were older, had held leadership posts, had been employed at NIST for a longer period of time and were at higher bands had more positive views of the transition from III to IV, IV to $\mathrm{V}$, and their own experiences. Results were more complex with views regarding the $V$ to ST transition. In this analysis the years employees had been at NIST was not related to views and the impact of band was curvilinear with those at the highest band (i.e. ST already) having the most positive views.

Substantial proportions of the respondents reported that they had taken or planned to engage in courses or training related to leadership skills, communication, and conflict resolution.

\footnotetext{
46 URM status was not included in the regressions because of the very small number of cases. The regressions only included variables that had been significant in the zero-order correlational analysis. When appropriate, the measure of seniority was used rather than individual variables.

${ }^{47}$ As explained earlier in this document timely promotion was measured by either time at current rank or time at previous rank before promotion.
} 
Only a minority indicated they weren't aware of such opportunities. Respondents with more seniority, those outside of physics, and women were more likely to have taken the trainings listed in the survey, while men, those in physics, as well as those not in leadership roles were more likely to say they did not want to do so. Employees who were less senior and had less positive views of the promotion process were more likely to say that they weren't aware of the opportunities. In addition, over two-thirds of the employees indicated that they had other professional development opportunities. These often included leadership roles outside of formal appointments, training and course work in various areas, official detail assignments, and work on NIST committees or in professional organizations. 
Table 1

Demographic and Employment-Related Variables, Survey and Total Population, Z-Ratios and Effect Sizes

\begin{tabular}{|c|c|c|c|c|}
\hline \multirow{2}{*}{$\begin{array}{l}\text { Variable and Categories } \\
\underline{\text { gge }}\end{array}$} & \multicolumn{2}{|c|}{ Proportions } & \multirow[b]{2}{*}{$\underline{\text { Z-ratio }}$} & \multirow[b]{2}{*}{ Effect Size } \\
\hline & $\underline{\text { Survey }}$ & Population & & \\
\hline LT 25 & 0.003 & 0.002 & 1.15 & 0.05 \\
\hline $25-34$ & 0.15 & 0.14 & 0.26 & 0.01 \\
\hline $35-44$ & 0.31 & 0.23 & 4.95 & 0.20 \\
\hline $45-54$ & 0.26 & 0.27 & -0.28 & -0.01 \\
\hline $55-64$ & 0.21 & 0.26 & -2.80 & -0.11 \\
\hline 65 and older & 0.06 & 0.09 & -2.98 & -0.12 \\
\hline \multicolumn{5}{|l|}{ Years at NIST } \\
\hline LT 1 & 0.06 & 0.04 & 2.51 & 0.10 \\
\hline $1-2$ years & 0.07 & 0.09 & -1.06 & -0.04 \\
\hline 3-5 years & 0.16 & 0.17 & -0.85 & -0.03 \\
\hline $6-10$ yrs & 0.20 & 0.19 & 0.82 & 0.03 \\
\hline $11-15$ yrs & 0.14 & 0.13 & 1.14 & 0.05 \\
\hline $16-20$ yrs & 0.09 & 0.07 & 2.12 & 0.09 \\
\hline GT 20 yrs & 0.27 & 0.31 & -2.42 & -0.10 \\
\hline \multicolumn{5}{|l|}{ Race-Ethnicity } \\
\hline URM & 0.08 & 0.06 & 2.05 & 0.09 \\
\hline Asian & 0.10 & 0.15 & -3.56 & -0.15 \\
\hline Non-Hispanic White & 0.83 & 0.79 & 1.99 & 0.08 \\
\hline \multicolumn{5}{|l|}{ Gender } \\
\hline Male & 0.63 & 0.76 & -6.96 & -0.29 \\
\hline Female & 0.37 & 0.24 & 6.96 & 0.29 \\
\hline \multicolumn{5}{|l|}{ Operating Unit } \\
\hline OU-A & 0.11 & 0.20 & -5.20 & -0.22 \\
\hline OU-D & 0.05 & 0.04 & 1.28 & 0.05 \\
\hline OU-F & 0.11 & 0.10 & 0.89 & 0.04 \\
\hline OU-G & 0.13 & 0.15 & -1.67 & -0.07 \\
\hline $\mathrm{OU}-\mathrm{C}$ & 0.32 & 0.24 & 4.25 & 0.18 \\
\hline OU-B & 0.02 & 0.05 & -2.88 & -0.12 \\
\hline OU-E & 0.26 & 0.22 & 1.78 & 0.07 \\
\hline \multicolumn{5}{|l|}{ Band } \\
\hline III & 0.25 & 0.23 & 0.76 & 0.03 \\
\hline IV & 0.45 & 0.49 & -1.88 & -0.08 \\
\hline V & 0.27 & 0.24 & 1.36 & 0.06 \\
\hline ST & 0.04 & 0.03 & 0.20 & 0.01 \\
\hline
\end{tabular}

Note: The number of respondents providing information on the variables ranged from 577 for race-ethnicity, 582 for operating unit, band and gender, to 613 for age, and 615 for years at NIST. Positive $z$ values and effect sizes indicate that a proportion was larger in the sample than in the population. 
Table 2

Highest Degree, Discipline and Previous Federal Experience

\begin{tabular}{|c|c|}
\hline Highest Degree & $\underline{\%}$ \\
\hline Less than bachelors & 1.0 \\
\hline Bachelors & 9.6 \\
\hline Masters & 19.7 \\
\hline PhD & 69.7 \\
\hline Total \% & 100.0 \\
\hline $\mathrm{N}$ & 613 \\
\hline Discipline & $\underline{\%}$ \\
\hline Biology & 4.0 \\
\hline Chemistry & 18.0 \\
\hline Computer Science & 10.7 \\
\hline Engineering & 28.0 \\
\hline Math & 2.7 \\
\hline Material Sciences & 7.0 \\
\hline Physics & 21.1 \\
\hline Social Sciences and Humanities & 7.5 \\
\hline Earth Sciences & 1.2 \\
\hline Total \% & 100 \\
\hline $\mathrm{N}$ & 601 \\
\hline Previous experience & $\underline{\%}$ \\
\hline Postdoc NIST & 35.4 \\
\hline Contract employee at NIST & 10.5 \\
\hline At another fed agency & 13.4 \\
\hline No previous Fed Experience & 40.8 \\
\hline Total \% & 100.0 \\
\hline $\mathrm{N}$ & 611 \\
\hline Length of Previous Federal Experience outside NIST & $\underline{\%}$ \\
\hline LT 1 year & 3.6 \\
\hline $1-2$ years & 45.7 \\
\hline $3-5$ yrs & 25.9 \\
\hline $6-10$ yrs & 11.0 \\
\hline $11-15$ years & 6.3 \\
\hline $16-20$ years & 3.3 \\
\hline GT 20 years & 4.1 \\
\hline Total \% & 100.0 \\
\hline $\mathrm{N}$ & 363 \\
\hline
\end{tabular}

Note: For analysis, the variable of highest degree was collapsed to PhD versus other, and discipline was collapsed to chemistry, engineer, physics, and other. The variable regarding employment outside of NIST was examined with the categories in the table as well as by collapsing to a dummy variable indicating only employment as a "fed" at NIST and other. 
Table 3

Time at Band and Time to Promotion by Band

\begin{tabular}{|c|c|c|c|c|}
\hline \multicolumn{5}{|c|}{ Time at Current Band by Band } \\
\hline \multirow[b]{2}{*}{$\underline{\text { Time }}$} & \multirow[b]{2}{*}{ Band III } & \multicolumn{3}{|c|}{ Band $V$ and } \\
\hline & & Band IV & $\underline{\text { Higher }}$ & $\underline{\text { Total }}$ \\
\hline Less than 1 year & 19.5 & 12.9 & 8.4 & 13.2 \\
\hline 1 to 5 years & 55.0 & 36.2 & 29.6 & 38.9 \\
\hline 6 to 10 years & 20.1 & 29.5 & 25.1 & 25.9 \\
\hline 11 to 15 years & 4.0 & 11.1 & 16.8 & 11.0 \\
\hline 16 or more Years & 1.3 & 10.3 & 20.1 & 11.0 \\
\hline Total (\%) & 100.0 & 100.0 & 100.0 & 100.0 \\
\hline $\mathrm{N}$ & 149 & 271 & 179 & 599 \\
\hline \multicolumn{5}{|c|}{ Time at Previous Band by Band } \\
\hline \multicolumn{5}{|c|}{ Band $V$ and } \\
\hline$\underline{\text { Time }}$ & Band IV & Higher & $\underline{\text { Total }}$ & \\
\hline 1 to 5 years & 49.2 & 26.5 & 39.0 & \\
\hline 6 to 10 years & 38.5 & 36.4 & 37.6 & \\
\hline 11 to 15 years & 9.6 & 26.5 & 17.2 & \\
\hline 16 or more Years & 2.7 & 10.6 & 6.2 & \\
\hline Total (\%) & 100.0 & 100.0 & 100.0 & \\
\hline $\mathrm{N}$ & 187 & 151 & 338 & \\
\hline \multicolumn{5}{|c|}{ Hired at Band by Band } \\
\hline & & Band $V$ and & & \\
\hline Hired at Band? & Band IV & $\underline{\text { Higher }}$ & $\underline{\text { Total }}$ & \\
\hline No & 69.3 & 91.0 & 77.5 & \\
\hline Yes & 30.7 & 9.0 & 22.5 & \\
\hline Total (\%) & 100.0 & 100.0 & 100.0 & \\
\hline $\mathrm{N}$ & 270 & 166 & 436 & \\
\hline \multicolumn{5}{|c|}{ Time to Promotion } \\
\hline & & & and $V$ and & \\
\hline Comparison to Mode & Band III & Band IV & $\underline{\text { Higher }}$ & $\underline{\text { Total }}$ \\
\hline Less than Timely (GE 6 years) & 25.5 & 35.2 & 66.9 & 41.7 \\
\hline Timely (LT 6 years) & 74.5 & 64.8 & 33.1 & 58.3 \\
\hline Total (\%) & 100.0 & 100.0 & 100.0 & 100.0 \\
\hline $\mathrm{N}$ & 149 & 270 & 166 & 585 \\
\hline
\end{tabular}


Table 4

Views of Promotion Process from III to IV, Univariate Statistics

\begin{tabular}{|c|c|c|c|c|c|c|}
\hline \multicolumn{7}{|c|}{ Percentage Distribution (Weighted) } \\
\hline Item & $\begin{array}{l}\text { Str. } \\
\text { Disagree }\end{array}$ & Disagree & $\underline{\text { Neutral }}$ & $\underline{\text { Agree }}$ & $\frac{\text { Str. }}{\text { Agree }}$ & $\underline{N}$ \\
\hline $\begin{array}{l}\text { I understand what is needed to } \\
\text { gain promotion from III to IV. }\end{array}$ & 18.1 & 19.9 & 17.1 & 21.0 & 24.0 & 592 \\
\hline $\begin{array}{l}\text { Most NIST ZP employees } \\
\text { understand what is needed to } \\
\text { gain promotion from III to IV. }\end{array}$ & 22.9 & 21.7 & 25.8 & 17.8 & 11.8 & 507 \\
\hline $\begin{array}{l}\text { The promotion criteria for } \\
\text { promotion from III to IV are } \\
\text { fairly applied. }\end{array}$ & 20.1 & 17.6 & 26.4 & 16.0 & 20.1 & 444 \\
\hline $\begin{array}{l}\text { The promotion criteria from III } \\
\text { to IV are appropriate for } \\
\text { people in my operating unit. }\end{array}$ & 12.7 & 13.3 & 27.3 & 22.1 & 24.7 & 466 \\
\hline $\begin{array}{l}\text { The promotion criteria from III } \\
\text { to IV reflect the stated mission } \\
\text { of NIST. }\end{array}$ & 10.8 & 19.1 & 29.0 & 19.7 & 21.4 & 462 \\
\hline
\end{tabular}

Averages and Standard Deviations by Measure

\begin{tabular}{|c|c|c|c|c|c|c|c|}
\hline \multirow[b]{2}{*}{ Item } & \multicolumn{2}{|c|}{$\frac{\text { DK Omitted, }}{\underline{\text { Unweighted }}}$} & \multicolumn{2}{|c|}{$\frac{\text { DK Omitted, }}{\underline{\text { Weighted }}}$} & \multicolumn{2}{|c|}{$\underline{\text { DK Neutral }}$} & \multirow{2}{*}{$\frac{\frac{\text { Don't }}{\text { Know }}}{\%}$} \\
\hline & Mean & $\underline{\mathrm{SD}}$ & Mean & $\underline{\mathrm{SD}}$ & Mean & $\underline{\mathrm{SD}}$ & \\
\hline $\begin{array}{l}\text { I understand what is needed to } \\
\text { gain promotion from III to IV. }\end{array}$ & 3.41 & 1.30 & 3.45 & 2.26 & 3.38 & 1.27 & 5.9 \\
\hline $\begin{array}{l}\text { Most NIST ZP employees } \\
\text { understand what is needed to } \\
\text { gain promotion from III to IV. }\end{array}$ & 2.90 & 1.04 & 2.94 & 1.98 & 2.92 & 0.94 & 19.4 \\
\hline $\begin{array}{l}\text { The promotion criteria for } \\
\text { promotion from III to IV are } \\
\text { fairly applied. }\end{array}$ & 3.16 & 1.16 & 3.32 & 3.24 & 3.11 & 0.98 & 29.4 \\
\hline $\begin{array}{l}\text { The promotion criteria from III } \\
\text { to IV are appropriate for } \\
\text { people in my operating unit. }\end{array}$ & 3.58 & 1.04 & 3.71 & 2.23 & 3.43 & 0.93 & 25.9 \\
\hline $\begin{array}{l}\text { The promotion criteria from III } \\
\text { to IV reflect the stated mission } \\
\text { of NIST. }\end{array}$ & 3.51 & 1.02 & 3.55 & 2.15 & 3.38 & 0.91 & 26.3 \\
\hline
\end{tabular}


Table 5

Mixed-Model Regression of Perceptions of Promotion III to IV on Gender, Timely Promotion

Experience, and Seniority, Total Group and by Band and Retirement Status

\begin{tabular}{|c|c|c|c|c|c|c|}
\hline \multicolumn{7}{|c|}{ Total Sample } \\
\hline & \multicolumn{2}{|c|}{ Model 1} & \multicolumn{2}{|c|}{ Model 2} & \multicolumn{2}{|c|}{ Model 3} \\
\hline Fixed Effects & $\underline{b}$ & s.e. & $\underline{b}$ & s.e. & $\underline{\mathrm{b}}$ & s.e. \\
\hline Male & $.38 * * *$ & 0.09 & $.33 * * *$ & 0.09 & $.19 *$ & 0.08 \\
\hline Timely Prom. & ----- & ----- & $-.15^{\mathrm{a}}$ & 0.09 & $.22 *$ & 0.09 \\
\hline Seniority & ----- & ----- & ----- & ----- & $.55^{* * *}$ & 0.06 \\
\hline Constant & $2.95 * * *$ & 0.07 & $3.04 * * *$ & 0.09 & $2.95 * * *$ & 0.08 \\
\hline \multicolumn{7}{|l|}{$\underline{\text { Random Effects }}$} \\
\hline Variance Const. & 0.00 & 0.00 & 0.00 & 0.00 & 0.00 & 0.00 \\
\hline Variance Resid. & $1.00 * * *$ & 0.06 & $0.97 * * *$ & 0.06 & $0.82 * * *$ & 0.05 \\
\hline \multicolumn{7}{|l|}{ Model Fit Statistics } \\
\hline Ch. $-2 \mathrm{LL}$ & $97.53 * * *$ & & $61.20 * * *$ & & $88.88^{* * *}$ & \\
\hline PRE & 0.04 & & 0.02 & & 0.16 & \\
\hline \multicolumn{7}{|c|}{ By Band } \\
\hline & & & & & Band $V$ and & \\
\hline & Band III & & Band IV & & Higher & \\
\hline$\underline{\text { Fixed Effects }}$ & $\underline{b}$ & $\underline{\text { s.e. }}$ & $\underline{b}$ & $\underline{\text { s.e. }}$ & $\underline{\mathrm{b}}$ & s.e. \\
\hline Male & 0.21 & 0.16 & 0.18 & 0.13 & 0.17 & 0.14 \\
\hline Timely Prom. & 0.23 & 0.25 & 0.11 & 0.13 & .24 & 0.14 \\
\hline Seniority & -0.001 & 0.34 & .27 & 0.15 & $.70 * * *$ & 0.16 \\
\hline Constant & $2.32 * * *$ & 0.29 & $3.00 * * *$ & 0.13 & $2.85^{* * *}$ & 0.21 \\
\hline \multicolumn{7}{|l|}{ Random Effects } \\
\hline Variance Const. & 0.00 & 0.00 & 0.002 & 0.01 & 0.01 & 0.02 \\
\hline Variance Resid. & $0.92 * * *$ & 0.11 & $0.88 * * *$ & 0.08 & $0.57 * * *$ & 0.07 \\
\hline \multicolumn{7}{|l|}{ Model Fit Statistics } \\
\hline Ch. -2 LL from $B L$ & $17.65 * * *$ & & $46.24 * * *$ & & $68.10 * * *$ & \\
\hline PRE from BL & 0.01 & & 0.04 & & 0.11 & \\
\hline
\end{tabular}


Table 5, Page 2

\begin{tabular}{|c|c|c|c|c|}
\hline \multicolumn{5}{|c|}{ By Retirement Status } \\
\hline & \multicolumn{2}{|c|}{$\underline{\text { Not Eligible }}$} & \multicolumn{2}{|c|}{ Eligible for Retirement } \\
\hline Fixed Effects & $\underline{B}$ & $\underline{\text { s.e. }}$ & $\underline{b}$ & $\underline{\text { s.e. }}$ \\
\hline Male & $.19 *$ & 0.10 & 0.14 & 0.16 \\
\hline Timely Promotion & $.31^{* *}$ & 0.11 & -0.03 & 0.16 \\
\hline Seniority & $.58 * * *$ & 0.08 & $.47^{* *}$ & 0.16 \\
\hline Constant & $2.89 * * *$ & 0.1 & $3.11 * * *$ & 0.20 \\
\hline \multicolumn{5}{|l|}{ Random Effects } \\
\hline Variance Const. & 0.00 & 0.00 & 0.00 & 0.00 \\
\hline Variance Resid. & $0.87^{* * *}$ & 0.06 & $0.66 * * *$ & 0.08 \\
\hline \multicolumn{5}{|l|}{ Model Fit Statistics } \\
\hline Ch. -2 LL from BL & $137.66 * * *$ & & $62.68 * * *$ & \\
\hline PRE from BL & 0.18 & & 0.13 & \\
\hline \multicolumn{5}{|c|}{$\begin{array}{l}\text { Note: For the total group analysis was based on } 544 \text { respondents in } 7 \text { OUs, } 13 \text { to } \\
177 \text { respondents per OU, average of } 77.7 \text {. Change in }-2 \text { LL and the PRE statistics are } \\
\text { based on comparisons to the less complex model (Model } 1 \text { to intercept only, } \\
\text { Model } 2 \text { to Model } 1 \text {, and Model } 3 \text { to Model } 2 \text { ). Degrees of freedom with each } \\
\text { increment }=1 \text {. For the analyses by band and retirement-eligibility, comparisons are } \\
\text { made to baseline, and df }=3 \text {. For Band III there were } 139 \text { cases, } 3 \text { to } 64 \text { per operating } \\
\text { unit, mean }=19.9 \text {; for Band IV, there were } 236 \text { respondents, } 7 \text { to } 69 \text { per OU, } \\
\text { average of } 33.7 \text {; for Band } V \text { there were } 152 \text { respondents, } 2-42 \text { per OU, average of } \\
21.7 \text {; for non-retirement eligible there were } 388 \text { respondents, } 8 \text { to } 135 \text { per OU, } \\
\text { average } 55.4 \text {; for retirement eligible there were } 138 \text { respondents, } 4-40 \text { per OU, } \\
\text { average of } 19.7 \text {. All OU's were represented in all analyses. But the ICC value, } \\
\text { measuring variation between OU's, was equal to zero. The variance associated } \\
\text { with the constant was } 0.0 \text {, resulting in the ICC value of } 0.0 \text {. Interactions of the } \\
\text { independent variables were not significant. * indicates } p<.05, * * \text { indicates } p<.01 \text {, } \\
\text { and } * * * \text { indicates } p<.001 \text {. }\end{array}$} \\
\hline
\end{tabular}


Table 6

Views of Promotion Process from IV to V, Univariate Statistics

\begin{tabular}{|c|c|c|c|c|c|c|c|}
\hline \multicolumn{8}{|c|}{ Percentage Distribution (Weighted) } \\
\hline$\underline{\text { Item }}$ & $\underline{\text { Str. Dis }}$ & Disagree & Neutral & Agree & Str. Agr. & $\underline{N}$ & \\
\hline $\begin{array}{l}\text { I understand what is needed to gain } \\
\text { promotion from III to IV. }\end{array}$ & 22.2 & 19.3 & 16.0 & 20.7 & 21.8 & 595 & \\
\hline $\begin{array}{l}\text { Most NIST ZP employees understand } \\
\text { what is needed to gain promotion } \\
\text { from III to IV. }\end{array}$ & 27.7 & 25.7 & 20.4 & 14.2 & 12.0 & 509 & \\
\hline $\begin{array}{l}\text { The promotion criteria for promotion } \\
\text { from III to IV are fairly applied. }\end{array}$ & 23.6 & 22.3 & 24.6 & 14.1 & 15.4 & 440 & \\
\hline $\begin{array}{l}\text { The promotion criteria from III to IV } \\
\text { are appropriate for people in my } \\
\text { operating unit. }\end{array}$ & 17.5 & 16.0 & 25.0 & 19.9 & 21.6 & 468 & \\
\hline $\begin{array}{l}\text { The promotion criteria from III to IV } \\
\text { reflect the stated mission of NIST. }\end{array}$ & 13.1 & 20.0 & 28.3 & 18.5 & 20.0 & 459 & \\
\hline \multicolumn{8}{|c|}{ Averages and Standard Deviations by Measure } \\
\hline & \multicolumn{2}{|c|}{$\frac{\text { DK Omitted, }}{\underline{\text { Unweighted }}}$} & \multicolumn{2}{|c|}{$\frac{\text { DK Omitted, }}{\underline{\text { Weighted }}}$} & \multicolumn{2}{|c|}{$\underline{\text { DK Neutral }}$} & $\frac{\text { Don't }}{\underline{\text { Know }}}$ \\
\hline$\underline{\text { Item }}$ & $\underline{\text { Mean }}$ & $\underline{\mathrm{SD}}$ & Mean & $\underline{\mathrm{SD}}$ & $\underline{\text { Mean }}$ & $\underline{\mathrm{SD}}$ & $\%$ \\
\hline $\begin{array}{l}\text { I understand what is needed to gain } \\
\text { promotion from III to IV. }\end{array}$ & 3.19 & 1.36 & 3.28 & 2.27 & 3.18 & 1.32 & 5.9 \\
\hline $\begin{array}{l}\text { Most NIST ZP employees understand } \\
\text { what is needed to gain promotion } \\
\text { from III to IV. }\end{array}$ & 2.67 & 1.12 & 2.74 & 1.98 & 2.73 & 1.01 & 19.5 \\
\hline $\begin{array}{l}\text { The promotion criteria for promotion } \\
\text { from III to IV are fairly applied. }\end{array}$ & 2.88 & 1.18 & 3.01 & 2.15 & 2.92 & 0.99 & 30.3 \\
\hline $\begin{array}{l}\text { The promotion criteria from III to IV } \\
\text { are appropriate for people in my } \\
\text { operating unit. }\end{array}$ & 3.29 & 1.16 & 3.16 & 2.27 & 3.22 & 1.01 & 25.8 \\
\hline $\begin{array}{l}\text { The promotion criteria from III to IV } \\
\text { reflect the stated mission of NIST. }\end{array}$ & 3.35 & 1.1 & 3.41 & 2.1 & 3.26 & 0.95 & 27.3 \\
\hline
\end{tabular}

Note: "DK" indicates "don't know." Weighted results omitted respondents who responded DK. 
Table 7

Mixed-Model Regression, Promotion IV to V on Gender, Physics, and Seniority, Total Group, by Band and Retirement Status

\begin{tabular}{|c|c|c|c|c|c|c|}
\hline \multicolumn{7}{|c|}{ Total Sample } \\
\hline & \multicolumn{2}{|c|}{ Model 1} & \multicolumn{2}{|c|}{ Model 2} & \multicolumn{2}{|c|}{ Model 3} \\
\hline Fixed Effects & $\underline{B}$ & s.e. & $\underline{b}$ & s.e. & $\underline{\mathrm{b}}$ & s.e. \\
\hline Male & $.43^{* * *}$ & 0.09 & $.41 * * *$ & 0.09 & $.25 * *$ & 0.09 \\
\hline Physics & ----- & ----- & $.21^{*}$ & 0.11 & 0.15 & 10 \\
\hline Seniority & ----- & ----- & ----- & ----- & $.51 * * *$ & 0.05 \\
\hline Constant & $2.71 * * *$ & 0.08 & $2.68 * * *$ & 0.07 & $2.81 * * *$ & 0.07 \\
\hline \multicolumn{7}{|l|}{ Random Effects } \\
\hline Variance Const. & 0.00 & 0.01 & 0.00 & 0.01 & 0.00 & 0.00 \\
\hline Variance Resid. & $1.09 * * *$ & 0.07 & $1.08 * * *$ & 0.07 & $.92 * * *$ & 0.06 \\
\hline \multicolumn{7}{|c|}{ Model Fit Statistics } \\
\hline Change in -2 LL & $93.72 * * *$ & & $21.42 * * *$ & & $87.87^{* * *}$ & \\
\hline PRE & 0.13 & & 0.01 & & 0.15 & \\
\hline \multicolumn{7}{|c|}{ By Band } \\
\hline & \multicolumn{2}{|c|}{ Band III } & \multicolumn{2}{|c|}{ Band IV } & \multicolumn{2}{|c|}{ Band $\mathrm{V}$ and Higher } \\
\hline Ind. Var. & $\underline{B}$ & s.e. & $\underline{b}$ & s.e. & $\underline{b}$ & s.e. \\
\hline Male & $.36^{*}$ & 0.16 & 0.04 & 0.14 & $.45^{* *}$ & 0.14 \\
\hline Physics & 0.11 & 0.22 & 0.22 & 0.17 & -0.09 & 0.16 \\
\hline Seniority & 0.08 & 0.26 & 0.003 & 0.15 & 0.22 & 0.15 \\
\hline Constant & $2.23 * * *$ & 0.29 & $2.81 * * *$ & 0.11 & $3.12 * * *$ & 0.19 \\
\hline \multicolumn{7}{|l|}{ Random Effects } \\
\hline Variance Const. & 0.00 & 0.00 & 0.00 & 0.00 & 0.03 & 0.04 \\
\hline Variance Resid. & $.81 * * *$ & 0.10 & $1.05^{* * *}$ & 0.09 & $.62 * * *$ & 0.07 \\
\hline \multicolumn{7}{|c|}{ Model Fit Statistics } \\
\hline \multicolumn{7}{|c|}{$\overline{C h .-2 \text { LL from }}$} \\
\hline $\mathrm{BL}$ & $12.79 * *$ & & $44.74 * * *$ & & $41.43^{* * *}$ & \\
\hline PRE from BL & 0.01 & & 0.02 & & 0.06 & \\
\hline
\end{tabular}


Table 7, Page 2

\begin{tabular}{|c|c|c|c|c|}
\hline \multicolumn{5}{|c|}{ By Retirement Status } \\
\hline & \multicolumn{2}{|c|}{$\underline{\text { Not Eligible }}$} & \multicolumn{2}{|c|}{$\underline{\text { Eligible for Retirement }}$} \\
\hline Ind. Var. & $\underline{B}$ & s.e. & $\underline{\mathrm{b}}$ & s.e. \\
\hline Male & $.25^{* *}$ & 0.1 & .29 & 0.18 \\
\hline Physics & 0.19 & 0.13 & 0.18 & 0.19 \\
\hline Seniority & $.58 * * *$ & 0.08 & $.91 * * *$ & 0.17 \\
\hline Constant & $2.87 * * *$ & 0.08 & $2.25 * * *$ & 0.23 \\
\hline \multicolumn{5}{|l|}{ Random Effects } \\
\hline Variance Const. & 0.001 & 0.01 & 0.05 & 0.06 \\
\hline Variance Resid. & $0.95 * * *$ & 0.07 & $0.74 * * *$ & 0.09 \\
\hline \multicolumn{5}{|l|}{ Model Fit Statistics } \\
\hline Ch. -2 LL from $B L$ & 113.04 & & 64.95 & \\
\hline PRE from BL & 0.15 & & 0.19 & \\
\hline \multicolumn{5}{|c|}{ 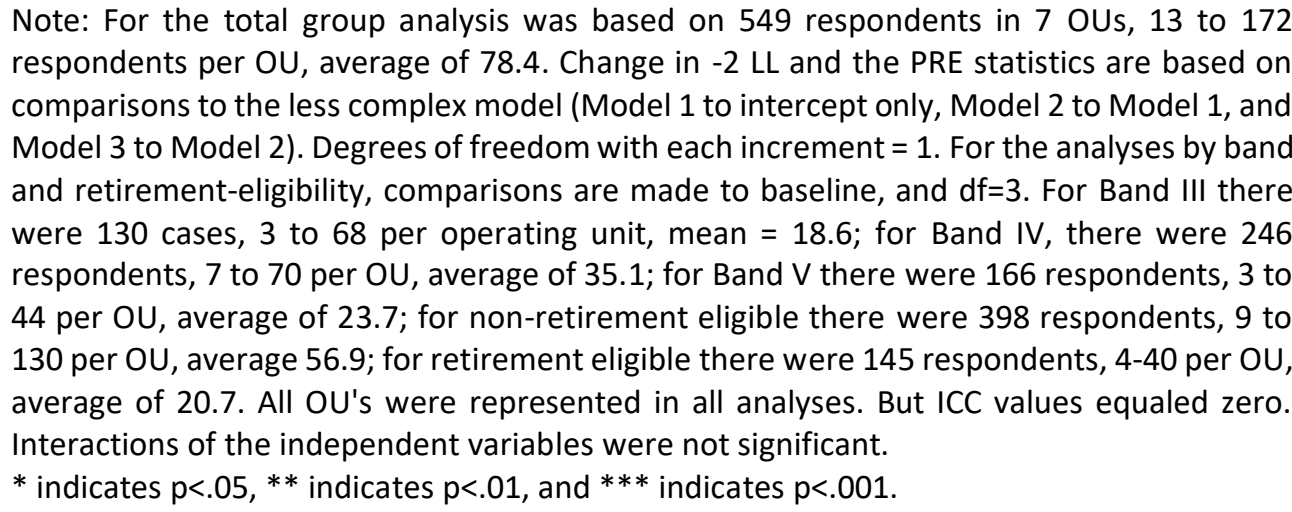 } \\
\hline
\end{tabular}


Table 8

Mixed-Model Logistic Regression of Awareness of ST Band on Gender, PhD, Postdoc at NIST, Physics, and Seniority

$\underline{\text { Model } 1} \quad \underline{\text { Model } 2}$

\begin{tabular}{lcccc} 
Ind. Var. & Odds Ratio & $\underline{Z}$ & Odds Ratio & $\underline{Z}$ \\
\cline { 2 - 3 } & 1.07 & 0.36 & 0.87 & -0.68 \\
PhD & $2.12^{* * *}$ & 3.3 & $2.30^{* * *}$ & 3.47 \\
NIST Postdoc & 1.32 & 1.17 & $1.73^{*}$ & 2.16 \\
Timely Promotion & $.64^{*}$ & -2.22 & 1.21 & 0.82 \\
Physics & $2.61^{* * *}$ & 3.28 & $2.24 * *$ & 2.65 \\
Seniority & ---- & 0.86 & $2.66^{* * *}$ & 6.13 \\
Constant & 1.22 & 0.27 & 0.97 & -0.13 \\
Var. Constant & 0.00 & 0.00 & 0.00 & 0.00 \\
Ch. -2LL from BL & $78.23^{* * *}$ & & $42.76^{* * *}$ &
\end{tabular}

Note: Change in -2LL value calculated from baseline. $\mathrm{N}=572$ respondents, 13 to 181 per OU, average of 81.7 . 
Table 9

Views of Promotion Process from V to ST, Univariate Statistics

Percentage Distribution (Weighted)

\begin{tabular}{|c|c|c|c|c|c|c|}
\hline Item & $\underline{\text { Str. Dis }}$ & Disagree & $\underline{\text { Neutral }}$ & Agree & Str. Agr. & $\underline{\mathrm{N}}$ \\
\hline $\begin{array}{l}\text { I understand what is needed to } \\
\text { gain promotion from V to ST. }\end{array}$ & 38.1 & 27.0 & 12.6 & 13.1 & 9.2 & 389 \\
\hline $\begin{array}{l}\text { Most NIST ZP employees } \\
\text { understand what is needed to } \\
\text { gain promotion from V to ST. }\end{array}$ & 40.8 & 34.7 & 14.2 & 5.1 & 5.1 & 331 \\
\hline $\begin{array}{l}\text { The promotion criteria for } \\
\text { promotion from V to ST are } \\
\text { fairly applied. }\end{array}$ & 26.8 & 18.3 & 31.7 & 9.8 & 13.4 & 224 \\
\hline $\begin{array}{l}\text { The promotion criteria from } \mathrm{V} \text { to } \\
\text { ST are appropriate for people in } \\
\text { my operating unit. }\end{array}$ & 16.0 & 19.7 & 32.4 & 16.4 & 15.6 & 244 \\
\hline $\begin{array}{l}\text { The promotion criteria from } V \text { to } \\
\text { ST reflect the stated mission of } \\
\text { NIST. }\end{array}$ & 14.0 & 20.0 & 34.0 & 14.4 & 17.6 & 250 \\
\hline
\end{tabular}

\begin{tabular}{|c|c|c|c|c|c|c|c|}
\hline \multirow[b]{2}{*}{ Item } & \multicolumn{2}{|c|}{$\frac{\text { DK Omitted, }}{\underline{\text { Unweighted }}}$} & \multicolumn{2}{|c|}{$\frac{\text { DK Omitted, }}{\text { Weighted }}$} & \multicolumn{2}{|c|}{ DK Neutral } & \multirow{2}{*}{$\frac{\frac{\text { Don't }}{\text { Know }}}{\%}$} \\
\hline & Mean & $\underline{S D}$ & Mean & $\underline{\mathrm{SD}}$ & Mean & $\underline{\mathrm{SD}}$ & \\
\hline $\begin{array}{l}\text { I understand what is needed to } \\
\text { gain promotion from } V \text { to ST. }\end{array}$ & 2.29 & 1.19 & 2.39 & 2.39 & 2.35 & 1.16 & 8 \\
\hline $\begin{array}{l}\text { Most NIST ZP employees } \\
\text { understand what is needed to } \\
\text { gain promotion from V to ST. }\end{array}$ & 1.96 & 0.87 & 2.03 & 2.03 & 2.19 & 0.88 & 21.7 \\
\hline $\begin{array}{l}\text { The promotion criteria for } \\
\text { promotion from V to ST are } \\
\text { fairly applied. }\end{array}$ & 2.69 & 1.08 & 2.86 & 2.86 & 2.84 & 0.77 & 47 \\
\hline $\begin{array}{l}\text { The promotion criteria from } \mathrm{V} \text { to } \\
\text { ST are appropriate for people in } \\
\text { my operating unit. }\end{array}$ & 3.05 & 1.02 & 3.2 & 3.2 & 3.03 & 0.78 & 42.3 \\
\hline $\begin{array}{l}\text { The promotion criteria from } V \text { to } \\
\text { ST reflect the stated mission of } \\
\text { NIST. }\end{array}$ & 3.13 & 1.03 & 3.32 & 3.32 & 3.08 & 0.79 & 40.9 \\
\hline
\end{tabular}

Note: "DK" indicates "don't know." Weighted results omitted respondents who responded DK. 425 respondents (67\% of total) said they were aware of the ST Band. Only those respondents were asked the questions. 
Table 10

Mixed Model Regressions of Scale Score Regarding Perceptions of Promotion from V to ST, Total Group and by Retirement Eligibility and Band

\begin{tabular}{|c|c|c|c|c|c|c|}
\hline \multicolumn{7}{|c|}{ Total Sample and by Retirement Eligibility } \\
\hline & \multicolumn{6}{|c|}{ Not Eligible for } \\
\hline & \multicolumn{2}{|c|}{ Total Group } & \multicolumn{2}{|c|}{$\overline{\text { Retirement }}$} & \multicolumn{2}{|c|}{ Eligible for Retirement } \\
\hline Fixed Effects & $\underline{b}$ & s.e. & $\underline{b}$ & s.e. & $\underline{b}$ & s.e. \\
\hline Male & $.23^{*}$ & 0.1 & $.23^{*}$ & 0.12 & 0.29 & 0.19 \\
\hline Band & $-.70^{*}$ & 0.31 & -0.56 & 0.37 & $-2.66^{* *}$ & 1.00 \\
\hline Band Sq. & $.19 * *$ & 0.06 & $.16^{*}$ & 0.08 & $.52^{* *}$ & 0.17 \\
\hline Age & $.11^{*}$ & 0.06 & $.18^{*}$ & 0.09 & 0.13 & 0.11 \\
\hline Constant & $2.33^{* * *}$ & 0.32 & $2.01^{* * *}$ & 0.38 & $4.91^{* * *}$ & 1.5 \\
\hline \multicolumn{7}{|l|}{$\underline{\text { Random Effects }}$} \\
\hline Variance Const. & 0.00 & 0.00 & 0.00 & 0.00 & 0.02 & 0.03 \\
\hline Variance Resid. & $.80 * * *$ & 0.06 & 0.82 & 0.08 & 0.69 & 0.09 \\
\hline \multicolumn{7}{|l|}{ Model Fit Statistics } \\
\hline Ch. -2 LL from $B L$ & $82.49 * * *$ & & 43.99 & & 36.48 & \\
\hline PRE from $B L$ & 0.11 & & 0.11 & & 0.16 & \\
\hline \multicolumn{7}{|c|}{ Results by Band } \\
\hline & \multicolumn{2}{|c|}{ Band III } & \multicolumn{2}{|c|}{ Band IV } & \multicolumn{2}{|c|}{ Band $V$ and Higher } \\
\hline Fixed Effects & $\underline{\mathrm{b}}$ & $\underline{\text { s.e. }}$ & $\underline{b}$ & s.e. & $\underline{b}$ & $\underline{\text { s.e. }}$ \\
\hline Male & 0.10 & 0.20 & 0.14 & 0.16 & $.40^{*}$ & 0.17 \\
\hline Age & -0.21 & 0.18 & $.22^{* *}$ & 0.09 & 0.1 & 0.1 \\
\hline ST Band & ----- & ----- & ----- & ----- & $.60 *$ & 0.31 \\
\hline Constant & $2.60 * * *$ & 0.46 & $1.44 * * *$ & 0.33 & $1.81^{* * *}$ & 0.45 \\
\hline \multicolumn{7}{|l|}{$\underline{\text { Random Effects }}$} \\
\hline Variance Const. & 0.00 & 0.00 & 0.00 & 0.00 & 0.00 & 0.00 \\
\hline Variance Resid. & $.64 * * *$ & 0.11 & $.82 * * *$ & 0.10 & $0.87^{* * *}$ & 0.10 \\
\hline \multicolumn{7}{|c|}{ Model Fit Statistics } \\
\hline Ch. -2 LL from $B L$ & 1.56 & & $32.67 * * *$ & & $24.59 * * *$ & \\
\hline PRE from BL & 0.02 & & 0.07 & & 0.07 & \\
\hline \multicolumn{7}{|c|}{$\begin{array}{l}\text { Note: For the total group analysis was based on } 357 \text { respondents in } 7 \text { OUs, } 11 \text { to } 122 \text { respondents per OU, } \\
\text { average of } 51 \text {. For non-retirement eligible, } n=236,8 \text { to } 88 \text { per OU, mean } 33.9 \text {; for retirement eligible, } n=119,3 \\
\text { to } 34 \text { per OU, average } 17 \text {; for Band III, } n=64,2 \text { to } 35 \text { per OU, average } 9.1 \text {; for Band IV, } n=143,5 \text { to } 47 \text { per OU, } \\
\text { average } 20.4 \text {; and for Band } V \text { and higher, } n=149,3 \text { to } 41 \text { per OU, average } 21.3 \text {. Change in }-2 \text { LL and the PRE } \\
\text { statistics are based on comparisons to the baseline, intercept-only, model. All OU's were represented in all } \\
\text { analyses. But ICC values equaled zero. Exploration of a model by band that included years at NIST rather than } \\
\text { age, indicated no significant associations with years at NIST. }{ }^{*} \text { indicates } p<.05,{ }^{* *} \text { indicates } p<.01 \text {, and } * * * \\
\text { indicates } p<.001 \text {. }\end{array}$} \\
\hline
\end{tabular}


Table 11

Respondents' Perceptions of Promotion-Related Experiences, Univariate Statistics

\begin{tabular}{|c|c|c|c|c|c|c|}
\hline \multicolumn{7}{|c|}{ Percentage Distribution (Weighted) } \\
\hline Item & $\underline{\text { Str. Dis }}$ & Disagree & Neutral & $\underline{\text { Agree }}$ & Str. Agr. & $\underline{\mathrm{N}}$ \\
\hline $\begin{array}{l}\text { I am confident that my } \\
\text { accomplishments will be } \\
\text { recognized and rewarded in } \\
\text { the promotion process in the } \\
\text { future. }\end{array}$ & 16.7 & 22.4 & 24.0 & 17.6 & 19.4 & 604 \\
\hline $\begin{array}{l}\text { I have productive } \\
\text { conversations with my } \\
\text { supervisor about my career } \\
\text { progress on an annual basis. }\end{array}$ & 13.3 & 21.3 & 21.6 & 21.9 & 21.9 & 616 \\
\hline $\begin{array}{l}\text { Other employees at NIST } \\
\text { who I know have had } \\
\text { positive experiences with the } \\
\text { NIST promotion process. }\end{array}$ & 17.0 & 23.5 & 25.9 & 17.2 & 16.5 & 553 \\
\hline $\begin{array}{l}\text { I have had positive } \\
\text { experiences with the NIST } \\
\text { promotion process. }\end{array}$ & 19.8 & 20.5 & 23.8 & 14.5 & 23.4 & 585 \\
\hline
\end{tabular}

Averages and Standard Deviations by Measure

\begin{tabular}{|c|c|c|c|c|c|c|c|}
\hline \multirow[b]{2}{*}{ Item } & \multicolumn{2}{|c|}{$\begin{array}{l}\text { DK Omitted, } \\
\text { Unweighted }\end{array}$} & \multicolumn{2}{|c|}{$\frac{\text { DK Omitted, }}{\underline{\text { Weighted }}}$} & \multicolumn{2}{|c|}{$\underline{\text { DK Neutral }}$} & \multirow{2}{*}{$\frac{\frac{\text { Don't }}{\text { Knou }}}{\%}$} \\
\hline & Mean & $\underline{S D}$ & Mean & $\underline{\mathrm{SD}}$ & Mean & $\underline{\mathrm{SD}}$ & \\
\hline $\begin{array}{l}\text { I am confident that my } \\
\text { accomplishments will be } \\
\text { recognized and rewarded in } \\
\text { the promotion process in the } \\
\text { future. }\end{array}$ & 3.29 & 1.16 & 3.35 & 2.22 & 3.29 & 1.14 & 3 \\
\hline $\begin{array}{l}\text { I have productive } \\
\text { conversations with my } \\
\text { supervisor about my career } \\
\text { progress on an annual basis. }\end{array}$ & 3.55 & 1.2 & 3.56 & 2.23 & 3.55 & 1.2 & 1 \\
\hline $\begin{array}{l}\text { Other employees at NIST } \\
\text { who I know have had } \\
\text { positive experiences with the } \\
\text { NIST promotion process. }\end{array}$ & 3.15 & 1.04 & 3.26 & 2.22 & 3.14 & 0.98 & 11.2 \\
\hline $\begin{array}{l}\text { I have had positive } \\
\text { experiences with the NIST } \\
\text { promotion process. }\end{array}$ & 2.25 & 1.19 & 3.32 & 2.26 & 3.23 & 1.16 & 6.2 \\
\hline
\end{tabular}

Note: "DK" indicates "don't know." Weighted results omitted respondents who responded DK. 
Table 12

Mixed Model Regressions of Scale Score Regarding Perceptions of Own Promotion Experiences, Total Group and by Retirement Eligibility and Band

\section{Total Sample and by Retirement Eligibility}

\begin{tabular}{|c|c|c|c|c|c|c|}
\hline \multirow[b]{3}{*}{$\underline{\text { Fixed Effects }}$} & \multicolumn{6}{|c|}{ Not Eligible for } \\
\hline & \multicolumn{2}{|c|}{$\underline{\text { Total Group }}$} & \multicolumn{2}{|c|}{$\underline{\text { Retirement }}$} & \multicolumn{2}{|c|}{ Eligible for Retirement } \\
\hline & $\underline{b}$ & s.e. & $\underline{b}$ & s.e. & $\underline{b}$ & s.e. \\
\hline Male & $.17^{*}$ & 0.08 & $.16 a$ & 0.09 & 0.18 & 0.16 \\
\hline Timely Promotion & $.30 * * *$ & 0.08 & $.38 * * *$ & 0.1 & 0.06 & 0.16 \\
\hline Leadership & -0.09 & 0.09 & -0.07 & 0.12 & -0.12 & 0.16 \\
\hline Band & $-.56^{*}$ & 0.24 & $-.55 a$ & 0.3 & -0.01 & 0.73 \\
\hline Band Sq. & $.20 * * *$ & 0.06 & $.19 * *$ & 0.08 & 0.1 & 0.14 \\
\hline Constant & $3.30 * * *$ & 0.25 & 3.24 & 0.29 & $2.62 * * *$ & 0.94 \\
\hline \multicolumn{7}{|l|}{ Random Effects } \\
\hline Variance Const. & 0.00 & 0.00 & 0.00 & 0.00 & 0.00 & 0.00 \\
\hline Variance Resid. & $0.73 * * *$ & 0.04 & $0.75^{* * *}$ & 0.05 & $0.68 * * *$ & 0.08 \\
\hline \multicolumn{7}{|l|}{ Model Fit Statistics } \\
\hline Ch. -2 LL from BL & $202.84 * * *$ & & $119.68 * * *$ & & $82.15^{* * *}$ & \\
\hline PRE from BL & 0.12 & & 0.12 & & 0.17 & \\
\hline \multicolumn{7}{|c|}{ Results by Band } \\
\hline & \multicolumn{2}{|c|}{ Band III } & \multicolumn{2}{|c|}{ Band IV } & \multicolumn{2}{|c|}{ Band $V$ and Higher } \\
\hline Fixed Effects & $\underline{\mathrm{b}}$ & s.e. & $\underline{\mathrm{b}}$ & s.e. & $\underline{b}$ & s.e. \\
\hline Male & 0.09 & 0.14 & 0.13 & 0.12 & $.38 * *$ & 0.14 \\
\hline Timely Promotion & $.57 * * *$ & 0.16 & $.23 a$ & 0.12 & $.27^{*}$ & 0.13 \\
\hline Leadership & -0.33 & 0.34 & -0.18 & 0.14 & 0.06 & 0.14 \\
\hline Senior Scientist & ----- & ----- & ----- & ----- & $.62^{* *}$ & 0.25 \\
\hline Constant & $2.79 * * *$ & 0.17 & $3.04 * * *$ & 0.12 & $3.17 * * *$ & 0.17 \\
\hline \multicolumn{7}{|l|}{ Random Effects } \\
\hline Variance Const. & 0.03 & 0.04 & 0.00 & 0.00 & 0.00 & 0.00 \\
\hline Variance Resid. & $0.72 * * *$ & 0.09 & $0.89 * * *$ & 0.08 & $0.70 * * *$ & 0.07 \\
\hline \multicolumn{7}{|l|}{ Model Fit Statistics } \\
\hline Ch. -2 LL from BL & $34.70 * * *$ & & $59.76 * * *$ & & $76.96 * * *$ & \\
\hline PRE from BL & 0.09 & & 0.06 & & 0.14 & \\
\hline
\end{tabular}

Note: For the total group analysis was based on 571 respondents in 7 OUs, 13 to 180 respondents per OU, average of 82. For non-retirement eligible, $n=403,8$ to 134 per OU, mean 57.6; for retirement eligible, $n=146,4$ to 42 per OU, average 20.9; for Band III, $n=1393$ to 63 per OU, average 19.9; for Band IV, $n=262,7$ to 71 per OU, average 36.0; for Band $V$ and higher, $n=159.2$ to 43 per OU, average 36.0. Change in $-2 L L$ and the PRE statistics are based on comparisons to the baseline, intercept-only, model. All OU's were represented in all analyses. ICC values equaled or were very close to zero. a indicates $p<.10,{ }^{*}$ indicates $p<.05,{ }^{* *}$ indicates $p<.01$, and $* * *$ indicates $p<.001$. 
Table 13

Professional Development Experiences and Interest by Type of Experience

\begin{tabular}{|c|c|c|c|c|c|}
\hline Actions and Plans & Have Taken & $\frac{\text { Plan to Take }}{\text { in Future }}$ & $\frac{\text { Do not Plan }}{\text { to Take }}$ & $\begin{array}{c}\text { Did Not } \\
\text { Know About }\end{array}$ & $\underline{N}$ \\
\hline Leadership Skills & 54.5 & 22.7 & 17.5 & 6.7 & 616 \\
\hline Communication Skills & 52.7 & 20.5 & 18.8 & 11.1 & 611 \\
\hline Conflict Resolution & 46.6 & 21.4 & 22.1 & 12.7 & 612 \\
\hline Federal Regulations & 25.0 & 12.6 & 34.4 & 31.9 & 605 \\
\hline Budget & 10.8 & 15.8 & 35.1 & 41.6 & 603 \\
\hline
\end{tabular}

Note: Data are percentages. Values in each row can add to more than $100 \%$ because respondents could mark more than one response. Data were only included in calculations if respondents provided an answer regarding a given area, and that is why the sample size $(n)$ varies from one area to another. 
Table 14

Regressions of Professional Development Experiences and Desires on Socio-Demographic Characteristics, Employment-Related Variables, and Promotion-Related Views, Final Reduced Models

\begin{tabular}{|c|c|c|c|c|c|c|c|c|c|c|}
\hline \multirow[b]{2}{*}{ Fixed Effects } & \multicolumn{2}{|c|}{ Have Taken Course } & \multicolumn{2}{|c|}{ Do Not Plan to Take } & \multicolumn{2}{|c|}{ Plan to Take } & \multicolumn{2}{|c|}{ Did Not Know Of } & \multirow{2}{*}{$\begin{array}{c}\text { Other } \\
\text { Experiences } \\
\text { OR }\end{array}$} & \multirow[b]{2}{*}{ Z } \\
\hline & $b$ & s.e. & $\underline{b}$ & s.e. & $b$ & s.e. & $\underline{b}$ & s.e. & & \\
\hline Male & $-.12 * * *$ & 0.03 & $.07^{*}$ & 0.03 & ----- & ----- & ----- & ----- & ----- & ---- \\
\hline Age & ----- & ----- & $.07^{* * *}$ & 0.01 & ----- & ----- & ----- & ----- & ----- & ---- \\
\hline Physics & $-.11 * * *$ & 0.04 & $.09 *$ & 0.04 & ----- & ----- & ----- & ----- & ----- & ----- \\
\hline NIST Fed Only & ----- & ----- & ----- & ----- & $-.06 * *$ & 0.02 & ----- & ----- & ----- & ----- \\
\hline Week Returned & ----- & ----- & ----- & ----- & $.03 * *$ & 0.01 & ----- & ----- & ----- & ----- \\
\hline Timely Pr. & ----- & ----- & ----- & ----- & ----- & ----- & ----- & ----- & $.54 * * *$ & -3.21 \\
\hline Leader & ----- & ----- & $-.15^{* * *}$ & 0.03 & ----- & ----- & ----- & ----- & ----- & ----- \\
\hline Seniority & $.21 * * *$ & 0.02 & ----- & ----- & $-.14^{* * *}$ & 0.01 & $-.05 * * *$ & 0.02 & ----- & ----- \\
\hline Prom. Positive & ----- & ----- & ----- & ----- & ----- & ----- & $-.06 * * *$ & 0.01 & ----- & ----- \\
\hline Constant & $.50 * * *$ & 0.04 & 0.003 & 0.06 & $.15^{* * *}$ & 0.02 & $.40 * * *$ & 0.05 & 3.29 & 7.79 \\
\hline \multicolumn{11}{|l|}{$\underline{\text { Random Effects }}$} \\
\hline Variance Const. & 0.01 & 0.00 & 0.005 & 0.004 & 0 & 0 & 0.00 & 0.00 & 0.00 & 0.00 \\
\hline Var. Resid. & $0.08 * * *$ & 0.01 & $.10 * * *$ & 0.01 & $0.07^{* * *}$ & 0.0038248 & $.08 * * *$ & 0.004 & ----- & ----- \\
\hline \multicolumn{11}{|c|}{ Model Fit Statistics } \\
\hline Ch -2 LL from BL & $174^{* * *}$ & & $86 * * *$ & & $126 * * *$ & & $46.53^{* * *}$ & & $107^{* * *}$ & \\
\hline PRE from BL & 0.24 & & 0.10 & & 0.19 & & 0.08 & & & \\
\hline
\end{tabular}

Note: Full details are in Table A-21. ICC values ranged from 0.0 for responses of plan to take in the future, didn't know of possibilities, and having other professional opportunities, to .07 for had taken a course and .08 for did not plan to take, as reflected in the significance associated with the variance associated with the constant term for the random effects. Views of promotion was measured as the average response given to views of promotion from III to IV, IV to $\mathrm{V}$, and own experiences. Because the measure of other experiences was a dichotomy logistic regression was used. ${ }^{*}=p<.05, * *=p<.01$ $* * *=p<.001$. 
Table 15

Logistic Mixed Model Regressions of Other Professional Development Experiences on SocioDemographic Characteristics, Employment-Related Variables, and Promotion Related Views, Final Reduced Models

\begin{tabular}{|c|c|c|c|c|c|c|c|c|}
\hline \multirow[b]{2}{*}{ Fixed Effects } & $\frac{\text { Super }}{\text { Lead }}$ & Leadership & $\underline{\text { Det }}$ & & Cours & vork & Committees/ & $\frac{\text { tees/ }}{\text { tions }}$ \\
\hline & $\underline{\mathrm{OR}}$ & $\underline{Z}$ & $\underline{\mathrm{OR}}$ & $\underline{Z}$ & $\underline{\mathrm{OR}}$ & $\underline{Z}$ & $\underline{\mathrm{OR}}$ & $\underline{Z}$ \\
\hline $\mathrm{PhD}$ & $1.68^{*}$ & 2.19 & ----- & ----- & ----- & ----- & ----- & ----- \\
\hline Leadership Role & $.51 * *$ & -2.89 & ----- & ----- & ----- & ----- & ----- & ----- \\
\hline Postdoc NIST & ----- & ----- & ----- & ----- & ----- & ----- & $2.29 * *$ & 3.07 \\
\hline NIST Fed Only & ----- & ----- & ----- & ----- & $1.99 * *$ & 3.09 & ----- & ----- \\
\hline Seniority & ----- & ----- & $3.42 * * *$ & 6.17 & $.53 * * *$ & -4.42 & ----- & ----- \\
\hline Constant & $.62^{*}$ & -2.86 & $.17 * * *$ & -10.42 & $.51 * * *$ & -4.57 & $.16^{* * *}$ & -9.77 \\
\hline \multicolumn{9}{|c|}{ Model Fit Statistics } \\
\hline Ch -2 LL from $B L$ & $15.92 * *$ & & $46.11^{* * *}$ & & $32.10 * * *$ & & $9.80 * *$ & \\
\hline
\end{tabular}


Table 16

Summary of Significant Correlations and Fixed Effects from Regressions of Scale Scores Related to Promotion by Level of Promotion

\section{Promotion III}

to IV

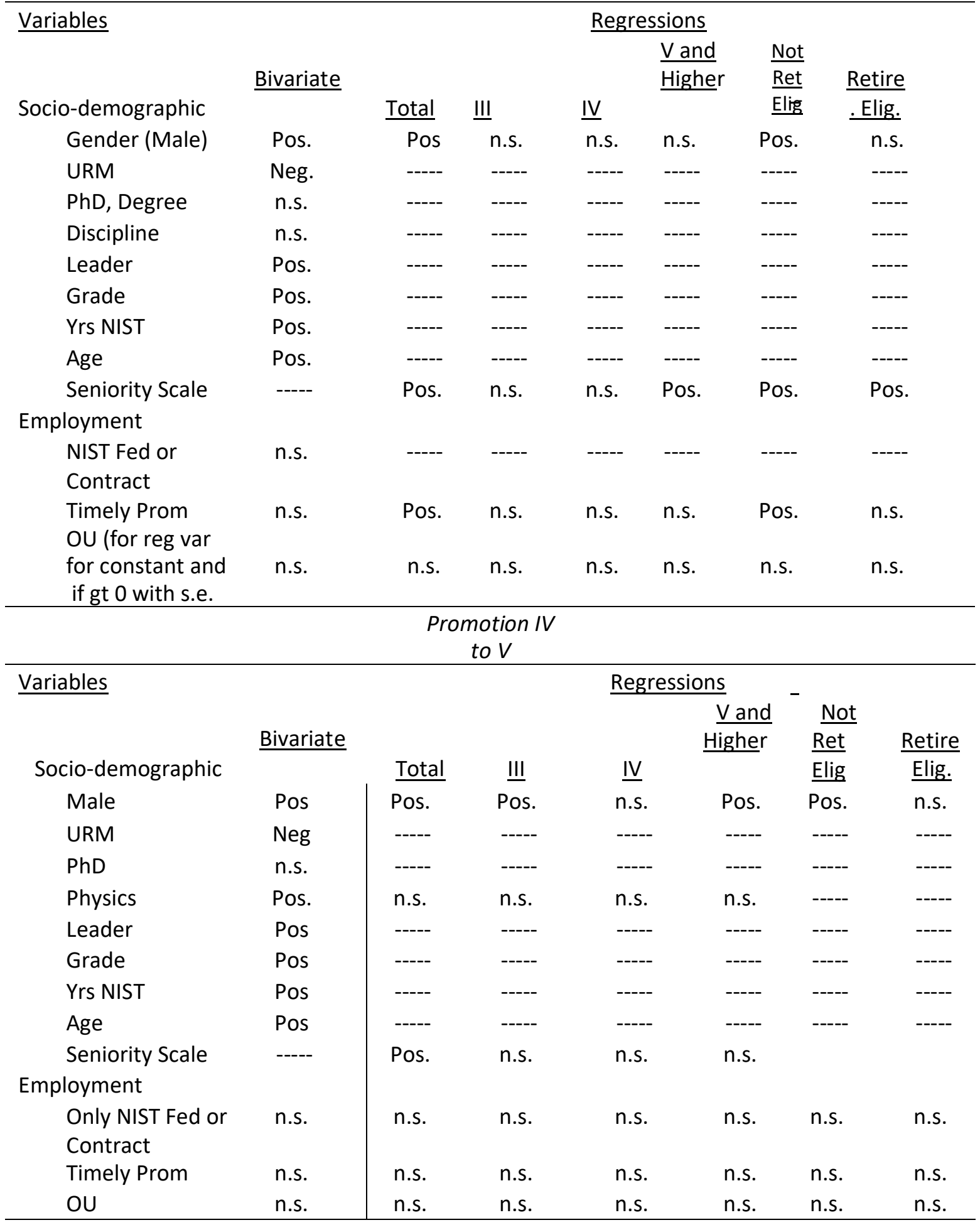


Table 16, Page 2

\section{Promotion V to ST}

\begin{tabular}{|c|c|c|c|c|c|c|c|}
\hline \multirow[t]{3}{*}{$\underline{\text { Variables }}$} & & \multicolumn{6}{|c|}{$\underline{\text { Regressions }}$} \\
\hline & & & & & & Not & \\
\hline & & & & & $\underline{\mathrm{V} \text { and }}$ & $\underline{\text { Ret }}$ & \\
\hline Socio-demographic & Bivariate & Total & III & $\underline{\text { IV }}$ & Higher & Elig & Retire. Elig. \\
\hline Male & Pos. & Pos. & n.s. & n.s. & Pos. & Pos. & n.s. \\
\hline URM, RE & Neg. & ------ & ------ & ------ & ------ & ------ & ------ \\
\hline PhD, Degree & ----- & ----- & ----- & ----- & ----- & ----- & ----- \\
\hline Discipline & ------ & ------ & ------ & ------ & ------ & ------ & ------ \\
\hline Leader & Pos. & ------ & ------ & ------ & ------ & ------ & ------ \\
\hline Band and Gr. Sq. & Pos. & Pos. & ------ & ------ & ------ & Pos. & Pos. \\
\hline Yrs NIST & n.s. & ------ & ------ & ------ & ------ & ------ & ------ \\
\hline Age & Pos. & Pos. & n.s. & Pos. & n.s. & Pos. & n.s. \\
\hline Seniority Scale & ----- & ----- & ------ & ------ & ------ & ------ & ------ \\
\hline \multicolumn{8}{|l|}{ Employment } \\
\hline NIST Fed or Contract & ----- & ----- & ----- & ----- & ----- & ----- & ----- \\
\hline Timely Prom & n.s. & n.s. & n.s. & n.s. & n.s. & n.s. & n.s. \\
\hline $\mathrm{OU}$ & n.s. & n.s. & n.s. & n.s. & n.s. & n.s. & n.s. \\
\hline \multicolumn{8}{|c|}{ Own Promotion } \\
\hline \multirow[t]{2}{*}{$\underline{\text { Variables }}$} & & \multicolumn{6}{|c|}{$\underline{\text { Regressions }}$} \\
\hline & & & & & $\underline{\mathrm{V} \text { and }}$ & $\underline{\text { Not }}$ & $\underline{\text { Retire. }}$ \\
\hline Socio-demographic & Bivariate & Total & $\underline{\text { III }}$ & $\underline{\text { IV }}$ & Higher & $\underline{\text { Ret Elig }}$ & Elig. \\
\hline Male & Pos. & Pos & n.s. & n.s. & Pos. & n.s. & n.s. \\
\hline URM & Neg. & ----- & ------ & ------ & ------ & ------ & ------ \\
\hline PhD, Degree & n.s. & ----- & ------ & ------ & ------ & ------ & ------ \\
\hline Discipline & n.s. & ------ & ------ & ------ & ------ & ----- & ------ \\
\hline Leader & Pos. & n.s. & n.s. & n.s. & n.s. & n.s. & n.s. \\
\hline Band and Gr. Sq. & Pos. & Pos. & Pos. & Pos. & n.s. & Pos. & n.s. \\
\hline Yrs NIST & n.s. & ------ & ------ & ------ & ------ & ------ & _------ \\
\hline Age & n.s. & ------ & ------ & ------ & ------ & ------ & ------ \\
\hline Seniority Scale & ----- & ----- & ------ & ------ & ------ & ------ & ------ \\
\hline \multicolumn{8}{|l|}{$\begin{array}{l}\text { Employment } \\
\text { Only NIST Fed or }\end{array}$} \\
\hline Contract & n.s. & ----- & ----- & ----- & ----- & ----- & ----- \\
\hline Timely Prom & Pos. & Pos. & Pos. & Pos. & n.s. & Pos. & n.s. \\
\hline OU & n.s. & n.s. & n.s. & n.s. & n.s. & n.s. & n.s. \\
\hline
\end{tabular}

Note: Methodological variables of missing data and week returned omitted because they were not significant in any analyses. The probability Band of .05 was used as the cut-off for determining significance. As noted in a footnote to the text, this criterion was conservative because the sampling fraction was not included in calculations. 


\section{Appendix A: Additional Statistical Tables}

Table A-1

Weights Assigned by Age, Gender, and Operating Unit

\begin{tabular}{|c|c|c|c|}
\hline Weight & Age Code & Gender Code & Operating Unit \\
\hline 0.644156 & 1 & 0 & 0 \\
\hline 0.243950 & 1 & 0 & 1 \\
\hline 0.533820 & 1 & 0 & 2 \\
\hline 0.504300 & 1 & 0 & 3 \\
\hline 0.439004 & 1 & 0 & 4 \\
\hline 0.841867 & 1 & 0 & 5 \\
\hline 0.507990 & 1 & 0 & 6 \\
\hline 2.819775 & 1 & 1 & 0 \\
\hline 0.871436 & 1 & 1 & 1 \\
\hline 0.986563 & 1 & 1 & 2 \\
\hline 1.004500 & 1 & 1 & 3 \\
\hline 0.859724 & 1 & 1 & 4 \\
\hline 2.324700 & 1 & 1 & 5 \\
\hline 0.884482 & 1 & 1 & 6 \\
\hline 1.618680 & 2 & 0 & 0 \\
\hline 0.746200 & 2 & 0 & 1 \\
\hline 0.535733 & 2 & 0 & 2 \\
\hline 1.070100 & 2 & 0 & 3 \\
\hline 0.723739 & 2 & 0 & 4 \\
\hline 0.832300 & 2 & 0 & 5 \\
\hline 0.672856 & 2 & 0 & 6 \\
\hline 2.004900 & 2 & 1 & 0 \\
\hline 1.131600 & 2 & 1 & 1 \\
\hline 1.088550 & 2 & 1 & 2 \\
\hline 1.756015 & 2 & 1 & 3 \\
\hline 1.004014 & 2 & 1 & 4 \\
\hline 3.314850 & 2 & 1 & 5 \\
\hline 1.053828 & 2 & 1 & 6 \\
\hline 1.087121 & . & 0 & 0 \\
\hline 0.380927 & . & 0 & 1 \\
\hline 0.534726 & . & 0 & 2 \\
\hline 0.787200 & . & 0 & 3 \\
\hline 0.524055 & . & 0 & 4 \\
\hline 0.838040 & . & 0 & 5 \\
\hline 0.586084 & . & 0 & 6 \\
\hline 2.185983 & . & 1 & 0 \\
\hline 0.972611 & . & 1 & 1 \\
\hline 1.051464 & . & 1 & 2 \\
\hline
\end{tabular}


Table A-1 Page 2

$\begin{array}{llll}1.455409 & \text {. } & 1 & 3\end{array}$

$\begin{array}{llll}0.941581 & . & 1 & 4\end{array}$

$2.819775 \quad$. 115

$\begin{array}{llll}0.984835 & . & 1 & 6\end{array}$

0.659148 . 0.

$\begin{array}{lll}1.197810 & . & 1\end{array}$

$\begin{array}{llll}1.313577 & 1 & . & 0\end{array}$

$\begin{array}{llll}0.607232 & 1 & . & 1\end{array}$

$\begin{array}{llll}0.812431 & 1 & \text {. } & 2\end{array}$

$\begin{array}{llll}0.785663 & 1 & . & 3\end{array}$

$\begin{array}{llll}0.630240 & 1 & \text {. } & 4\end{array}$

$\begin{array}{llll}1.689200 & 1 & . & 5\end{array}$

$\begin{array}{llll}0.766828 & 1 & . & 6\end{array}$

$\begin{array}{llll}1.870172 & 2 & . & 0\end{array}$

$\begin{array}{llll}1.015980 & 2 & . & 1\end{array}$

$\begin{array}{llll}0.954081 & 2 & . & 2\end{array}$

$\begin{array}{llll}1.521800 & 2 & . & 3\end{array}$

$\begin{array}{llll}0.925400 & 2 & . & 4\end{array}$

$\begin{array}{llll}2.487333 & 2 & \text {. } & 5\end{array}$

$\begin{array}{llll}0.970200 & 2 & . & 6\end{array}$

1.660441 . . $\quad 0$

$\begin{array}{llll}0.748179 & . & . & 1\end{array}$

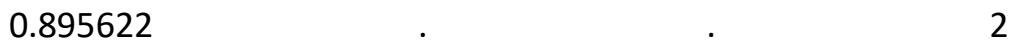

$1.199110 \quad$. $\quad 3$

$\begin{array}{llll}0.763959 & . & . & 4\end{array}$

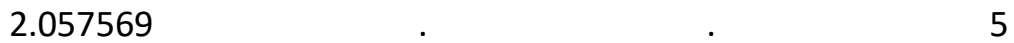

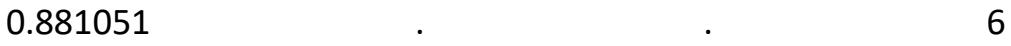

$0.788462 \quad 1$.

1.1914792.

$\begin{array}{lll}0.490838 & 1 & 0\end{array}$.

$\begin{array}{lll}0.913617 & 2 & 0\end{array}$.

$\begin{array}{lll}1.047353 & 1 & 1\end{array}$.

$\begin{array}{lll}1.299039 & 2 & 1\end{array}$

Note: Codes for age were 1=less than 25 to 44 and $2=45$ and older. Codes for Gender were $0=$ female and $1=$ male. Codes for Operating Unit were $0=O U-A$, $1=$ OU-D, 2 = OU-F. $3=$ OU-G, $4=$ OU-C, $5=$ OU-B, and $6=$ OU-E. A code of "." indicated that the data were missing. Weights were calculated by dividing the proportion in the population by the proportion in the sample. Thus, if a given group were under-represented in the sample the associated weight would be greater than 1 . Those with no data on any weighting variable were assigned a weight of 1.0 
Table A-2

Years at Current Band and Years at Rank Before Promotion by Gender and Band

\begin{tabular}{|c|c|c|c|c|}
\hline \multicolumn{5}{|c|}{ Years At Band by Gender and Band } \\
\hline Band III & Women & Men & Total & Cohen's d \\
\hline Mean & 2.03 & 2.18 & 2.10 & -0.19 \\
\hline SD & 0.74 & 0.86 & 0.80 & \\
\hline Count & 71 & 72 & 143 & \\
\hline \multicolumn{5}{|l|}{ Band IV } \\
\hline Mean & 2.57 & 2.75 & 2.68 & -0.15 \\
\hline SD & 1.04 & 1.22 & 1.16 & \\
\hline Count & 96 & 163 & 259 & \\
\hline \multicolumn{5}{|c|}{ Band $\mathrm{V}$ and Higher } \\
\hline Mean & 2.95 & 3.15 & 3.10 & -0.16 \\
\hline SD & 1.29 & 1.25 & 1.26 & \\
\hline Count & 43 & 130 & 173 & \\
\hline \multicolumn{5}{|l|}{$\underline{\text { Total }}$} \\
\hline Mean & 2.47 & 2.78 & 2.67 & -0.27 \\
\hline SD & 1.06 & 1.22 & 1.17 & \\
\hline Count & 210 & 365 & 575 & \\
\hline \multicolumn{5}{|c|}{ Analysis of Variance Results } \\
\hline & $\mathrm{F}$ & df & Prob. & \\
\hline Gender & 2.97 & 1,569 & 0.09 & \\
\hline Band & 25.1 & 2,569 & $<.0001$ & \\
\hline Interaction & 0.02 & 2,569 & 0.98 & \\
\hline \multicolumn{5}{|c|}{ Average Years at Previous Band before Promotion by Gender and Band } \\
\hline Band IV & $\underline{\text { Women }}$ & Men & Total & Cohen's d \\
\hline Mean & 2.71 & 2.62 & 2.65 & 0.11 \\
\hline SD & 0.69 & 0.81 & 0.77 & \\
\hline Count & 68 & 111 & 179 & \\
\hline \multicolumn{5}{|c|}{ Band $V$ and Higher } \\
\hline Mean & 3.14 & 3.22 & 3.20 & -0.08 \\
\hline SD & 1.07 & 0.92 & 0.96 & \\
\hline Count & 36 & 110 & 146 & \\
\hline
\end{tabular}


Table A-3

Years at Current Band and Years at Rank Before Promotion by Gender and Operating Unit

\begin{tabular}{|c|c|c|c|c|}
\hline \multicolumn{5}{|c|}{ Years at Current Band } \\
\hline Operating Unit & $\underline{\text { Women }}$ & $\underline{\text { Men }}$ & $\underline{\text { Total }}$ & Cohen's d \\
\hline \multicolumn{5}{|l|}{ OU-A } \\
\hline Mean & 2.43 & 2.59 & 2.52 & -0.14 \\
\hline SD & 1.10 & 1.16 & 1.13 & \\
\hline Count & 30 & 34 & 64 & \\
\hline \multicolumn{5}{|l|}{ OU-D } \\
\hline Mean & 1.73 & 2.39 & 2.14 & -0.59 \\
\hline SD & 0.65 & 1.29 & 1.13 & \\
\hline Count & 11 & 18 & 29 & \\
\hline \multicolumn{5}{|l|}{ OU-F } \\
\hline Mean & 2.61 & 2.89 & 2.81 & -0.22 \\
\hline SD & 1.29 & 1.24 & 1.25 & \\
\hline Count & 18 & 44 & 62 & \\
\hline \multicolumn{5}{|l|}{ OU-G } \\
\hline Mean & 3.03 & 2.82 & 2.90 & 0.18 \\
\hline SD & 1.18 & 1.19 & 1.18 & \\
\hline Count & 29 & 44 & 73 & \\
\hline \multicolumn{5}{|l|}{$\mathrm{OU}-\mathrm{C}$} \\
\hline Mean & 2.40 & 2.96 & 2.72 & -0.50 \\
\hline SD & 0.98 & 1.17 & 1.12 & \\
\hline Count & 77 & 103 & 180 & \\
\hline \multicolumn{5}{|l|}{ OU-B } \\
\hline Mean & 2.20 & 2.88 & 2.62 & -0.57 \\
\hline SD & 1.10 & 1.25 & 1.19 & \\
\hline Count & 5 & 8 & 13 & \\
\hline \multicolumn{5}{|l|}{ OU-E } \\
\hline Mean & 2.29 & 2.66 & 2.56 & -0.31 \\
\hline SD & 0.87 & 1.29 & 1.20 & \\
\hline Count & 38 & 108 & 146 & \\
\hline \multicolumn{5}{|l|}{ Total } \\
\hline Mean & 2.45 & 2.78 & 2.66 & -0.28 \\
\hline SD & 1.05 & 1.23 & 1.18 & \\
\hline Count & 208 & 359 & 567 & \\
\hline
\end{tabular}


Table A-3, Page 2

\begin{tabular}{|c|c|c|c|c|}
\hline \multicolumn{5}{|c|}{ Analysis of Variance Results } \\
\hline & $\mathrm{F}$ & df & Prob. & \\
\hline Gender & 6.29 & 1,553 & 0.01 & \\
\hline Operating Unit & 2.48 & 6,553 & 0.02 & \\
\hline Interaction & 1.14 & 6,553 & 0.34 & \\
\hline \multicolumn{5}{|c|}{ Years at Previous Band before Promotion } \\
\hline Operating Unit & Women & Men & Total & Cohen's d \\
\hline \multicolumn{5}{|l|}{ OU-A } \\
\hline Mean & 2.67 & 2.90 & 2.75 & -0.24 \\
\hline SD & 0.97 & 0.99 & 0.97 & \\
\hline Count & 18 & 10 & 28 & \\
\hline \multicolumn{5}{|l|}{ OU-D } \\
\hline Mean & 2.50 & 2.45 & 2.47 & 0.06 \\
\hline SD & 1.00 & 0.69 & 0.74 & \\
\hline Count & 4 & 11 & 15 & \\
\hline \multicolumn{5}{|l|}{ OU-F } \\
\hline Mean & 3.00 & 3.16 & 3.11 & -0.17 \\
\hline SD & 1.05 & 0.94 & 0.96 & \\
\hline Count & 10 & 25 & 35 & \\
\hline \multicolumn{5}{|l|}{ OU-G } \\
\hline Mean & 2.75 & 2.76 & 2.76 & -0.01 \\
\hline SD & 1.06 & 0.79 & 0.86 & \\
\hline Count & 12 & 29 & 41 & \\
\hline \multicolumn{5}{|l|}{$\mathrm{OU}-\mathrm{C}$} \\
\hline Mean & 3.03 & 3.00 & 3.01 & 0.03 \\
\hline SD & 0.70 & 0.96 & 0.87 & \\
\hline Count & 36 & 66 & 102 & \\
\hline \multicolumn{5}{|l|}{ OU-B } \\
\hline Mean & 3.33 & 3.50 & 3.43 & -0.17 \\
\hline SD & 0.58 & 1.29 & 0.98 & \\
\hline Count & 3 & 4 & 7 & \\
\hline \multicolumn{5}{|l|}{ OU-E } \\
\hline Mean & 2.70 & 2.89 & 2.85 & -0.21 \\
\hline SD & 0.86 & 0.91 & 0.90 & \\
\hline Count & 20 & 72 & 92 & \\
\hline
\end{tabular}


Table A-3, Page 3

\begin{tabular}{|c|c|c|c|c|}
\hline Total & Women & Men & Total & Cohen's d \\
\hline Mean & 2.85 & 2.93 & 2.90 & -0.08 \\
\hline SD & 0.87 & 0.92 & 0.90 & \\
\hline Count & 103 & 217 & 320 & \\
\hline \multicolumn{5}{|c|}{ Analysis of Variance Results } \\
\hline Variable & $\underline{F}$ & $\underline{\mathrm{df}}$ & Prob. & \\
\hline Gender & 0.4 & 1,306 & 0.53 & \\
\hline Operating Unit & 1.6 & 6,306 & 0.15 & \\
\hline Interaction & 0.15 & 6,306 & 0.99 & \\
\hline
\end{tabular}

Note: A negative effect size (Cohen's d) indicates that women were at band for fewer years than men. Average scores reflect the codes on the categories shown in Table 3 in the text. 
Table A-4

Descriptive Statistics (Means, Standard Deviations, N), Independent Variables

Variable

Mean

Std. Dev.

$\underline{N}$

Socio-Demographic Variables

Gender (Male)

0.63

0.48

582

URM

0.06

0.24

577

Age

3.71

1.13

613

$\mathrm{PhD}$

0.70

0.46

613

Field of Study (Dummy Variables)

Chemistry

0.18

0.38

601

Engineering

0.28

0.45

601

Physics

0.21

0.41

601

Employment Related Variables

Operating Unit (Dummy Variables)

$$
\text { OU-D }
$$

OU-F

OU-G

$\mathrm{OU}-\mathrm{C}$

OU-B

OU-E

Band

Years at NIST

Leadership

Positions before NIST (Dummy variables)

NIST Postdoc

Contract Employee, NIST

Only NIST Fed

Timely Promotion

Seniority Scale

Response-Related Variables

Missing GE 3 Demo./Employment Variables

Week returned Survey

Note: The omitted category for dummy variables were other areas for field of study,

administrative and other for operating unit, and other federal agencies for positions before NIST.
599

0.11

0.31

599

0.13

0.34

599

0.32

0.47

599

0.02

0.15

599

0.26

0.44

599

2.09

0.81

605

4.64

1.87

615

0.33

0.47

620

0.35

0.48

611

0.10

0.31

611

0.41

0.49

611

0.58

0.49

585

0.01

0.81

624

0.04

0.21

633

2.05

1.19

633 
Table A-5

Inter-correlations (Pearson's r) of Independent Variables

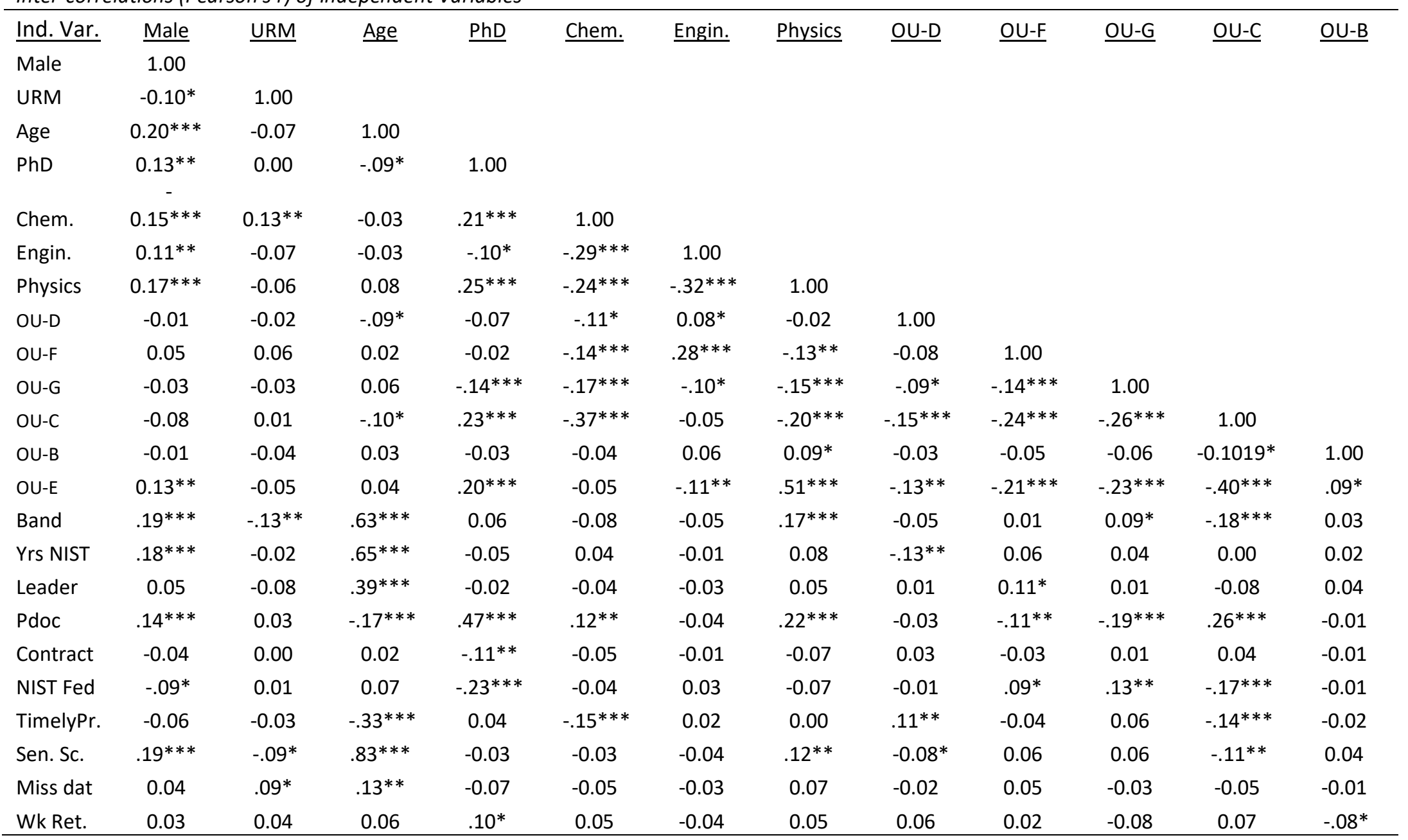


Table A-5, Page 2

\begin{tabular}{|c|c|c|c|c|c|c|c|c|c|c|}
\hline Ind. Var. & $\underline{\mathrm{OU}-\mathrm{E}}$ & Band & $\underline{\text { Yrs NIST }}$ & $\underline{\text { Leader }}$ & $\underline{P d o c}$ & Contract & $\underline{\text { NIST Fed }}$ & TimelyPr. & $\frac{\text { Sen. }}{\text { Scale }}$ & $\frac{\text { Miss }}{\text { data }}$ \\
\hline OU-E & 1.00 & & & & & & & & & \\
\hline Band & $.10^{*}$ & 1.00 & & & & & & & & \\
\hline Yrs NIST & 0.05 & $.59 * * *$ & 1.00 & & & & & & & \\
\hline Leader & -0.04 & $.57 * * *$ & $.36 * * *$ & 1.00 & & & & & & \\
\hline Pdoc & $.15^{* * *}$ & -0.06 & 0.02 & -0.04 & 1.00 & & & & & \\
\hline Contract & -0.02 & -0.03 & -0.03 & -0.03 & $-.25 * * *$ & 1.00 & & & & \\
\hline NIST Fed & -0.03 & -0.02 & 0.02 & -0.03 & $-.61 * * *$ & $-.28 * * *$ & 1.00 & & & \\
\hline TimelyPr. & 0.01 & $-.32 * * *$ & $-.58 * * *$ & $-.16 * * *$ & $-.14 * * *$ & 0.05 & 0.06 & 1.00 & & \\
\hline Sen. Scale & 0.05 & $.86 * * *$ & $.81^{* * *}$ & $.72 * * *$ & $-.08^{*}$ & -0.02 & 0.01 & $-.43 * * *$ & 1.00 & \\
\hline Miss data & 0.07 & -0.01 & $0.0800 *$ & 0.06 & -0.07 & 0.04 & 0.00 & 0.01 & $.10 * *$ & 1.00 \\
\hline Week Ret. & 0.00 & 0.01 & 0.01 & 0.01 & 0.06 & 0.04 & -0.06 & -0.01 & 0.02 & 0.05 \\
\hline
\end{tabular}

Note: ${ }^{* * *}$ indicates $p<.001,{ }^{* *}$ indicates $p<.01,{ }^{*}$ indicates $p<.05$. See Tables $1-2$ and A-2 for fuller definitions of variables. 
Table A-6

Average Count of Don't Know (DK) Responses Regarding Promotion Band III to IV by Demographic and Employment Related Variables

\begin{tabular}{|c|c|c|c|c|c|}
\hline \multicolumn{6}{|c|}{ Dichotomous Variables } \\
\hline Variable and categories: & Mean & $\underline{N}$ & $\underline{\text { t-ratio }}$ & Probability & Effect Size \\
\hline \multicolumn{6}{|l|}{ No demographics } \\
\hline Have data & 1.06 & 600 & & & \\
\hline No data & 1.33 & 27 & 0.89 & 0.37 & 0.17 \\
\hline \multicolumn{6}{|l|}{ Gender } \\
\hline Female & 1.23 & 211 & & & \\
\hline Male & 0.99 & 366 & 1.85 & 0.06 & 0.15 \\
\hline \multicolumn{6}{|l|}{ URM } \\
\hline No & 1.08 & 537 & & & \\
\hline Yes & 1.00 & 35 & 0.28 & 0.78 & 0.05 \\
\hline \multicolumn{6}{|l|}{ PhD } \\
\hline No & 1.04 & 184 & & & \\
\hline Yes & 1.07 & 424 & 0.23 & 0.81 & 0.02 \\
\hline \multicolumn{6}{|l|}{ Only NIST Fed employee } \\
\hline No & 0.94 & 360 & & & \\
\hline Yes & 1.27 & 246 & 2.59 & 0.01 & 0.21 \\
\hline \multicolumn{6}{|l|}{ Have had leadership post } \\
\hline No & 1.32 & 414 & & & \\
\hline Yes & 0.58 & 200 & 5.65 & $<.0001$ & 0.47 \\
\hline \multicolumn{6}{|l|}{ Timely Promotion } \\
\hline No & 0.81 & 242 & & & \\
\hline Yes & 1.28 & 338 & 3.65 & 0.0003 & 0.30 \\
\hline \multicolumn{6}{|c|}{ Categorical Variables } \\
\hline Race-ethnicity 3 cats & $\underline{\text { Mean }}$ & $\underline{\text { Count }}$ & $\underline{F}$ & prob. & \\
\hline URM & 1 & 35 & & & \\
\hline Asian & 1.24 & 55 & & & \\
\hline Non-Hisp White & 1.06 & 482 & 0.37 & 0.69 & \\
\hline \multicolumn{6}{|c|}{ Other Employment Experience } \\
\hline Postdoc NIST & 0.86 & 215 & & & \\
\hline Contract at NIST & 1.16 & 63 & & & \\
\hline Other Fed Agency & 0.98 & 82 & & & \\
\hline \multicolumn{6}{|l|}{ Only NIST Fed } \\
\hline employee & 1.27 & 246 & 2.89 & 0.035 & \\
\hline
\end{tabular}




\begin{tabular}{|c|c|c|c|c|}
\hline$\underline{\text { Variable }}$ & Mean & $\underline{\text { Count }}$ & $\underline{F}$ & prob. \\
\hline \multicolumn{5}{|l|}{ Band } \\
\hline III & 1.42 & 149 & & \\
\hline IV & 1.07 & 269 & & \\
\hline $\mathrm{V}$ & 0.75 & 161 & & \\
\hline ST & 0.57 & 21 & 5.73 & 0.0007 \\
\hline \multicolumn{5}{|c|}{ When Returned Survey } \\
\hline Week 1 & 1.21 & 303 & & \\
\hline Week 2 & 1.11 & 114 & & \\
\hline Week 3 & 0.94 & 83 & & \\
\hline Week 4 & 0.78 & 127 & 2.59 & 0.05 \\
\hline \multicolumn{5}{|l|}{ Discipline } \\
\hline Chemistry & 0.94 & 108 & & \\
\hline Engineering & 1.05 & 165 & & \\
\hline Physics & 1.13 & 126 & & \\
\hline Other & 1.12 & 197 & 0.37 & 0.77 \\
\hline \multicolumn{5}{|l|}{ Operating Unit } \\
\hline OU-A & 1.43 & 68 & & \\
\hline OU-D & 0.54 & 28 & & \\
\hline OU-F & 0.61 & 66 & & \\
\hline OU-G & 1.65 & 77 & & \\
\hline $\mathrm{OU}-\mathrm{C}$ & 0.88 & 190 & & \\
\hline OU-B & 1.15 & 13 & & \\
\hline OU-E & 1.14 & 152 & 4.61 & 0.0001 \\
\hline \multicolumn{5}{|l|}{ Years at NIST } \\
\hline LT 1 & 1.97 & 37 & & \\
\hline 1 to 2 & 1.8 & 44 & & \\
\hline 3 to 5 & 1.06 & 98 & & \\
\hline 6 to 10 & 1.22 & 125 & & \\
\hline 11 to 15 & 0.91 & 89 & & \\
\hline 16 to 20 & 1.09 & 56 & & \\
\hline GT 20 & 0.62 & 161 & 6.64 & $<.0001$ \\
\hline
\end{tabular}


Table A-6, Page 3

Variable

Age

Lt 25 to 34

35 to 44

45 to 54

55 to 64

GE 65

Degree

LE Bachelors

Masters

PhD

\section{Mean}

1.54

1.15

0.94

0.94

0.47

0.9

1.11

1.07
Count

91

191

162

130

34

63

121

424
F prob.

4.05

0.003

Note: Scale is the count of responses of "Don't Know" to the questions regarding promotion from Band III to IV. Probabilities for t-values are two-tail. Effect size is Cohen's $d$ and based on the common standard deviation of 1.56 . 
Table A-7

Mixed Model Poisson Regressions of Count of Don't Know Responses to Questions Regarding Promotion III to IV on Variables Significant in Bivariate Analysis, Total Sample and by Band and Retirement Eligibility

\begin{tabular}{|c|c|c|c|c|c|c|}
\hline \multicolumn{7}{|c|}{ Total Sample } \\
\hline \multirow[b]{2}{*}{ Ind. Variables } & \multicolumn{2}{|c|}{ Model 1} & \multicolumn{2}{|c|}{ Model 2} & \multicolumn{2}{|c|}{ Model 3} \\
\hline & $\underline{b}$ & s.e. & $\underline{b}$ & s.e. & $\underline{b}$ & $\underline{\text { s.e. }}$ \\
\hline Male & $-.20 *$ & 0.08 & $-.17^{*}$ & 0.08 & -0.08 & 0.08 \\
\hline NIST Fed Only & $.23 * *$ & 0.08 & $.25 * *$ & 0.08 & $.24 * *$ & 0.08 \\
\hline Timely Prom. & ----- & ----- & $.37 * * *$ & 0.09 & 0.05 & 0.1 \\
\hline Sen. Scale & ----- & ----- & ----- & ----- & $-.45 * * *$ & 0.06 \\
\hline Constant & 0.02 & 0.16 & -0.22 & 0.17 & -0.14 & 0.18 \\
\hline Var. Constant & 0.12 & 0.08 & 0.12 & 0.08 & 0.15 & 0.10 \\
\hline Ch. $-2 \mathrm{LL}$ & $108.49 * * *$ & & $58.54 * * *$ & & $53.66 * * *$ & \\
\hline \multicolumn{7}{|c|}{ Results by Band } \\
\hline & \multicolumn{2}{|c|}{ Band III } & \multicolumn{2}{|c|}{ Band IV } & \multicolumn{2}{|c|}{ Band $\mathrm{V}$ and Higher } \\
\hline Ind. Variables & $\underline{b}$ & s.e. & $\underline{b}$ & s.e. & $\underline{b}$ & s.e. \\
\hline Male & -0.02 & 0.14 & -0.17 & 0.12 & -0.19 & 0.21 \\
\hline NIST Fed Only & 0.21 & 0.15 & $.39 * * *$ & 0.12 & -0.13 & 0.19 \\
\hline Timely Prom. & 0.12 & 0.18 & $.34^{*}$ & 0.14 & 0.05 & 0.19 \\
\hline Constant & 0.25 & 0.22 & -0.3 & 0.21 & -0.47 & 0.4 \\
\hline Var. Constant & 0.06 & 0.06 & 0.13 & 0.11 & 0.53 & 0.48 \\
\hline Ch., -2 LL from base & $24.36 * * *$ & & $51.87 * * *$ & & $50.44 * *$ & \\
\hline \multicolumn{7}{|c|}{ Results by Retirement Status } \\
\hline & \multicolumn{2}{|c|}{$\underline{\text { Not Eligible }}$} & \multicolumn{2}{|c|}{ Eligible } & & \\
\hline Ind. Variables & $\underline{b}$ & s.e. & $\underline{b}$ & $\underline{\text { s.e. }}$ & & \\
\hline Male & -0.05 & 0.09 & -0.38 & 0.24 & & \\
\hline NIST Fed Only & $.23 * *$ & 0.09 & 0.14 & 0.23 & & \\
\hline Timely Prom. & -0.05 & 0.11 & $.54 * *$ & 0.21 & & \\
\hline Sen. Scale & $-.38 * * *$ & 0.08 & $-.99 * * *$ & 0.24 & & \\
\hline Constant & 0.003 & 0.19 & 0.24 & 37 & & \\
\hline Var. Constant & 0.15 & 0.10 & 0.20 & 0.17 & & \\
\hline Ch., $-2 \mathrm{LL}$ from base & $104.39 * * *$ & & $85.23 * * *$ & & & \\
\hline
\end{tabular}

Note: All models included operating unit as a random effect. There were no significant differences associated with the variation between units (indicated by the variance of the constant in the results in the table). For the first panel the -2 log likelihood value (a measure of model fit) is compared to baseline for Model 1 . Subsequent -2LL values are compared to the adjacent, less complex, model. For the second and third panels all change in $-2 \mathrm{LL}$ values involve comparisons to the baseline $-2 \mathrm{LL}$ value. ${ }^{* * *}$ indicates $p<.001$, i.e. that a given model provides a significantly better fit. 
Table A-8

Average Values of Scale Score of Perceptions Regarding Promotion Band III to IV by Demographic and Employment Related Variables

\begin{tabular}{|c|c|c|c|c|c|}
\hline \multicolumn{6}{|c|}{ Dichotomous Variables } \\
\hline Variable and categories: & Mean & $\underline{N}$ & $\underline{\text { t-ratio }}$ & Probability & Effect Size \\
\hline \multicolumn{6}{|l|}{ No demographics } \\
\hline Have data & 3.18 & 576 & & & ef size \\
\hline No data & 3.03 & 24 & 0.71 & 0.48 & 0.15 \\
\hline \multicolumn{6}{|l|}{ Gender } \\
\hline Female & 2.96 & 202 & & & \\
\hline Male & 3.32 & 352 & 4.05 & 0.0001 & -0.35 \\
\hline \multicolumn{6}{|l|}{ URM } \\
\hline No & 3.21 & 515 & & & \\
\hline Yes & 2.72 & 35 & 2.81 & 0.005 & 0.48 \\
\hline \multicolumn{6}{|l|}{ PhD } \\
\hline No & 3.19 & 175 & & & \\
\hline Yes & 3.18 & 408 & 0.08 & 0.93 & 0.01 \\
\hline \multicolumn{6}{|l|}{ Only NIST Fed employee } \\
\hline No & 3.20 & 350 & & & \\
\hline Yes & 3.14 & 230 & 0.73 & 0.47 & 0.06 \\
\hline \multicolumn{6}{|l|}{ Have had leadership post } \\
\hline Yes & 2.94 & 395 & & & \\
\hline No & 3.67 & 193 & 8.6 & $<.0001$ & -0.72 \\
\hline \multicolumn{6}{|l|}{ Timely Promotion } \\
\hline No & 3.25 & 236 & & & \\
\hline Yes & 3.10 & 320 & 1.72 & 0.09 & 0.15 \\
\hline \multicolumn{6}{|c|}{ Categorical Variables } \\
\hline Race-ethnicity 3 categories & $\underline{\text { Mean }}$ & $\underline{\text { Count }}$ & $\underline{F}$ & prob. & \\
\hline URM & 2.72 & 35 & & & \\
\hline Asian & 3.29 & 49 & & & \\
\hline Non-Hisp White & 3.21 & 466 & 4.07 & 0.0175 & \\
\hline \multicolumn{6}{|c|}{ Other Employment Experience } \\
\hline Postdoc NIST & 3.17 & 211 & & & \\
\hline Contract at NIST & 3.15 & 60 & & & \\
\hline Other Fed Agency & 3.32 & 79 & & & \\
\hline \multicolumn{6}{|l|}{ Only NIST Fed } \\
\hline employee & 3.14 & 230 & 0.67 & 0.57 & \\
\hline
\end{tabular}


Table A-8, Page 2

\begin{tabular}{|c|c|c|c|c|}
\hline$\underline{\text { Variable }}$ & $\underline{\text { Mean }}$ & $\underline{\text { Count }}$ & $\underline{F}$ & prob. \\
\hline \multicolumn{5}{|l|}{ Band } \\
\hline III & 2.58 & 147 & & \\
\hline IV & 3.17 & 254 & & \\
\hline $\mathrm{V}$ & 3.66 & 155 & & \\
\hline ST & 4.16 & 4.16 & 41.76 & $<.0001$ \\
\hline \multicolumn{5}{|c|}{ When Returned Survey } \\
\hline Week 1 & 3.12 & 288 & & \\
\hline Week 2 & 3.14 & 111 & & \\
\hline Week 3 & 3.33 & 79 & & \\
\hline Week 4 & 3.22 & 122 & 1.03 & 0.38 \\
\hline \multicolumn{5}{|l|}{ Discipline } \\
\hline Chemistry & 3.09 & 105 & & \\
\hline Engineering & 3.15 & 152 & & \\
\hline Physics & 3.35 & 120 & & \\
\hline Other & 3.16 & 195 & 1.41 & 0.24 \\
\hline \multicolumn{5}{|l|}{ Operating Unit } \\
\hline OU-A & 3.15 & 63 & & \\
\hline OU-D & 3.27 & 29 & & \\
\hline OU-F & 3.34 & 64 & & \\
\hline OU-G & 3.11 & 73 & & \\
\hline $\mathrm{OU}-\mathrm{C}$ & 3.12 & 186 & & \\
\hline OU-B & 2.89 & 13 & & \\
\hline OU-E & 3.24 & 142 & 0.73 & 0.62 \\
\hline \multicolumn{5}{|l|}{ Years at NIST } \\
\hline LT 1 & 2.76 & 35 & & \\
\hline 1 to 2 & 2.62 & 41 & & \\
\hline 3 to 5 & 2.98 & 96 & & \\
\hline 6 to 10 & 2.87 & 118 & & \\
\hline 11 to 15 & 3.27 & 85 & & \\
\hline 16 to 20 & 3.41 & 54 & & \\
\hline GT 20 & 3.63 & 155 & 12.18 & $<.0001$ \\
\hline
\end{tabular}


Table A-8, Page 3

Variable

Age

Lt 25 to 34

35 to 44

45 to 54

55 to 64

GE 65

Degree

LE Bachelors

Masters

$\mathrm{PhD}$

\section{$\underline{\text { Mean }}$}

2.66

3

3.33

3.53

3.59

3.15

3.21

3.18
Count

91

182

153

124

32

63

112

408
F prob.

14.16

$<.0001$

0.93

Note: Scale based on unweighted variables with responses of Don't Know omitted.

Probabilities for t-values are two-tail. Effect size is Cohen's $d$ and based on the common standard deviation of 1.02 
Table A-9

Average Count of Don't Know (DK) Responses Regarding Promotion Band IV to V by Demographic and Employment Related Variables

\begin{tabular}{|c|c|c|c|c|c|}
\hline \multicolumn{6}{|c|}{ Dichotomous Variables } \\
\hline Variable and categories: & Mean & $\underline{N}$ & $\underline{\text { t-ratio }}$ & Probability & Effect Size \\
\hline \multicolumn{6}{|l|}{ No demographics } \\
\hline Have data & 1.07 & 603 & & & \\
\hline No data & 1.36 & 28 & 0.95 & & 0.19 \\
\hline \multicolumn{6}{|l|}{ Gender } \\
\hline Female & 1.26 & 213 & & & \\
\hline Male & 0.97 & 368 & 2.21 & 0.03 & 0.19 \\
\hline \multicolumn{6}{|l|}{ URM } \\
\hline No & 1.1 & 541 & & & \\
\hline Yes & 1.06 & 35 & 0.16 & 0.88 & 0.03 \\
\hline \multicolumn{6}{|l|}{ PhD } \\
\hline No & 1.21 & 185 & & & \\
\hline Yes & 1.01 & 426 & 1.43 & 0.15 & 0.13 \\
\hline \multicolumn{6}{|l|}{ Only NIST Fed employee } \\
\hline No & 0.96 & 362 & & & \\
\hline Yes & 1.26 & 247 & 2.33 & 0.02 & 0.19 \\
\hline \multicolumn{6}{|l|}{ Have had leadership post } \\
\hline No & 1.39 & 417 & & & \\
\hline Yes & 0.49 & 201 & 7 & $<.0001$ & 0.58 \\
\hline \multicolumn{6}{|l|}{ Timely Promotion } \\
\hline No & 0.90 & 242 & & & \\
\hline Yes & 1.23 & 341 & 2.55 & 0.01 & 0.21 \\
\hline \multicolumn{6}{|c|}{ Categorical Variables } \\
\hline Race-ethnicity 3 cats & $\underline{\text { Mean }}$ & $\underline{\text { Count }}$ & $\underline{F}$ & prob. & \\
\hline URM & 1.06 & 35 & & & \\
\hline Asian & 1.14 & 56 & & & \\
\hline Non-Hisp White & 1.09 & 485 & 0.04 & 0.96 & \\
\hline \multicolumn{6}{|c|}{ Other Employment Experience } \\
\hline Postdoc NIST & 0.91 & 216 & & & \\
\hline Contract at NIST & 1.23 & 64 & & & \\
\hline Other Fed Agency & 0.89 & 82 & & & \\
\hline \multicolumn{6}{|l|}{ Only NIST Fed } \\
\hline employee & 1.26 & 247 & 2.62 & 0.05 & \\
\hline
\end{tabular}


Table A-9, Page 2

\begin{tabular}{|c|c|c|c|c|}
\hline$\underline{\text { Variable }}$ & Mean & $\underline{\text { Count }}$ & $\underline{F}$ & prob. \\
\hline \multicolumn{5}{|l|}{ Band } \\
\hline III & 1.91 & 148 & & \\
\hline IV & 1 & 273 & & \\
\hline $\mathrm{V}$ & 0.48 & 161 & & \\
\hline ST & 0.33 & 21 & 28.51 & $<.0001$ \\
\hline \multicolumn{5}{|c|}{ When Returned Survey } \\
\hline Week 1 & 1.14 & 307 & & \\
\hline Week 2 & 1.04 & 115 & & \\
\hline Week 3 & 1.02 & 82 & & \\
\hline Week 4 & 1.04 & 127 & 0.24 & 0.87 \\
\hline \multicolumn{5}{|l|}{ Discipline } \\
\hline Chemistry & 1.2 & 108 & & \\
\hline Engineering & 0.96 & 167 & & \\
\hline Physics & 0.94 & 127 & & \\
\hline Other & 1.18 & 197 & 1.19 & 0.31 \\
\hline \multicolumn{5}{|l|}{ Operating Unit } \\
\hline OU-A & 1.38 & 68 & & \\
\hline OU-D & 0.59 & 29 & & \\
\hline $\mathrm{OU}-\mathrm{F}$ & 0.70 & 66 & & \\
\hline OU-G & 1.34 & 77 & & \\
\hline $\mathrm{OU}-\mathrm{C}$ & 1.16 & 191 & & \\
\hline OU-B & 1.46 & 13 & & \\
\hline OU-E & 0.95 & 153 & 2.42 & 0.03 \\
\hline \multicolumn{5}{|l|}{ Years at NIST } \\
\hline LT 1 & 1.97 & 37 & & \\
\hline 1 to 2 & 1.84 & 45 & & \\
\hline 3 to 5 & 1.34 & 99 & & \\
\hline 6 to 10 & 1.12 & 125 & & \\
\hline 11 to 15 & 0.9 & 89 & & \\
\hline 16 to 20 & 0.8 & 56 & & \\
\hline GT 20 & 0.67 & 162 & 7.34 & $<.0001$ \\
\hline
\end{tabular}


Table A-9, Page 3

\begin{tabular}{|c|c|c|c|c|}
\hline Variable & Mean & $\underline{\text { Count }}$ & $\underline{F}$ & prob. \\
\hline \multicolumn{5}{|l|}{ Age } \\
\hline Lt 25 to 34 & 1.75 & 92 & & \\
\hline 35 to 44 & 1.15 & 193 & & \\
\hline 45 to 54 & 0.9 & 162 & & \\
\hline 55 to 64 & 0.85 & 131 & & \\
\hline GE 65 & 0.58 & 33 & 6.86 & $<.0001$ \\
\hline \multicolumn{5}{|l|}{ Degree } \\
\hline LE Bachelors & 1.38 & 65 & & \\
\hline Masters & 1.11 & 120 & & \\
\hline PhD & 1.01 & 426 & 1.71 & 0.18 \\
\hline
\end{tabular}

Note: Scale is the count of responses of "Don't Know" to the questions regarding promotion from Band IV to V. Probabilities for t-values are two-tail. Effect size is Cohen's $d$ and based on the common standard deviation of 1.54 . 
Table A-10

Mixed Model Poisson Regressions, Count of Don't Know (DK) Responses Regarding Promotion IV to V

\begin{tabular}{|c|c|c|c|c|c|c|}
\hline \multicolumn{7}{|c|}{ Total Sample } \\
\hline & \multicolumn{2}{|c|}{ Model 1} & \multicolumn{2}{|c|}{ Model 2} & \multicolumn{2}{|c|}{ Model 3} \\
\hline Ind. Variables & $\underline{b}$ & s.e. & $\underline{b}$ & $\underline{\text { s.e. }}$ & $\underline{b}$ & s.e. \\
\hline Male & $-.19 *$ & 0.08 & $-.16 a$ & 0.08 & -0.002 & 0.08 \\
\hline \multicolumn{7}{|l|}{ NIST Cont. or Fed } \\
\hline Only & $.31 * * *$ & 0.08 & $.30 * * *$ & 0.08 & $.31 * * *$ & 0.09 \\
\hline Timely Prom. & ----- & ----- & $.30 * * *$ & 0.09 & $-.17 a$ & 0.10 \\
\hline Sen. Scale & ----- & ----- & ----- & ----- & $-.67 * * *$ & 0.07 \\
\hline Constant & -0.02 & 0.13 & -0.2 & 0.14 & -0.14 & 0.16 \\
\hline Var. Constant & 0.05 & 0.04 & 0.06 & 0.05 & 0.09 & 0.07 \\
\hline Ch. - $2 \mathrm{LL}$ & $115.26 * * *$ & & $54.69 * * *$ & & $112.54 * * *$ & \\
\hline \multicolumn{7}{|c|}{ Results by Band } \\
\hline & \multicolumn{2}{|c|}{ Band III } & \multicolumn{2}{|c|}{ Band IV } & \multicolumn{2}{|c|}{ Band $\mathrm{V}$ and Higher } \\
\hline Ind. Variables & $\underline{b}$ & s.e. & $\underline{b}$ & s.e. & $\underline{b}$ & s.e. \\
\hline Male & 0.13 & 0.13 & -0.17 & 0.13 & -0.04 & 0.26 \\
\hline \multicolumn{7}{|l|}{ NIST Cont. or Fed } \\
\hline Only & $.36 * *$ & 0.14 & $0.23 a$ & 0.13 & -0.02 & 0.23 \\
\hline Timely Promotion & -0.14 & 0.14 & 0.01 & 0.14 & 0.35 & 0.24 \\
\hline Constant & $.46^{*}$ & 0.2 & 0.01 & 0.16 & $-1.13 * *$ & 0.44 \\
\hline Var. Constant & 0.05 & 0.05 & 0.02 & 0.04 & 0.46 & 0.43 \\
\hline Ch., $-2 \mathrm{LL}$ from base & $34.94 * * *$ & & $37.31^{* * *}$ & & $36.10 * * *$ & \\
\hline \multicolumn{7}{|c|}{ Results by Retirement Status } \\
\hline & \multicolumn{2}{|c|}{$\underline{\text { Not Eligible }}$} & \multicolumn{2}{|c|}{ Eligible } & & \\
\hline Ind. Variables & $\underline{b}$ & s.e. & $\underline{b}$ & $\underline{\text { s.e. }}$ & & \\
\hline Male & 0.02 & 0.09 & $-.50 *$ & 0.22 & & \\
\hline \multicolumn{7}{|l|}{ NIST Cont. or Fed } \\
\hline Only & $.22^{*}$ & 0.09 & 0.27 & 0.24 & & \\
\hline Timely Prom. & $-.21 \mathrm{a}$ & 0.11 & 0.34 & 0.21 & & \\
\hline Sen. Scale & $-.73 * * *$ & 0.09 & $-1.47 * * *$ & 0.23 & & \\
\hline Constant & 0.11 & 0.18 & 0.62 & 0.38 & & \\
\hline Var. Constant & 0.10 & 0.08 & 0.25 & 0.23 & & \\
\hline Ch., $-2 \mathrm{LL}$ from base & $169.70 * * *$ & & $97.04 * * *$ & & & \\
\hline
\end{tabular}

Note: All models included operating unit as a random effect. There were no significant differences associated with the variation between units (indicated by the variance of the constant in the results in the table). For the first panel the -2 log likelihood value (a measure of model fit) is compared to baseline for Model 1 . Subsequent $-2 \mathrm{LL}$ values are compared to the adjacent, less complex, model. For the second and third panels all change in -2 LL values involve comparisons to the baseline $-2 \mathrm{LL}$ value. ${ }^{* * *}$ indicates $p<.001$, i.e. that a given model provides a significantly better fit. ** indicates $p<.01 ;{ }^{*}$ indicates $p<.04$, and a indicates $p<.05$. 
Table A-11

Average Values of Scale of Perceptions Regarding Promotion Band IV to V by Demographic and Employment Related Variables

\begin{tabular}{|c|c|c|c|c|c|}
\hline \multicolumn{6}{|c|}{ Dichotomous Variables } \\
\hline Variable and categories: & Mean & $\underline{N}$ & $\underline{\text { t-ratio }}$ & Probability & Effect Size \\
\hline \multicolumn{6}{|l|}{ No demographics } \\
\hline Have data & 2.97 & 580 & & & \\
\hline No data & 2.97 & 25 & 0.04 & 0.97 & \\
\hline \multicolumn{6}{|l|}{ Gender } \\
\hline Female & 2.71 & 206 & & & \\
\hline Male & 3.13 & 353 & 4.61 & $<.0001$ & \\
\hline \multicolumn{6}{|l|}{ URM } \\
\hline No & 3.03 & 517 & & & \\
\hline Yes & 2.21 & 35 & 4.46 & $<.0001$ & \\
\hline \multicolumn{6}{|l|}{ PhD } \\
\hline No & 2.91 & 173 & & & \\
\hline Yes & 3.01 & 414 & 1.07 & 0.28 & \\
\hline \multicolumn{6}{|l|}{ Only NIST fed employee } \\
\hline No & 2.99 & 351 & & & \\
\hline Yes & 2.05 & 233 & 0.49 & 0.62 & \\
\hline \multicolumn{6}{|l|}{ Have had leadership post } \\
\hline No & 2.76 & 393 & & & \\
\hline Yes & 3.39 & 199 & 7.05 & $<.0001$ & \\
\hline \multicolumn{6}{|l|}{ Timely Promotion } \\
\hline No & 3.03 & 232 & & & \\
\hline Yes & 2.88 & 329 & 1.64 & 0.1 & \\
\hline \multicolumn{6}{|c|}{ Categorical Variables } \\
\hline Race-ethnicity 3 cats & Mean & Count & $\underline{F}$ & prob. & \\
\hline URM & 2.21 & 35 & & & \\
\hline Asian & 3.09 & 52 & & & \\
\hline Non-Hisp White & 3.02 & 465 & 10.04 & 0.0001 & \\
\hline \multicolumn{6}{|l|}{ Other Employment Experience } \\
\hline Postdoc NIST & 2.93 & 212 & & & \\
\hline Contract at NIST & 3.1 & 60 & & & \\
\hline Other Fed Agency & 3.06 & 79 & & & \\
\hline Only NIST fed employee & 2.95 & 233 & 0.64 & 0.59 & \\
\hline
\end{tabular}


Table A-11, Page 2

\begin{tabular}{|c|c|c|c|c|}
\hline Variable & Mean & Count & $\mathrm{F}$ & prob. \\
\hline \multicolumn{5}{|l|}{ Band } \\
\hline III & 2 & 136 & & \\
\hline IV & 3 & 265 & & \\
\hline V & 4 & 160 & & \\
\hline ST & 4 & 20 & 49 & $<.0001$ \\
\hline \multicolumn{5}{|c|}{ When Returned Survey } \\
\hline Week 1 & 3 & 297 & & \\
\hline Week 2 & 3 & 110 & & \\
\hline Week 3 & 3 & 79 & & \\
\hline Week 4 & 3 & 119 & 0 & 1 \\
\hline \multicolumn{5}{|l|}{ Discipline } \\
\hline Chemistry & 3 & 100 & & \\
\hline Engineering & 3 & 162 & & \\
\hline Physics & 3 & 124 & & \\
\hline Other & 3 & 191 & 3 & 0 \\
\hline \multicolumn{5}{|l|}{ Operating Unit } \\
\hline OU-A & 3 & 63 & & \\
\hline OU-D & 3 & 29 & & \\
\hline OU-F & 3 & 64 & & \\
\hline OU-G & 3 & 76 & & \\
\hline $\mathrm{OU}-\mathrm{C}$ & 3 & 180 & & \\
\hline OU-B & 3 & 13 & & \\
\hline OU-E & 3 & 149 & 2 & 0 \\
\hline \multicolumn{5}{|l|}{ Years at NIST } \\
\hline LT 1 & 2 & 36 & & \\
\hline 1 to 2 & 2 & 42 & & \\
\hline 3 to 5 & 3 & 92 & & \\
\hline 6 to 10 & 3 & 122 & & \\
\hline 11 to 15 & 3 & 85 & & \\
\hline 16 to 20 & 3.17 & 57 & & \\
\hline GT 20 & 3.35 & 154 & 8.71 & $<.0001$ \\
\hline
\end{tabular}


Table A-11, Page 3

\begin{tabular}{|c|c|c|c|c|}
\hline Variable & $\underline{\text { Mean }}$ & $\underline{\text { Count }}$ & $\underline{F}$ & prob. \\
\hline \multicolumn{5}{|l|}{ Age } \\
\hline Lt 25 to 34 & 2.38 & 88 & & \\
\hline 35 to 44 & 2.79 & 187 & & \\
\hline 45 to 54 & 3.11 & 153 & & \\
\hline 55 to 64 & 3.33 & 126 & & \\
\hline GE 65 & 3.6 & 32 & 16.68 & $<.0001$ \\
\hline \multicolumn{5}{|l|}{ Degree } \\
\hline LE Bachelors & 2.78 & 59 & & \\
\hline Masters & 2.97 & 114 & & \\
\hline $\mathrm{PhD}$ & 3.01 & 414 & 1.22 & 0.3 \\
\hline
\end{tabular}

Note: Scale comprised of responses to the questions regarding promotion from Band IV to $\mathrm{V}$ as described in text. Probabilities for t-values are two-tail. Effect size is Cohen's d and based on the common standard deviation of 2.97. 
Table A-12

Proportion Aware of ST Rank by Demographic and Employment Related Variables

\begin{tabular}{|c|c|c|c|c|c|}
\hline \multicolumn{6}{|c|}{ Dichotomous Variables } \\
\hline & & & & & Effect \\
\hline Variable and categories: & Mean & $\underline{N}$ & $\underline{\text { t-ratio }}$ & Probability & Size \\
\hline \multicolumn{6}{|l|}{ No demographics } \\
\hline Have data & 0.67 & 605 & & & \\
\hline No data & 0.64 & 28 & 0.33 & 0.74 & 0.06 \\
\hline \multicolumn{6}{|l|}{ Gender } \\
\hline Female & 0.63 & 213 & & & \\
\hline Male & 0.70 & 369 & 1.81 & 0.07 & 0.15 \\
\hline \multicolumn{6}{|l|}{ URM } \\
\hline No & 0.68 & 542 & & & \\
\hline Yes & 0.63 & 35 & 0.62 & 0.54 & 0.11 \\
\hline \multicolumn{6}{|l|}{$\mathrm{PhD}$} \\
\hline No & 0.52 & 186 & & & \\
\hline Yes & 0.74 & 427 & 5.62 & $<.0001$ & 0.47 \\
\hline \multicolumn{6}{|l|}{ Only NIST Fed employee } \\
\hline No & 0.73 & 362 & & & \\
\hline Yes & 0.6 & 249 & 3.24 & 0.001 & 0.28 \\
\hline \multicolumn{6}{|l|}{ Have had leadership post } \\
\hline No & 0.61 & 418 & & & \\
\hline Yes & 0.81 & 202 & 5.05 & $<.0001$ & 0.43 \\
\hline \multicolumn{6}{|l|}{ Timely Promotion } \\
\hline No & 0.72 & 244 & & & \\
\hline Yes & 0.63 & 341 & 2.31 & 0.02 & 0.19 \\
\hline \multicolumn{6}{|c|}{ Categorical Variables } \\
\hline Race-ethnicity 3 cats & Mean & Count & $\underline{F}$ & prob. & \\
\hline URM & 0.63 & 35 & & & \\
\hline Asian & 0.65 & 57 & & & \\
\hline Non-Hisp White & 0.68 & 485 & 0.32 & 0.73 & \\
\hline \multicolumn{6}{|l|}{ Other Employment Experience } \\
\hline Postdoc NIST & 0.78 & 216 & & & \\
\hline Contract at NIST & 0.59 & 64 & & & \\
\hline Other Fed Agency & 0.68 & 82 & & & \\
\hline Only NIST Fed employee & 0.60 & 249 & 6.61 & 0.0002 & \\
\hline
\end{tabular}


Table A-12, Page 2

\begin{tabular}{|c|c|c|c|c|}
\hline$\underline{\text { Variable }}$ & $\underline{\text { Mean }}$ & $\underline{\text { Count }}$ & $\underline{F}$ & prob. \\
\hline \multicolumn{5}{|l|}{ Band } \\
\hline III & 0.50 & 149 & & \\
\hline IV & 0.63 & 273 & & \\
\hline V & 0.87 & 161 & & \\
\hline ST & 1.00 & 22 & 23.05 & $<.0001$ \\
\hline \multicolumn{5}{|c|}{ When Returned Survey } \\
\hline Week 1 & 0.68 & 308 & & \\
\hline Week 2 & 0.68 & 115 & & \\
\hline Week 3 & 0.65 & 83 & & \\
\hline Week 4 & 0.65 & 127 & 0.17 & 0.91 \\
\hline \multicolumn{5}{|l|}{ Discipline } \\
\hline Chemistry & 0.68 & 108 & & \\
\hline Engineering & 0.64 & 168 & & \\
\hline Physics & 0.87 & 127 & & \\
\hline Other & 0.57 & 198 & 11.04 & $<.0001$ \\
\hline \multicolumn{5}{|l|}{ Operating Unit } \\
\hline OU-A & 0.53 & 68 & & \\
\hline OU-D & 0.45 & 29 & & \\
\hline OU-F & 0.65 & 66 & & \\
\hline OU-G & 0.65 & 78 & & \\
\hline OU-C & 0.71 & 191 & & \\
\hline OU-B & 0.85 & 13 & & \\
\hline OU-E & 0.73 & 154 & 3.16 & 0.0047 \\
\hline \multicolumn{5}{|l|}{ Years at NIST } \\
\hline LT 1 & 0.46 & 37 & & \\
\hline 1 to 2 & 0.49 & 45 & & \\
\hline 3 to 5 & 0.59 & 99 & & \\
\hline 6 to 10 & 0.62 & 125 & & \\
\hline 11 to 15 & 0.69 & 89 & & \\
\hline 16 to 20 & 0.77 & 57 & & \\
\hline GT 20 & 0.82 & 163 & 6.76 & $<.0001$ \\
\hline
\end{tabular}


Table A-12, Page 3

Variable

Age

Lt 25 to 34

35 to 44

45 to 54

55 to 64

GE 65

Degree

LE Bachelors

Masters

$\mathrm{PhD}$

\section{Mean}

Count

92

0.49

0.67

0.68

0.79

0.74

0.38

0.59

0.74

Note: The dependent variable is the dummy variable associated with knowledge of the ST band. Probabilities for t-values are two-tail. Effect size is Cohen's $d$ and based on the common standard deviation of. 47. 
Table A-13

Average Count of Don't Know (DK) Responses Regarding Promotion Band V to ST by Demographic and Employment Related Variables

\begin{tabular}{|c|c|c|c|c|c|}
\hline \multicolumn{6}{|c|}{ Dichotomous Variables } \\
\hline Variable and categories: & Mean & $\underline{N}$ & $\underline{\text { t-ratio }}$ & Probability & Effect Size \\
\hline \multicolumn{6}{|l|}{ No demographics } \\
\hline Have data & 1.60 & 406 & & & \\
\hline No data & 1.53 & 17 & 0.17 & 0.86 & 0.04 \\
\hline \multicolumn{6}{|l|}{ Gender } \\
\hline Female & 1.80 & 133 & & & \\
\hline Male & 1.53 & 259 & 1.47 & 0.14 & 0.16 \\
\hline \multicolumn{6}{|l|}{ URM } \\
\hline No & 1.66 & 367 & & & \\
\hline Yes & 1.56 & 1.45 & 0.53 & 0.59 & 0.06 \\
\hline \multicolumn{6}{|l|}{$\mathrm{PhD}$} \\
\hline No & 1.95 & 96 & & & \\
\hline Yes & 1.51 & 316 & 2.18 & 0.03 & 0.25 \\
\hline \multicolumn{6}{|l|}{ Only NIST fed employee } \\
\hline No & 1.52 & 262 & & & \\
\hline Yes & 1.93 & 150 & 1.14 & 0.25 & 0.24 \\
\hline \multicolumn{6}{|l|}{ Have had leadership post } \\
\hline No & 1.86 & 253 & & & \\
\hline Yes & 1.21 & 163 & 3.81 & 0.0002 & 0.37 \\
\hline \multicolumn{6}{|l|}{ Timely Promotion } \\
\hline No & 1.35 & 175 & & & \\
\hline Yes & 1.86 & 215 & 2.88 & 0.004 & 0.29 \\
\hline \multicolumn{6}{|c|}{ Categorical Variables } \\
\hline Race-ethnicity 3 cats & Mean & $\underline{\text { Count }}$ & $\underline{F}$ & prob. & \\
\hline URM & 1.45 & 22 & & & \\
\hline Asian & 1.47 & 36 & & & \\
\hline Non-Hisp White & 1.68 & 331 & 0.37 & 0.69 & \\
\hline \multicolumn{6}{|c|}{ Other Employment Experience } \\
\hline Postdoc NIST & 1.51 & 168 & & & \\
\hline Contract at NIST & 1.37 & 38 & & & \\
\hline Other Fed Agency & 1.66 & 56 & & & \\
\hline Only NIST fed & & & & & \\
\hline employee & 1.73 & 150 & 0.65 & 0.58 & \\
\hline
\end{tabular}




\begin{tabular}{|c|c|c|c|c|}
\hline$\underline{\text { Variable }}$ & $\underline{\text { Mean }}$ & $\underline{\text { Count }}$ & $\underline{F}$ & prob. \\
\hline \multicolumn{5}{|l|}{ Band } \\
\hline III & 2.36 & 74 & & \\
\hline IV & 1.82 & 171 & & \\
\hline V & 1.12 & 140 & & \\
\hline ST & 0.27 & 22 & 14.92 & $<.0001$ \\
\hline \multicolumn{5}{|c|}{ When Returned Survey } \\
\hline Week 1 & 1.67 & 209 & & \\
\hline Week 2 & 1.64 & 78 & & \\
\hline Week 3 & 1.74 & 53 & & \\
\hline Week 4 & 1.29 & 83 & 1.14 & 0.33 \\
\hline \multicolumn{5}{|l|}{ Discipline } \\
\hline Chemistry & 1.41 & 73 & & \\
\hline Engineering & 1.82 & 108 & & \\
\hline Physics & 1.50 & 109 & & \\
\hline Other & 1.70 & 113 & 1.10 & 0.35 \\
\hline \multicolumn{5}{|l|}{ Operating Unit } \\
\hline OU-A & 2.14 & 36 & & \\
\hline OU-D & 1.70 & 13 & & \\
\hline OU-F & 1.67 & 43 & & \\
\hline OU-G & 1.90 & 51 & & \\
\hline OU-C & 1.54 & 134 & & \\
\hline OU-B & 1.64 & 11 & & \\
\hline OU-E & 1.37 & 113 & 1.19 & 0.31 \\
\hline \multicolumn{5}{|l|}{ Years at NIST } \\
\hline LT 1 & 2.76 & 17 & & \\
\hline 1 to 2 & 2.23 & 22 & & \\
\hline 3 to 5 & 1.79 & 58 & & \\
\hline 6 to 10 & 2.03 & 78 & & \\
\hline 11 to 15 & 1.36 & 61 & & \\
\hline 16 to 20 & 1.66 & 44 & & \\
\hline GT 20 & 1.11 & 133 & 4.82 & 0.0001 \\
\hline
\end{tabular}




\begin{tabular}{|c|c|c|c|c|}
\hline Variable & Mean & $\underline{\text { Count }}$ & $\underline{F}$ & prob. \\
\hline \multicolumn{5}{|l|}{ Band } \\
\hline III & 2.36 & 74 & & \\
\hline IV & 1.82 & 171 & & \\
\hline V & 1.12 & 140 & & \\
\hline ST & 0.27 & 22 & 14.92 & $<.0001$ \\
\hline \multicolumn{5}{|c|}{ When Returned Survey } \\
\hline Week 1 & 1.67 & 209 & & \\
\hline Week 2 & 1.64 & 78 & & \\
\hline Week 3 & 1.74 & 53 & & \\
\hline Week 4 & 1.29 & 83 & 1.14 & 0.33 \\
\hline \multicolumn{5}{|l|}{ Discipline } \\
\hline Chemistry & 1.41 & 73 & & \\
\hline Engineering & 1.82 & 108 & & \\
\hline Physics & 1.50 & 109 & & \\
\hline Other & 1.70 & 113 & 1.10 & 0.35 \\
\hline \multicolumn{5}{|l|}{ Operating Unit } \\
\hline OU-A & 2.14 & 36 & & \\
\hline OU-D & 1.70 & 13 & & \\
\hline $\mathrm{OU}-\mathrm{F}$ & 1.67 & 43 & & \\
\hline OU-G & 1.90 & 51 & & \\
\hline $\mathrm{OU}-\mathrm{C}$ & 1.54 & 134 & & \\
\hline OU-B & 1.64 & 11 & & \\
\hline OU-E & 1.37 & 113 & 1.19 & 0.31 \\
\hline \multicolumn{5}{|l|}{ Years at NIST } \\
\hline LT 1 & 2.76 & 17 & & \\
\hline 1 to 2 & 2.23 & 22 & & \\
\hline 3 to 5 & 1.79 & 58 & & \\
\hline 6 to 10 & 2.03 & 78 & & \\
\hline 11 to 15 & 1.36 & 61 & & \\
\hline 16 to 20 & 1.66 & 44 & & \\
\hline GT 20 & 1.11 & 133 & 4.82 & 0.0001 \\
\hline
\end{tabular}


Table A-13, Page 3

Variable

$\underline{\text { Mean }}$

$\underline{\text { Count }}$

\section{F}

prob.

Age

Lt 25 to 34

2.51

45

35 to 44

1.74

129

45 to 54

1.4

110

55 to 64

1.45

102

GE 65

0.7

26

5.89

0.0001

Degree

LE Bachelors

2.48

25

Masters

1.76

71

PhD

1.51

316

$4 \quad 0.0191$

Note: Scale is the count of responses of "don't know" to the questions regarding promotion from Band V to ST. Probabilities for t-values are two-tail. Effect size is Cohen's $d$ and based on the common standard deviation of $1.74 . \mathrm{N}=423$, mean $=1.60$. 
Table A-14

Mixed Model Poisson Regressions, Count of Don't Know (DK) Responses Regarding Promotion V to ST

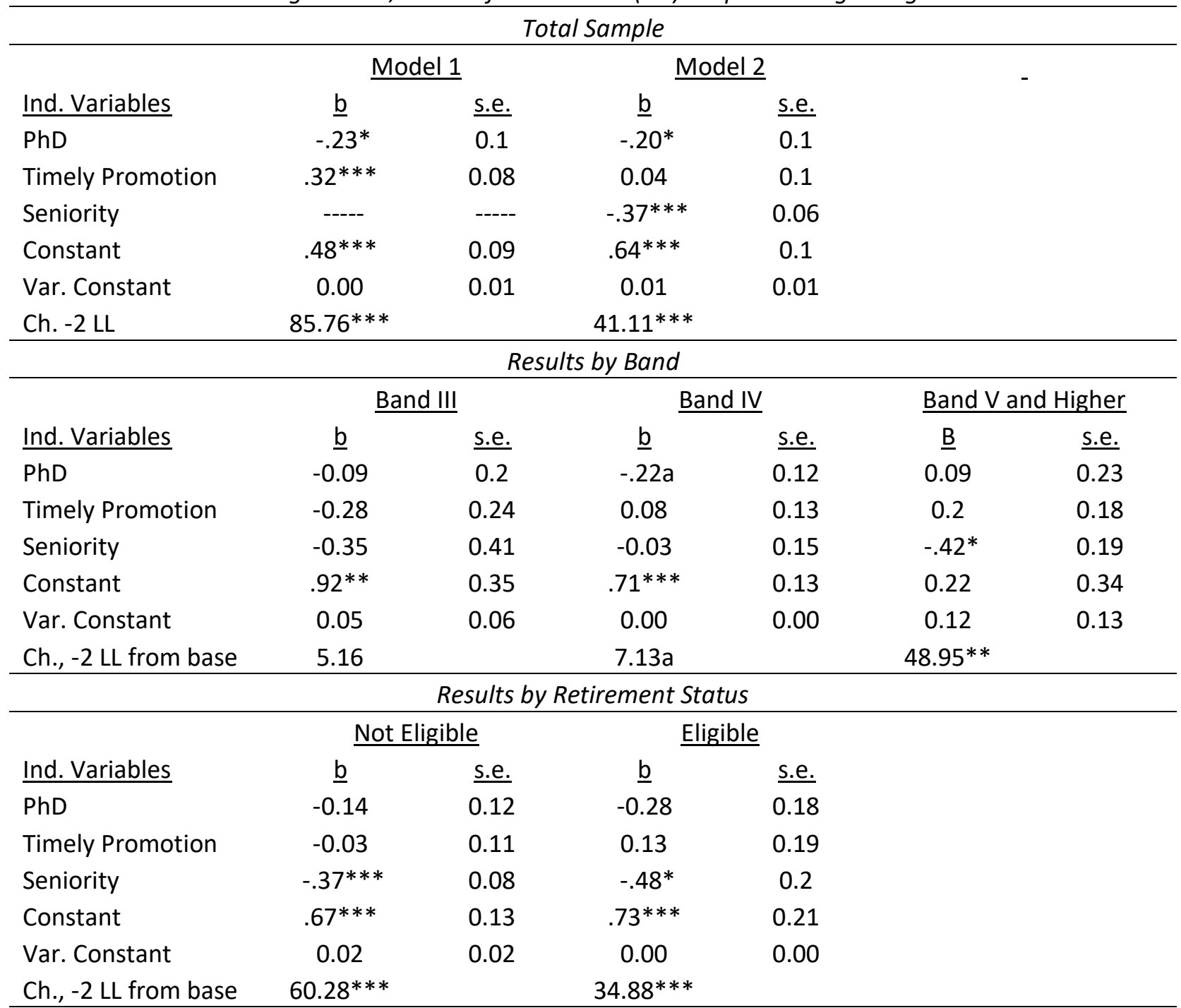

Note: All models included operating unit as a random effect. There were no significant differences associated with the variation between units (indicated by the variance of the constant in the results in the table). For the first panel the -2 log likelihood value (a measure of model fit) is compared to baseline for Model 1 . The value for Model 2 is compared to the value for Model 1. For the second and third panels all change in $-2 \mathrm{LL}$ values involve comparisons to the baseline $-2 \mathrm{LL}$ value. $* * *$ indicates $p<.001$, i.e. that a given model provides a significantly better fit. ${ }^{* *}$ indicates $p<.01 ; *$ indicates $p<.04$, and a indicates $p<.05$. For the total group $n-383,10$ to 132 respondents per operating unit, average 54.7; for Band III $n-71,3$ to 39 per OU, average 10.1; for Band IV, $n=167$, 5 to 53 per OU, average 23.9; for Bands $V$ and higher, $n=145,2$ to 43 per OU, average 20.7; for not eligible for retirement $n=258,7$ to 96 per OU, average 36.9; for those eligible for retirement, $n=124,3$ to 36 per OU, average 17.7. 
Table A-15

Average Scale Score, Perceptions of Promotion from Band V to ST by Demographic and Employment Related Variables,

\section{Dichotomous Variables}

\begin{tabular}{|c|c|c|c|c|c|}
\hline Variable and categories: & Mean & $\underline{N}$ & $\underline{\text { t-ratio }}$ & Probability & Effect Size \\
\hline \multicolumn{6}{|l|}{ No demographics } \\
\hline Have data & 2.41 & 376 & & & \\
\hline No data & 2.42 & 17 & 0.49 & 0.96 & 0.00 \\
\hline \multicolumn{6}{|l|}{ Gender } \\
\hline Female & 2.19 & 125 & & & \\
\hline Male & 2.52 & 239 & 3.17 & 0.002 & 0.14 \\
\hline \multicolumn{6}{|l|}{ URM } \\
\hline No & 2.42 & 339 & & & \\
\hline Yes & 2.13 & 21 & 1.38 & 0.17 & 0.12 \\
\hline \multicolumn{6}{|l|}{$\mathrm{PhD}$} \\
\hline No & 2.31 & 84 & & & \\
\hline Yes & 2.44 & 298 & 1.09 & 0.27 & 0.05 \\
\hline \multicolumn{6}{|l|}{ Only NIST Fed employee } \\
\hline No & 2.40 & 244 & & & \\
\hline Yes & 2.43 & 138 & 0.30 & 0.77 & 0.01 \\
\hline \multicolumn{6}{|l|}{ Have had leadership post } \\
\hline No & 2.30 & 232 & & & \\
\hline Yes & 2.57 & 155 & 2.78 & 0.006 & 0.11 \\
\hline \multicolumn{6}{|l|}{ Timely Promotion } \\
\hline No & 2.34 & 165 & & & \\
\hline Yes & 2.41 & 196 & 0.73 & 0.47 & 0.03 \\
\hline \multicolumn{6}{|c|}{ Categorical Variables } \\
\hline Race-ethnicity 3 cats & Mean & Count & $\underline{F}$ & prob. & \\
\hline URM & 2.13 & 21 & & & \\
\hline Asian & 2.44 & 33 & & & \\
\hline Non-Hisp White & 2.41 & 306 & 0.96 & 0.38 & \\
\hline \multicolumn{6}{|l|}{ Other Employment Experience } \\
\hline Postdoc NIST & 2.38 & 158 & & & \\
\hline Contract at NIST & 2.58 & 36 & & & \\
\hline Other Fed Agency & 2.34 & 50 & & & \\
\hline Only NIST Fed employee & 2.43 & 138 & 0.56 & 0.64 & \\
\hline
\end{tabular}


Table A-15, Page 2

\begin{tabular}{|c|c|c|c|c|}
\hline Variable & Mean & $\underline{\text { Count }}$ & $\underline{F}$ & prob. \\
\hline \multicolumn{5}{|l|}{ Band } \\
\hline III & 2.12 & 66 & & \\
\hline IV & 2.35 & 154 & & \\
\hline V & 2.45 & 136 & & \\
\hline ST & 3.45 & 22 & 12.15 & $<.0001$ \\
\hline \multicolumn{5}{|c|}{ When Returned Survey } \\
\hline Week 1 & 2.40 & 195 & & \\
\hline Week 2 & 2.41 & 73 & & \\
\hline Week 3 & 2.33 & 48 & & \\
\hline Week 4 & 2.48 & 77 & 0.29 & 0.83 \\
\hline \multicolumn{5}{|l|}{ Discipline } \\
\hline Chemistry & 2.28 & 68 & & \\
\hline Engineering & 2.31 & 97 & & \\
\hline Physics & 2.57 & 105 & & \\
\hline Other & 2.45 & 103 & 1.87 & 0.13 \\
\hline \multicolumn{5}{|l|}{ Operating Unit } \\
\hline OU-A & 2.32 & 30 & & \\
\hline OU-D & 2.48 & 12 & & \\
\hline OU-F & 2.37 & 38 & & \\
\hline OU-G & 2.52 & 48 & & \\
\hline OU-C & 2.30 & 126 & & \\
\hline OU-B & 2.76 & 11 & & \\
\hline OU-E & 2.51 & 106 & 0.92 & 0.48 \\
\hline \multicolumn{5}{|l|}{ Years at NIST } \\
\hline LT 1 & 2.32 & 15 & & \\
\hline 1 to 2 & 2.15 & 20 & & \\
\hline 3 to 5 & 2.41 & 55 & & \\
\hline 6 to 10 & 2.22 & 68 & & \\
\hline 11 to 15 & 2.43 & 58 & & \\
\hline 16 to 20 & 2.40 & 40 & & \\
\hline GT 20 & 2.55 & 127 & 1.24 & 0.28 \\
\hline
\end{tabular}


Table A-15, Page 3

\begin{tabular}{|c|c|c|c|c|}
\hline Variable & Mean & Count & $\underline{F}$ & prob. \\
\hline \multicolumn{5}{|l|}{ Age } \\
\hline Lt 25 to 34 & 2.20 & 41 & & \\
\hline 35 to 44 & 2.19 & 119 & & \\
\hline 45 to 54 & 2.42 & 101 & & \\
\hline 55 to 64 & 2.64 & 95 & & \\
\hline GE 65 & 2.79 & 26 & 4.69 & 0.001 \\
\hline \multicolumn{5}{|l|}{ Degree } \\
\hline LE Bachelors & 2.31 & 21 & & \\
\hline Masters & 2.32 & 63 & & \\
\hline PhD & 2.44 & 298 & 0.60 & 0.55 \\
\hline
\end{tabular}

Note: Scale comprises responses to the questions regarding promotion from Band $V$ to ST. Probabilities for t-values are two-tail. Effect size is Cohen's $d$ and based on the common standard deviation of 2.41. $\mathrm{N}=393$, mean $=2.41$. 
Table A-16

Model Fit Statistics, Mixed Model Regressions of Perceptions of Promotion from V to ST by Gender, Seniority Scale, Band, Leadership and Age

\begin{tabular}{|c|c|c|c|c|c|c|}
\hline \multirow{2}{*}{\multicolumn{2}{|c|}{ Model }} & \multirow{3}{*}{$\frac{-2 \mathrm{LL}}{1013.08}$} & \multirow{3}{*}{$\frac{\text { Comp. }}{\text { Model }}$} & \multirow{3}{*}{$\underline{\mathrm{Ch}}$ in $-2 \mathrm{LL}$} & \multirow{3}{*}{ prob. } & \multirow{3}{*}{$\underline{\text { PRE }}$} \\
\hline & & & & & & \\
\hline 1) & $B L$ & & & & & \\
\hline 2) & $M$ & 961.77 & 1 & 51.31 & $<.001$ & 0.04 \\
\hline 3) & $\mathrm{M}, \mathrm{ST}$ & 947.49 & 2 & 14.28 & $<.001$ & 0.04 \\
\hline 4) & M, ST, SSSQ & 945.48 & 3 & 2.01 & $<.20$ & 0.01 \\
\hline 5) & $M, G$ & 943.67 & 2 & 69.40 & $<.001$ & 0.05 \\
\hline 6) & $\mathrm{M}, \mathrm{G}, \mathrm{GSQ}$ & 936.90 & 5 & 6.78 & $<.01$ & 0.02 \\
\hline 7) & $\mathrm{M}, \mathrm{G}, \mathrm{GSQ}, \mathrm{A}$ & 930.59 & 6 & 6.31 & $<.02$ & 0.01 \\
\hline 8) & $\mathrm{M}, \mathrm{G}, \mathrm{GSQ}, \mathrm{A}, \mathrm{L}$ & 926.09 & 7 & 4.49 & $<.05$ & -0.002 \\
\hline
\end{tabular}

Note: The letters in the descriptions of models are paired as follows: $B L=B a s e l i n e, M=M a l e, S T=S e n i o r i t y$ Scale, SSSQ=Square of Seniority Scale, G=Band, GSQ=Square of Seniority Scale, A=Age, L=Leadership. The degrees of freedom associated with each model change was 1 . The fixed effect coefficient associated with Leadership in Model 8 was not statistically significant. 
Table A-17

Average Count of Don't Know (DK) Responses Regarding Respondents' Promotion-Related Experiences by Demographic and Employment Related Variables

Dichotomous Variables

\begin{tabular}{|c|c|c|c|c|c|}
\hline Variable and categories: & Mean & $\underline{N}$ & $\underline{\text { t-ratio }}$ & Probability & Effect Size \\
\hline \multicolumn{6}{|l|}{ No demographics } \\
\hline Have data & 0.21 & 601 & & & \\
\hline No data & 0.4 & 20 & 1.59 & 0.11 & 0.21 \\
\hline \multicolumn{6}{|l|}{ Gender } \\
\hline Female & 0.24 & 212 & & & \\
\hline Male & 0.19 & 366 & 1.04 & 0.30 & 0.05 \\
\hline \multicolumn{6}{|l|}{ URM } \\
\hline No & 0.21 & 538 & & & \\
\hline Yes & 0.17 & 35 & 0.47 & 0.64 & 0.04 \\
\hline \multicolumn{6}{|l|}{ PhD } \\
\hline No & 0.17 & 186 & & & \\
\hline Yes & 0.23 & 423 & 1.33 & 0.19 & 0.07 \\
\hline \multicolumn{6}{|l|}{ Only NIST Fed employee } \\
\hline No & 0.20 & 360 & & & \\
\hline Yes & 0.22 & 247 & 0.46 & 0.64 & 0.02 \\
\hline \multicolumn{6}{|l|}{ Have had leadership post } \\
\hline No & 0.25 & 416 & & & \\
\hline Yes & 0.15 & 200 & 2.36 & 0.02 & 0.11 \\
\hline \multicolumn{6}{|l|}{ Timely Promotion } \\
\hline No & 0.12 & 243 & & & \\
\hline Yes & 0.28 & 338 & 3.68 & 0.0003 & 0.17 \\
\hline \multicolumn{6}{|c|}{ Categorical Variables } \\
\hline Race-ethnicity 3 cats & Mean & $\underline{\text { Count }}$ & $\underline{F}$ & prob. & \\
\hline URM & 0.17 & 35 & & & \\
\hline Asian & 0.25 & 57 & & & \\
\hline Non-Hisp White & 0.21 & 481 & 0.23 & 0.79 & \\
\hline \multicolumn{6}{|l|}{ Other Employment Experience } \\
\hline Postdoc NIST & 0.19 & 215 & & & \\
\hline Contract at NIST & 0.14 & 64 & & & \\
\hline Other Fed Agency & 0.28 & 81 & & & \\
\hline Only NIST Fed employee & 0.22 & 247 & 1.07 & 0.36 & \\
\hline
\end{tabular}


Table A-17, Page 2

\begin{tabular}{|c|c|c|c|c|}
\hline$\underline{\text { Variable }}$ & Mean & Count & $\underline{F}$ & prob. \\
\hline \multicolumn{5}{|l|}{ Band } \\
\hline III & 0.28 & 148 & & \\
\hline IV & 0.21 & 273 & & \\
\hline V & 0.15 & 158 & & \\
\hline ST & 0.05 & 22 & 2.57 & 0.05 \\
\hline \multicolumn{5}{|c|}{ When Returned Survey } \\
\hline Week 1 & 0.22 & 303 & & \\
\hline Week 2 & 0.13 & 113 & & \\
\hline Week 3 & 0.21 & 80 & & \\
\hline Week 4 & 0.28 & 125 & 1.56 & 0.20 \\
\hline \multicolumn{5}{|l|}{ Discipline } \\
\hline Chemistry & 0.25 & 106 & & \\
\hline Engineering & 0.14 & 167 & & \\
\hline Physics & 0.25 & 127 & & \\
\hline Other & 0.23 & 197 & 1.42 & 0.24 \\
\hline \multicolumn{5}{|l|}{ Operating Unit } \\
\hline OU-A & 0.29 & 68 & & \\
\hline OU-D & 0.10 & 29 & & \\
\hline $\mathrm{OU}-\mathrm{F}$ & 0.14 & 65 & & \\
\hline OU-G & 0.31 & 77 & & \\
\hline OU-C & 0.16 & 189 & & \\
\hline OU-B & 0.31 & 13 & & \\
\hline OU-E & 0.25 & 154 & 1.67 & 0.13 \\
\hline \multicolumn{5}{|l|}{ Years at NIST } \\
\hline LT 1 & 0.84 & 37 & & \\
\hline 1 to 2 & 0.42 & 45 & & \\
\hline 3 to 5 & 0.21 & 98 & & \\
\hline 6 to 10 & 0.16 & 125 & & \\
\hline 11 to 15 & 0.09 & 89 & & \\
\hline 16 to 20 & 0.19 & 57 & & \\
\hline GT 20 & 0.12 & 160 & 13.47 & $<.0001$ \\
\hline
\end{tabular}


Table A-17, Page 3

Variable

Age

Lt 25 to 34

35 to 44

45 to 54

55 to 64

GE 65

Degree

LE Bachelors

Masters

PhD

\section{Mean}

0.34

0.17

0.20

0.17

0.26

0.25

0.12

0.23
Count

91

192

162

130

34

65

121

423
F prob.

$2.11 \quad 0.08$

Note: Scale is the count of responses of "Don't Know" to the questions regarding respondents' promotion-related experiences. Probabilities for $\mathrm{t}$-values are two-tail. Effect size is Cohen's $d$ and based on the common standard deviation of .53. $\mathrm{N}=621$, mean $=.22$. 
Table A-18

Average Scaled Scores, Respondents' Perceptions of their Promotion-Related Experiences by Demographic and Employment-Related Variables

Dichotomous Variables

\begin{tabular}{|c|c|c|c|c|c|}
\hline Variable and categories: & Mean & $\underline{N}$ & $\underline{\text { t-ratio }}$ & Probability & Effect Size \\
\hline \multicolumn{6}{|l|}{ No demographics } \\
\hline Have data & 3.34 & 604 & & & \\
\hline No data & 3.05 & 20 & 1.39 & 0.16 & 0.32 \\
\hline \multicolumn{6}{|l|}{ Gender } \\
\hline Female & 3.20 & 212 & & & \\
\hline Male & 3.45 & 369 & 3.19 & 0.002 & 0.27 \\
\hline \multicolumn{6}{|l|}{ URM } \\
\hline No & 3.37 & 541 & & & \\
\hline Yes & 2.81 & 35 & 3.57 & 0.0004 & 0.61 \\
\hline \multicolumn{6}{|l|}{$\mathrm{PhD}$} \\
\hline No & 3.32 & 186 & & & \\
\hline Yes & 3.33 & 426 & 0.18 & 0.86 & 0.01 \\
\hline \multicolumn{6}{|l|}{ Only NIST Fed employee } \\
\hline No & 3.34 & 0.05 & & & \\
\hline Yes & 3.32 & 0.06 & 0.24 & 0.81 & 0.02 \\
\hline \multicolumn{6}{|l|}{ Have had leadership post } \\
\hline No & 3.25 & 417 & & & \\
\hline Yes & 3.51 & 202 & 3.28 & 0.001 & 0.28 \\
\hline \multicolumn{6}{|l|}{ Timely Promotion } \\
\hline No & 3.23 & 244 & & & \\
\hline Yes & 3.39 & 340 & 2.01 & 0.05 & 0.17 \\
\hline \multicolumn{6}{|c|}{ Categorical Variables } \\
\hline Race-ethnicity 3 cats & Mean & Count & $\underline{F}$ & prob. & \\
\hline URM & 2.81 & 35 & & & \\
\hline Asian & 3.45 & 57 & & & \\
\hline Non-Hisp White & 3.37 & 484 & 6.6 & 0.002 & \\
\hline \multicolumn{6}{|l|}{ Other Employment Experience } \\
\hline Postdoc NIST & 3.28 & 215 & & & \\
\hline Contract at NIST & 3.44 & 64 & & & \\
\hline Other Fed Agency & 3.42 & 82 & & & \\
\hline Only NIST Fed employee & 3.32 & 249 & 0.80 & 0.50 & \\
\hline
\end{tabular}


Table A-18, Page 2

Variable

Band

$\begin{array}{lll}\text { III } & 3.21 & 148\end{array}$

IV $\quad 3.21 \quad 273$

$\begin{array}{lll}\mathrm{V} & 3.55 & 161\end{array}$

$\begin{array}{lll}\text { ST } & 4.36 & 22\end{array}$

$15.75<.0001$

When Returned Survey

Week 1

$3.35 \quad 306$

Week 2

3.24

113

Week 3

3.37

80

Week 4

3.34

125

0.48

0.69

Discipline

Chemistry

$3.19 \quad 107$

Engineering

$3.32 \quad 168$

Physics

3.47

127

Other

3.37

198

1.86

0.13

Operating Unit

OU-A

3.48

68

OU-D

3.40

29

OU-F

3.27

66

OU-G

3.46

78

OU-C

3.22

190

OU-B

3.63

13

OU-E

3.38

154

1.41

0.21

Years at NIST

LT 1

1 to 2

3 to 5

6 to 10

11 to 15

16 to 20

GT 20

$3.60 \quad 37$

$3.35 \quad 45$

$3.27 \quad 98$

$3.19 \quad 125$

$3.31 \quad 89$

$3.32 \quad 57$

$3.44 \quad 163$

\begin{tabular}{lll}
37 & & \\
5 & & \\
98 & & \\
25 & & \\
89 & & \\
7 & & \\
63 & 1.5 & 0.18 \\
\hline
\end{tabular}


Table A-18, Page 3

\begin{tabular}{|c|c|c|c|c|}
\hline Variable & Mean & $\underline{\text { Count }}$ & $\underline{F}$ & prob. \\
\hline \multicolumn{5}{|l|}{ Age } \\
\hline Lt 25 to 34 & 3.39 & 91 & & \\
\hline 35 to 44 & 3.25 & 193 & & \\
\hline 45 to 54 & 3.30 & 162 & & \\
\hline 55 to 64 & 3.43 & 131 & & \\
\hline GE 65 & 3.40 & 35 & 0.88 & 0.48 \\
\hline \multicolumn{5}{|l|}{ Degree } \\
\hline LE Bachelors & 3.27 & 65 & & \\
\hline Masters & 3.34 & 121 & & \\
\hline $\mathrm{PhD}$ & 3.33 & 426 & 0.15 & 0.86 \\
\hline
\end{tabular}

Note: Dependent variable is summative scale of responses to questions regarding respondents' promotion-related experiences. Probabilities for $\mathrm{t}$-values are two-tail. Effect size is Cohen's $d$ and based on the common standard deviation of .92. $N=624$, mean $=3.33$. 
Table A-19

Model Fit Statistics, Mixed Model Regressions of Respondents' Perceptions of their Promotion-Related Experiences by Gender, Timely Promotion, Leadership, and Band

Compared to Baseline Compared to Comparator

\begin{tabular}{|c|c|c|c|c|c|c|c|c|}
\hline Mo & & $-2 \mathrm{LL}$ & Resid Var & Ch -2 LL & PRE & Model & Ch -2 LL & PRE \\
\hline 1) & $B \mathrm{~B}$ & 1591.60 & 0.84 & & & & & \\
\hline 2) & $M$ & 1495.80 & 0.80 & $95.80 * * *$ & 0.04 & 1 & $95.80 * * *$ & 0.04 \\
\hline 3) & $\mathrm{M}, \mathrm{PT}, \mathrm{L}, \mathrm{G}$ & 1400.86 & 0.75 & $190.75^{* * *}$ & 0.09 & 2 & $94.94 * * *$ & 0.05 \\
\hline 4) & M, PT, L, G, GSQ & 1388.76 & 0.73 & $202.85^{* * *}$ & 0.10 & 3 & $12.10 * * *$ & 0.02 \\
\hline 5) & $\mathrm{M}, \mathrm{PT}, \mathrm{G}, \mathrm{GSQ}$ & 1405.00 & 0.74 & $186.60 * * *$ & 0.10 & 3 & -4.14 & 0.01 \\
\hline $\left.4^{\prime}\right)$ & $\mathrm{M}, \mathrm{PT}, \mathrm{L}, \mathrm{G}, \mathrm{GSO}$ & 1388.76 & 0.73 & $202.84 * * *$ & 0.10 & 5 & $16.24 * * *$ & 0.0 \\
\hline
\end{tabular}

Note: The letters in the descriptions of models are paired as follows: $B L=B$ aseline, $M=M a l e, P T=$ Timely Promotion, $\mathrm{G}=\mathrm{Band}, \mathrm{GSQ}=$ Square of Seniority Scale, L=Leadership. The degrees of freedom associated with the change from Model 2 to 3 was 3; degrees of freedom for other changes was 1 . Based on the model fit statistics and comparisons, Model 4 $(\mathrm{M}, \mathrm{Pt}, \mathrm{L}, \mathrm{G}$, and GSQ) was chosen as the best fit 
Table A-20

Correlations of Measures of Professional Development Experiences with Socio-Demographic and Employment Related Variables and Views and Experiences of Promotion

\begin{tabular}{|c|c|c|c|c|c|}
\hline Ind. Variables & $\underline{\text { Have Taken }}$ & Plan to Take & $\frac{\text { Don't Plan to }}{\underline{\text { Take }}}$ & $\begin{array}{l}\text { Did Not } \\
\text { Know About }\end{array}$ & $\begin{array}{l}\text { Other } \\
\text { Experiences }\end{array}$ \\
\hline \multicolumn{6}{|c|}{$\overline{\text { Socio-Demographics }}$} \\
\hline Male & $-.11 *$ & 0.03 & $0.15^{* * *}$ & $-0.09 *$ & -0.04 \\
\hline URM & 0.01 & -0.01 & $-0.09 *$ & 0.08 & -0.01 \\
\hline Age & $0.26 * * *$ & $-0.32 * * *$ & $0.14 * * *$ & $-0.19 * * *$ & 0.05 \\
\hline $\mathrm{PhD}$ & $-0.19 * * *$ & 0.08 & $0.09 *$ & 0.01 & -0.01 \\
\hline Chemist & 0.03 & 0.00 & -0.05 & 0.02 & -0.02 \\
\hline Engineer & 0.04 & 0.00 & -0.01 & 0.00 & 0.01 \\
\hline Physicist & $-0.15 * * *$ & -0.04 & $0.16 * * *$ & 0.00 & 0.01 \\
\hline \multicolumn{6}{|c|}{ Employment-Related } \\
\hline OU-D & 0.02 & 0.04 & -0.02 & 0.00 & 0.05 \\
\hline OU-F & $0.08 *$ & -0.03 & $-0.09 *$ & 0.03 & 0.03 \\
\hline OU-G & -0.03 & -0.01 & 0.07 & -0.03 & 0.01 \\
\hline OU-C & -0.05 & 0.06 & 0.00 & -0.01 & -0.01 \\
\hline OU-B & -0.01 & -0.07 & $0.10 *$ & -0.03 & 0.00 \\
\hline OU-E & $-0.16 * * *$ & -0.02 & $0.13^{* *}$ & 0.05 & -0.04 \\
\hline Band & $0.39 * * *$ & $-0.35 * * *$ & 0.04 & $-0.21 * * *$ & $0.17^{* * *}$ \\
\hline Years at NIST & $0.29 * * *$ & $-0.37 * * *$ & $0.13 * * *$ & $-0.18 * * *$ & $0.18 * * *$ \\
\hline Leadership & $0.45^{* * *}$ & $-0.27 * * *$ & $-0.13 * *$ & $-0.15 * * *$ & 0.09* \\
\hline NIST Postdoc & $-0.11 * *$ & $.10^{*}$ & -0.02 & 0.05 & 0.04 \\
\hline NIST Contract & -0.03 & 0.07 & 0.02 & -0.06 & -0.07 \\
\hline Other Fed Agency & -0.02 & $-0.11 * *$ & 0.07 & 0.07 & -0.02 \\
\hline Timely Prom. & $-0.20 * * *$ & $0.23 * * *$ & 0.02 & 0.03 & $-0.14 * * *$ \\
\hline $\begin{array}{l}\text { Seniority Scale } \\
\text { Methodological }\end{array}$ & $0.44 * * *$ & $-0.41 * * *$ & 0.04 & $-0.22 * * *$ & $0.15^{* * *}$ \\
\hline$\overline{\text { Missing Demo. }}$ & 0.06 & $-0.08^{*}$ & 0.00 & -0.01 & 0.04 \\
\hline Week Returned & -0.05 & $0.11^{* *}$ & 0.01 & -0.07 & 0.00 \\
\hline \multicolumn{6}{|c|}{ Promotion Related Perceptions } \\
\hline Prom. III to IV & $.25^{* * *}$ & -0.09 & 0.03 & $-.25 * * *$ & $.10^{*}$ \\
\hline Prom. IV to V & $.14^{* * *}$ & -0.10 & 0.09 & $-.20 * * *$ & $.10^{*}$ \\
\hline Prom. $V$ to ST & -0.01 & -0.04 & 0.10 & -0.10 & -0.05 \\
\hline Own Prom. & -0.001 & 0.02 & 0.08 & $-.13^{* * *}$ & 0.03 \\
\hline
\end{tabular}

Note: Correlations were Pearson Product Moment Correlations. ${ }^{* *}=p<.001,{ }^{* *}=p<.01 ;{ }^{*}=p<.05$. Measure of other experiences was a dummy variable with 1 indicating had other experiences 
Table A-21

Regressions of Experiences and Plans Related to Professional Development on Socio-Demographic Characteristics, Employment-Related Variables, and Promotion-Related Views and Experiences, Full and Reduced Models

Have Taken the Course

\begin{tabular}{|c|c|c|c|c|c|c|}
\hline \multirow[b]{2}{*}{$\underline{\text { Ind. Variables }}$} & \multicolumn{2}{|c|}{$\underline{\text { Full Model }}$} & \multicolumn{2}{|c|}{$\underline{\text { Reduced } 1}$} & \multicolumn{2}{|c|}{$\underline{\text { Reduced } 2}$} \\
\hline & $\underline{B}$ & s.e. & $\underline{b}$ & s.e. & $\underline{b}$ & s.e. \\
\hline Male & $-.12 * * *$ & 0.03 & $-.12 * * *$ & 0.03 & $-.12 * * *$ & 0.03 \\
\hline PhD & $-.07 *$ & 0.03 & -0.04 & 0.03 & ----- & ----- \\
\hline Physics & $-.11^{* *}$ & 0.04 & $-.10 * *$ & 0.04 & $-.11 * * *$ & 0.04 \\
\hline OU-F & 0.07 & 0.07 & ----- & ----- & ----- & ---- \\
\hline OU-E & -0.05 & 0.07 & ----- & ----- & ----- & ----- \\
\hline Pdoc NIST & 0.03 & 0.03 & ----- & ----- & ----- & ---- \\
\hline Timely Pr. & -0.01 & 0.03 & ----- & ----- & ----- & ---- \\
\hline Seniority & $.20 * * *$ & 0.02 & $.21 * * *$ & 0.02 & $.21 * * *$ & 0.02 \\
\hline Views Prom 3,4,5 & 0.02 & 0.02 & ----- & ----- & ----- & ---- \\
\hline Constant & $.49 * * *$ & 0.06 & $.53 * * *$ & 0.04 & $.50 * * *$ & 0.04 \\
\hline Variance Const. & 0.00 & 0.00 & 0.00 & 0.00 & 0.01 & 0.00 \\
\hline Var. Resid. & $0.08 * * *$ & 0.01 & $0.08 * * *$ & 0.01 & $0.08 * * *$ & 0.01 \\
\hline Ch -2 LL from $B L$ & $216^{* * *}$ & & $176^{* * *}$ & & $174 * * *$ & \\
\hline PRE from BL & 0.26 & & 0.24 & & 0.24 & \\
\hline \multicolumn{7}{|c|}{ Plan to Take in Future } \\
\hline & \multicolumn{2}{|c|}{ Full Model } & \multicolumn{2}{|c|}{$\underline{\text { Reduced }}$} & & \\
\hline$\underline{\text { Ind. Variables }}$ & $\underline{B}$ & s.e. & $\underline{b}$ & $\underline{\text { s.e. }}$ & & \\
\hline Seniority Scale & $-.14 * * *$ & 0.02 & $-.14 * * *$ & 0.01 & & \\
\hline P Doc NIST & 0.01 & 0.03 & ----- & ------ & & \\
\hline NIST fed Only & $-.06 *$ & 0.03 & $-.06 * *$ & 0.02 & & \\
\hline Timely Promotion & $.05 a$ & 0.02 & ----- & ------ & & \\
\hline No Demographics & -0.12 & 0.18 & ----- & ------ & & \\
\hline Wk. Returned Survey & $.03 * * *$ & 0.01 & $.03 * *$ & 0.01 & & \\
\hline Constant & $.12^{* * *}$ & 0.03 & $.15^{* * *}$ & 0.02 & & \\
\hline Variance Const. & 0 & 0 & 0 & 0 & & \\
\hline Var. Resid. & $0.07 * * *$ & 0.004 & $0.07^{* * *}$ & 0.004 & & \\
\hline Ch -2 LL from BL & $121 * * *$ & & $126^{* * *}$ & & & \\
\hline PRE from BL & 0.18 & & 0.19 & & & \\
\hline
\end{tabular}


Table A-21, Page 2

\begin{tabular}{|c|c|c|c|c|}
\hline \multicolumn{5}{|c|}{ Don't Plan to Take in Future } \\
\hline & \multicolumn{2}{|c|}{ Full Model } & \multicolumn{2}{|c|}{$\underline{\text { Reduced }}$} \\
\hline Ind. Variables & $\underline{b}$ & $\underline{\text { s.e. }}$ & $\underline{B}$ & $\underline{\text { s.e. }}$ \\
\hline Male & $.07^{*}$ & 0.03 & $.07 *$ & 0.03 \\
\hline Age & $.07 * * *$ & 0.01 & $.07 * * *$ & 0.01 \\
\hline $\mathrm{PhD}$ & -0.002 & 0.03 & & \\
\hline Physics & $.08^{*}$ & 0.04 & $.09 *$ & 0.04 \\
\hline OU-F & -0.01 & 0.09 & & \\
\hline OUs C, B, E & 0.09 & 0.06 & & \\
\hline Leader & $-.15^{* * *}$ & 0.03 & $-.15^{* * *}$ & 0.03 \\
\hline Constant & -0.04 & 0.07 & 0.003 & 0.06 \\
\hline Variance Const. & 0.004 & 0.003 & 0.005 & 0.004 \\
\hline Var. Resid. & $.10 * * *$ & 0.01 & $.10 * * *$ & 0.01 \\
\hline Ch -2 LL from BL & $88.61 * * *$ & & $86.43 * * *$ & \\
\hline PRE from BL & 0.10 & & 0.10 & \\
\hline \multicolumn{5}{|c|}{ Did Not Know About } \\
\hline & \multicolumn{2}{|c|}{ Full Model } & \multicolumn{2}{|c|}{$\underline{\text { Reduced }}$} \\
\hline$\underline{\text { Ind. Variables }}$ & $\underline{\mathrm{b}}$ & $\underline{\text { s.e. }}$ & $\underline{B}$ & $\underline{\text { s.e. }}$ \\
\hline Male & -0.02 & 0.02 & ----- & ---- \\
\hline Seniority Scale & $-.06 * * *$ & 0.02 & $-.05 * * *$ & 0.02 \\
\hline Prom. Views (III-V) and Exp. & $-.05 * * *$ & 0.01 & $-.06 * * *$ & 0.01 \\
\hline Constant & $.39 * * *$ & 0.05 & $.40 * * *$ & 0.05 \\
\hline Variance Const. & 0.00 & 0.00 & 0.00 & 0.00 \\
\hline Var. Resid. & $.08 * * *$ & 0.004 & $.08 * * *$ & 0.004 \\
\hline Ch -2 LL from BL & $72.11^{* * *}$ & & $46.53 * * *$ & \\
\hline PRE from BL & 0.11 & & 0.08 & \\
\hline
\end{tabular}


Table A-21, Page 3

\begin{tabular}{lcccc}
\hline \multicolumn{5}{c}{ Had Other Professional Development Experiences } \\
\hline & Full Model & Reduced \\
Model & \\
Ind. Variables & OR & $\mathrm{Z}$ & OR & $\mathrm{Z}$ \\
Seniority & 1.20 & 1.20 & ----- & ----- \\
Timely Prom & $.61^{*}$ & -2.28 & $.54^{* * *}$ & -3.21 \\
Prom views (III-V) & 1.14 & 1.15 & ----- & ----- \\
Constant & $2.25^{*}$ & 2.23 & 3.29 & 7.79 \\
Variance Const. & 0.00 & 0.00 & 0.00 & 0.00 \\
Ch =2 LL from BL & $107^{* * *}$ & & $107^{* * *}$ & \\
\hline
\end{tabular}

Notes: Logistic regression was used when the dependent variable was a dichotomy (the report of other professional experiences). Variables in the full model were those that were significant in the bivariate analysis in Table A-20. Views of promotion were averaged across all of the measures to alleviate the high collinearity between these values. The change in - $2 \mathrm{LL}$ has a chi-square distribution and the associated degrees of freedom correspond to the number of independent variables in a model. ICC values ranged from 0.0 for responses of plan to take in the future, didn't know of possibilities, and having other professional opportunities, to .07 for had taken a course and .08 for did not plan to take. Sample size and average cases per OU were as follows: 500, 71.4 for have taken a course; $568,81.1$ for plan to take; $560,79.3$ for not planning to take; $566,84.9$ for didn't know of possibilities; and 533, 76.1 for reports of other experiences. 
Table A-22

Correlations of Measures of Other Professional Development Experiences with Socio-

Demographic and Employment-Related Variables and Views and Experiences of Promotion

Independent

Variables

Socio-Demographics

Male

URM

Age

PhD

Chemist

Engineer

Physicist

Employment-Related

OU-D

OU-F

OU-G

OU-C

OU-B

OU-E

Band

Years at NIST

Leadership

NIST Postdoc

NIST Contract

Other fed Agency

Timely Prom.

Seniority Scale

Methodological

Missing Demo.
Week Returned

Courses/ Leadership Training

0.01

0.05

$0.13^{* *}$

$-0.09$

0.08

0.09

0.09

0.06

$-0.06$

0.00

0.06

$-0.03$

0.03

0.03

$-0.15^{* *}$

$0.12 *$

$-0.02$

$-0.09$

$-0.02$

$-0.01$

$-0.05$

$-0.05$

Promotion Related Perceptions

Prom. III to IV

Prom. IV to $\mathrm{V}$

Prom. $V$ to ST

Own Prom.
$-0.05$

0.06

0.12

0.06

$$
\begin{aligned}
& -0.09 \\
& -0.03
\end{aligned}
$$

$$
-0.20 * * *
$$

$-0.10$

0.02

0.00

$-0.09$

0.00

$-0.01$

0.04

$-0.02$

$-0.01$

$-0.03$

$-0.26 * * *$

$-0.23 * * *$

$-0.08$

$-0.10$

$-0.02$

$0.16^{* *}$

0.11

$-0.24 * * *$

$-0.04$

0.04

$-0.05$

$-0.01$

$-0.11^{*}$

$0.15^{* *}$

$-0.16 * *$

0.08

$-0.12 *$

$-0.04$

$-0.14 *$

$-0.05$
Committees/ Other/

Detail Organizations

0.02

$-0.01$

$0.12 *$

$-0.03$

$-0.05$

$-0.01$

$-0.02$

$-0.05$

$-0.03$

0.06

$-0.08$

$-0.03$

0.01

0.01

$-0.09$

$-0.02$

0.10 *

0.08

0.03

$-0.01$

0.03

0.02

0.09

$-0.06$

$0.17^{* *}$

0.09

$-0.02$

0.01

$-0.11^{*}$

0.05

$-0.03$

0.04

0.00

$-0.04$

$0.36 * * *$

0.05

$-0.08$

Note: Correlations were Pearson Product Moment Correlations. ${ }^{* * *}=p<.001,{ }^{* *}=p<.01 ;{ }^{*}=$ $p<.05$. All measures were dummy variables with 1 indicating that the response was given. Only respondents who provided a description of their experiences were included in the analysis. $n=389$. 
Table A-23

Regressions of Other Professional Development Experiences on Socio-Demographic Characteristics, Employment-Related Variables, and Promotion-Related Views and Experiences, Full and Reduced Models

Supervisory, Leadership Positions

Full Model

\begin{tabular}{|c|c|c|c|c|}
\hline$\underline{\text { Independent Variables }}$ & $\underline{\mathrm{OR}}$ & $\underline{Z}$ & & \\
\hline PhD & $1.68^{*}$ & 2.19 & & \\
\hline Leadership Role & $.51 * *$ & -2.89 & & \\
\hline Constant & $.62^{*}$ & -2.86 & & \\
\hline Variance Const. & 0 & 0 & & \\
\hline Ch -2 LL from BL & $15.92^{* *}$ & & & \\
\hline \multicolumn{5}{|c|}{ Detail Assignments } \\
\hline & \multicolumn{2}{|c|}{ Full Model } & \multicolumn{2}{|c|}{$\underline{\text { Reduced Model }}$} \\
\hline Independent Variables & $\underline{\mathrm{OR}}$ & $\underline{Z}$ & $\underline{\mathrm{OR}}$ & $\underline{Z}$ \\
\hline $\mathrm{PhD}$ & 0.62 & -1.59 & ----- & ----- \\
\hline OU-D & 0 & -0.02 & ----- & ----- \\
\hline Seniority & $3.35^{* * *}$ & 5.42 & $3.42 * * *$ & 6.17 \\
\hline Views Prom III-IV & 1.04 & 0.21 & ----- & ----- \\
\hline Constant & $.22^{* *}$ & -2.5 & $.17^{* * *}$ & -10.42 \\
\hline Variance Const. & 0 & 0 & 0 & 0 \\
\hline Ch -2 LL from BL & $70.30^{* * *}$ & & $46.11 * * *$ & \\
\hline \multicolumn{5}{|c|}{ Courses, Training, Mentored } \\
\hline & \multicolumn{2}{|c|}{$\underline{\text { Full Model }}$} & \multicolumn{2}{|c|}{$\underline{\text { Reduced Model }}$} \\
\hline Independent Variables & $\underline{\mathrm{OR}}$ & $\underline{z}$ & $\underline{\mathrm{OR}}$ & $\underline{z}$ \\
\hline NIST Fed Only & $1.98 * *$ & 3.05 & $1.99 * *$ & 3.09 \\
\hline Seniority & $.56 * * *$ & -3.77 & $.53 * * *$ & -4.42 \\
\hline Views Prom, All Bands and Own & 0.83 & -1.33 & ----- & ----- \\
\hline Constant & 0.95 & -0.12 & $.51 * * *$ & -4.57 \\
\hline Variance Const. & 0 & 0 & 0 & 0 \\
\hline Ch -2 LL from BL & $33.88 * * *$ & & $32.10 * * *$ & \\
\hline
\end{tabular}


Table A-23, Page 2

Committee Work, NIST and Professional Organizations

\begin{tabular}{|c|c|c|c|c|}
\hline \multirow[b]{2}{*}{ Independent Variables } & \multicolumn{2}{|c|}{ Full Model } & \multicolumn{2}{|c|}{$\underline{\text { Reduced Model }}$} \\
\hline & $\underline{\mathrm{OR}}$ & $\underline{Z}$ & $\underline{\mathrm{OR}}$ & $\underline{Z}$ \\
\hline P Doc NIST & $2.09 *$ & 2.06 & $2.29 * *$ & 3.07 \\
\hline NIST Fed only & 0.86 & -0.38 & ----- & ----- \\
\hline Constant & $.18^{* * *}$ & -5.78 & $.16^{* * *}$ & -9.77 \\
\hline Variance Const. & 0 & 0 & 0 & 0 \\
\hline Ch -2 LL from BL & $9.94 *$ & & $9.80 * *$ & \\
\hline \multicolumn{5}{|c|}{$\begin{array}{l}\text { Note: Because the dependent variables were dichotomous, logistic regressions were used throughout the } \\
\text { analysis. OR refers to odds ratios. Degrees of freedom for the test of change in the }-2 \text { Log Likelihood } \\
\text { statistic correspond to the number of independent variables in a model. Regressions were not conducted } \\
\text { for the measure of "other" responses given the very skewed distribution. The measure of promotion views } \\
\text { for the analysis reporting a detail assignment involved only transition from III to IV; the measure for the } \\
\text { analysis of course work and training involved views of promotion at all bands and respondents' own } \\
\text { experiences. }{ }^{*} \text { indicates } p<.05,{ }^{* *} p<.01 \text {, and }{ }^{* * *}=p<.001 . N=373 \text { respondents, } 8 \text { to } 115 \text { per operating } \\
\text { unit, average }=53.3 \text {. }\end{array}$} \\
\hline
\end{tabular}


Table A-24

Summary of Significant Correlations or Fixed Effects Related to DK Responses by Dependent Measure

\begin{tabular}{|c|c|c|c|c|c|c|c|}
\hline \multicolumn{8}{|c|}{ Promotion III to IV } \\
\hline \multirow[t]{2}{*}{$\underline{\text { Variables }}$} & \multirow{2}{*}{$\begin{array}{c}- \\
\text { Bivariat }\end{array}$} & \multicolumn{6}{|c|}{$\underline{\text { Regressions }}$} \\
\hline & & Total & & & Band & Not elig & \\
\hline Socio-demographic & $\underline{\mathrm{e}}$ & Group & Band III & Band IV & $\underline{\mathrm{V}+}$ & ret & Elig ret \\
\hline Gender & n.s. & n.s. & n.s. & n.s. & n.s. & n.s. & n.s. \\
\hline URM, RE & ------ & ------ & ------ & ------ & ------ & ------ & ------ \\
\hline PhD, Degree & ------ & ------ & ------ & ------ & ------ & ------ & ------ \\
\hline Discipline & ------ & ------ & ------ & ------ & ------ & ------ & ------ \\
\hline Leader & Neg & ------ & ------ & ------ & ------ & ------ & ------ \\
\hline Band & Neg & ------ & ------ & ------ & ------ & ------ & ------ \\
\hline Yrs NIST & Neg. & ------ & ------ & ------ & ------ & ------ & ------ \\
\hline Age & Neg. & ------ & ------ & ------ & ------ & ------ & ------ \\
\hline Seniority Scale & ----- & Neg. & ----- & ----- & ----- & Neg. & Neg. \\
\hline \multicolumn{8}{|l|}{ Employment } \\
\hline \multicolumn{8}{|l|}{ Only NIST fed or } \\
\hline Contract & Pos & Pos. & n.s. & Pos. & n.s. & Pos. & n.s. \\
\hline Timely Prom & Pos. & n.s. & n.s. & Pos. & n.s. & n.s. & Pos. \\
\hline OU & Yes & n.s. & n.s. & n.s. & n.s. & n.s. & n.s. \\
\hline \multicolumn{8}{|c|}{ Promotion IV to $\mathrm{V}$} \\
\hline \multirow[t]{2}{*}{$\underline{\text { Variables }}$} & - & \multicolumn{6}{|c|}{$\underline{\text { Regressions }}$} \\
\hline & Bivariat & Total & & & Band & Not elig & \\
\hline Socio-demographic & $\underline{\mathrm{e}}$ & Group & Band III & Band IV & $\underline{\mathrm{V}+}$ & $\underline{\text { ret }}$ & Elig ret \\
\hline Gender (Male=1) & Neg. & n.s. & n.s. & n.s. & n.s. & n.s. & Neg. \\
\hline URM, RE & ------ & ------ & ------ & ------ & ------ & ------ & ------ \\
\hline PhD, Degree & ------ & ------ & ------ & ------ & ----- & ------ & ------ \\
\hline Discipline & ------ & ------ & ------ & ------ & ------ & ------ & ------ \\
\hline Leader & Neg & ------ & ------ & ------ & ------ & ------ & ----- \\
\hline Band & Neg & ------ & ------ & ------ & ------ & ------ & ------ \\
\hline Yrs NIST & Neg. & ------ & ------ & ------ & ------ & ------ & ------ \\
\hline Age & Neg. & ------ & ------ & ------ & ------ & ------ & ------ \\
\hline Seniority Scale & ----- & Neg. & ----- & ----- & ----- & Neg. & Neg. \\
\hline \multicolumn{8}{|l|}{ Employment } \\
\hline \multicolumn{8}{|l|}{ Only NIST fed or } \\
\hline Contract & Pos & Pos. & Pos. & n.s. & n.s. & Pos. & n.s. \\
\hline Timely Prom & Pos. & n.s. & n.s. & n.s. & n.s. & n.s. & n.s. \\
\hline OU & Yes & n.s. & n.s. & n.s. & n.s. & n.s. & n.s. \\
\hline
\end{tabular}


Table A-24, Page 2

Promotion V to ST

\begin{tabular}{|c|c|c|c|c|c|c|c|}
\hline \multirow[t]{2}{*}{$\underline{\text { Variables }}$} & \multirow[t]{2}{*}{ - } & \multicolumn{6}{|c|}{$\underline{\text { Regressions }}$} \\
\hline & & Total & & & & Not elig & \\
\hline Socio-demographic & Bivariate & Group & Band III & Band IV & Band V+ & ret & Elig ret \\
\hline Gender (Male=1) & n.s. & ------ & ------ & ------ & ------ & ------ & ------ \\
\hline URM, RE & ------ & ------ & ------ & ------ & ------ & ------ & ------ \\
\hline PhD, Degree & Neg. & Neg. & n.s. & n.s. & n.s. & n.s. & n.s. \\
\hline Discipline & ------ & ------ & ------ & ------ & ------ & ------ & ------ \\
\hline Leader & Neg. & ------ & ------ & ------ & ------ & ------ & ------ \\
\hline Band & Neg. & ----- & ------ & ------ & ----- & ----- & ----- \\
\hline Yrs NIST & Neg. & ------ & ------ & ------ & ------ & ------ & ------ \\
\hline Age & Neg. & ------ & ------ & ------ & ------ & ------ & ------ \\
\hline Seniority Scale & ----- & Neg. & n.s. & n.s. & Neg. & Neg. & Neg. \\
\hline Employment & & & & & & & \\
\hline NIST fed or Contract & ----- & ----- & ----- & ----- & ----- & ----- & ----- \\
\hline Timely Prom & Pos. & n.s. & n.s. & n.s. & n.s. & n.s. & n.s. \\
\hline OU & n.s. & n.s. & n.s. & n.s. & n.s. & n.s. & n.s. \\
\hline
\end{tabular}

Note: Positive means that those with a higher score on a variable more often marked DK. All regressions were Poisson mixed models with operating unit as random effect. The best fitting regression model for the total group was used for analyses within sub-groups. A probability level of LE .05 used as cut-off for determining significance. 


\section{Appendix B: Open-Ended Comments Regarding Other Professional Development Experiences}

The comments below were given in response to this question: "Have you had any other professional development opportunities at NIST, such as non-supervisory leadership roles, training, or detail assignments? Please describe these opportunities." Comments have been edited slightly to remove elements that might identify individuals.

- Informal leadership of projects is common. Also, I have had many opportunities it participate in Group budget/research planning activities

- Project management course, leading a successful proposal for purchasing complex systems for research at NIST, leading collaboration efforts, leading efforts (and learning the process) to get a US patent successfully awarded for our group's work, other professional development courses, etc.

- Detailed to OU as science advisor

- Scientific Advisor to Lab Office

- General guidelines

- Provided an opportunity to direct the operation of experimental facility. Provided an opportunity to lead a team of 10 researchers in field work.

- Taking on responsibilities outside my regular research activities that have value to NIST

- Professional society leadership, postdoctoral mentor, project leadership

- Gender difference workshop, mentoring program (as a mentor), cross-cultural sensitivity presentations, safety training

- I am the President of ... [and examples of activities given].

- The Foundations in Leadership Program (FLP) is for non-supervisory positions who are interested in Leadership. I took this course a couple years before entering an actual leadership position.

- A variety of leadership roles in a professional society related to my NIST work.

- Accolade awards committee member

- Program Coordination Office; US Measurement System Task Force

- Details, temporary assignments, others duties as assigned

- Technical training classes (IT); PMLP Course

- Support when requesting training

- Cleanroom training, machine shop training

- Career coaching program for NRC postdocs

- One year scientific adviser position in an OU lab office

- One-on-one career coaching offered to NIST NRC Postdoctoral Associates and supported by the NIST IAAO. It was and continues to be an important part of my career development.

- Helping lead the division Al interest group

- Supervised small research teams.

- NLP, software carpentry class, sketch notes class, PEAR and WiSTEM seminars 
- I took some of the Leadership for All courses on Conflict Resolution and Team Building.

- Project leader

- Early in my career, NIST had a program to send staff to work for 6 months or so at private companies to grow technically and professionally. I participated in this.

- I was acting ... for a period of 8 months.

- I am co-lead for a 60 person collaboration that operates largely outside NIST. I have organized workshops and reviews, also largely outside NIST. NIST allows these activities, though they are up to the individual. I have taken project management courses at NIST and have been part of the mentorship program.

- I took FLP and PMLP courses, and have had a variety of official (project leader) and unofficial leadership opportunities.

- NIST has supported me in obtaining my doctorate and provided opportunities for training to learn new skills, e.g., software. The only leadership opportunity that I have been given is to oversee my research projects.

- Through university association, have done their year-long leadership course

- Project Leader; 8 month scientific exchange program in ...[another country]

- Leading projects

- Attending professional community conventions.

- Served as a project leader for many years.

- Technical project management

- Project leader

- Led a technical team.

- Program Manager for the ... Program, Secretary of ... Commission

- NIST Next Leadership Program

- [Organization] executive chair, leadership and communication training workshops and seminars

- Took "building the next generation" and "new leaders" training. They are good about offering these courses, but there are not as many official leadership positions as there are people who want to move up. These courses have been helpful with non-official leadership positions such as project leaders and leader of task groups.

- Participation in NIST Directors' Program Coordination Office and opportunities to serve on committees in DC

- Other agency detail

- I was temporarily promoted to Band 5 during absence of my supervisor. I had an informal detail with another OU. I have been through the NLP. I have informally supervised pathways students and SURF students.

- Field work at sea on ships

- FLP and PMLP

- Joined PEAR-leadership team.

- Safety courses, presentation opportunities

- I have organized an externally funded research program.

- I participated in the sixth Project Management and Leadership Program (PMLP). 
- I took a Project Management course and a course on calculating uncertainties

- Participated in the full (3 modules, about $1 \mathrm{mo}$ ) "Learning as Leadership" curriculum

- Training/mentoring of summer students under SURF and STEM programs

- Project Management Foundations of Leadership Acting Group Leader

- Leadership of technical teams with specific technical goals

- I participate in several leadership development opportunities including the New Leaders Foundation Program, EEO Collateral Counselor, NIST Mentor, WiSTEM Board Member, SEBA Vice President, and CLC trainings.

- Project Leader Safety reviews Helping strategic planning

- Supervising graduate students and SURF students

- Detailed to a computer communications group for a short time. Detailed to the Advanced Technology Program for a summer.

- Training directed towards my daily work

- Detail to the Program Coordination Office, President of ... (NIST Chapter)

- NIST is pretty good about sending us to conferences. Most staff is interested in working together.

- Technical team leadership role, international standards development activities, project lead activities

- Leadership training

- Year-long project leader and supervisor leadership training, coaching

- Participated in New Leader Program at NIST in ...

- I have acted as project lead several times on projects within our group at NIST. This required that I perform project planning, work with others to ensure that the tasks are executed according to schedule, and document and report out on findings.

- Safety, Property Management

- Detail to Program Office. Special assignments at the Institute and Department levels. Detail to another Agency (State Department) Completed Candidate Development Program Attended Federal Executive Institute.

- Project Leader/Technical Expert; Leadership Coach; Mentor; Standards Organization Sub-Committee Chairman

- There have been some really great supervisor training opportunities recently. Just before ..., I took a series of training courses required by the DoC. They were very useful in terms of handling difficult employees. I wish I had had them years earlier. The NIST New Leader Program covered some of this material, but not clearly.

- I have taken NIST leadership courses and have had detail opportunities

- Trainings, leadership on projects and proposal teams

- Project leadership, some minimal project leadership and management training, most of the latter has been uninspiring (the answer is not more training, its better training!)

- Project leader, which is non-supervisory. Participation on .... Invited reviewer for ... internal award process Participation in the New Leader Program Organizer for internal (1) and external (2) NIST workshops 
- I am a project leader and lead a group of 3 postdoctoral fellows. Although most of my leadership experiences are primarily focused on guiding their research projects, I have informally dealt with personnel issues such as conflict resolution.

- Leadership 4 All Training

- Project leadership.

- Supervision of Postdocs and summer students Division safety officer Led trainings on safety protocols

- Project leader for a team of 3-6 scientists. Set research direction and execution, but do not deal with personnel issues.

- Yes, primarily through the new leaders program. This was a year-long course with frequent skill building sessions

- Mindful Leadership, CFC Leadership, 360 analysis... NIST supports a lot, and you have to ask.

- Training classes mostly.

- Training classes, joining organizations that train

- At the request of my Laboratory Director, I took a one-week project management course and evaluated its usefulness for our managers to also take.

- Project Lead Position New Leaders Program at NIST Acting Program Director position

- Mentoring students

- MYOB

- Foundations of leadership program

- Training for various tasks related to my job tasks; not related to general professional development.

- I am formally a part of a cross-divisional project where I do not have direct supervisory authority over all participants.

- Being mentored by a senior professional in my group; taking the lead on some projects.

- Mentor for a SURF student

- Non-supervisory group leader and have taken many leadership courses described above.

- Project management and leadership program

- NLP, OSTP detail

- Mentor program

- Aspiring Leaders Development Program

- Project Leader/Project Management Technical Community of Interest leadership

- Participation in strategic working groups

- Early in my career I took training to be an EEO counselor; I have attended short courses on improving communication skills

- Member of diversity council, part of mentoring program, ... counselor, chair of local ... committee, representing NIST ... at national meetings

- I lead a laboratory and have been a co-investigator on collaborative project with outside agencies. 
- Great opportunities to work with other business units; had opportunity to work with DOC HQ on specific position related tasking; university Band education, etc.

- Leading technical projects

- I did a detail in another OU temporarily at a higher Band than my current position.

- Experiment design training

- I spent two years at the ... serving as a detail in ...

- COTR Training, Specific technical trainings.

- I have been given the opportunity to lead numerous projects/programs (but not people, other than students and guests). I have completed the NIST FLP. I completed a 6-month detail to another office (although I requested 12 months and feel that it would have been more productive and long-lasting if given 12 months). Other detail assignments within my division have been sidetracked in 2019 (government shutdown) and 2020 (COVID-19)

- Project leader working with a contractor who coordinated activities mostly with me

- Project leader Postdoctoral advisor Informal mentoring

- Detailed to Laboratory office as ..., detail to Office ..., and led a NIST-wide student program.

- Training in the form of technical workshops held at external organizations to gain technical skills.

- Safety committees and organization, DSR, graduate student advisor, child care center BOD

- Summer School at BIPM for two weeks. (technical)

- FLP13 and PLM9

- I was Acting Group Leader for one year. I was Acting [higher level] for ....

- Project leader; PCO Rotator; FEI

- Leading cross-OU committees/panels

- Participated in the leadership team of the Postdoc Association at NIST (now called PEAR). Participation in the Executive Board of the Women in STEM group at NIST. Participated in the New Leader Program.

- Most notable was one-year detail in Director's office, which provided insights into the broader NIST community and the interactions outside of NIST (e.g., White House, Congress)

- I managed several multi-million dollar construction contracts inside occupied labs with very minimal oversight by my management. It was my responsibility to find and develop the working relationships I needed to make these projects happen on budget and schedule.

- New Leader Program Participant. Other communications courses through the CLC.

- I try to attend a variety of seminars as they are offered, such as negotiation skills, diversity training, etc.

- Research project management. Management of shared facilities/equipment. Oversight of undergraduate, graduate and postdoctoral researchers. 
- A committee formerly known as the .... gave bench-level scientists an opportunity to give constructive input direct to the NIST director for ideas on how to improve the organization/agency. It was a good committee to serve on for learning some inside baseball about how the agency worked and networking with other people outside of their OU. This committee was widely despised by the upper management.... Eventually this committee was marginalized with limited influence and I believe it may have later been disbanded.

- Mentorship

- I lead teams of 15+ people in NIST to meet project goals. This range from establishing project goals, tasks, personnel, and schedule. I provide guidance on deliverable and presented work to the management at the completion of the project. I did this for two different projects and one of the project received a NIST award. But I was still denied a project leadership position and was informed that I should not say I was a leader of any of the projects.

- Participated in the Foundations of Leadership Program.

- Foreign travel to work with collaborators

- Committee representatives/leads from division to NIST Band

- By request, served as a detailee advisor to a Senior Executive at HHS for 8 months.

- year long leadership class

- Detail assignment with another division.

- (1) Limited role as project manager in a cross-OU capacity. While this is a very active effort, there are significant challenges in the organization to perform in this capacity. To accomplish goals, there is an up the chain across and down the chain path. A significant effort required to establish cross OU work, making headway, many challenges and established org culture/inertia to work through. OU's operate independently.

- Acting office chief for 6 months; project leader for 2 projects for the past 6 years; informal deputy to office chief for the past 4 years; currently acting ...

- I have served on a few committees, giving me a voice about certain issues. I also feel that my current supervisor does accept and implement suggestions when he can.

- $[\mathrm{OU}]$... Program, leading projects in my group

- Detail assignments (2) MBA

- Mentoring Postdocs and undergraduate students

- Prefer to not; would identify me.

- Informal classes that are offered (for example) to train NSF postdoctoral fellow advisers. Detailed as an observer to the kick-off event of a big long-term research program in a foreign country.

- Detail

- "Project leadership", which is a point of contact who reports interactions and results of a multi-member team to a supervisor.

- PEAR-planned career development seminars and mentoring.

- Project leadership training, professional development (non-NIST; external) training 
- Non-supervisory project team leadership, detail opportunity (although not taken)

- Liaison role with ... Div. Chiefs and ... management council ([administrative position, acting)

- Detailed to the program office and the lab office.

- Very good opportunities for attending profession related classes and conferences.

- [Non-NIST Training] - Certificate of Policy Strategy

- They're routinely announced, and usually lead to agencies downtown or temporary appointments at other labs.

- I have had some opportunities, internal and external, to develop and demonstrate my leadership skills. I serve as ..., a challenging role because it comes with no authority. I have to work with staff and management to make sure I get what I need for compliance. I was also given an opportunity to participate as Executive Secretary on an external committee involving numerous government agencies. It was a good experience to work with the co-chairs and other members and to see the higher-Band impact our agencies have in shaping the policy of the administration.

- project leadership at local level, asked to lead cross OU efforts as lead, established as NIST-sourced leader for project areas in some international standard areas

- I participated in the NIST New Leaders Program as a new group leader. It offered training, mentoring, and peer interaction. I have served as a ... which helped develop a broader vision of NIST's mission and impact as well as strengthen profession networks. I have taken numerous other training courses and participate with national consortium and national and international standards bodies.

- Did some work down at DOC. Led many projects. Graduate studies in MIS etc.

- Project Leader

- (Keeping it vague) I have had opportunities to interact and guide the development of important policy documents with high levels of management with informal mentorship included as part of the assignments.

- Fundamentals of Leadership course

- Leading an IMS team, participating in an IMS team, participating in and leading ... projects, detail for ATP proposal review

- Leadership Development

- I work with Postdocs, UMD graduate students and SURF students.

- Detail in the Lab Office

- Negotiation workshop hosted by PEAR and CRDO

- Detail to NIST Directors office to spearhead a reorganization of the Laboratory programs. Detail as Acting Associate Director of Laboratory Programs.

- Worked in the director's office supporting the program coordination office

- I have had the opportunity to take temporary assignments to other parts of NIST and to DOC

- I had a 6 month detail in a different Division, I've had a variety of trainings, I'm part of the mentoring program.

- career coaching 
- Project Management Leadership Program (PMLP)

- Various trainings ranging from learning ASL, how to use software, bystander training, and communicating one's own accomplishments

- Detail to Program Coordination Office, serving on interagency groups

- Career development seminars

- Advisor to PREP researcher

- Non-supervisory, technical leadership of graduate students and summer students who essentially are contractors.

- I have led committees and been on detail assignments, which have changed my career for the better. I appreciate the opportunities I have had, especially since they are so rare.

- I have had the opportunity to participate in a training series entitled "Leadership for All". I would like to participate in a detail or a leadership position but it is not particular clear how I can become involved in / hear about these opportunities.

- Participated in NIST New Leaders Program

- Asked to be a co-chair for a NIST-led symposium. Supervised students. Project management training. intro to standards training. Experimental design training. WiSTEM board member

- Training, worked in non-supervisory roles

- Detail assignments to the Program Coordination Office, SES candidate development training

- Building the Next generation leadership course

- Currently serving as a project lead

- Project Management \& Leadership Program (PMLP)

- Future Leader Program, various training courses for professional development.

- I was send to [another country] for [program]. I consider this training that contributed to my professional development.

- Training offered by the manufacturer of our equipment. Short course offered by my division.

- NIST Leadership Program.

- Project leadership; mentoring (SHIP, SURF, postdoctoral researchers, and PEAR)

- I took a git class.

- Performed lead duties for small projects, my opinion is respected when come up with process improvements and I'm allowed to develop and lead these improvements.

- Many different kinds of mandatory training. Latest one was teleworking for managers.

- Work-related training

- I was detailed to the NIST .... I was also detailed to the ... in [another government agency] for ....

- One year in the NIST Program Office.

- Mentoring short-term researchers

- Job-related skills workshops and courses 
- I was selected and participated in the NIST Foundations of Leadership Program; I was selected and completed a 1-year detail assignment as a scientific adviser in [an OU]; I applied and was selected to do a detail in the NIST...; I did a 1-year detail in the office of the ...; I led a partnership with a local university; I have held various other leadership roles within the organization

- Informal mentoring and supervision of contractors, postdocs and students

- I am currently participating in the NIST mentoring program and the postdoc career coaching.

- I am project leader, so I use my leadership training skills in that capacity

- I have participated in small technical committees or working groups that spanned multiple operating units (labs) at NIST.

- Numerous courses on workplace skills, ranging from interpersonal communications to use of software tools. Of all the places I've worked in and out of the government, NIST provides the most training opportunities.

- Lead on multiple research projects

- I have taken some courses offered through CLC and on-campus offered to staff.

- Project leadership, mentoring of students and technical staff.

- I have participated in the BTNG training as well as the NLP leadership training.

- I am the Associate Director for ... at the [OU]. I do not have direct supervisory responsibilities in this role but co-manage the activities in that program. I am also a CoDirector of the ... programs (Note that I am a co-founder of ...). I served on [an advisory committee] when it existed.

- I took a detail; it allowed me to get away from an abusive division chief.

- Leading a Technical Program throughout several Divisions

- I am a participant in the Foundations of Leadership Program and have been officially mentored for 2 years (2 different mentors) and am taking EMC2 training this year.

- Formal Mentoring, Career Coaching

- Detail to lab office as a science advisor which provided a higher Band perspective of the lab and NIST.

- Technical management of complex projects

- There is never enough time in the day to spend time on training, unfortunately. I have had opportunities offered to me, but the workload does not allow it.

- I am a Non-supervisory Project Leader and have been in this position for nearly 8 years. I was a Non-supervisory Program Manager for 3 years. I have taken the Building the Next Generation leadership class. Similarly, I have taken the New Leaders Program leadership class. I have also served as a mentor to numerous NIST employees.

- I've taken training related to how to write a good annual review statement - that was helpful to me.

- Group delegate for ... committee, sit on the ... executive board, direct PI/mentor to multiple postdocs and graduate students, Mentorship Training

- Opportunity to be PI for grants Occasional training to enhance technical skills 
- I have taken external leadership courses (academic and third party), served on detail in leadership roles in another agency, and completed multi-agency career development programs.

- ... team leader, ... seminar leader

- I led an OU-wide program for several years. I also attended the FLP and PMLP leadership training before I became a supervisor.

- The management of documentation and calibration service

- Detail in Program Coordination Office

- Mentoring program; Technical training including: Computer based and Class room training

- Leadership training courses.

- Have taken classes essential for career development and have been given the opportunity to take additional leadership classes

- Foundations of Leadership Program. A 1 year program operated by the HR department. Includes a 1-week intensive off-site training, plus monthly 3-hour seminars.

- Management of S\&T program in NIST focus area.

- The nature and role of my position means I have the opportunity to take on a lot of nonsupervisory leadership oriented assignments.

- Leadership courses offered by NIST. Detail opportunities were never discussed.

- I was an ... counselor

- Training: mentorship program, statistical design of experiment. Also, have led some technical training courses and software carpentry

- I mentor undergraduate students as often as I can. I also take advantage of training courses that are offered at the conferences I attend yearly.

- I went to a number of different seminars during my first few years. One was a simulated negotiation of creating a standards document. There was also one on how to write accomplishment summaries (for annual evaluation). Generally, these have all been well put together \& beneficial for me. (The only exception was a seminar I went to on PowerPoint presentations, which was way more basic than I expected and turned out to be a waste of time.)

- Project management. NIST Leadership Training.

- Foundations of Leadership program - yearlong program designed for future leaders at NIST

- I have taken some training, mostly scientific training related to my field.

- Project leadership; supervising my own Postdoc; leadership activities in "extracurricular" clubs

- Detail position to Office of ..., Fellowship position to [another government agency], oneyear acting position as [higher administrator]

- mandatory supervisor courses

- I performed supervisory work over multiple years but was not a supervisor

- program lead 
- I have served three times over ... years as a detailee to fill in for my direct supervisor. All were eye-opening and gave me a great chance to see the next level of leadership. I have also done details crossing campuses, although those are more challenging.

- Leader of several technical projects and small teams, advisory positions within laboratory

- Several detail positions, leadership positions in affinity groups, project lead

- I was asked to fill in for my retiring supervisor - he was a ZP-5 and I was a ZP-4. This meant managing the Group's budget and employees across [sites]. I gladly accepted the challenge. For the 18 months I was in the temporary position I was not given additional (ZP-5) pay.

- Training related directly to job such as project management, acquisitions, required training such as IT security, etc.

- I took a variety of courses on project leadership (which is informal leadership of a technical project), conflict resolution, and productive work habits.

- Was supported while pursuing a graduate degree.

- Leading a project with a team. Being the primary POC and training for a piece of equipment. Safety representative. Chairing committees.

- I have taken leadership courses, supervised/mentored numerous summer/intermittent students (SURF, SHIP, Pathways).

- NRC mentor, NIST mentoring program, student mentor, staff led councils

- Details for myself or for others to join my team. Long term personal development through education institutions

- Program Coordination Office

- What opportunities?

- I led an employee resource group. This was not formally recognized in any way, but was acknowledged in my performance review as internal service.

- Leading high profile project teams without supervisory authority over the team members, technical and leadership training

- I lead a project. I can make decisions but I am not the supervisor of the other scientist on the team.

- Multiple roles/detail opportunities that have been mutually beneficial to all parties at NIST, but will not detail specifics as to not be identified. However, of note, these opportunities were not open calls, but I was selected by senior leaders - while this was of benefit to me, this process is not a best practice and could potentially be applied inequitably.

- $\quad$ NIST Leadership Training

- course training for new IT technologies

- Project leadership, working group leadership, safety task force leadership, etc.

- I have had the opportunity to lead projects and experiments, but not in a supervisory manner.

- I have had the opportunity to be a mentor within my group.

- Certification 
- I was tapped to work a detail in the PCO or as a Commerce Science Fellow, but declined.

- I am currently a project leader.

- As part of my leadership class I participated in a special project on a NIST wide topic. I lead a portion of an Initiative proposal. I am a non-supervisory project leader. I have been in leadership roles outside of NIST, as part of my NIST related duties.

- Coordinator of re-certification and QA programs within my group

- Served as project leader

- informal supervisory roles, leadership training retreat

- Team and project leader positions that are non-supervisory.

- FLP, PMLP, leading projects with other employee support

- I was put on detail at the US Mission to the EU for a month working in the commercial service office.

- Participating the NIST-wide mentoring program run by the Mentoring Connection

- Career counseling program through the NRC.

- I have been at NIST for more than ... years and have been in many leadership roles. I am an alumnus of the [training program] at the ..., and have taken a couple of the NIST classes through the Leadership and Employee Development program, as well as have participated in mentoring and coaching programs at NIST.

- Program Office detail position, role as coach and mentor for NIST New Leaders training program, participation in NIST New Leaders program

- Currently leading my own project Attended the Foundations for Leadership Program

- Team leader of a specific research team

- NIST Foundations of Leadership Program NIST New Leader Program MML SURF (Summer Undergraduate Research Fellowship) Coordinator - [variety of division level positions]

- I informally managed a younger scientist for 2 years. I managed a contractor group of around 10 contractors for several years. I've led government wide programs in their initiation stage (before NIST handed them to other agencies).

- Service on ad hoc committees

- Various research-domain training courses.

- Chair of the ... Committee, ... Coordinator of my Operating Unit NIST Representative on ... subcommittee

- I attended technical courses

- Detail positions, international participation, standard developing organizations, chair/organize conferences

- I had/took an opportunity to be detailed part-time outside my division.

- $\quad$ project lead, student mentor in SURF and pathways

- Team building within inter-generational persons. Public info and communication.

- This is a self-identifying question as there are few opportunities.

- I mentor many graduate students and postdocs.

- Project/program leadership 
- Non-supervisory leadership roles (I'm on the board of an affinity group (...) and have been on leadership with ... for 3 years), training (FLP), or detail assignments (currently am ... as the permanent is doing a detail in ...)

- Building the Next Generation and Project Management

- Leading projects and teams

- From my earliest years at NIST, ... years ago, I was a project leader, which is where the real action happens at NIST. This is where we form teams and work on research projects together, and where we get to know each other's strengths and weaknesses. Some of my projects were NIST funded, and some were other-agency funded. There are tons of opportunities at NIST for researchers who have ideas to become project leaders, and for most of my career I resisted being promoted since I felt I could have greater impact on the science by being a project leader.

- I worked for ... for a year

- Currently enrolled in NIST mentoring program

- Training related to or specific to my role

- Served as PI on several OA programs involving other NIST employees (fed and assoc).

- Training in related subject matter.

- I'm a mentor in the NIST mentee program

- Chair a committee or team to develop consensus recommendations.

- As a project leader

- Project leader. Leader and participant in ad hoc groups.

- I informally supervise junior staff (ZP-III and below) members. However, I am not recognized as their "official" supervisor, when in fact, their official supervisor has very little knowledge of their activities.

- Several years ago, I volunteered but was not selected for a leadership development program. I am currently a project leader. I was recently asked to become a Group Leader but did not accept this responsibility because of the many downsides. It has been many years since the GL position has been understood to be a stepping stone to promotion within the division.

- We get email notices all of the time on courses offered by NIST.

- Project leader, detail appointment to other NIST Organizations

- Project Leader of several projects.

- I was part of a year-long training for "high performers." My Division had a lot of leadership training in a group setting. I had a professional consultant/adviser for a few months when I was a Group Leader.

- Program Office, Women's Executive Leadership program, details to acting division chief, served as acting lab director, acting lab deputy

- Leadership training for non-supervisors

- IT training classes

- I participated in the NIST Foundations of Leadership program which involved a week long offsite course followed by a once-a-month seminar for the rest of the year. 
- Program manager with budget and supervisory role; program manager with budget and NO supervisory role.

- Non-supervisory position, temporary assignments

- Currently on detail (5-7 years) as a program manager. Have also been asked to lead strategic planning groups and to start a new NIST-wide affinity group.

- I have had non-supervisory opportunities to lead projects that require collaboration from NIST and other Federal Employees and consultation with the private sector.

- Mentorship program (I was a mentee and plan to volunteer as a mentor next year).

- Program leader, project management

- I have been given opportunities to lead teams for competitive grants; opportunities in leadership roles in informal organizations related to NIST; the opportunity to take the lead on projects.

- Intensive off-site leadership courses, mindful leadership, facilitation

- Mentor in the mentor program. NIST-wide workshop co-chair.

- We're very good about offering courses via CLC and our admin teammates email out notifications on other courses. Our division has brought in trainers for training on ... processes and offered them to the entire division, which was helpful.

- Mentoring graduate and undergraduate students, informally leading teams

- I participated in an E-Gov Leadership year long set of cohort type gatherings alongside of other Agency (Feds) similar level staff.

- Project lead, committee leadership positions.

- Detail assignment to work at the lab-office. But this could have been a disastrous move if I wasn't deliberate about getting out after 1 year. Instead it turned out pretty well.

- Mentoring students, postdocs, and international guest researchers.

- Leading a team and a public consortium

- Project leader

- I completed the Aspiring Leaders Development Program.

- My division and group tries to identify projects commensurate with an individual's Band and ability that he/she can be responsible for. This includes multi-person projects that require a degree of leadership skills. I had multiple opportunities to lead well-defined aspects of projects before moving on to more formal leadership positions.

- Leadership involvement with ... organization, taken statistics workshops, informally the principle investigator of a project.

- team lead, technical training, taking SURF students

- Small project management. IMS principle investigator.

- I have pursued a wide variety of training opportunities. Naming them would identify me. Think you should know not to ask.

- I have had non-supervisory roles as a program manager and project leader.

- Secondments, details, fellowships

- I have led dozens of projects over the years and currently on detail

- I have led standards groups and taken technical training courses.

- Scientific presentation seminar, diversity seminar 
- The 6 month project management program.

- ... committees and boards

- NIST Project Management and Leadership program, project manager for several projects

- Mentoring training...; various communications trainings; advising ... students, grad students, postdocs

- Program coordinator role

- A Detail Assignment

- I supervise students and postdocs as an adjunct faculty member at ....

- Training in workplace success techniques

- NIST Mentoring Program, NRC Postdoc Career Coaching Program

- Responsible for day to day supervision of research associates, but not their performance reviews. Mentoring classes.

- Foundations of Leadership

- Co-teaching a course at a university as a postdoc Mentoring numerous undergraduates Foundations of Leadership course (competitive; yearlong) Mentoring postdoc Involvement in 3 mentoring programs over 6 years Co-running ... at a professional society meeting Organizing multiple sessions at conferences over the years

- Project leader, principle investigator

- Detailed once for 3-4 months to the ... within NIST...; informally led and continue to lead

- Largely stakeholder engagement on a voluntary basis. While this is encouraged as part of our duties, it is not formally promoted, nor does it count toward performance plans as much more than a check box. For instance, I've designed and led workshops, working groups, etc. for external and internal stakeholders. Those get folded into visibility or technology transfer as appropriate, where they apparently count for little in my favor during performance review.

- Program Office

- Project leader, lab safety officer, other committees

- I have chaired committees and led research projects.

- FLP

- I was detailed to the program coordination office for a year. I had mentioned to a colleague at OSTP that it's surprising that since we're "one federal family" that opportunities to move amongst the various federal agencies is nearly impossible, even if just for a detail of a year.

- Subject Matter Expert to ....

- Program office

- Program Coordination Office Detail

- Lead on many interlaboratory studies, position papers, experimental designs, Divisional safety committee

- Contracting, writing, diversity 
- Prefer not to disclose this information. Have done internal details with another OU, have done detail outside of NIST

- Project lead on small mission critical projects

- I was detailed to the lab office to organize an international conference on burgeoning safety regulations for consumer products. This assignment ensured my promotion ...

- A long-term detail ... to establish a NIST laboratory

- Hired to be a NIST detailee to ...

- Training for certification programs

- Project management (design and implementation); informal coordination of team (seven members that act as a team to deliver services, but are not officially treated as a team)

- Program Office detail Executive leadership development training

- Chair, NIST ...

- I have mentored ... and I am currently co-mentoring ....

- Organizational and career development opportunities hosted by ...

- Unofficially supervising students, working on specific higher profile projects, interacting with outside funding opportunities, and collaborating with other people both inside and outside of NIST

- Yes, I have been on worthwhile details!

- Ability to fund and direct ... students, ability to host NRC Postdocs, NIST Foundations of Leadership program, leading workshops, committee participation

- Travel to conferences and workshops that could be considered professional development.

- In my office on nearly all projects I participate as a team lead, for lack of a better word, without supervisory authority but for all purposes acting as a supervisor. 


\section{Appendix C: Open-Ended Comments Regarding Professional Development Experiences That Would Be Helpful}

The comments below were given in response to this question: What type of professional development opportunities or courses would be helpful in your NIST career?

- I'm not very interested in taking courses. I would like people to reach out to who can help me with specific situations. I've signed up for the formal mentoring programs, but too much time is spent in "training", not enough left for connecting with the mentor.

- NIST has lots of Byzantine processes for hiring, purchasing, evaluation, budgets ...etc. Would definitely be helpful for Group Leaders to have a "here is what you need to know" training. Having never had any other leadership training it is hard to know what would be helpful.

- Leadership training

- Practical budgeting skills. Performance planning that actually applies to NIST researchers and isn't all about counting widgets.

- Communication, situational leadership, emotional intelligence, conflict resolution, and more communication

- Understanding what is expected by NIST of someone wishing to advance to another band and practical ways to implement

- Project management. Budgeting. NIST offers courses that I've learned by word of mouth, but they aren't advertised appropriately, and it seems, to me, that you must be selected regardless of interest in taking the courses being communicated.

- Meeting management, postdoctoral mentoring

- I've taken a lot of courses myself. It would be helpful if NIST had meaningful and preferably mandatory sexual harassment prevention training.

- Leadership courses and guidance.

- Current set of classes and seminars covers it all

- Leading technical staff, grant/proposal writing, strategic outreach

- I have been pleased with the opportunities that I have had. I have also received positive feedback from subordinates.

- Collaboration development is a topic that is not brought up much. Collaborations are a necessity in modern research. Making contacts, reaching out, how to determine if a colleague is a good match to a current project or NIST's mission. Topics like this would help young staff develop and increase productivity.

- Regular training and conference attendance

- Clear and precise expectations and awareness of course opportunities

- Project planning and management 
- Something about NIST Culture

- Serving in a formal outreach capacity; spending time at another metrology institute or at a corporate location

- Project management (including certification potential)

- Simplify the ability to recruit non-citizen postdocs

- Less micromanagement and more independence for researchers.

- Details within NIST, details within the federal government, project leader training (1st time as a supervisor)

- It would be nice to have one on developing Professional Development Plans especially ones that are directly related to opportunities at NIST.

- Early in my career, I would have benefited from opportunities which helped me to "network" with others around NIST. That is, as an introvert, I didn't want to or realize the importance of connecting with people throughout the organization in order to know first-hand what is going on and to be informed of what collaborations are possible. I now see the benefit of this network building but haven't known how to make it happen. I think this is probably NOT a formal training, but would be better as putting early career staff in assignments that have them working with people outside their group.

- Public speaking

- Both mentoring and being mentee.

- I think managerial shadowing or periodic acting manager positions would help aspiring leaders to understand those roles better, and better enable their decisions on intended career path.

- Project management; Detail assignment; Apprenticeship.

- Clear statements about the promotion criteria that would prohibit subjective evaluation from the management. The existing ones allow stretching the rules in either direction.

- SES development classes

- Encouragement and funding to get technical training fairly applied to all staff with clear criteria and public disclosure.

- Negotiation, Federal Executive Institute, PC programming language.

- My group leader is thinking of retiring soon and mentioned the possibility of taking over for her. If this opportunity is presented and I decide to take it, I will take all the required development opportunities. This would teach me NIST based administration policies. Leadership is easy if you lead by example. I'm very successful at project management because of this strategy.

- Project management, MS Office tool use : Excel and Word, technical tool use and SPARQL and relate language queries

- Understanding promotion requirements and federal regulations.

- Career mentorship, leadership opportunities

- Project Planning and Budgeting 
- Anything. More regular training opportunities in Boulder would be useful.

- A group leader manual for new Group Leaders

- I'd love to see more detail options - it breeds good will between OUs and staff benefit from the ability to work in other groups/divisions/OUs. Also, for anyone that will be moving into a Division Chief position or higher, there should be some preparation of things they need to know about the business of NIST. I think we often forget how important it is for managers to better understand HR, Finance, Procurement, etc. It's another area where I have seen SESs not know anything about these areas at all.

- Time management and sustaining work ethic

- Soft skills.

- Executing CRADAs and Interagency agreements. Real professional development for junior scientists is best served by them starting new initiatives with new, external stakeholders. Internal performance metrics should be balanced with externally validated metrics such as external stakeholder investment.

- Courses like the uncertainties course: it was defined, there was lots of practice throughout the two days and there were two people whom we could ask questions and who led the class. So, courses like that: defined, hands-on, with lots of practice and based around practical needs and practical application. My experience with "social" courses is that they tend to encompass a lot and just be boring with lots of sitting and listening. Personally, I read books for growth in these areas (think 7 Habits of Highly Successful Leaders, How to Win Friends and Influence People, The Obstacle is the Way, Tribes, The Power of Habit, The 4 Agreements, Conscious Business, Emergent Strategy, more; even personal finance books really help to hone this skill which transfers into any kind of money work, even at work - at NIST). I guess I get bored with how sociallyrelated topics are taught in courses (I worked at NREL in the past, another federal lab where I had experience with these courses). For me anyway, the books are much better, and if I take a course, I'm excited for hands-on, group work, presentations, practice, practicality of application...

- Mentoring and Coaching Skills,

- I am of retirement age and do not plan to take any career development courses

- Budget execution course

- Understanding NIST budgetary process, including initiative development. Understanding details of the hiring process

- Navigating Career Advancement for the Mid-Career Balancing Work and Family Bias Training for the Hiring Processes Recruiting and Retaining Underrepresented Groups

- Leadership ones listed previously in this survey.

- Better documentation of criteria for promotion

- Too late now.

- Understanding the ZP schedule and advancement potentials 
- Assertiveness training, networking, schmoozing: things that will get you recognized outside of NIST.

- Project management and budgeting

- I don't think that the problems with professional development at NIST can be solved with courses.

- Leadership courses for non-supervisory roles, project leadership best practices, career advancement networking forums, courses on effective meeting management

- Budget execution, conflict resolution, people management, federal regulations

- Training that addresses issues beyond technical expertise, such as 'how to have impact' with research; communication with leadership, peers and nontechnical people; how to develop standing outside of NIST (it is a key aspect of becoming a ZP IV and V)

- I would prefer a scientific sabbatical at an external laboratory to improve my skills.

- I would like more formal training on project planning, and execution. My biggest concern is delegating work to people that I do not hold a supervisory position over. How do you do that while acknowledging their other work, but then also prioritizing your own work? It's a balance that I am not good at finding.

- How NIST works. How to work within the NIST infrastructure

- Executive leadership courses

- Depends upon the purpose

- Courses to learn to improve one's ability to self-advocate. NIST is an organization of people who are not comfortable in that role, therefore the self-promoters are the big winners at NIST.

- Budget training/development; leadership course for AFTER you've had 1-2 years under your belt as a supervisor. Some duties of a first line supervisor weren't what I expected/anticipated and it would be good to have the leadership course now that I know what some of my true hurdles/weaknesses are.

- There are two types of training I would recommend. First, because all researchers need to work collaboratively, this type of training is essential. This has been one of the most difficult aspects of work at NIST: we need to work together with diverse skills to excel. Second, leaders should be given more opportunities for person-to-person skill development. Because most leaders come from the research pool (which is appropriate for NIST), these skills need additional development and value.

- Additional focus on leadership development budget management

- It seems there needs to be a course that explains what constitutes unethical behavior in the workplace. For example, severely overstating claims in papers or proposals, continually stealing credit for a team member's work, scooping, trying to take over someone else's project, kicking a co-author off the authorship list at the last minute but keeping their data in the paper... the list goes on. These and more seem to be common practice. Do people not know that these practices are unethical? If there is a course that 
clearly teaches that it is unethical, then you as a witness or target have a reason to call out that person or report it to a supervisor. But if a behavior is never defined as unethical, then you have no grounds on which to intervene and may even get push-back for intervening, so such behavior continues which hurts other people's careers.

- Retirement planning

- Improvement of negotiation skills

- Proposal writing and budget planning for research

- I don't think courses will do any good. If management wants to suppress your career from moving up, they will do regardless of what you know or can contribute. Courses will be good for personal knowledge and to advise others below you, but not to be promoted.

- Budget training.

- People skills for scientists

- Budget development and management

- I have picked up most of what I need; however, for a new manager, understanding and navigating the EEO process is crucial. I had a very bad experience with this process.

- Unsure

- Budget Analysis and Execution

- How to manage scientists.

- Learning programming, not just a short couple of seminars, but a proper class lasting a longer period of time.

- Software

- Communications, project management, technical short courses/seminars

- Leadership, coaching programs

- Courses on how to become one of the "boys."

- Leadership without supervisory authority.

- Communications and public engagement; the role of NIST within the U.S. government, and international standards organizations.

- Mentoring

- I plan on developing my technical expertise by organizing meetings in my field and leading novel research projects.

- Budget

- Performance Management Restructuring

- I've taken A LOT of professional development classes and things have really changed over the years. I often feel my time is better spent working directly with my teams.

- Technical disciplines; Project/program funding opportunities - more specifically, I know that there is internal (STRS) funding and also customer-based funding when a customer funds NIST to do a defined SOW. What other sources of funding can/can't NIST pursue e.g., other agencies' program grant/funding opportunities? 
- Introductory management classes, even for those who don't become managers.

- Courses geared toward scientific leadership as opposed to going in to management. Becoming a Group Leader holds no appeal.

- NIST has increased its training for leadership, but policies and procedures are always changing. It would be useful to have more real time training that is issue specific and brief. Something similar to a management focused YouTube channel.

- Senior management courses

- None, I am at the end of my career

- The FLP courses were extremely helpful. I have also been assuming leadership roles in external professional scientific organizations to demonstrate my abilities.

- Communication courses

- Supervisory/management training, leadership training

- Understanding bias; communication styles training; any courses that promote crosscommunication across NIST laboratories

- I'm towards the end of my career so that is difficult to say. However, I suggest the following for younger staff: 1) Consider creating a rotation program for new hires that allows them to work in 3 or 4 locations around NIST their first year. They could then be matched with a position at the end of the first year, or possibly do a 2nd year with 2 rotations (picked from one of those in the first year.). Private companies and way back DOE did it with their new engineers. NOTE: DOE might still do it, I just don't know. 2) the best experience that I got out of the New Leader program was meeting people from across NIST including those outside of the technical programs. It has proven to be an invaluable resource. My office often jokes that I know everyone at NIST. It isn't true but it seems like it to them. Therefore, I recommend that having similar opportunities for employees early in their career not just for those that have been deemed "leadership" quality. 3) In general, NIST technical staff are introverts; however, many are great team members. Encourage the quiet workers to stretch themselves. Send them to conferences to tag along with a seasoned employee just to get the experience. I know that when I was a young ...., one of my bosses wanted me to write papers to present at a conference. I was not confident enough to do it at that time; however, I truly believe that if I had been able to see the quality of presentations or poster sessions, and had a mentor in the process that I would have done it more eagerly.

- I would like courses on strategic and budget planning, other high level responsibilities, to be available to me.

- Don't necessarily want to supervise, but that seems to be the only way to advance to a certain extent. Tech people get left behind.

- How to train a manager?

- I think I have gotten the training I need.

- The NIST New Leader Program was very helpful in molding my leadership style. 
- Learning how to move within NIST when unhappy with local priorities.

- Project management training. More conflict resolution training. Note: NIST should make sure to invite instructors from a diverse pool, for example, invite more women, more women and men of color, Hispanics, Native Americans, Pacific Islander, etc.

- Additional training courses

- I'm a late career person, looking to retire fairly soon. So, in my case, I don't want or expect further development opportunities.

- Manager retreats, across NIST operating units, to understand and support other units challenges and strengths.

- Additional leadership courses dealing with managing conflict and motivating staff.

- If bringing in funding and managing money are expected of Band V's, or Band IV's hoping to move to Band V, then training in those areas would be helpful--not just helpful but critical. It's unclear to me whether that is or is not a true requirement for advancement at NIST. It would seem that taking the time to learn the FAR, contracts, budgets, etc. would severely detract from research and technical skills, so is it a requirement to manage money or not if you want to advance in a research role rather than a leadership role? Are there even any opportunities for research advancement or is always tied to leadership? Currently based on what I've seen, it seems that you can only go so far in research, and after that it's management and leadership.

- I feel like there are currently quite a few professional development opportunities at NIST. I do wish I had taken some of them earlier in my career.

- It's not the professional development opportunities per se that are missing. It is the leadership positions themselves that are both limited in number and very highly restricted to a small select group of staff, handpicked by the management. Most Leadership positions are not open to any real competition. Group Leaders are an obvious example of non-competitive leadership positions. The Division Chief has full discretion to pick anyone he or she likes, independent of qualifications or merit. Those handpicked Group Leaders eventually become our upper level managers, there really isn't any other viable career path into management for bench level staff. So it's not very useful to focus on professional development opportunities when in reality it is a culture of cronyism that determines the actual opportunities for leadership at NIST.

- Research management, industry outreach

- I've really don't know at this point.

- More project leader and analyst assignments/details would be helpful if openly filled. Those opportunities are very limited which, combined with few supervisory positions, leaves little room for professional growth for many people.

- NIST isn't very clear about how I can continue to conduct research outside of projects that do not result in publications outside of internal reports. After my term is done, I worry that I will not have a competitive edge in the (academic or other) market due to 
the lull of publications. It would be great to have opportunities or courses that clearly outline how I can continue my programmatic research agenda while advancing organizational goals.

- With a change in research direction, technical training in the new area.

- I have been on the waiting list for a particular course for over 8 years. It might be best to offer more sessions for courses that are in high demand.

- How to do evaluations or management evaluations

- Given where I am in my career: SES training

- It would be helpful to have something that explains the requirements and responsibilities of the higher ranks. If it exists, I don't know where to find it.

- I might be able to answer this if I had time to take the courses already offered, again in my case time is the problem not lack of courses.

- Project management, budget management

- Allowed to compete equally for internal funding. Management selects the same people for opportunities again and again. Being invited to participate in leadership opportunities.

- I think NIST has gone down a somewhat dangerous path in spending a lot of time and money trying to develop leaders for the future with employees that are too early in their careers or just really don't have the correct experience or knowledge in a given specialty to lead. Finally, the worst is while a person may understand all the leadership skills, they DO NOT have the correct personality to be an effective, successful leader. So, to answer the question, I think there are plenty of professional development opportunities at NIST. The problem is they are not always given to the most appropriate or deserving employees.

- Courses are only the "top-down" part of the answer, where advice is handed down to the lower ranks. It is just as important to fix systemic problems right where they arise at the top. NIST has been plagued by legal inefficiencies (for example concerning other agency contracts) and by systemic career problems (most glaring for affiliates that can't even be recognized with NIST awards) in (at least) the last 15 years. It does not take a panel of experts to identify these problems, because they are common knowledge and upper management has acknowledged them. Still, no progress has been made in solving them. No number of classes and courses can fix these issues.

- Effective communications. Leading change.

- Courses that continue to develop my leadership skills and that broaden my perspectives as a leader.

- Project- and group-level budgeting, specific to a division. Each division does it differently - sometimes dramatically differently. I do not mean how one describes a project task code or legal requirements. I mean the essences of prioritizing resource allocation in a chronic time of too little funding. 
- How to find out about getting a detail or part-time opportunity at NIST or other agencies.

- There is not a lack of training. Awareness and engagement are the keys. Staff often tend to be unaware or disengaged about their role in the whole process. This is probably most pronounced at the bench scientist level, but somewhat also true at the supervisory levels.

- I am happy with the opportunities and courses available. One exception is restrictions on travel and conference attendance that sometimes occur, but those are largely not within NIST's power.

- Not sure. I'm a ZP-V and am closing in on the end of my NIST career.

- Budget and cash flow - understand how funding flows and when \$\$ really is a limit. Project proposal / presentation as it applies to NIST. We do not have well defined transparent project management processes.

- Writing and Project Management

- Technical research courses

- Probably any/all, but I don't have much of an appetite for it. I see the need for such training, and maybe could find some of it beneficial, but the genre runs thick with $80 / 20$ rules, grit, swingin' for the fences and other nauseating gimmicks. If that's leadership, let someone else do it.

- $\quad$ NIST does a pretty good job of providing opportunities for staff. The Foundations in Leadership course is excellent. The trick is communicating the opportunities to everyone. There is has been some improvement in this area. But, I wonder sometimes if I get announcements because I have taken a class from the sponsoring group before, or maybe because I'm part of a particular mailing list.

- A course entitled "how the successful can avoid becoming managers"

- All my experiences have been helpful. I have observed that people returning from a detail do not get an opportunity to exercise the skills that they developed upon return. It may be helpful to have leadership assignments within the OU.

- The ones mentioned in the previous panel would be nice.

- Managing a budget

- Grant/proposal writing. Grant management. OU Agreements. How to get something through RACO in less than two years. How to work inside a cumbersome bureaucracy.

- Effective Communication Between Generations and Gender Interpersonal Skills

- I would say the FLP program was very beneficial. regular short courses on conflict resolution, dealing with difficult people, project planning, and budgeting would be useful Leadership

- Detail. Supervisory role.

- Courses in procurement regulations 
- Managing/growing team with diverse skill sets

- The role of emotional intelligence in effective management and effective leadership

- More course work on HR and performance related duties. More course work on team building and strategic planning. More overt programs mentoring/coaching junior or early career employees.

- Leadership training

- Leadership courses

- With so many reorganizations and shuffling of groups and scientists with opaque picks of who is to lead, no professional development opportunities on Earth would be possible to unlock what should be a merit-based promotion to a supervisory level.

- Scientific writing courses; networking with people in my field to open collaboration opportunities

- Detail to other agencies; business, management, policy courses

- Seminars to explain the criteria for promotion and career paths in NIST.

- Leadership courses, effective communication, writing proposals, budgeting.

- The new NIST Mentoring program should be very beneficial, but I signed up as a mentor because it sounded like they needed more mentors than mentees. I could benefit from a mentor myself. It would be nice to have focused development topics too, like writing grant proposals or creating collaborations.

- More trust and chances to lead

- A look at what has help other individual's get promoted / what their paths were. For those of us in standards development positions, there is little opportunity for advancement. The criterion used to determine whether or not you are suited for promotion does not take have room for that type of work. It would be valuable to have more access to our division and laboratory management. There are several programs at NIST where the laboratory level administrators are active in the review and revision process, the ... staff does not have that same presence. That kind of face time would be invaluable. Show us you care, we need to know.

- Leadership training, energy/time management

- Technical training opportunities

- The Alternative Personnel Management System needs to be rethought. How it is used throughout NIST is not uniform. This leads to scores across NIST, across OUs, and across Divisions that are not comparable. Those scores are used, in part, for promotions, so promotions are not equitable. There is also level inflation that makes the scores less and less meaningful over the years. (If everyone is an ' $A$ ' student then no one is an ' $A$ ' student.)

- Dealing with bias from teammates. I am a younger woman and the project lead, and some teammates are hesitant to take my guidance as they have more experience than I do. It can be challenging sometimes to get the work out that I'm asking for. 
- NIST already offers a wide range of training and opportunities, both in class and online via CLC.

- Anything related to budget/financial aspects. Opportunities to manage people.

- I think the new mentorship program will be a useful professional development program, though I have not had the opportunity to partake yet.

- What I would like to know is if identity-based professional development opportunities are supported. For example, I know my group leader attended a conference specifically for .... Is that type of meeting eligible for financial support from NIST? Or do I need to take personal leave if I want to attend a conference for ... scientists, for example?

- Formal training for supervisory leadership roles

- Meaningful membership in standards organizations (leading committees, proposing standards, voicing feedback, etc.) How to organize a symposium and/or conference.

- How to manage my career - I have no idea what the requirements for promotion are.

- SURF/other intern mentorship courses Public speaking course

- NA. I'm already at the top of the ladder.

- Programming skills

- I'd like to see more courses devoted to developing leadership skills in staff who are not even considering a management or supervisory career path.

- None now because I am only a few years from retirement. It would be helpful if NIST encouraged or even funded taking a "sabbatical" at another institution for 3-6 months.

- More leadership roles outside of NIST - committee leadership, international activities, etc.

- I'm happy to be able to do the mentoring and career coaching opportunities here.

- Courses that provide more "soft skills" training that available to everyone. There have been leadership programs that participants are selected to attend by management. This can contribute to unconscious bias.

- Something similar to the New Leader program for supervisors with 5-10 years of supervisory experience. Some refresher content, but also more advanced topics related to experiences they've had.

- Giving presentations, auditing skills, public speaking

- Details, leadership training

- Development of coaching skills for those in supervisory roles

- I think that NIST provides enough courses and professional development opportunities to educate employees on the skills needed for success within the organization. A more significant issue for NIST, however, is that the organizational structure tends to be "stovepiped" - Employees have limited opportunities to interact with managers, leaders, etc. across NIST and/or to influence directly the decisions and actions of NIST leaders. There is a perceived lack of trust on the part of the leadership. Greater flexibility and openness to "bottom-to-top" projects (rather that "top-down") would provide more 
opportunities for employees to demonstrate their leadership capabilities. As stated previously, my career benefited greatly from informal access to managers, fellows, etc. across NIST.

- I can't answer this question, because it's not clear what the requirements for advancement are. While there are stated criteria, they do not appear to be applied objectively.

- External to NIST mentoring.

- More 6 month to 1 year detail opportunities so staff can see where they can thrive within the organization.

- I believe I have taken a sufficient amount of professional development courses. It would be nice if more people in leadership took these courses. Unfortunately, there are numerous personnel in positions of leadership that aren't great leaders. My observation is that they are selected to be leaders because they do great technical work. Being an outstanding technical contributor does not automatically make someone an outstanding leader. Unfortunately, this is part of NIST's culture - existing leadership does not do a good job of identifying and cultivating outstanding leadership talent. We say we do, yet when it comes time for promotion, technical success is more prized than leadership success.

- I suppose learning more about promotions, since I don't seem to know anything about that from my first 9 months here

- Project leadership. I was volun'told' to be a project leader and was given no training. After 6 months I said that I didn't want to do it next year and I'm not. I know I'm not management material so why put me in that situation.

- I have taken advantage of many of these kinds of programs. Frankly, if you are asking what else I need to learn to be qualified for promotion, you have lost sight of the point of this study. I have many of the skills, in many cases more than my male peers, but have been systematically discriminated against for my entire career.

- Understanding local politics for promotions and securing a permanent position.

- Continuing leadership courses are always helpful

- Short term sabbatical opportunities at other institutions.

- Presentation skills, Research writing, Publishing

- Training on how to work with industry, universities, and OAs on how to implement interactions and find funding opportunities.

- More assistance in understanding the hiring and review process. There needs to be a better translation between the HR language and the experiences I have in managing my employees.

- Training on how to attract outside research. Training on how to find out the "state of the art" in industry, and how to better find research areas that will have a high impact.

- Management, not only of science projects, but programs and S\&T operations. 
- More on how to foster good employee development. It's so easy to get pulled into the day to day grind, and at least in my experience NIST has never really placed an importance on the organization developing its people (i.e. making that a prime role of the managers) rather it takes a very stereotypical scientific approach of individual driven achievement

- Detail opportunities

- More projects.

- Attending conferences and trainings are helpful.

- Leadership training

- Please repeat the leadership for all (L4A) courses. There was great interest in these classes and I wasn't able to register for all of them (they were filled months in advance). I thought they were very useful. Also, it would be helpful to have more opportunities to be "technical project leaders" to gain experience directing others (students, Postdocs, co-workers, etc.).

- I feel like there are professional development opportunities available already.

- Management Training Opportunities

- The first thing that occurs to me is that I'd like to learn how to optimize group work. (If I'm running a group -- not necessarily as a formal supervisor, just as a temporary leader - what's the best way to optimize the process so that I get the best Band of work from everyone?) NIST may already have offered something like this (I've been busy with research these days and haven't caught all the announcements.)

- Potential career paths, opportunities. What else is at NIST type opportunities.

- Tips on time management, as well as strategies to learn how to work towards a promotion.

- I would be interested in more guidance on how to be a more effective self-promoter without being a "shameless self-promoter."

- Program management

- Leadership courses are incredibly important to me. I like chance to both learn more about my own leadership style but also how to best adapt my style to lead others. I also feel that it is important to be aware of our unconscious biases. These affect our work styles much more than we realize, in my opinion.

- Individualized Development Plans where you set out what is needed to get promoted early on.

- More on-site COR (contracting officer's representative) and professional project management courses.

- More courses to help navigate the bureaucracy. Based on my experience, it seems like we have a large number of tools and mechanisms (e.g., recruitment, retention, conflict resolution, etc.) that we simply don't know about or know how to access.

- Writing and communication training project management 
- Ability to get an advanced degree while still on the job.

- The opportunity to actually, formally supervise staff, not just empty encouragement/promises (I have had this going on for 6 years now).

- Leadership skills, project/team management.

- Opportunities for details on NIST satellite locations, funding outside of the group budget for NIST institutional health activities

- Budget, budget, budget!!! The overall process, different types of funding, how they are leveraged, how to use them, responsibilities that come with managing different types of funding, etc. This is a total mystery to many new supervisors who are never taught about the funding opportunities at NIST or how to manage funds from year to year, etc. Yes, we have AOs and SMAs but they are also sometimes new or do not now of the options other than those they have experience with. As so many organizations are budget-challenged, NIST should address the budget education needs and get everyone to a baseline with knowledge and capabilities, so they can be more fiscally aware.

- Communication skills and organizational skills

- I feel that I have been given every opportunity to develop or advance that was appropriate, some of which were suggested to me and some of which I pursued.

- Clarity on the pathway from the NRC postdoc program through the term system would be useful.

- How about a training class for supervisors and upper management that teaches them you can't hire people in leadership roles that don't know how to do the work of the people they are supervising. For example, you can't have an individual who has a business degree, or is an electrician, or an automotive mechanic supervising a group of civil, structural, mechanical, and electrical engineers. And the same is true going the other way. You can't have an engineer supervising a group of accountants, or electricians, or automotive mechanics. Yet that is exactly what they try here and wonder why the new supervisor is failing.

- Trying to bridge the generational divides

- Perhaps knowing other avenues within NIST that I can pursue, but I don't what those are because they are not advertised.

- Presentations on options for detail assignments; seminars on expectations / criteria for promotion.

- Courses focused on project leadership, which should include budgeting, planning, team building, etc. It is surprising that people can be project leaders without any training just because they may not have supervisory authority.

- Understanding fed. govt budget/money/grant management

- Recognizing and addressing bias that results in reduced workplace diversity.

- Class to understand what is required to receive a promotion, not just a yearly raise.

- Program manager ("hands on") 
- Ongoing/refresher leadership training type classes. Like: Creating, working with, directing diverse teams and groups; Managing conflict; Dealing with your management; Negotiation training; etc.

- Soft skills like communication, tough conversations, etc. are always needed. Refreshers are good too. Once you have had some on the job experience in using these skills, you can potentially gain more from taking a class again (or a more advanced class). Continued education for supervisors and managers might be good. Maybe several classes to choose from? required to take only one every couple years?

- Additional training that is appropriate to the new focus of my shifting job responsibilities, which are very different than my formal (college) training prepared me to do.

- Things that help to build connections across the different Laboratories at NIST

- Mentorship -- the system you have now is not even close to covering those who need it.

- A "future faculty development" opportunity for postdocs would be very helpful.

- I will have to think about this more deeply. Most are along leadership/management track. In reality there are only so many management positions open, so this is disingenuous. Professional stagnation in mid-career is common, and it might be valuable to consider what kinds of opportunities and retraining might be available for people in these positions.

- Courses that highlight what roles NIST needs for its employees to fulfill beyond bench scientist and group leader

- Ones tailored for earlier career employees. It's hard to understand what will be applicable, particularly when there are no immediate openings for promotion.

- While I have taken many development activities/courses, one can always learn! But I don't have a specific recommendation as to what content, probably a wide range of options to choose from would be best

- I don't know that many that's available. But the only program that's available requires nomination, and I tried 10 years, never get nominated/selected. There are times I'm not even sure if my name got submitted, after talking to my management group.

- Effective communication and presentation skills

- It really is not necessarily about taking classes it is about management be fair and honest and communicating what the staff person can do to be promoted.

- Detail at another agency

- Emotional intelligence. Anything dealing with soft skills in general. No one gets hired here that does not possess the "hard" skills, but the most difficult challenges faced by everyone is peer-to-peer skills.

- I tried to take the NIST leadership training program several times after it was advertised NIST wide, only to be told that I wasn't allowed to because they had other people in 
mind for those slots. It should be made more clear how to formally apply to that program and the criteria for selection published.

- Understanding budgeting, leadership and conflict resolution

- I am a learner. So, I welcome any professional development opportunity. I have couple of certification and would like to maintain them.

- I've had the chance to take a number of professional development classes through FLP. Outside of FLP, there seem to be a lot of opportunities for free professional development classes offered by NIST.

- Patent application process.

- None. I am full time technical person. I am not interested in any professional development activity.

- A professional leadership training opportunity from leading institutions such as Harvard Business School or others will be helpful.

- Working with different cultures, working with difficult people, conflict resolution, personality recognition and working with different personalities, team building (it takes different types of people to make an effective team and how to work with them)

- Opportunities that broaden inclusivity for people involved in cross-lab, cross-campus efforts.

- I really enjoyed the FLP and am happy those courses are now available through Leadership 4 All but I'm not sure who takes those courses since they may not feel the need or the permission to take them. For advancing my career, other opportunities that might be helpful: understanding all of the avenues of working with outside people (like CRADA, Interagency Agreement, etc.).

- PMLP, taking it now

- Continued technical training courses

- Budget and regulations introductions

- I had good mentors, who were project leaders on projects that needed my skills, and who took me under their wings and showed me opportunities.

- Entrepreneurship

- Opportunities to learn about how to gain experience outside of NIST via details and how to identify those opportunities.

- Project Management Supervisory-related training Management of personnel/staff

- I'm not interested in professional development. I'm 58 years old. I want this job to be fulfilling for the limited time I'll still be here. If I were doing to develop into something, I would have done it by now.

- Courses on "leadership" versus "management."

- The last thing needed are more courses 
- I strongly believe leadership skills cannot be taught in a course. Rather, leadership suitability is function of personality and people skills. Most of our "leaders" have taken extensive courses and are horrible leaders.

- How to manage independent-mind technical staff.

- None - not planning on moving up to ZP V position.

- Informational sessions on requirements and expectations for promotion to the various levels that include the limits there may be on the number of possible promotions.

- Currently seeking professional leadership opportunities outside of NIST.

- Since most of our division (in PML), the culture is for them to focus on the lab work and not "waste" time with other training opportunities. I would like to take advantage of the existing courses but can't justify it.

- I really don't know. I would think the appropriate courses depend on the duties but I'm not well-informed about what the responsibilities are of a group leader, for instance.

- More courses that assist with general metrology, statistics and other general technical skills.

- Project management, more training in how to manage a team

- Helpful: detail opportunities; small grants/research awards. General comment: NIST is a flat organization. Once you have been promoted past ZP-III there is very little in the way of showing to the outside world that your career is moving forward and not stuck in neutral. Your title doesn't change, selection for supervisory positions (group leader level) often happen without open calls, and opportunities for recognition are limited. In particular this is problem for those who fall in the 'influencer' category i.e. people without a formal title who wield an unseen influence by being active in the NIST community. While other agencies will often reward such employees with small awards at the OU or division level that is not the case at NIST.

- Managing research units (as opposed to administrative units), Contractor/associates management

- Leading others without direct authority. Budgets for non-supervisory people. Alternate career paths to SES/ST (meaning for those of us who don't have the group leader/division chief/ OU director trajectory within a laboratory program).

- Communication skills

- Budget

- How to negotiate; how to represent your accomplishments; how to establish clear expectations with your supervisor

- I am interested in a detail to another part of DOC in the future.

- A series of summarized what basic admin systems are needed for what processes. Also, the whole contracting process is a mystery, mostly depending on which $\mathrm{CO}$ one works with... 
- A course on the specifics of research funding mechanisms, processes, and responsibilities would be helpful.

- Attending the leadership classes would be helpful (either future leaders or new leaders) but there need to be more opportunities.

- As far as I understand, completing professional development courses or opportunities do not necessarily contribute to any consideration for promotion.

- More opportunities to lead research projects that involve leading/managing other people.

- Technical courses

- All of them

- Project management training and budgeting.

- Possibly time management, project management, communication skills, etc. I think some of these are available but it does not always seem strongly encouraged to take time away from research to attend such training opportunities. FYI - I am not a "career federal employee" since I have a temporary appointment, and have tried to best answer the questions regarding my status though it is not permanent and does not fit some of the answers.

- Mentoring, skills for promotions, how to find about opportunities

- Don't know - I am comfortable in my career and my level. ST's and Fellows ought to be for the select few Now just looking for new and interesting research directions

- I am quite senior and should give back at this point.

- Mentorship seminar or similar

- Detail assignments, mentoring, a clear statement on what continuing education I can have financially supported.

- understanding federal regulations, change management, leading \& working across generations, multi-cultural sensitivity/norms

- Stretch assignments to help you prepare for the next Band

- Training about process of moving from term NIST appointment to career conditional, to career appointment (including negotiations); time management skills; project management skills

- Resiliency, Keeping a positive attitude in tough situations, etc.

- The opportunities for "detail" should be centrally managed by HR - this would eliminate a supervisor from denying an employee an opportunity, and would routinely publish detail opportunities for all staff to apply for. Putting the standard federal career planning template into a system, or allowing employees to optionally input career path desires into a system would allow HR to review the data, and help establish "detail" opportunities to match.

- Interaction with the public

- Understanding the Fellows process 
- Michelle Obama in her autobiography Becoming said that "Sameness breeds more sameness". Unless we intentionally create training opportunities for minorities and females so that they can be ready to assume leadership roles, diversity will be an empty slogan and promotion will still be tilted towards those who assume leadership positions in the same sameness.

- A way to network with colleagues across OUs/divisions/groups, Organizational knowledge of NIST

- Leadership course

- Don't need any other offerings at the moment, but I find the mentoring experiences incredibly valuable especially going into them with concrete development goals.

- I think it would be helpful for a supervisor to provide some guidance of what short term (6months to a year) milestones are important in career development and how they fit with my career goals. I find it very difficult to see how my performance plan can possibly align in any way with the promotion guidelines and as a result see no path to progress to a promotion.

- Formal career progression planning, within the NIST context, and how to get there. Mentorship helps, but is too little. While professional development isn't discouraged, neither is it encouraged in measurable, nor transparent, ways.

- I think they have good offerings. I just have not had the opportunity to take advantage of any of the courses.

- Skills building

- Budget awareness

- More opportunities for leadership in committee work, and more support for mentoring opportunities.

- Mentoring employees

- Formal Project planning monitoring Anything related to conflict management the entire NIST technical staff should have required statistical skills competency a NIST course on NIST's role in the world's standards organizations (i.e. ISO, BIPM etc.) this is largely self-learned. We don't have a course or really any materials on the real purpose of NIST and our relation to commerce. Most people here think they're at NIST to do their own research Training for SES

- Mentoring - this is already in place and I'm enrolled in it.

- How to toot one's own horn, how to right a CV or award nomination

- The ones that have been useful were: technical meetings, offsite teaching metrology to graduate students, international presentations.

- Not necessarily professional development, but certainly more supervisory opportunities for staff would be good. If the criteria for promotion is supervisory experience, but there are no opportunities to develop/gain such supervisory experience, then how can one every hope to get promoted within the organization? 
- How to delegate responsibilities and how to organize staff

- 1) How to understand and avoid institutional racism / bias. 2) Less focus on winning "Nobel Prizes"

- Outside of the bench scientist role

- Retiring soon.

- Semi-regular courses to outline promotion process and requirements.

- _Anything_that assumed you arrived with some prior knowledge (rather than always starting assuming you know nothing), with a preference for opportunities to practice improving communication and de-escalating conflict.

- Rotational assignments/details across operating units

- Probably would be good to know what the formal criteria are for promotion. Possibly "project leader" as a formal role might be helpful for someone below Group Leader.

- I'm not sure.

- When I was promoted to a supervisory role, I was given no training on the basics of what is expected of me in this role. I now have direct reports asking me, as their supervisor, questions that I also do not know the answer to, but also don't even know who to ask. The lack of local human resource managers in the Boulder campus also makes even finding the correct person to ask challenging.

- Effective mentoring

- How to get a promotion, improve annual performance reviews, identify research/collaboration opportunities

- Understanding rules for disciplining poor performance and poor conduct.

- Those required by CFR Title 5 Subpart C

- Periodic short duration leadership opportunities. There seem to be many tasks that Group Leaders are expected to take on (funding tracking and allocation, hiring, wrangling with other Group Leaders for staff support or funding, time card management, what information can be shared) that they seem thrown into. Giving other staff the opportunity to see these and attempt them would lower the learning curve.

- Free access to online education resources such the Coursera

- Actual detail assignment to serve in a supervisory authority; my lack of specific on-thejob experience is an issue for looking at future jobs.

*35 respondents said Don't Know, NA, Not Sure, Retiring, or none needed; and these responses were not included in the list. 


\section{Report 7: Open-Ended Comments Regarding Promotion on NIST Survey ${ }^{48}$}

The survey of NIST ZP employees that was administered in March 2020 solicited openended comments regarding the promotion process, and 263 employees responded. Women were more likely than men and those in Bands IV and V were more likely than those in Band III to provide a type of comment. There was also a tendency for fewer responses from those in OU$\mathrm{D}$ and OU-F and for the youngest and oldest respondents. (Table 1)

In July and August of 2020 three COACh-team members systematically examined these comments. After extensive consultation and discussion, they classified the responses into 7 categories: 1) communication/transparency, 2) accountability/management, 3) morale or culture, 4) hiring, 5) retention, 6) organizational structure, and 7) other or not applicable. Because respondents often remarked on multiple aspects comments could be coded in more than one category. Each of the coders independently examined and classified two-thirds of the comments. As a result, each comment was coded by two people. After independently coding each comment, the members of each coding pair met and resolved any differences in coding that might have appeared.

A little more than a third of the comments were classified as communication or transparency and another third as accountability or management. Next most common was organizational structure, followed by morale or culture. (See Table 2 below.) About $10 \%$ of the comments were in both communications and accountability/ management, but that was the only pairing with substantial overlap.

The association of individuals' characteristics with the type of comments given was then examined. There were no differences by gender, identification as URM, or OU in the types of expressed concerns. There were a few associations with pay band, age, and discipline, but these associations were not overly strong. Those at Band IV were more likely to have comments classified as involving accountability and management, and the youngest employees were least likely to give such comments. Middle-aged employees were most likely to give comments classified as involving organizational structure, and these comments were also more often given by chemists and those in the disciplines classified as "other."

In general, these patterns appear to confirm conclusions from other analyses that the concerns regarding promotion are widespread throughout NIST and not confined to certain subgroups.

\footnotetext{
${ }^{48}$ The comments were coded by C. Rohlfing, J. Tucker, and J. Stockard. Stockard conducted the quantitative analyses. The report was finished September 14, 2020.
} 


\section{Tables}

Table 1

Percentage of Respondents Giving Comments by

Demographic Variables

\begin{tabular}{|c|c|c|}
\hline$\underline{\text { Variables }}$ & $\underline{\%}$ & Chi-Square \\
\hline \multicolumn{3}{|l|}{ Gender } \\
\hline Women & 50.7 & \\
\hline Men & 38.5 & $8.23 * *$ \\
\hline \multicolumn{3}{|l|}{ Minority Status } \\
\hline Not URM & 42.6 & 0.48 \\
\hline URM & 48.6 & \\
\hline \multicolumn{3}{|l|}{ Band } \\
\hline III & 36.2 & $8.68^{*}$ \\
\hline IV & 47.3 & \\
\hline V & 44.7 & \\
\hline ST & 22.7 & \\
\hline \multicolumn{3}{|l|}{ Operating Unit } \\
\hline OU-A & 54.4 & $10.70^{\mathrm{a}}$ \\
\hline OU-B & 44.8 & \\
\hline $\mathrm{OU}-\mathrm{C}$ & 45.4 & \\
\hline OU-D & 30.8 & \\
\hline OU-E & 43.5 & \\
\hline OU-F & 23.1 & \\
\hline OU-G & 42.9 & \\
\hline \multicolumn{3}{|l|}{ Discipline } \\
\hline Chemistry & 44.4 & 0.32 \\
\hline Engineering & 41.1 & \\
\hline Physics & 42.5 & \\
\hline Other & 42.9 & \\
\hline \multicolumn{3}{|l|}{ Age } \\
\hline $25-34$ & 32.6 & $7.85^{\mathrm{a}}$ \\
\hline $35-44$ & 46.1 & \\
\hline $45-54$ & 46.9 & \\
\hline $55-64$ & 41.2 & \\
\hline 65 and older & 31.4 & \\
\hline Total & 42.7 & \\
\hline
\end{tabular}

Note: ${ }^{* * *}=p<.001,{ }^{* *}=p<.01,{ }^{*}=p<.05, a=p<.10$ 
Table 2

Distribution of Comments Among the Coding Categories

\begin{tabular}{ll}
\hline Category & $\frac{\% \text { of }}{\text { total }}$ \\
\hline Communication/Transparency & 0.36 \\
Accountability/Management & 0.36 \\
Morale/Culture & 0.12 \\
Hiring & 0.03 \\
Retention & 0.04 \\
Organizational Structure & 0.20
\end{tabular}

Table 3

Cross-Tabulations of Comments with Demographic Variables (\% Mentioned)

\begin{tabular}{|c|c|c|c|c|c|c|}
\hline \multicolumn{7}{|c|}{ Accountability and Management } \\
\hline Band & $\underline{\text { III }}$ & $\underline{\text { IV }}$ & $\underline{\mathrm{V}}$ & $\underline{\mathrm{ST}}$ & & Chi-Sq \\
\hline Percent & 22 & 43 & 33 & 40 & & $7.19, p=.07$ \\
\hline Age & $\underline{25-34}$ & $\underline{35-44}$ & $\underline{45-54}$ & $\underline{55-64}$ & ge 65 & $\frac{\text { Chi-Sq }}{11.11, p=}$ \\
\hline Percent & 10 & 37 & 39 & 39 & 55 & .03 \\
\hline \multicolumn{7}{|c|}{ Organizational Structure } \\
\hline Discipline & Chemistry & Engineering & Physics & Other & & Chi-Sq \\
\hline Percent & 27 & 13 & 15 & 26 & & $6.25, p=.10$ \\
\hline Age & $\underline{25-34}$ & $\underline{35-44}$ & $\underline{45-54}$ & $\underline{55-64}$ & ge 65 & Chi-Sq \\
\hline Percent & 13 & 16 & 32 & 19 & 9 & $8.96, p=.06$ \\
\hline
\end{tabular}

Note: The \%'s refer to the percentage of respondents within a category that gave a comment classified in a given manner. For instance, $22 \%$ of those in Band III gave a comment classified as regarding accountability and management. Those who did not give a comment were not included in the analysis. There were no significant associations with comments classified as involving communication or morale/culture. Analyses were not done with categories of hiring and retention because of small $n$. 


\section{Appendix: Open-Ended Comments Regarding Promotion Process, Policy, and Experiences}

The comments below were given in response to this question: "Please feel free to add any other comments or information that you believe will help COACh understanding more about promotion processes at NIST." They have been edited to remove elements that might be linked to an individual.

- I have only been at NIST just over a year, and have never gone through the promotion process myself. I am using "don't know" for Not applicable. Finding support for improving my leadership in keeping with my own encouraging, nurturing style has been difficult. As a ..., I have been involved in many promotion discussions..., and I believe the process is fair and that those involved in the process are actively trying to rectify past "wrongs." Whether or not someone is put up for promotion is a different situation, more difficult to make uniform. I believe it is important to announce the people who have been promoted and to celebrate them....

- Hard to know if ZP4, and ZP5 bands are awarded fairly because, with only a few exceptions, I don't know who is a ZP4 or ZP5

- Personally, I've had a positive experience with the promotion process. However, talking with colleagues I've found that my experience is exceptional and have yet to find anyone who has had a similar experience. I credit this to my direct management, a bit of luck, and my being forward with my management about my goals over the course of many years.

- The process seems to strongly relay on whether a) the management up the chain favors you or your supervisor, and b) you have a strong mentor who advocates on your behalf. The promotion process does not seem to be objective and based on accomplishments and contributions of a person. The whole process is also strongly biased against NIST associates. There is evidence that there is bias against women.

- The original so-called "study" was extremely flawed. Didn't meet any scientific standards. Those involved in doing the study and those in the program office clearly don't recognize this.... I would hope the hired outsiders will point this out quickly at the start. If they don't analyze the initial so-called "study" in detail there is no hope for a valid study. The initial study started with a clear bias in that they set out to PROVE there was a bias. And of course, they did "prove" it. Not scientifically of course.

- Criteria for promotion from ZP4 to 5 are not clearly defined. In my personal experience, senior management does not always correctly recognize relative contributions of specific individuals in team projects, which would be a problem when applied to promotions.

- NIST promotion process is run by fundamental scientists rewarding other fundamental scientists doing fundamental research. The promotion process reflects this fundamental 
bias because scientists are in charge. It is sort of like a university without any students. Unfortunately, NIST does have a mission and that mission is not to develop candidates for the National Academy of Sciences, or Engineering. NIST's mission is to solve critical problems for the US Public. It would be nice if the promotion process reflected the NIST mission more and daycare for scientists less.

- I've had both positive and negative experiences with the promotion process at NIST.

- I feel that my experience doesn't reflect the typical process....

- There is in general a lack of communication when people are taking on new roles in the organization. This could be a new role reflected in their recent promotion or as assigned. It is a weakness in the organization as those who need to know in order to keep things running smoothly in their operations, don't always know when new roles/people are assigned/reassigned.

- I've heard (seen statistics) there is a gender bias in the promotion process at NIST.

- There is too much mystery about promotion, especially to ZP-V, ST and Fellows.

- Differences in individual responsibilities make it difficult to give clear guidance on what is needed to be promoted. In my experience, it was a constantly moving target.

- My laboratory publishes its guidelines for each band. However, it still feels like a combination of a black-box and a back-room political process. In addition, many of the junior folks I know, myself included, have been told directly or received the implication that they're expected to work "above their pay band" for at least a couple of years to prove that they deserve promotion to said band.

- Information about promotions is purely word of mouth between staff peers of similar ages/time at NIST.

- I believe there are objective criteria for promotions at NIST. But there are also subjective factors that come into play - when someone is promoted, it increases the salary cost and that has to be on manager's minds. There is a sense of needing to prevent "inflation" in our operating costs. Another subjective factor that can come in is how well the person being considered for promotion is at getting along with other people. This is hard to measure but has a strong influence on whether their supervisor wants to promote them and whether the rest of the supervisors agree to the promotion. In my opinion, this is a reasonable criteria but hard to quantify.

- This is not something I spend any time worrying or thinking about. I am paid well enough to do work I enjoy. Climbing ladders doesn't interest me.

- Promotions are not applied uniformly; some staff are promoted much earlier than others for reasons other than performance. Promotions also appear to be applied in an inconsistent way across NIST. This leads to a poor perception of the system.

- If promotions require input, assessment, and decisions from division chief or higher, then once a candidate is close to being considered for a promotion, direct feedback (written or otherwise, but not filtered through a group leader). It would be helpful for 
the candidate to understand what their strengths and weaknesses are specific to the promotion from all decision making persons. Second, it should be mandated or enforced that OU budget should not be considered at all in the promotion. If they are, then the candidate MUST be informed, so the candidate can make the decision to leave or stay at that OU.

- The promotion process at NIST is opaque and highly subjective. It lacks a defined and clear set of criteria by which an employee can be evaluated. In the past decade, the promotion criteria are continuously changing. First, it was related to the number of publications. Now it depends on how many people are aware of your research at NIST and outside NIST. The "said" expectation is that an employee must produce world-class research to be promoted, but due to the highly subjective nature of this, I am aware of a few exceptions to this rule. Overall, I am not satisfied with the promotion process at NIST. Lack of transparency and clear guidelines is not a morale booster. It makes NIST a less attractive place to work.

- All jobs in my unit are posted on USA Jobs and open to applicants outside of NIST. To attract the best talent independent of current position the focus should be on the quality of the hiring process and career development not promotion of internal staff.

- There has been no effort by my division or OU to present any of this information ever.

- Promotions are unevenly applied, not by EEO category but by clique. Promotions are not evenly applied across NIST for the same job classification and function (supervisor status). It is common for an employee to need to leave NIST or transfer to a different division in order to be promoted. Staff from the outside are hired in to NIST at IV and V bands with less qualifications than existing staff at Band III and IV respectively. ZP promotions are based extremely heavily on publication factor and number of publications rather than the impact of the work. Promotions are not based on the difficulty of the work but rather on the number of publications. Promotions are not based on teamwork or organizational success, i.e., employees' promotion ability is not increased by helping others succeed or the organization succeed. The fastest path to success is to publish as many peer reviewed journal articles as possible with disregard for colleagues and institutional health. Opportunities are not available to all, success is heavily biased to those that have the opportunity to work with project continuity so that a volume of literature can be published, conferences can be attended, and a national and international reputation can be developed in a technical area. These opportunities are not evenly applied.

- The promotion process is not clearly explained anywhere. The only chances to discuss are during the mid-year review and end-of-year review with the supervisor. Individual contribution and actual effort are not often recognized. Project leader or outspoken members tend to get more recognition while actual work was conducted by project members or associates. First author journal paper should be given higher recognition during evaluation. 
- Promotion criteria from a III to a IV and from a IV to a V are a moving target. Management will not exactly say what the criteria are. [details given of difficult processes].... So, in summary, I had to put up a fight for any promotion I received while at NIST.

- Promotions to the upper bands (ZP5, Senior Researcher, and NIST Fellow) are not clear to me.

- The promotion process took $\sim 1$ year from the time I was informed till when it actually happened.

- It seems like the promotion process is often based on how much money you bring in. It is also based a lot on other people, so if you have a lot of $\mathrm{Vs}$ in your division who are just hanging around and not retiring or moving on, you won't get promoted to $\mathrm{V}$ because there are already too many. Also happens going from III to IV, to some extent.

- For many young employees, the NIST definition of promotion is not in alignment with their own personal views. For example, people who are temporary staff (Postdoc, term, visiting-researcher) they would consider conversion from temporary to permanent as a "promotion". This is not a promotion in the absolute strict definition sense, but it is for all practical purposes to this set of people. One of the biggest issues regarding equity is the uneven application of criteria for conversion to permanent staff.

- Honestly, I feel that the promotion process is ambiguous because there isn't a formal process if your position did not have promotion potential. I am currently a .... have not heard of any situation where a person was "promoted" because their management felt they were doing Band 5 work, as a Band 4 employee. That's why I say that it's fairly ambiguous. Lastly - there are also many examples of staff being promoted to Band 5 supervisory positions for the reason that they have "put in the time" and are "capped out". That is not a reason for promotion. I've seen individuals better suited for ST or SL positions versus SES, some that shouldn't be leading groups but are doing so because they are capped out. It has not left me with much confidence in promotion for abilities versus salary caps.

- I've only been at .... for 8 months, so my knowledge of promotion is very minimal.

- I am mainly only aware of the promotion criteria and process within my OU, not other NIST OUs.

- I have not been provided any information about how to best promote from a temporary postdoc position to a full-time staff position.

- I am fairly new to NIST as a 2-year term NRC Postdoc. From what I've heard, is that Postdoc retention is very low, thereby making promotions an irrelevant topic. I have also heard that retention is extremely variable, no matter how good of a scientist you are. This definitely makes morale low. 
- Promotion opportunity of junior scientists is very limited by senior personnel far past retirement age due to finite NIST budget. Increasingly term employees are transitioned to associate status through third parties to reduce costs.

- The criteria for promotion from III to IV are not clearly communicated. There are OUspecific guidelines posted on the website for promotion criteria; however, the promotion process is dependent upon the group leader and division leader approval. The group leader must be an advocate for the staff in order for the promotion to occur. If the group leader is not advocating in an effective manner on the behalf of the staff, the promotion will not occur, even if the staff meets all listed criteria for promotion. Although there are documents stating recommended criteria for promotion, the promotion process is biased because it is solely based on the group leader advocating for the staff.

- Promotion criteria are sometimes not applied uniformly across NIST Operating Units

- I believe OU's should reevaluate the promotional potential of ZP appointments in the Office of the Director. There are limited opportunities for promotion among the SES track. Individuals in these roles are generally white men. I see no women of color in ZP track management roles at NIST. Additionally, I recommend OU's evolve from the past mindset of when/how "promotions" are determined. My understanding is staff have the option to negotiate salaries for promotions and my OU did not present this option. Instead, you start at the bottom of the pay band resulting in years of progressing to the next band. This could potential lead to the employee leaving the agency because of the slow movement through the band.

- NIST management makes arbitrary decisions about promotions. I feel completely left out of the process. NIST does not communicate goals for success or make reasonable/fair evaluations of success. NIST is not an environment in which success is rewarded or even desired, in some cases.

- Promotions strongly depend on the Group Leader. Some help their staff fairly. Others use the promotion process as revenge on staff they take personal dislike to.

- The leap from IV-V is really vague

- Band V promotions are not handled uniformly, at least over a period of time. The requirements seemingly change every few years. It's also very dependent on your management. I lucked out both in my timing and in having a strong advocate. But I see people now who are better than me who aren't even being put up for promotion.

- Leaving the III to IV promotion at the Division-level leads uneven application of promotion criteria across Division and within Division. This promotion is the least transparent of all promotions, yet is the most important to most careers and the most common promotion.

- Our lab director treats everyone as children. If you do as ... wants, perhaps you can become a favorite, and you might advance in various ways. If you don't, [the director] 
will find ways to make your life stay at NIST unrewarding....I see the problem more related to [the] approach and cannot see any viable solutions to this problem.

- In my experience, promotion at NIST strongly depends on one's immediate group leader. If the group leader is unbiased with respect to research interests, education level , gender, race, etc. there are (in my Division at least), few institutional barriers to promotion. The fact that I .... and have been promoted to .... serves as a testament. However, my journey ... took ... years to accomplish, not for lack of publications, talks, NIST reports of analysis or technical skill. Rather, the largest barrier to promotion I experienced was not being provided with the appropriate opportunities (team and project leadership, cutting edge research and international roles) required for ... promotion. I have had [multiple].... Group Leaders and ... Division chiefs in my career. Of the ... GLs, only one was unbiased ... and allowed me these needed activities. Group leaders have an enormous amount on their plates. All too often interaction with their group members suffers as a result of too much to do and too little time. The largest improvements in the promotion process at NIST can be realized by focusing on Group Leaders training with respect to impartiality and equity and rebalancing their work load to provide time for greater group member interaction and career advancement.

- The process is strongly influenced by the supervisor's view of what is worthy work for promotion. Different supervisors may come to different conclusions about the same person and body of work, depending on where they see the 'bar' for advancing.

- Although I've been compensated more than fairly in recent years at NIST, I do not foresee it ever leading to a band promotion. I understood your questions to be asking about band promotions, so I kept my answers at that level. Honestly, in my time here, I have not known anyone at a ZP-III or higher who has received a band promotion.

- Your question on "Other employees at NIST who I know have had positive experiences with the NIST promotion process." is poorly designed. Taken literally if I know some people who have had positive experiences I should answer "agree" or better even if I know other people who have had very bad experiences. You should have at least asked the corresponding bad experience question directly.

- The promotion from ZP IV to V is not consistent with the NIST merit-based culture, the primary factor enabling the successful execution of the NIST mission. That culture encourages and breeds staff to be the "best in the world" at their craft, which requires one to assemble a body of work that merits objective arguments of the achievement. The so-called objective bar for this requirement has been a moving target, with priorities shifting from publication impact to contributing to financial health to taking on management roles to standards development activities and so on. One can achieve all of these requirements over their career, but if they fall short in whatever the requirement is the present priority, they will fall short of the promotion. In short, if your career is out of phase with the promotion criteria priority of the day, don't expect a promotion. 
- There has been little communication in the past about promotions. I only have my own experience to go by and I was topped out as.... before promotion was even mentioned by my supervisor. It then took at least another year before the promotion went through. There were never a candid conversation with my supervisor, just that ... will try and see what ... can do but the process was never explained as to how a promotion worked. I unfortunately did not force the conversation either, just took the news at face value until one day was told, you got a promotion. And I still feel NIST does not value staff as much if they do not have a PhD, regardless of their experiences and abilities.

- I am a .... The promotion to ... was a horrible experience because [details omitted]..... The Group Leader is a pinch point and researchers have no recourse if their $G L$ is a roadblock to promotion. Plus, the criteria were a moving target taking years and years to fulfill.

- A holistic examination of the "promotions problem" is needed here since there are multiple root causes hidden in plain sight. For example, NIST's antiquated Alternative Personnel System was based on Jack Welch-era policies; these were abandoned long ago by the private sector (including GE) but were unfortunately codified into law for NIST. Also, the flawed re-org from ten years ago resulted in numerous projects falling under Division Chiefs who have no understanding of or engagement with them. Anecdotally, promotions were more frequent and more regular before the re-org than before. These and other core issues need to be addressed for a fair promotion system to result.

- It seems pretty random

- It looks as though each OU has their own set of requirements for promotion. People can be promoted from, let's say from III to IV, to avoid being capped at their salaries, while others classified as III in a different OU need to show a lot more accomplishments than those that were promoted without any specific accomplishments, just the promise. It all depends who your manager is, and if you are in "good terms" with him/her. People's biases play a big role in promotions, it is not necessarily subjective.

- The promotion process feels very subjective and can make colleagues of a similar band feel competitive with one another.

- I think the biggest problem at NIST is that there are more highly qualified employees than available ZP-V or ST positions. NIST has a lot of people who are capped at ZP-IV and ZP-V top bands and thus not eligible for any kind of performance-based raises. Being capped for multiple years has an effect on the morale and frustrations slowly build, especially if someone younger gets promoted to the next band.

- Criteria are not set in stone, if management wants to promote someone for any reason they will make it happen. A criteria I have been told is important I know 1 colleague never completed and another never even attempted but something else they did offsets 
that.... Historically writing papers is too heavily weighted and puts measurement staff at a disadvantage over research staff.

- I started at NIST in March of 2018.... In my experience promotion has not been addressed

- The process is highly dependent on one's supervisor. Some supervisors are very good at promoting their people while others do very little. In my case moving to a ..., I had to promote myself and put the package in front of my supervisor.... The point is that unless I pushed it I would have been a ... for much longer.

- ST/Fellow promotion "process" is a secretive good ol boy racket.

- There is a huge variation across NIST and much of the process depends on your direct supervisor.

- If the right people advocate for you it makes a difference. A promotion doesn't have anything to do with performance.

- My understanding of promotion from ZP IV to $V$ is that the person must be recognized as an expert (perhaps international) in their field. To become such an expert, you must focus and specialize - perhaps be selfish is your work. To the contrary, one who is selfless and responds to broad needs of the organization is placed at a disadvantage in this structure.

- I have no idea what the process is, nor the criteria for promotion to different bands. I know that I had been here long enough, and felt that I had enough to show for my work \& abilities, so I asked for a promotion \& it was granted. My only basis was the time frame and accomplishments of the career path of the person hired just before I was.

- My experience to date has been positive, but it is really not clear how I would move forward at this point in my career. Once capped, the issue is not discussed. Supervisors just indicate you are capped and appreciate the work I do, but no real discussions about where I can go from here.

- Since the promotion criteria is merit based, there is no requirement for time in a current band. This seems like it would benefit employees performing at higher bands. But my experience has been that I am told that I am doing everything right for a promotion and that it is a matter of time. So there is an unwritten rule that you have to be performing above your current Band for $x$ number of years. I was hired at a relatively low band but have received good reviews and reasonable salary increases. So I oscillate between being somewhat satisfied with my progression and upset that my work is being undervalued. I was advised (after the fact) that I missed a key opportunities to negotiate for a higher salary during my conversion from term to full.

- I haven't even been here a year yet, so it's hard to answer some of these questions.

- It's clear that most ZP employees are not aware how their performance is related to getting promoted. Frankly, even those who have been promoted to ZP-5 most often 
can't articulate to a ZP-4 what it takes to get there. I look forward to learning about the positive changes that arise from this worthwhile project. All the best!

- The criteria have changed dramatically over the last 20 years, although no one in management would admit it.

- The criteria for promotion from Band IV to $V$ and beyond is old, and does not distinguish between operational versus research positions. At times, it seems criterion is based more on management perception than fact.

- Standards for promotion are linked to writing papers and traditional researcher positions. People who are working with software or data are still required to check the box and write the same number of papers as coworkers. Industry experience is sometimes discounted even when it is obvious that the person does not have a large publication record because they brought significant industry experience to NIST.

- Not promotion related, but when being changed from term to permanent, I was fortunate that I was told that I could negotiate my salary. Unfortunately, I was going through this process at the same time as another individual with less time ( 2 vs. 4 years), progress, and experience as me and he was given a significantly larger pay increase and much more research freedom (we were in the same division but different groups, and these negotiations were at the division level).

- Leadership at NIST is trying to improve the transparency and consistency of the promotion process, but there are many growing pains. For instance, some Federal hires and promotion processes that I am aware of have potentially been influenced by nonsupervisory colleagues "looking out for" the person being hired or considered for promotion. In these outside influences, there may be known or unknown biases at play which disproportionately help certain groups of people more than others.

- I worked under a supervisor that refused to promote me from a ZP-III to a ZP-IV, for over 6 years even though everyone else in that position at NIST had a ZP-V. When I moved to a different organization at NIST, my immediate supervisor didn't understand why I didn't have my ZP-IV years ago and immediately promoted me.

- There is no consistency across NIST at all. People in some divisions have very relaxed promotional guidelines and moved up very quickly. I had great reviews every year but took $20+$ years for a promotion.

- It all depends on the manager. Last one was great, very supportive and in tune with needs and expectations. Current manager is belittling for everything, gives information out after it is needed, and clearly gives preferential treatment to buddies. I don't expect anything good.

- I really don't have any idea on the criteria for promotion. I don't pay attention either as I have been a ... since I got to NIST (seven years) and am just now getting to the thought process of becoming a ...V.

- I came to NIST topped out.... Criteria seemed to be almost arbitrary. 
- It also seems like a taboo topic.

- ZP employees lack clarity on the promotion process. Some operating units have guidelines online, but the employees sometimes don't know the information is available or don't truly understand what the guidelines are saying (up to different interpretations). I believe that we would benefit from having the opportunity of attending yearly seminars that detail (and update) the criteria for promotion at the different bands for ZP employees.

- The ST/SES status is a total mystery. How to even aim for it. In my Division/Group, we have to compete with the private sector for personnel with highly-sought skills, such as cyber security and $\mathrm{Al} / \mathrm{ML}$. Applying the same promotion criteria as for basic scientists does not always make sense, especially if trying to retain valuable staff.

- For 5 years I tried to understand what it would take to move from III to IV, I was a high performer and achieved all goals set for my performance. I was not promoted until I applied and received a supervisor position. The man I interviewed against at NIST was promoted to a IV after the interview so he would not lodge a complaint, even though he was a low performer.

- In my experience, the promotion process has been pretty opaque. Basically, the management team gets together and discusses who to promote, with little warning or feedback to the employees involved. And, as far as I could tell, my own promotion from III to IV was postponed for three years due to budgetary considerations (according to my group leader at the time). I was told that the division didn't have enough money to afford the larger salary that I would get as a IV, so I couldn't be promoted. As I recall, there was a three-year delay between my group leader first asking me for a packet to support my promotion and my actual promotion. In other words, more than anything else, promotions seem to depend on the zeal of your immediate boss and on financial considerations.

- Band or step promotions are mostly baked in early on in an individual's career based on personal relationships with his or her supervisor and other managers.

- The promotion process is strongly dependent upon who supports the person being promoted and who allows that person opportunities to gain the experience required for promotion. A lot of time experiences required for promotion are denied.

- Promotions and job changes (e.g., details) are not transparent. It is very difficult to know who is in which pay band, or even how many people within a group or division are in a given pay band. This is particularly true in the ZP-III to ZP-IV range. While ZP-V promotions are (at least sometimes) announced, the others are not. Thus, is it very difficult to know whether one is progressing comparably with peers or to have data for discussion if one isn't progressing comparably.

- I am not certain that this may apply to term appointments 
- The main problem among technical staff isn't promotion among federal employees, it's the decisions made about who is converted from a contractor to a federal employee, and who is converted from a temporary employee to a permanent.

- I have had to change research areas at the request of NIST managers. This has highly delayed or eliminated my potential to be promoted to a ZP5 because of the way the criteria are written (long standing career, reputation in the field, etc.)

- I have been capped for years, was told by a supervisor that "In 50 years, nobody will care about anything you do at NIST." That is the most hurtful and disrespectful thing a supervisor has ever said to me

- The promotion process is managed by the OU lab offices and is not something that staff in general are communicated to unless their direct supervisor is an advocate. It is mostly managed confidentially. That is both good and not so good, because it contributes to a general lack of trust that the network of management is open and fair.

- Our group has no technician, I spend a large amount of my time doing tasks a technician would normally do. I am not given enough time to do the things I know would advance my career, which makes learning more about how to get promoted a moot point. I have been telling management we need a technician for 10 years, and it has been made clear we won't be getting one. So, I feel like my choices are to look for another job or live with it.

- I really don't understand how to get to ST (Nobel Prize, maybe?). Almost everyone I know is at the same band they were when they were hired, be it 2 years ago or 30 years ago.

- The bottom line on promotions from ZP III to ZP IV is how hard your Group Leader is willing to fight for you. Some Group Leaders have personalities that are more inclined to be cheerleaders for their group members, while in other groups that is not the case. It is my opinion that this particular promotion has A LOT of inequities regardless of the fact that there are specific promotion criteria. If the employee that is seeking a promotion does not have a supportive Group Leader, I have seen this promotion take much longer for certain people. This has created a lot of resentment in certain Divisions at NIST. There is the perception that "it's not what you know" (or in this case what you've achieved), but how well your Group Leader likes you and is willing to make your case.

- As far as the commoners can tell, the promotion criteria for fellows are not even known to the promoters themselves. In other words, it strongly appears like they are made up to fit the desired outcome.

- The bar for promotion from ZP III to IV is not so high as to cause significant issues in getting promoted for a PhD researcher. Non-PhDs in a PhD-heavy OU can have a more difficult time. Not sure about in OUs that have lower \%s of PhDs. ZP IV-V promotions seem to have a much higher bar, even though the pay differential has decreased 
substantially in high locality pay areas like DC and Boulder. There are no set number of promotion slots for ZP III-IV or IV-V, but there are for promotion to Fellow / ST, which causes those promotions to be much more opaque.

- Supervisors keep talking about how they have been made aware of the situation about not promoting minorities and women and say they are working on it but nothing happens. Someone recently filed a complaint with the Equal Opportunity Office and they fought the person tooth and nail until they won.

- I am a supervisor and have taken part in discussions about promotion from III to IV and from IV to V.... While my OU publishes "stature documents," they are not sufficiently detailed to provide a clear picture of the criteria for promotion. The discussion invariably comes down to the classic "academic" measures: number of publications, number of citations, h-index, number of invited talks. I do not honestly believe that most NIST supervisors truly value other measures of success, such as extent and quality of stakeholder engagement. It appears, to me, to come down to each supervisor's perception of what constitutes "intelligence," and I believe that alone is what they feel needs to be addressed in a promotion discussion. Since most NIST supervisors got into those positions after serving for years as scientists, they seek numbers. Only. They seem largely unable to think beyond that. "Value" extends way beyond that, but I have been unable to convince anyone otherwise, with few exceptions. Another important factor in the IV to $\mathrm{V}$ process is that the decision appears to be made by comparing candidates, rather than by individual merits. A $\vee$ candidate could be successful in one year, yet fail in a different year, based solely on who the "competition" is. As a ...., I have never been told of any specific qualities of a staff member who is ready for a IV to V. I have largely developed my own for the III to IV. It is very frustrating.

- I think it is rather opaque and subjective. It is also my impression that it is distorted by pressure to retain talent, such that talent (or the perception thereof) - namely, the promise of success rather than accomplishment itself - often motivates promotions.

- The process is a closed box that is managed and controlled by the division and lab leadership. How the various parts that go into a promotion package are weighted is not disclosed. It's nuanced.

- Evaluation is entirely by your direct supervisor. I'm struggling with understanding what he is requiring. In 5 years, none of his people have been promoted but he fired ....

- NIST has made efforts in the last few years, and my Division even before that, to articulate what is required for promotion. However, an important aspect to consider is whether the management is really engaged in helping staff achieve promotion. I was shocked to learn that one of my colleagues is still a ZP-III, even though he's been running a significant facility for several years, as many of his co-workers have moved on to other things. Apparently, he has not been promoted because he doesn't have 1st author papers. Why? It's possible he has shirked the opportunities, but it's seems just 
as likely that management has not encouraged or given him the opportunity, possibly because he does not have a PhD. My own promotion experience has been mixed. I was asked by Division Chief to take part in an extracurricular activity. I was interested, but nervous how it would affect my progress. I told him that my group leader said I was working at a ZP-IV Band, but I just needed some another paper or two to get there. My Division Chief assured me that my participation in the extracurricular activity would count. Shortly, after that conversation, I was promoted. That was a pretty good experience. I asked and received. Many people at NIST think the promotion from ZP-IV to $\mathrm{ZP}-\mathrm{V}$ is a moving target. It's hard to untangle all the factors when considering if it is fairly applied. Many of us are high achieving people who are used to succeeding. The level of talent at NIST is quite high. It can be surprising for us to realize that talent and hard work will not guarantee promotion. This leads to frustration and difficulty in understanding what really separates one co-worker from another. This is how I feel about my current position as a .... I have a lot of people rooting for me to get promoted, and my managers have worked to improve my portfolio of activities. I appreciate these efforts. But, some days, it seems overwhelming for me to accomplish all the things required and then maintain that level of effort. Some days, I wonder if people who are currently ZP-V are really doing all the things that I being asked to do just to get there. I often feel it's futile to "try" to get to ZP-V, that it's better to just take pleasure in my work and get it done, and if promotion comes, great. I suppose this is one of way of saying the process seems nebulous and somewhat arbitrarily applied. Of course, there are definitely people who deserve it. It's just that there seems to be a significant middle ground where it's not clear why some people are or are not ZP-V. Circling back to the ZP-III I mentioned earlier, I have heard managers say recently that it's really important for staff to talk to their managers about promotion ambitions. Of course, I agree. But, it has been said in such a way, that it sounds like the responsibility is solely on the staff, that it's our fault if we haven't gotten promoted. If only we had talked to our managers, we would have been promoted! I resist this notion. I think it's crucial that managers are proactive in helping their staff along the promotion staff, especially ZP-IV to ZP-V. The Division Chief has to put the staff person up for promotion and defend them to all the other Division Chiefs at a closed meeting. They know the "unwritten things" that are needed to get promoted. So, they need to be involved in helping staff get those things on their resume. There has to be true partnership among staff and their managers to ensure that staff are getting the information and opportunities needed for promotion and a sense of trust that the effort is not wasted or the promotion unfairly applied.

- The promotion process from a Band 4 to 5 is not at all objective. The judges of the promotion are not at all familiar with the person's area of expertise, nor work product, and seem to place little value on leadership skills. The quote that I have heard is that good leadership is a "Band 4" skill. The skills I am referring to include pursuing key objectives for NIST like improving diversity and quality in work products through 
mentoring--which requires both strong technical as well as social skills. It is pathetic that NIST (or at least my lab) does not prioritize these contributions for promotion purposes. I hope this doesn't just sound like sour grapes, because it is sour grapes, but also true.

- The lack of "in-band" promotions is unfortunate for people that take on significant responsibilities if they are low in Band 4

- I do not have an opportunity to promote the careers of individuals at NIST as I work alone. However, I do feel that the mission and what is needed for promotion are well understood and spelled out.

- Seems like to become a fellow you have to threaten to go somewhere better.

- I had a very long delay between one promotion and the next because of criteria that were non-ideal, but believe it has worked out OK for me recently.

- too few steps, so the next step is a large barrier, particularly near the top

- I am aware of what is needed for my next promotion, but unaware of what's needed for other promotions.

- In the above questions I answered agree to indicate that 'most' staff have a positive experience. But I know that some do not. Sometimes these people can be quite vocal, which damages moral

- I had a lot of difficulties with answering the questions (as you could see from the "Don't know" answers). For me at NIST (I have been here ... years), I came here to do science and to this day I don't even know the different pay bands. I have been fortunate in my research success, and over the years have been promoted several times from pay bands I didn't know to new pay bands I still don't know. To the extent I care about such things (which is not much), the metric that matters is "status in my field" as compared to the international peerage of scientists. With this in mind, how NIST labels me is immaterial provided I have sufficient research resources. The only time I knew the details was when I was promoted to ..., which was a pretty big deal.

- The goals my division sets forth in my performance plan differ in weight and in direction from the stated requirements for IV to V promotion. One must navigate around the division and supervisor's understanding of the NIST mission in order to achieve the OU's vision of what a ZP-IV should have accomplished to be promoted. This is counterproductive.

- I have been at NIST for less than 2 years. There are many aspects of the promotion process that I have yet to experience.

- Indicative of my responses to this survey, I am frustrated by the lack of available information regarding Band promotions at NIST. I spoke with my Group Leader, Division Chief, and laboratory leadership more than two years ago trying to gain an understanding of the criteria for Band promotions. None of them was willing to offer quantitative metrics against which an employee might gauge their promotion potential. 
The only information they were willing to provide were anonymized written materials from other candidates within the laboratory but outside of my division. After reviewing their materials, I found that I had already met each major metric that I could deduce from those materials (for example number of journal papers and/or other archival publications, number of citations including h-index, i-10 index, etc., leadership roles in major codes and standards committees, strong reputation in the field, demonstrated value to NIST). After bringing this issue to my Group Leader's attention during my performance review, he belittled the importance of all of the metrics I had identified and instead imposed alternative arbitrary benchmarks for me that had to be met before he/she would "even consider" bringing my promotion case to the management council.

- I know other people who have had positive experiences with the promotion processes, but *also* people who have not. I'm not sure that was an informative question. I've also had positive experiences in the past but some negative experiences in the present. I'm not sure how you answer both ways except to say Neither Disagree nor Agree.

- The squeaky wheel gets the grease. Those that complain and push and argue and even play the minority card are the ones who get promoted. The quieter ones who just do their jobs well without making a fuss don't get recognized as they should.

- My experience is within division ..., so I cannot speak to the experiences elsewhere. With that in mind, I have the following impression of the promotion process. Employees receive no direct interaction from the division of laboratory level staff. It is unclear to talk to about the promotion process and the requirements to "move up" within the organization. It would be helpful if employees were provided a list of accomplishments or achievements that stood out for the individuals being promoted annually. Things that will get you promoted don't appear to be consistent. Not all supervisors are good advocates, who should personnel talk to about career advancement if they cannot approach their supervisor for whatever reason? I was out on .... leave in ...., at my annual performance review I was told that I did not have the same "number of tangible outputs as my peers". This strikes me as a soft way to tell employees they will be penalized for being absent for medical reasons. That is, in fact, illegal.

- Promotions should be based mostly on technical merit (quality of research) and less on social merit (reputation in field).

- My supervisor is fantastic on feedback and recognizing my work. They're very in tune with the work we do and tasks that I perform outside of my typical workload and recognized regularly. This seems to be a rare occurrence

- I generally have no idea what the process is.

- I have never heard anyone actually discuss their promotion process.

- Early career employee - have not yet encountered promotion

- I was just hired as a federal employee in ...., so I still don't know a lot about the promotion process 
- Some programs at NIST have very high impact, but by their nature require work that is not widely visible either externally or within NIST itself. This can make it difficult for staff working in those programs to be promoted, but in general staff who choose to work in these areas understand this challenge. Also, there are many difficulties in evaluating staff for promotion opportunities based only on tangible, visible outputs, and it is understandable why some managers rely in part on a staff member's reputation among her peers during the promotion process. This can make it hard for some demographic groups at NIST to receive a fair evaluation. There appear to be many examples of this, including gender, but also (say) staff with dietary restrictions that prevent them from socializing daily at the NIST cafeteria with their group.

- The whole NIST hiring and promotion process is broken. It does not work as intended and most promotions (especially the ZP III -- IV) appear more political in nature than merit-based.

- I was promoted from a ZP-III to a ZP-IV when I became pay-capped as a III. While I am a strong achiever and took on increasing leadership and responsibility, it didn't feel like I was promoted based on my accomplishments, it was more out of necessity. Now I've been a ZP-IV for ... years and am performing as a V, yet I don't know if I'll ever be promoted again. There is a lot of ambiguity and uncertainty about this process at NIST.

- I was one of the lucky ones to be promoted from III to IV pretty easily. (This was also quite a few years ago.) It seems to be every case is a unicorn--every person vying for promotion to IV is told a different story about what's required. Promotions above IV seem more straightforward (from what I can tell).

- I have only been here a year so I haven't really been in a position to be promoted yet which I assume is why I don't really know about promotions.

- Promotion at NIST, particularly for going from IV to V, is almost exclusively done by going into management, and if your boss decides to keep you out of the management "club", then your potential for career advancement was flushed down the toilet. Like most things in life, promotions at NIST are a form of a beauty contest.

- The promotional process is highly dependent on the employee's direct management chain. If the group leader and division chief are not championing their staff and preparing them for promotion (which can take years), then it is almost moot. Management styles vary so widely within operating units and even within a division.

- There are distinct, and for the most part justifiable, differences among OUs regarding promotion. This is particularly true at the top end of the bands.

- I have been employed for less than a year, so my responses may be an outlier for this survey.

- I am not sure what you hope to gain with these questions but I think they pretty much suck. I have no clue what you have to do to be a III to a IV! So how would I fairly answer these questions and I clearly don't know about anyone else! 
- My supervisor does not openly discuss these topics. Performance is only discussed at performance review time and typically only covers the signing of the necessary forms, no career growth/promotion aspects. If promotion is discussed, I must raise it.

- Some of my colleagues perceive the promotion criteria as moving targets. They get mixed messages from immediate supervisor and higher level supervisor. It is clear that there should not be a strict rubric that applies to everyone since everyone's responsibilities and talents are different. However, it seems that supervisors should work with each other and coordinate with each employee to develop different performance metrics and pathways to promotion. These paths should be documented but can evolve as the needs of the OU change. Consistent communication with the employee every step of the way is key. In my own case, promotion potential was not my personal motivation as long as my salary and raises were commensurate with my needs. I was frequently surprised by the promotions I received along the way since I really didn't have an understanding of the criteria for advancement at the time. My career benefited the most from the informal guidance that I received from managers, fellows, etc. across NIST. Flexibility and removal of barriers to access was important for my own success.

- I was made to believe that it was extremely hard to get a promotion from III to IV and then when it finally happened everyone was amazed that I wasn't hired as a IV. I had had 2 previous .... and more than enough papers.

- In general, there is presently little funding for long-term research positions at NIST. They only open up when someone retires. The lack of long-term research positions means there is a lack of promotion opportunities because I cannot expect to be at NIST more than a couple of years (unless a researcher in my field happens retire before then). Similarly, I feel there is little opportunity for my accomplishments to be rewarded in the future because I am unlikely to have a job at NIST in the future.

- Promotions are not applied uniformly at the division level. Likewise, I believe there is a disconnect between the lab and division levels in terms of when someone is ready for promotion.

- I'm fairly new here and haven't had an annual review yet. Although, the topic of promotions (or what gets you promoted) is fairly mysterious to me and not something that's come up in conversation with my supervisors - (although I know about the scoring system and how to get a raise based on how well you meet you performance plan goals). Yeah, I know absolutely nothing about it actually.

- In my OU, the singular focus on publishing as the sole criteria for promotions makes for lots of bad papers. Standards, data, and software outputs and impacts should also be considered.

- The longer I've been with NIST and the more I learn about the promotion process, I understand how significant supervisor bias and area of expertise can influence 
performance ratings and promotions. Especially in the case of multiple supervisors in short time frames.

- These questions are very simple. There is a lot of context and complexity behind many of the answers.

- I didn't understand for a long time that I had to initiate the promotion process for myself. I waited much too long for my supervisor to start the conversation with me rather than starting it myself. I suspect that many people are overlooked or wait longer for a promotion than they should because they are uncomfortable with the idea of promoting themselves.

- For more than 10 years I was told there is no way to be promoted to a 5 without a PhD and without managing staff. This misinformation stalled any hope of promotion.

- There are many problems with the promotion process at NIST. One issue is that the process is not standard between laboratories. In my lab there has been little review of the process for several years, and the review process seems outdated. There is apparently little consideration for what the applicant's job actually entails, and impacts that fall outside a narrow scope are not considered. Additionally, it seems that white males are actually being promoted at a lower rate than others with similar qualifications (to be clear, all those promoted are still qualified, but other qualified people are not). There are several in my lab who have left out of frustration, and I'm sure there will be more. The entire promotion process needs to be reworked. This does not seem very important to management, but it's a stay-or-leave decision for staff.

- I have been promoted from a ZP II to a ZP IV during my time at NIST. I have no idea what criteria was used to justify the promotion. I was not part of the promotion process, it was just something that occurred.

- PhD scientists at NIST have lower salaries compared to other federal or national laboratories. Female PhD scientists with fewer promotional opportunities have worse situations.

- Too much of the NIST process is supervisor dependent and personality driven. This is true from the perspective of both the promotion of and employee and engagement of different supervisors, and how the OU Directors dominate the decision points for the Fellows and Band 5s. Often they bring organizational grudges with them, competition between OUs for limited slots (in the case of fellows), personal ignorance of a type of research, bias of what type of activity or achievements are fellow worthy etc.

- Opportunities are lacking for someone to prove and provide their value outside of their group or role. Cross-OU interactions are arbitrarily encouraged/discouraged because they may not align with that particular group/division/OU's mission (exceptions are IMS etc.). There are huge hurdles in obtaining external funding, even when there are willing collaborators and agencies - this is a mismatch between responsibilities and organizational ability to expedite such activities. 
- I have only been at NIST for a year and a half. My answers may be skewed by lack of time at NIST.

- I think the promotion process varies significantly across NIST and is highly dependent on local management and the scientist's relationship with their manager.

- I've only been at NIST for about <1 year, so promotion criteria and potential has not been on my radar.

- The process of moving from Postdoc to permanent position is pretty opaque, and I was surprised that after ... years of Postdoc, it is policy that you come in at lowest of ZP-III, meaning there is effectively no promotion or (official) career development that comes out of the Postdoc time, which seems unfair.

- There is no potential for promotion here. I think it may be a matter of a group's budget. People are retiring, but I don't see anyone being promoted or new people being hired. Promotions aren't announced (besides the upper bands), but you can find out bands on public databases.

- In general, I have always felt that my efforts at NIST are appreciated. My supervisor has regularly made comments about my research successes at work, and we have a very supportive environment. And, I've been gradually promoted since I started working and feel like my pay is adequate. That said, the evaluation process at work is not entirely clear to me. The ratings that my supervisor gives me on my annual performance evaluations -- though they're always positive -- seem a bit arbitrary. (How did ... decide the categories in which I've met expectations, and the ones in which ones I've "exceeded" expectations? I've never been clear on that.) This is not a major concern, but it's possible that the system could be made a little more meritocratic.

- I am not looking for promotion within my current team or role.

- Previous supervisor did not promote fairly, but current supervisor does.

- There seems to be an arbitrary/implicit "cap" on how many people can get promoted per cycle. This seems unfair because someone should get promoted if they deserve a promotion. It also seems folks at NIST like to think they are being fair by enforcing ratings to follow some perceived distribution, but this is nonsense and unfair. If someone performs well, they should be rated accordingly. I've been lucky in my unit, but I've heard this from others, so it's essentially hearsay but thought I'd mention

- My promotion from III to IV took longer than I expected, and longer than my supervisor expected. Neither of us are exactly certain why that is the case. This was also true for a colleague of mine who entered the group around the same time and the same band as me. The most recent promotion from IV to $V$ in my group came in 2008 (I think), and he has since left the group. So, there is no really close example to follow. At least two people from my group over the last 10 years have reached maximum pay at Band IV, then left NIST and been promoted rather quickly, putting them in position to return to NIST as maxed out $\mathrm{V}$ and even SES. 
- I am a newer employee who came in as a band ..., so I am not familiar with the promotion process and will not be seeking additional promotions.

- The criteria for promotion from III-IV-V-ST are posted but are subjective. I think providing support for first-line supervisors to explain the criteria and help their staff understand how their current situation fits into the structure would be helpful because most staff are looking to their first line supervisors to explain things.

- I do not know much about the current III-IV as I went through this process decades ago, but I do know where to find the information if I needed it. There is similar transparency in IV-V. The ST position is totally opaque to me, but I do know it exists.

- What is not fairly distributed is negotiating salary when being promoted. I was told this could not be done, but know of several instances in which it was.

- I was a ZP-.. and was asked to fill in for my boss, a ZP-... [details about perceptions of unfair compensation for extra responsibilities.]

- From a cultural perspective, the promotion from ZP-V to ST isn't a practical option because there are so few STs (limited by law...I think). From experience, the ones who get there do so because the employee aggressively lobbied for it over a long period of time.

- The promotion criteria are a bit vague and determinations for III to IV seem to be made on a division level on a case by case basis. In some ways, it makes sense as researches have different strengths and play different roles in the division. However, it would be nice for the promotion criteria language to reflect this and the organization as a whole explicitly embracing this diversity.

- I have understood that not having an "advanced" degree, whether that is a masters or doctorate can preclude you from selection to more senior leadership positions. It is not my experience that having a masters or doctorate is the qualifying characteristic of a good leader.

- It seems like self-advocacy and persistence are important for getting a promotion, and you can't just rely on being recognized for doing good work. As a result, I have gotten the impression that promotions tend to go to those who "talk the loudest".

- There is no consistency in promotion processes because it relies on group leader endorsement. Group leaders value accomplishments differently which is particularly difficult if your contributions are not similar to your group leader's (ex. institutional health versus scientific recognition or differing scientific fields). Also, ZP V promotion still has a connotation of international recognition and it is not clear that you can attain ZP V status through dedicated internal NIST activities and recognition.

- Some areas at NIST add requirements to being promoted that are above and beyond those required by HR/OPM. I don't believe this practice is positive or should be allowed. Some have to leave the area they are in to gain a promotion due to the artificial requirements. 
- I believe the promotion process is fairly applied for "conventional" promotions - people who spend their whole career at NIST and are traditional bench science researchers. It gets potentially problematic when the formula doesn't apply - candidate does not spend whole career at NIST, takes a leave of absence, threatens to take another job if not promoted, performs duties that are not classic scientific method (defined here as plan, collect data, publish results), works part-time for a period, etc. How non-traditional contributions are valued is unclear and the interpretations may be subject to inconsistency.

- There isn't a promotion process in my OU, (which is ...), for ZP-III to ZP-IV or ZP-IV to ZP$V$. The only way you get to the next band is if someone leaves and they post the position on USAjobs.gov. Once the job is posted, you can apply for the position and if you are qualified, they will interview you.

- I have been at NIST for 5 years in a small group of other (< 5 year) federal employees and guest researchers (non-federal), so I have not known any instances of promotion at all. Hence my ignorance of the system!

- Promotion processes at NIST are highly scattered in implementation depending on OU, Division, and group. Essentially, a strong supervisory advocate is needed and not all staff have this. Additionally, supervisors "put their own spin" on the requirements for promotion and too often these follow a meritocracy and minimize efforts that make NIST a better place.

- There is nothing transparent about it. It is shrouded in secrecy. I also don't think that it is fair that you aren't only compared to your peers in your group. You are compared to peers in other working groups as well and the work you are doing may never directly compare to the work they are doing.

- Since the reorganization of 2010-2011, it has not been as clear what the IV-to-V promotion criteria are, because my OU assumed Divisions with different methods.

- My positive experiences with the promotion process is that eventually I have been promoted. The exact reasons I was initially not promoted, and then was promoted, have never been fully clear to me.

- I have not been particularly concerned with promotion or status within NIST, since I have been generally satisfied with my job roles and expectations. I would guess that regardless of my title, I have been remunerated beyond my expectations.

- While the criteria are transparent, it always remains a concern how they will be implemented. Admittedly, I'm not one intending to pursue this advancement, but more out of lack of opportunity/availability than desire.

- The 3rd question for \#5 does not make sense as written. I don't know what you're asking for. Also, you should be aware that the questions you are asking about ST/Fellow aren't really on point. There's no promotion track for those positions, these are akin to 
honorary titles and NIST is very limited on these titles. I don't believe that you will get good information from the responses to those questions.

- Upper management, depending on who is in charge and their background, has a strong filter based on their own experiences and biases, such that a limited subset of NIST research (and promotions, etc.) are valued to the exclusion of other activities (and people) who are still within the broad NIST mission range.

- I have been told few different stories about how to get from a 3 to 4 . I have seen people get promotion without having to do what I was told I must do and be capable of. I truly don't know what criteria is require to promote from 3 to 4.

- Many times, the promotion is not attainable due to the lack of funds within the group and then a person sits and lingers as they cannot be promoted because of the lack of funds. Also, many times it appears that there are the "golden children" who are selected by management to be accelerated up the promotion chain and others are ignored.

- It is my impression, as an ... employee, that the criteria for promotions are not uniform across NIST. I've heard that in some other OUs, postdocs, when hired on as permanent staff, are automatically hired in at a ZP-IV Band from a ZP-III. Whether or not this is the case, the perception of this practice makes for disparity among younger staff with regards to their value to the organization that can persist through their career. ... does a good job of communicating the criteria for promotions by posting 'stature' documents on an internal website. The issue with this is that even though there are agreed upon criteria, I believe that there are biases that effect how those criteria are applied. I've heard someone in management say '...knowing if someone is ready for promotion is like pornography, you know it when you see it.' I believe that there are enough people in management positions who control promotions that have positive biases towards staff who have followed a 'traditional' research path that the promotion process is faulty. It is my perception that to become promoted in ... you have to 'fit' with a group of people that have been promoted in the past. This practice is not inclusive and leaves little room to support staff who make significant impacts to NIST and NIST mission who do not 'fit the mold'.

- For $5.1 \mathrm{I}$ answered ...., but the fact of the matter is that I cannot be receive a higher salary because I am topped-out. For 5.2, I have conversations more frequently than 1 yr. And you need a free text box for the section 4 questions, or an NA. In the ... division, we have no chance of becoming STs due to the nature of our work. We ...., which will never get anyone anything resembling a Nobel prize....

- Except for at the ST Band, promotions seem fair to me and the process transparent. I have 2 friends who are women that have left NIST because of the promotion process. One felt forced into management roles (because we feel desperate for women to be managers) and wanted to remain a scientist. The other wanted management roles only 
to feel very limited in her career path by a senior manager (who oddly was also a woman).

- My experience is that the promotion process varies widely from OU to OU and even division to division, so the process "at NIST" is not well defined.

- I was hired as ZP IV and have not had any first-hand with the promotion process. However, my supervisor has informed me that I am "in the queue" for a promotion to ZP V.

- I don't believe that the NIST promotion process form ZP4 to ZP5 is uniform and it is not clear how some people got promoted and other deserving candidates have not been promoted.

- There seems to be a lot of politics in promotions. It is less of what you do and more of who you do that for. If you work for a strong outspoken supervisor, it is highly likely to get recognition and promotions, otherwise you get excuses of well this or well that. I am aware of many people that work like mad doing the work of 2-3 individuals that get very little recognition and others that do very little technical work but are social with upper management that get recognition for things that are day to day work.

- Promotion depends on an employee's immediate supervisor. If that relationship is good, then generally accomplishments are recognized / promotions happen when they should. If that relationship is bad, then careers get derailed and may not recover.

- I said I "strongly agree" with understanding the ZP III to ZP IV promotion only because I was promoted 2 years ago and in hindsight, I understand what management is looking for. However, if I were still a ZP III, I'm not sure I'd understand what they're looking for. I don't understand the difference between someone becoming a Senior Scientist vs. Fellow. Seems like Fellow is a bit "better" than Senior Scientist but why?

- Personal favorites seem to be the ones who get promotions.

- I am a topped-out $\mathrm{V}$, so I really am in a quandary as to how to answer your first two questions in Section 5. I don't talk about my promotion possibilities with my boss since I don't want to be promoted - I am happy as a topped out ... and the next Band of management would pay me no more so I don't want to be promoted, and your survey does not seem to appreciate this. Hopefully my middle-of-the road answers will not be seen as a negative, as is my impression of what often/usually happens in these surveys. You should not assume that everyone at NIST wants to be promoted!

- At NIST 1yr in ZP track - all the promotion criteria I have had to look up on my OU's website on my own. I have not been directed to those except for being mentioned by my supervisor. To their credit, the publication of these criteria is helpful.

- I came to NIST as a ZP-IV so I do not have much meaningful feedback about going from III to a IV.

- There is no merit based promotion process. There is too much of a buddy system at NIST as most employees have been there in excess of 10 years. Senior management is 
set in their way and there is little or no room for advancement especially for my demographic, regardless of performance.

- I literally have no experience with the promotion process. I started as a ZP4 in ..., and ... years later I am still a (pay-capped) ZP4. I can say with $100 \%$ confidence that I will never be a ZP5, and I'm fine with that. The secrecy about promotions over the past 20 years has always astounded me. In a normal organization, a promotion would be an occasion for a public party with cake and punch. Here it's typically (less now, I guess) been accorded the level of a state secret. As for the 5 to Fellow promotion, I don't know any active scientist at NIST who has been made a fellow. (All the fellows I know are retired) I'm sure that my supervisor would be more than happy to talk with me about promotion with me if I wanted. When I stopped being a ..., I made a conscious decision to make my job into something that I could enjoy, and to do projects that I thought were rewarding, rather than trying to find ways to be promoted or to try to figure out what management thought was important. Frankly, the financial incentive to go from 4 to 5 is minimal. I'm sure that if I were doing 5-Band work I could ask for a promotion and get one. But everything you have to do to be $\mathrm{a} \mathrm{V}$ is something that I think is horrible and unfulfilling. Why would I subject myself to that for an extra $\$ 20 \mathrm{~K} /$ year? I get to do the projects I think are important now. Being a 5 would not get me more freedom or resources, and only an insignificant pay increase.

- At the NIST campus in Boulder there are few opportunities to be promoted to ZP V. It is not a prominent path for promotion for scientists and researchers.

- In recent years, some NIST OUs have published the criteria for promotions on their internal websites. Actual promotions depend on advocacy by one's supervisor. NIST should make it easier for staff members who feel unappreciated to transfer among groups, divisions, and even OUs.

- Women and senior employees have severe glass ceiling problems, particularly for the category from Band V to ST

- I feel confident that my accomplishments will be recognized because my supervisor recognizes my work and efforts, but not all supervisors are objective. In the past, my ratings changed as my supervisor changed even though my actual performance and activities were not altered. What is required for promotions is fuzzy; however, measuring the success of a researcher is also fuzzy.

- Promotion actions taken in the past affect the present. I believe the current division chief to be fair in ... dealings with division staff. I understand that staff members currently seeking a promotion should submit a package highlighting their arguments. There are subjective components to the process, including how to compare technical prowess to impact through changes in standards, but I generally trust the current leadership to discuss this fairly. Under a past division chief, I understand that certain favored staff members were promoted from ZP-III to IV and IV to V with little effort on 
their part to assemble supporting documents. My own project that was ... was shut down under this leadership, and I have reconciled myself to finishing my career under my current title. I am concerned that a change in division leadership could affect the current perception of fairness in promotion practices within my division.

- I started as ZP III. First boss promoted one staff member to ZP IV so ... would be eligible for promotion to ... (ZP V). The next boss figured we all do the same job, so promoted many of us to ZP IV. The first boss was only concerned with ... favorite. The second boss was concerned about all of us.

- I am in Pay Band ZPV and have been for about ... years.

- It seems that few research scientists are aware of the long term criteria for promotion beyond the ZP-IV pay band. This is in part a fault of a lack of mentoring by management. It is also due to a lack of initiative by the research scientists to learn about promotion criteria. It is believed by many that NIST ST positions are being used as retention bonuses for perceived superstar researchers whether or not they have had a history of success at NIST. There are not a set of known criteria for the few that are promoted into this elite pay band.

- I really only know about ZPIV to ZPV ....

- I came in as a term.... and have stayed on as a term for an additional 3 years. My experience has been that maybe promotions aren't discussed for term employees, which would put me at a disadvantage if I were to become permanent.

- I have been incredibly fortunate in my supervisors. They have advocated for me and have made it clear what I needed to get done to advance within NIST. However, based on data from my peers, my perception is that it is all too easy to have a supervisor who does not advocate, does not clearly communicate requirements, or worse actively discriminates against some group members.

- Most early/mid-career employees don't have a clear idea of how they should be advocating for themselves and what opportunities are available to them that would help them in the long term

- The path to a ZP-V is not well known, and seems to differ based on each organization. There should exist a clear path for operations staff versus research staff, as the requirements for promotion potential are different. In a recent promotion for myself, my years of increasing leadership in a variety of areas should have sufficed, but as I understood, I am expected to engage more in another area. All fine, however the decision making process was not at all clear.

- It's easier to switch jobs into a higher position than to organically 'grow' and be recognized as ready for promotion in my experience.

- I have also had negative experiences with the NIST promotion process, and I know others at NIST who have had negative experiences. 
- I am an ..., and the promotion process was never explained to me. What is relevant to people in my position is how to even become staff in the first place. How to become more than just temporary or interim is a huge discussion among my peers.

- The barrier to ZPV promotion processes seems disproportionately large compared to ZPIV and ZP III without a historic, legal, or other rational explanation. NIST ST promotions (and ZPV promotions for that matter) seem to be more geared around $\mathrm{h}$ factors and numbers of publications rather than supporting the NIST mission.

- I think there is far more confusion and dissatisfaction around the process for moving from term employee to permanent employee and/or moving from PREP to term or permanent than there is around promotions among permanent employees.

- I entered as ZP IV, so I have no experience with moving from III to IV. By observation it appears to move to $V$ you have to become an SMA (Senior Management Advisor) or higher, taking on a lot of duties involving management of other people, away from technical duties. I and, by observation most of my teammates, would prefer technical work to managing people, even in exchange for more money.

- I feel that our year end reviews and ratings are completely arbitrary

- It appears that each OU (NIST Laboratory) had different criteria and thus the appearance of a non-standard set of evaluation criteria and process (anything "nonstandard", of course, is not good ;-)

- I have the impression that the promotion process places significant emphasis on whose "turn" it is rather than on accomplishments.

- People don't discuss their own promotional process. So, there is no frame of reference. Also, why is the burden on the scientist to self-promote? Why we put this burden on line managers? I find self-promotion extremely distasteful, maybe that's my problem!

- Promotion in my OU is based more on popularity than on merit. The criteria for ZP are a moving target- particularly for the V. It's an obvious 'old boys' network and it's been that way for years. Very frustrating to those of us in limbo.

- There is no process. It is about luck ;)

- I feel strongly that NIST should try and add a review panel for evaluating anonymized IV$\mathrm{V}$ promotion packages. In my OU, relationships with division management are way too important.

- I have never been promoted at NIST, so my perspectives are not well informed.

- While I have been at NIST for ... years, I have only been a Fed for ... years. As a result, I have had very little exposure to the promotion process. I know of one person promoted from ZP III to ZP IV (becoming a project leader) and they were very deserving of the promotion.

- The process is a little nebulous. It is largely up to the immediate supervisor who decides whether to put you forward. After a couple of tries (call comes out twice per year), it gets to a Division level specialist who puts together a package and pulls information 
from the library on publication record and impact analysis. Then you just wait. The emphasis seems to be less on the bench work and in favor of external exposure. Perhaps it reflects the philosophy of the organization and awards certain types of achievement.

- I have only been here a few years and was hired at a fairly high Band so promotion has not been appropriate.

- I don't know what pay band anyone is, except for Fellows since they are named such. I'm relatively new to NIST but as far as I can tell no one talks openly about the promotion process. I can only guess the band of the people I work with.

- Even if two employees are promoted by management at the same time, HR applies at different rates and there is no retroactive pay and benefits for those processed later

- Until every successful promotion package at NIST (appropriately scrubbed of PII) is published, the entire promotion process will be viewed as unfair which, in fact, it is. If the process is cloaked in secrecy, deserving candidates will not know that they should push for advancement; most GLs, DCs mean well, but do not know how to put together a decent package. There are a variety of ways a candidate can meet the stature requirements, but they and their supervisor may not have a good example to follow. The idea of publishing the packages has been brought up many times, but, in the past, laboratory leaders said they wanted to protect the privacy of those that were promoted. Why? I think it was to guard against charges of discrimination. Looking at the promotion numbers, that is exactly what has happened. Besides that, the promoted should be proud of their accomplishments.

- (...) laboratory provides guidance for promotion at NIST at the following link.

- HR policy does not want to take responsibility for promotions. I am in the process now and HR would rather I apply for a ZPIV than take responsibility for promoting me from III to IV.

- I have been at NIST for a little more than 1 year. I am not aware of what is required for promotion, and my manager hasn't discussed the promotion process, promotion requirements, or promotion potential. That said, I don't expect to have these conversations until I have at least two years of experience at NIST and have made significant contributions. I do perceive my management chain to be very supportive, though I'm not aware of any promotions in my division. That said, the division has only been around for a few years. Finally, I don't hear about promotions in the NIST community and believe it may be NIST culture not to advertise or make public promotions. (Surely promotions happen somewhere, right?) It would be worthwhile to advertise the qualities and accomplishments of individuals who are selected for promotion, but care must be taken not to bias toward those who naturally have higher visibility roles vs. bias against those do a great job everyday doing work which is less visible/prominent. 
- It's a little difficult to search through NIST materials to find a write-up of Bands II, III, IV and V. I felt that I was doing Band IV work way before I was recognized for it (my manager said I was the strongest case he'd ever had for the promotion which in my mind, means that he hadn't recognized my contributions soon enough) and I felt that others were promoted without satisfying a lot of the Band IV criteria. It's how well liked you are sometimes, not the work you do.

- In my OU there are no true "performance plans" rather "compliance/ethics plans" that allow NIST to point to deficiencies of the employee when needed. The template for the performance plan clearly defines how to establish expectations between standard and exceptional performance, but none of the performance plans are detailed in this manner. Performance plans boilerplate integrity and compliance areas, for example, embracing diversity is on everyone's performance plan. How am I to meet standard performance expectations to embrace diversity, and how do I exceed in these expectations? Again, these items allow NIST to point out deficiencies and have documentation to backup disciplinary actions. This is important and needed, but should NOT be a performance plan item. It should be set-a-side as a separate agreement that the employee must re-commit to and sign annually. The federal government in general has tons of this annual or bi-annual training and agreements on the learning center, so why not one more to cover ethics, compliance, and integrity items. This how most major corporate organizations separate performance from compliance/ethics, and still enforce and manage both. How is performance judged in my OU? - complete supervisor subjectivity and personal preference. I've seen several promotional job postings written for a specific individual in mind. Normally following a period of "temporary detail" the job posting includes specialized experience that ironically matches the employee's most recent position, and includes the skill-sets gained during the "temporary details. These same job postings normally occur with short turnaround times ( 5 days or less) and are posted on Fridays before a Federal Holiday. Promotional selections were widely communicated for a new division, even prior to the new division being established. No job posting, no opportunity, simply management pointed and selecting - not for a promotion within their current job description, but a promotion to a brand new job description - in fact a brand new, not yet established, division. . [...specific concerns regarding travel and telework ...] These types of practices breed a cynical environment, where staff simply clock-in and clock-out, keep their heads down, just do what management asks - no more, no less. No suggestions, whatever the work performance or outcome, who cares! At NIST, it's more important that you have a great relationship with your supervisor than it does to have great performance. Within job description promotions and performance evaluations are based entirely off making the supervisor pleased, not based on clearly defined expectations. It's a culture of favoritism at nepotistic levels, based on who you know, and how long you've know them. It transcends gender and is a problem for all staff. 
- The III-IV promotion is pretty clear. The IV-V promotion is vague. Too many times people are promoted because of their managerial duties instead of technical merits. This is fine if the selection of managers is transparent. Unfortunately, the leadership is very homogeneous and does not reflect the diversity of the NIST workforce.

- There are the published, freely available sources of promotion information and there are the unwritten ones. There are a lot of conflicting situations or statements regarding the written and unwritten promotion processes/requirements. There are also many individualized experiences concerning promotion that are seemingly direct reflections of your supervisor or management's ability or willingness to advocate for you.

- For the second item, please understand that not everyone has had conversations with their supervisors on promotion, especially for people already at Band V.

- Timing of promotion from III to IV seems to be driven more by reaching pay band cap than by change in responsibilities.

- There are a lot of side comments about what it takes to get promoted from a 4 to a 5 , but no one really knows the criteria. Everyone says 'it's very tough' or 'you need to be at NIST for a long time' but I have not seen this in writing anywhere.

- I did not understand/realize that I was below average until I saw the NIST aggregated performance ratings released on Feb 11, 2020.

- The path to ZP5 requires strong publication record and engagement with the top level of research at NIST and outside NIST. It is less obvious what higher level of achievement is required for a higher promotion, but awards and leadership in a field would be expected.

- I have been with NIST longer than 3/5 of my Group coworkers, hold the same degree (in most instances from the same university), get positive reviews from my supervisor, yet have the lowest salary of anyone in my Group. It is likely because I started at a lower salary when hired, yet in conversations with my supervisor regarding this matter, I walk away feeling greedy or ungrateful for my job. It's hard to shake that. I will be converted from ..... in the next few months and although I'm excited I'm also anxious because of what I perceive as an inequity.

- The only thing "productive" about conversations to this point has been that my supervisor is aware of my desire to pursue promotion, and that only in the last year. Prior to that my efforts at bringing up the topic were unsuccessful.

- Many employees don't realize we have slots for so many ZP-III, ZP-IV, and ZP-V employees. We can't automatically increase someone from a III to a IV. The person has to apply for a vacancy or the position has KPP to IV when posted.

- I'm a V, but from a technical background. I now manage a division that has a number of non-traditional ZP-IV's and I'm very worried that since they don't fit the "mold" for promotion i.e. international recognition and publications that they won't be considered. I've been at NIST for my entire ... year career and we don't have good (any) options for 
anyone that makes strong contributions to the NIST mission in nontraditional ways to be promoted to higher Bands. My frustration is that I have two .... that are absolutely critical to my operation and are capped ... because HR has an artificial glass ceiling for ... employees... simply unacceptable and this impacts largely women as they're more likely in the .... pay band.

- I've never seen any kind of documentation about the promotion progress.

- My perception of promotion at NIST is that you have to apply for an opening at the next band. This is contrary to my experience in private sector where work and accomplishments alone drive the promotion process.

- I'm ..., well past worrying about promotion. I continue to work because I enjoy the work $\&$ my colleagues. 2) Promotion opportunities for the younger folk radically improved $\sim 6$ years ago with a major reorganization.

- The lack of transparency and fairness in promotions, particularly in the senior bands (e.g. ZPV to ST/Fellow) is particularly disheartening. It is even more disappointing to see the gap between the stated positions by NIST leadership and their actions when it comes to promotions. NIST managers need to walk the talk. My experience with promotions has convinced me beyond a doubt that performance (as reflected in my annual performance reviews) has very little correlation to promotions and recognition. The system is broken and needs to be revamped. Not fixed because that will only mean minor changes around the edges. The lack of diversity in NIST leadership is another factor that I believe is a strong contributor to the disparity in promotions. Data from previous studies at NIST clearly attest to the situation about disparity in promotions and disparity in diversity in leadership.

- This is a 'fraternity'. You must be liked to get promoted.

- I have not been at NIST that long (have not gone through a cycle of the performance plan) thus I only have a vague idea of how the promotional process works.

- I am a .... with .... to retirement. So, I don't care about promotion. When I was a supervisor, I found one employee who had been overlooked for promotion for a long time. I think it was because she was ..... I got her the much deserved promotion very quickly.

- I had no experience with pay band having lived with the general schedule of levels and steps in the .... before coming to NIST. [details about experiences and comparisons with GS system]

- Some employees at NIST who I know have had positive experiences with the NIST promotion process, and others not so positive.

- I came in as a IV, so I never studied the III-IV promotion. I never had a discussion with anyone about the $\mathrm{V}$-senior promotion. I only saw the criteria from IV-V once when my supervisor showed me a document privately. I don't know how to get such a document.

- It's a very nebulous process that is not clearly defined early in your career. 
- Within my OU, promotion also appears to have a strong dependence on projected budgets. This seems inevitable, but difficult to include explicitly in promotion criteria (especially when there is a distinction between permanent/base funding and temporary sources).

- NIST does not participate in CFR Title 5 Subpart C. Basically, all of the information in the report is unfounded.

- My impression is that the conversion from a ZP III to IV happens when you are pay capped at the ZP III Band and tends to be fairly automatic if you have had good reviews, the division management looks at your work favorably, and your group leader has enough to support your case. The ZP IV to V promotion tends to not be automatic, and requires winning internal/external funding, clear external recognition, competing job offer. There also seems to be clear correlation with sometime in the management track as group or center leader. The promotion to fellow/senior scientist seems to be Nobel Prize level work, but also seems that each OU/Division is given a number of slots they can fill.

- I was told that promotions come naturally with time at NIST. I wasn't told what is required to be promoted, just that you will eventually be promoted in time.

- My own personal situation has been much better than stories that I have heard from colleagues in other parts of NIST. I think in my case the fact that my work unit is small and part of ... made the process easier, once my office director was committed to promoting me. 


\section{Part III \\ Focus Groups}

The reports in Part III summarize findings from focus groups that were held from October to December, 2020. They were designed to supplement information obtained from earlier data gathering and to solicit employees' views of recommendations for change. Separate sessions were held for ZP staff, ZP Group Leaders, and ZT staff. Participants in some of the sessions were randomly selected, while others were composed of volunteers.

Following the procedures used with the analysis of open-ended survey questions, transcripts of the focus groups were carefully analyzed to identify common themes. Three general themes were identified in the analysis of focus groups with the ZP and ZT staff groups (Reports 8 and 10, respectively): 1) the need for better communication and transparency, 2) issues with accountability of management in the promotion process, and 3) issues involving organizational structure and culture. The analysis of the group leader sessions (Report 9) identified similar concerns, as well as issues more directly related to their roles such as the preparation of staff for promotion, training and planning, and communication with those at higher bands within the organization. Participants in all of the groups provided numerous recommendations for improving the promotion process and these are included in each of the reports.

The reports that follow describe the methodology that was used and give examples of each of the themes noted above. They also include extensive lists of recommendations to improve the promotion process that were volunteered by participants. Appendix B to this document includes more detailed guidance for conducting focus groups for those wishing to replicate the work. 


\section{Report 8: Summary of Focus Groups Conducted with NIST ZP Staff in November $2020^{49}$}

This report summarizes the results of six focus groups conducted in November 2020 with ZP staff. A separate report (Report 9) summarizes results of two focus groups with Group Leaders conducted in December 2020. The focus groups were Phase 3 of COACh's data analysis procedures. They were designed to assess and refine our conclusions from archival and survey data gathered and analyzed in Phases 1 and 2 and to help guide the development of final recommendations. While we had originally planned to conduct the groups on site, due to COVID19 they were conducted via Zoom.

The first section below describes the methodology used to conduct the groups and the analysis procedures, the second summarizes comments and concerns expressed by the participants, and the third summarizes recommendations that they made for change. Five attachments are included: A) a summary of the gender composition of the focus groups, B) the consent form that was signed by all participants, C) the questions that were presented to the participants, D) quotes from the focus groups that illustrate the themes discussed in the text, and E) a quantitative analysis of the transcripts of the focus group sessions.

\section{Methodology}

Sections below describe the participants and ways they were selected, the procedures used in the focus groups, and the method of analysis.

\section{Participants and Sampling Procedures}

Potential participants for the first four ZP staff focus groups were randomly selected using a systematic selection procedure with stratification by gender. A NIST staff member was responsible for selecting potential participants and sending invitations to participate that explained the purpose of the groups. Those expressing interest were directed to the COACh website at the University of Oregon to select a day and time to participate. Participants in two additional ZP focus groups were not randomly selected, and were open to anyone who was interested. A NIST staff member identified potential participants and sent an email to them similar to that sent to those who were randomly selected.

Anonymity was addressed by having only one COACh team member (the "organizer") know the names and email addresses of those who signed up to participate. A Focus Group Consent form (Attachment $A$ ) was sent to each participant and read at the beginning of each

\footnotetext{
${ }^{49}$ This report was written by M. Noviski and J. Tucker and completed February 5, 2021.
} 
group meeting to get verbal agreement from each participant. The sampling and security processes were approved by the IRB boards of both NIST and the University of Oregon.

The COACh team limited each focus group to 10 people for discussion purposes. When a group exceeded that size, those who wanted to participate were placed on a waiting list and, if the group did not fill, a reminder email invitation was sent to encourage them to join. After the conclusion of the focus groups, participants added to the waitlist who had not participated, were sent an email through Survey Monkey, inviting them to send recommendations to the registrar about improving the promotion process or anything else they wished to share.

The registrar shared only comments and recommendations with the COACh team, with no identifying information. A total of twelve out of eighteen staff on the waiting lists responded after the sessions.

The sampling strategy for the four randomly selected groups called for 3/10 of the participants to be women, yet women were more likely than men to accept an invitation to participate. Thus, women comprised at least half of each of the groups and were three-fifths of all participants in the four groups (Attachment B). While the gender of participants was not included in the transcripts that were coded, COACh staff did not observe differences in the comments of men and women. The survey administered to NIST employees in the spring of 2020 found that women sometimes expressed more concerns regarding promotion than men. This greater concern may be associated with women's over-representation in the first four focus groups. No attempt was made to stratify by race-ethnicity, though most of the groups included a participant who was a member of a minority group.

\section{Procedures}

Each focus group was limited to a maximum of ten (10) participants in order to allow everyone to speak. This limit was especially important since all the focus group sessions were conducted online. Participants were asked not to use their real names by renaming themselves with a pseudonym on the Zoom website. In addition, some participants did not use video.

The organizer started the focus group sessions, assisted NIST members logging on and off, and resolved any technical issues with Zoom. She also ran the recording of the sessions, read the consent form that had been sent to all participants and asked for their agreement (Attachment A). There were two moderators: a lead moderator, experienced in running focus groups, and the research moderator who monitored questions and asked follow-up probes. In addition, the rest of the COACh team was encouraged to act as observers to be sure everyone heard the answers correctly. The team was introduced to the ZP staff online during introductions and they asked follow-up questions as needed.

After participants verbally indicated their consent, the lead moderator read ground rules, which were again accepted verbally by each group member, and presented an "ice breaker" 
question to help participants relax and encourage involvement. The initial substantive question, which followed the icebreaker, was carefully formulated to be simple, focused on promotions and open-ended, to avoid unintentional leading of answers from participants. The additional probes (bulleted) were more directive and the moderators also followed the group discussions, inserting subsequent questions when appropriate (Attachment C).

Analysis

Written transcripts were sent to members of the COACh team, three of whom coded all six ZP transcripts. Units of analysis used were usually sequences of sentences, although a single sentence or complete dialogue may have also been coded. The team required at least two coders to agree for validity. Another COACh team member used the NVIVO software program to identify frequency graphs of codes of the group responses, as well as quotes and coder comments (Attachment E).

\section{Findings}

The first main question for all six ZP staff groups was about how NIST could improve the promotion process, with subsequent probes about getting information and understanding that process. Sections below describe key themes that appeared in all of the focus groups. Very similar comments appeared in all of the groups, both those with randomly selected participants and volunteers. The discussion below describes these related to three key areas: transparency and communication, accountability of managers, and organizational structure and culture. More extensive examples of comments associated with each area are in Attachment D. While specific comments or views expressed by participants might involve more than one of these areas, we believe that it is important to recognize that each of these elements underlie employee concerns, especially as we move to considering potential recommendations for change.

\section{Transparency and Communication}

All groups responded initially by describing the need for transparency at all bands of promotion; and, as noted in the more quantitative analysis in Attachment $E$, this theme was by far the issue most often expressed. A special area of concern was the promotion from a ZP-IV to ZP-V. Participants used terms to describe the process and requirements for ZP-V, such as "black hole of mystery - nobody knows how it works" and "this cloudy thing."

The focus group members understood that part of the promotion decisions, particularly for ZP-V, had to be flexible and depended on the qualifications of the person being promoted. However, they also thought there could be discussions about past decisions that their division either agreed or disagreed with as examples, and they wanted to have more transparent descriptions of some of the "hurdles" they would have to clear in order to be considered for ZPV. 
In most of the focus groups there were discussions about having standards, metrics or a rubric that would make the requirements for promotion at any band more transparent. Several participants mentioned that this did not mean a check list of criteria, but something clearer and more substantial. One person gave an example of NIST's Senior Executive Service having a "fiveor ten-point rubric that spans many things and has five or ten bullet points under each item..." This participant said: "Wow, go figure that the highest band actually has a rubric; why don't the rest of us?"

In addition to transparency, participants in the groups wanted more honest communication from their direct supervisor about issues related to promotion. Many ZP staff would like to understand more about the changes of percentages for salaries and bonuses in the yearly budgets and several also said that they did not mind being told about a reduction in budget for promotions if the supervisor were open and direct about the situation. They also said they have been told that there is a limit for the number of promotions and called this information a "technique." When asked, NIST HR did not support the statement of limits to the number of promotions, illustrating the way in which misinformation, or myths, about the promotion process are held by employees.

In general, ZP staff thought that communication about who has been promoted to what band has not been open in the past, either because the person who was promoted, the Group Leader or both did not want this information known. Lack of communication and transparency about promotions or awards is unusual for any organization and is worth examining as an organizational communications and morale issue. One participant said: “...some of the Group Leaders didn't even know that (salary information) was accessible...And yet all that information is in the public domain anyway, so we're not treating each other with the same sort of transparency that we even treat the public."

\section{Accountability of Managers}

In many of the focus groups, participants felt as if the promotion process were something that was not discussed by their management: “...there is this sort of like, I don't know, taboo around the whole topic and I can understand why there would be like this touchiness about it coming from certain Group Leaders." Another comment was about the process: "...going from III to IV is really between the group leader and the division chief; and then IV to V, the impression that I got, even though it's a black hole, is the division chief and other Division Chiefs in the OU, they sit around and vote type thing." They also thought that "there's sort of a black hole of information between the division level and the lab level. And then there's this clash between the Group Leaders and the division Band." The ZP staff seem to understand the management processes; however, they also don't trust the information they have.

There was general agreement in most of the groups that a ZP staff member's direct supervisor or Group Leader has a major effect on their promotion prospects: "The pay band for 
promotion to $\mathrm{V}$ was delayed for three years because I was put in a group whose leader, I was fundamentally incompatible with." Another person said, "The Group Leader has enormous power over the promotion process. And, having an equitable Group Leader makes all the difference." A number of ZP staff would like to see regular 360 assessments and more open competition for selecting Group Leaders.

Participants noted that their supervisors completed the staff's performance evaluations every year and can give opportunities, resources, encouragement and support leading to future promotions. Many supervisors, Group Leaders and project leaders, even those who might not have wanted to manage, do perform those duties for all of their ZP staff. However, due to lack of management development training, oversight and competence or biases, some supervisors are seen by staff as not supporting promotions for at least some of the staff or being unfair or inconsistent. More than one person said that some employees are favorites and given opportunities to develop more than others. One woman, who was on a waiting list, sent comments to the team calling the promotion process "a painful experience", and a successful scientist who asked her supervisor about necessary requirements for promotion said "I was mocked and told "do something incredibly difficult, with limited resources, to get promoted."

In another group, a participant was interested in defining the roles and responsibilities of a project leader, which he found "incredibly unclear in one case", saying the project leader should perform the role, rather than staff on their team. "They say that they value everyone but they really tend to value project leaders more so that leads to discord and I think unfair promotion." Other comments were: "And I think, at least in my division it's also partially a popularity contest. I think I've seen the pre-retirement promotion. So basically, the vast majority of ZP V promotions that I have observed have been people that are planning to retire in a year" and...I feel as if women get this more...getting the goalpost moved on them more..."

There were comments from participants in the groups about taking initiative and learning how to advance on their own (one was pleased to find and read books on how to succeed) or they had gotten advice from experienced colleagues or management in their own division or other divisions. One person said: "what has helped me the most has been when there's been a group leader or a project leader who has experience in something and gives me documents from past, successful promotions."

The ZP staff in these focus groups wanted clear and honest communication about the requirements for promotion from their supervisor. One person said that it was important for direct management to "have an honest rubric that is used to evaluate people for whatever it is, whether it's an award; whether it's for promotion or even just a performance plan. We would remove a lot of that systematic bias." One staff member gave an example of what she called "gender bias", saying she had asked what she needed to have and was told that she needed 
"more papers." However, when she asked her supervisor to tell her how many more, "he could not answer and I said, well, give me a number. I mean how can I meet the target if I don't know what the target is?" Another participant said "they (management) just said we need more impact and I'm like, okay, so is that the rubrics or here are the things: 25 awards, 225 papers is my impact factor?" (management says) no, well you're not ready you know, have an ...impact."

In addition to vague terminology like "more papers" and "impact," participants discussed what they called 'techniques' that supervisors used: ..."so, in my group, it wasn't safety; it was extra-mural outreach. That's the same thing...it's kind of arbitrary." He quoted his supervisor as saying they did that "because we managers get a floating point or two." A staff member in one group said in their division, there was going to be a separate category for those kind of items in the performance plan.

Another member said there was "an understanding by ZP staff of the difficulty of metrics for research." However, he continued, when discussing staff having access to promotion examples: "that are almost like precedent, you (the supervisor) have the flexibility in making decisions, as long as those decisions are transparent and the process by which some decision was come to is transparent."

The same kind of honesty and transparency was requested by ZP staff about other areas related to promotions. One was the budget: "But, even if there are zero dollars to go around, to say, hey, we don't have what we're supposed to, but we've seen you build on your performance, but we have no money for raises. That's perfectly fine. But don't make up some ratings which are not real." Another issue was hiring related to budget. A participant stated "...very few hires and I feel like everyone in my division is either Band V or Band IV (who) have just given up on getting Band $\mathrm{V}$ because they've been strapped for cash (for years)."

Another area where staff wanted honest communication was about going on details. Some staff believes that these lead to promotions and one person said their supervisor told them the detail was not a path to a promotion, which she thought was "excellent management." Another person thought her supervisor was too negative about details, saying that it was where scientific careers go to die. The ZP staff member wanted support in the division for more flexibility in career pathways for promotion, because she thinks "...NIST needs people who will do something other than count publications, who will do things for the good of the institution or for some customer base out there..."

A number of focus group participants wanted supervisors and managers to be trained before they were in their positions, if possible, and to have their promotion decisions reviewed, either by a committee at the time of promotions or by data collected over time and published for leaders. The ZP staff in one group agreed with the person who said: "if the upper-level management doesn't make it clear that they expect these promotions and evaluations to be done with integrity, then they're probably not going to be." 


\section{Organizational Structure and Culture}

Comments that were categorized as related to organizational structure and culture involved many different aspects such as policies, processes, career planning, mentoring, and the system of pay bands. Comments included in Attachment D illustrate how they also involved issues of fairness and consistency, turnover of employees, the time taken for promotion, and diversity and inclusion.

When the focus groups were asked about what could be done to improve promotions, one person thought that "...some sort of transparency and kind of standardized structure across (the organization) for both promotions and hiring...are essential." There was also discussion about career planning and professional development. Some of the comments included: "...every year they discuss career goals, but more on the technical side rather than another kind of path, and I've been talking about promotion for years but the criteria are never clear to me and sometimes they say, I think you're ready next year or next year - it's been like this for a while" or "In our performance plans there's a little professional development section but it's like $1 \%$ of the performance plan, and it has a weighting of like zero" and, finally, "I only had one lab director ask me what my career goals were, you know, in (over 40) years."

Related to career planning and development, one group had a lot of discussion about mentoring, particularly from ZP-5 and higher-band scientists. They knew these people were there at NIST, but thought they might not be interested in mentoring younger people because, as one person said,

It's because there's not any incentive at all for the older folks to not silo themselves, to not sit at the window and try to finish their work that they've been doing for 15 years and retire, because there's no systemic incentive to engage with younger people.

Another issue directly related to promotion was pay Bands and the pay system, which were discussed in several groups. One person thought that because of the ZP banded steps, people could move through the bands and move up with salary even if they weren't being promoted. Others compared the NIST and GPS systems with varying positions on whether many fewer bands were good or not. What is clear is that many ZP staff don't understand the differences between the bands at NIST and other levels in the federal system and that the bands at NIST are fewer, requiring more time and accomplishments to achieve promotions. A representative comment was: "It (the promotion process) was all just kind of confusing and it was also a very long process."

\section{Recommendations for Change}


The focus group participants discussed a number of ways in which the NIST promotion process and related policies could be improved. Specific recommendations that they offered are listed below. Those from the four groups with randomly selected ZP staff are first, followed by volunteer ZP staff, and then written comments received from those who were not able to participate but were on the wait list.

Recommendations from the four randomized ZP groups:

- Provide examples of promotion packages that are used when people get promoted

- De-couple evaluations from budgets.

- Set up a rubric or guide ("not a checklist") of requirements for promotions, much like the ZP scientists have for graduate student presentations.

- Have a consistent framework, so that people can judge their own merit.

- Have clear descriptions of how people have moved forward successfully.

- Broaden out the definitions of what you need to do to get promoted and what is "promotion worthy".

- It would be helpful to know that there are different ways to advance your career, not just one track or two.

- Have an 'honest rubric' for evaluations.

- Have data available at the division level of the number of women and underrepresented minorities are at Bands IV and V.

- Group leaders need to be as transparent about salaries as the public information.

- Be clear with staff if the budget won't allow higher percentages or promotions (note: NIST HR stated that the budget should not impact promotions).

- Define the roles of project leader versus program leader.

- Remove the managerial bottleneck. Make things less about impression and perception and more about metrics.

- Create a standing committee in each division where an employee could make the case for promotion with evidence of publications, talks and service.

- Like Rockwell, have a salary setting board, where they looked at what the competitive salaries were for a given set of attributes; for a given set of experiences.

- Replace the term: "career development plan", since it may be seen as like the "performance improvement plan." Need to be clear the career development plan means career growth.

Recommendations from the two open-enrollment ZP groups:

- Have small, actionable, measurable steps in the performance plans to see the track.

- Be explicit in a job posting if a Ph.D. or degree is required; desirable or not essential.

- For Band V promotions, expand letters of support and nominations beyond NIST.

- Broaden the review process for promotion with colleagues or committees. 
- Publication by HR of all available training (w/links) at NIST, Commerce, and in the Fed Govt.; procedures to apply and get approved; and whose budget pays for the training.

- Have a committee review promotion package (provides objectivity beyond manager)

- Re-examine the grievance process (bring in outside Federal experienced mediators).

- The Foundations of Leadership should be funded and taken before staff are leaders.

- Check belief that minority and other staff both got bronze awards but different \% raises.

- Have an anonymous suggestion box where staff can put in ideas for change.

Recommendations sent by waitlist participants:

- Find a way (for promotion in) the guest researcher program, which is full of women and minorities, who move on to other institutions, because they have no path at NIST. Some spend years (as) postdocs (or) contractors and leave with...institutional knowledge and connections.

- Reinstate core times (9-11 am and 1-3 pm) for meetings for people who work part time, so that these top researchers will not become marginalized and leave NIST.

- Time off should be available as a promotion/negotiation tool. When eligible for promotion, I would like to have my PTO accrue at a faster rate instead of or in addition to pay.

- Need a periodic 360 evaluation of management: there is no way to evaluate Group Leaders or Division Chiefs. FEVs does only so much.

- Clarify whether or not promotions are actually limited by number of promotions available in a division.

- The promotion process should be straightforward; supervisors should be trained in the process. Promotion should be the supervisor's decision, with concurrence by supervisor's supervisor.

- De-mythologize the belief that women and minorities are being "passed over"_by men or being promoted alongside men who haven't cleared as high a bar.

- Broaden expectations and criteria for promotion beyond funding and publications.

- Measure and report progress in gender equality.

- Have regular 360 assessments of Group Leaders and more transparent open competition for new Group Leaders.

- Written justification of an employee's rating by a supervisor should be reviewed one band up and by a lab-level committee, to ensure uniformity.

- Supervisors should ask employees in career development sessions if they have advocates or champions. If not, leaders should help identify someone to fill that role.

- Group Leaders should be required to start career and promotion discussions with employees on their first day at NIST. 
- Supervisors need to be honest about promotion at NIST - it is different from academia, in that scientists may stay closer to the bench and there may not be as many leadership positions.

- Share a link to the reports from COACh with identified issues and potential solutions.

- Have an actionable vision for change and an action plan with a directly responsible person.

\section{Summary}

The data obtained from the focus groups was remarkably consistent. Participants in each of the groups, whether randomly selected or volunteers, expressed similar views. We identified similar views with both the qualitative coding of the transcripts, as described above, and the more quantitative analysis, summarized in Attachment E. Moreover, the perspectives and opinions presented were generally similar to and consistent with those obtained in listening sessions in our first phase of data gathering and in analysis of survey data in the second phase.

In summary, participants in the six ZP staff focus groups were forthcoming and honest, with a minimum of complaining and more interest in improving the system for everyone. Employees seemed to understand the complexity of NIST's organizational structure and appeared very willing to work with their leaders on the task of positive changes. This good will, dedication, and interest could bode well for productive organizational change. 


\section{Attachment A: Focus Group Consent Form}

COACh is conducting research on the promotion practices of STEM Federal Workforce here at NIST. Thank you for participating in our Focus Group and by participating you are giving your consent for COACh to use your responses in their research.

Each Focus Group will be recorded and those recordings will be securely stored on the University of Oregon servers. The UO Information Services has set up a secure site on their servers, which is compliant with NIST Security requirements and the NIST Security Team has reviewed and approved our security plan. The recordings will be stored for the duration of our contract with NIST and then archived for 3 years as required by Federal Retention Rules.

All responses will be confidential and your identity or any other identifiers about you will be protected and not used in our research, any reports that are presented will use aggregate data collected from this group. Any information that is obtained in connection with this study and that can be identified with you will remain confidential and will be disclosed only with your permission.

Remember, this is completely voluntary and you may withdraw your consent at any time.

COACh is supported by the National Institute of Standards and Technology to conduct this research.

If you have any questions, please feel free to contact Dr. Geraldine Richmond, Department of Chemistry, 1253 University of Oregon, Eugene, OR 97403, (541) 346-0116 or Priscilla Lewis, COACh Manager, coach@uoregon.edu.

If you have questions regarding your rights related to participation in this survey, contact: Office of Human Subjects Compliance, University of Oregon, Eugene, OR 97403, (541) 3462510.

NIST Research Protections Office: Anne Andrews, Director of Research Protections Office, anne.andrews@nist.gov

UO IRB Protocol Number: 12092019.022

NIST IRB Protocol Number: PCO-2020-0193 


\section{Attachment B: Gender Composition of Focus Group Participants}

$\begin{array}{lccc} & \text { Male } & \text { Female } & \text { Total } \\ \begin{array}{l}\text { Focus Group 1 } \\ \text { Nov 9, 1 pm EST }\end{array} & 3 & 3 & 6 \\ \text { Focus Group 2 } & 3 & 7 & 10 \\ \text { Nov 9, 3 pm EST } & 3 & 4 & 7 \\ \begin{array}{l}\text { Focus Group 3 } \\ \text { Nov 12, 1 pm EST }\end{array} & & & 9 \\ \text { Focus Group 4 } & 4 & 5 & 32 \\ \text { Nov 12, 3 pm EST } & 13 & 19 & \\ \text { Totals: } & & & \end{array}$

Note: In addition, there were twenty participants in the open enrollment ZP staff focus groups. The first open group had eight males and two females and the second open group had five males and five females. There were twelve waitlist respondents who responded, for a total of sixtyfour (64) ZP staff. 


\section{Attachment C: ZP Focus Group Questions}

1. How can NIST improve the promotion process?

Communication/Transparency Probes:

- How easy is it to get information about promotions?

- How easy is it to understand what is required for promotion?

Accountability Probes:

- What could supervisors or managers do to improve the promotion process?

- Do you have regular performance planning discussions with your supervisor?

- Do you or someone you know have a career development plan?

2. If there were something that could be changed, what would you want it to be? (policy; process; practice, etc.)

3. Ending Question: Is there anything we didn't ask that you think is important? 


\section{Attachment D: Key Themes with Quotes}

\section{Transparency and Communication}

Transparency:

- Promotion from postdoc to permanent: "It was great but I didn't understand any of what went on sort of behind the scenes in that and I would say I still don't understand it."

- "Same for going from ZP IV to V. And that kind of aims with accountability, we don't even know how to hit that mark, if they can't tell us what hurdles we're trying to clear first."

- Promotion standards or rubric (not a checklist of criteria to meet): “...here are the past decisions that we agree with as a current organization (and) the ones we disagree with, (then) it becomes something we can actually discuss with words as opposed to this cloudy thing."

- "...the ZP IV and ZP V, that is like a black hole of mystery - nobody knows how it works."

- "Yeah, there's the Senior Executive Service I think it is like they actually have it's like a five- or 10-point rubric that spans many things and then there's like five or 10 bullet points under each item like you need to be hitting at least a certain number of these to even be considered...I stumbled across it ...and was like, wow, go figure that the highest band actually has a rubric, why don't the rest of us?"

\section{Communication:}

- “...I don't know if there are any limits to what could be done for performance increases each year..."

- “...some of the Group Leaders didn't even know that (salary information) was accessible...and they try to...blot out people's salaries from statistics...and then they report out their findings that they've tried to aggregate. They'll try to remove people's names from what they make or vice versa. And yet all that information is in the public domain anyway, so we're not treating each other with the same sort of transparency that we even treat the public."

\section{Accountability of Management}

- ..." we need to have an honest rubric that is used to evaluate people for whatever it is, whether it's an award, whether it's for a promotion or even just a former performance plan. We would remove a lot of that systematic bias."

- "But even if there are zero dollars to go around, (just) say, hey, we don't have what we're supposed to but we've seen you build on your performance but we have no money for raises. That's perfectly fine. But don't make up some ratings, which are not real." 
- "And if the upper-level management doesn't make it clear that they expect these promotions and evaluations to be done with integrity, then they're probably not going to be."

- “...there is this sort of like, I don't know taboo around the whole topic and I can understand why there would be like almost this touchiness about it coming from certain Group Leaders..."

- "...what has helped me the most has been when there's been a group leader or a project leader who has in experience in something and gives me documents from past successful promotions."

- Understanding by staff of the difficulty of metrics for research - if have promotion examples: "that are almost like precedent, right, you have flexibility in making decisions as long as those decisions are transparent and the process by which some decision was come to, is transparent."

- "...your group leader, you know, as you said, is either not super competent or has a bias in a certain direction. In my case it was definitely a gender bias... For example, I've been told that I need to have more papers, and when I asked my supervisor well how many more papers, do I need I was never given an answer. He could not answer and I said well, give me a number. I mean how can I meet the target if I don't know what the target is?"

- "...they (management) just said we need more impact and I'm like, okay, so, is that like the rubrics or here are the things, 25 Awards 225 papers is my Impact Factor? No well you're not ready you know, have an impact."

- '...so, in my group, it wasn't safety; it was extra-mural and intra-mural outreach. That's the same thing...it's kind of arbitrary...because we (managers) get a floating point or two..."

- "And, back to the promotion...going from III to IV is really between the group leader and the division chief, and then IV to V, the impression that I got even though it's a black hole is like division chief and other Division Chiefs in the OU like they sit around and vote type thing."

- "there's sort of this black hole of information between the division level and the lab level. And then there's this clash between the Group Leaders and the division level..."

- "(Colleague) mentioned the advice on the detail not being a path to a promotion..., just so you know the expectations are clear this will not lead this way and that's excellent management, that's the kind of thing that I think we're missing at NIST."

- "...So, if I can chime in on the idea of details - in the eyes of my group leader that's where scientific careers go to die. I've had the discussion with her a couple of times now about trying to do various types of details and every time it's no, no, no...but, on the other hand, NIST needs people who will do something other than counter publications, who will do things for the good of the institution or for some customer base out there..."

- "...it was incredibly unclear in that case, what the roles and responsibilities of a project leader is generally; what the program lead's roles and responsibilities are, and we actually have a document that we had to get it was somewhere in the SharePoint, 
somewhere that the lab level had put a lot of effort into carefully defining exactly what a project leader's roles are, what they're expected to do; what kind of milestones to supply."

"...very few new hires and I feel like everyone in my division is either Band V or Band IV (who) have just given up on getting Band $\mathrm{V}$ because they've been strapped for cash (for years)."

\section{Organizational Structure and Culture}

- "Well, I mean, some sort of transparency and kind of standardized structure across (both) promotions and hiring, I think, are essential."

\section{Career planning:}

- "I tried. My group leader shot mine down-she wanted nothing to do with it. Because I'm a bench scientist she was essentially you're too good in the lab. That should be your career development focus-- getting good at that and becoming the biggest name that you can versus outside sources of career development (e.g., administrative or career growth)."

- "...you might need a little bit of a culture shift there to thinking that career development plans are something good and that you should be having those conversations regularly it's not that you're doing what I need to improve."

- "...every year they discuss career goals, but more on the technical side rather than other kind of path, and I've been talking about promotion for years but the criteria are never clear to me and sometimes they say, I think you're ready next year or next year - it's been like this for a while."

- "In our performance plans there's a little professional development section but it's like $1 \%$ of the performance plan, and it has a weighting of like zero."

\section{Mentoring:}

- "It's because there's not any incentive at all for the older folks to not silo themselves, to not sit at the window and try to finish their work that they've been doing for 15 years and retire, because there's no systemic incentive to engage with younger people."

\section{Pay Bands:}


- "Inside of the ZP three banded steps, you are technically moving through those pay bands, even if you're not getting promoted. So, then we know that it's an issue of is my salary actually going up because of my performance, which it can a number of times, and I still never get a promotion. So, the promotion doesn't affect me financially..."

\section{Comparison to Federal GPS systems:}

- "Trust me, it's so much better and more transparent to easily glide from what would be 11 and 12, and for my 13 and 14, which are, you know, ZP-III and ZP-IV. It's far superior to the old system."

\section{Fairness:}

- "...how do I score relative to kind of the person next door, or maybe how are the people, who in my mind are the underperformers, how are they scoring? And, is it a fair system?"

- "They say that they value everyone but they really tend to value project leaders more so that leads to discord and I think unfair promotion."

- "...I was told that I needed to bring in funding...so, I brought in funding, and then I was told that I didn't have enough publications...I asked...how many more do I need and wasn't given an answer...From comparing notes, I feel as if women get this more...getting the goalpost moved on them more..."

- "The pay band for promotion to five was delayed for three years because I was put in a group whose leader, I was fundamentally incompatible with."

\section{Turnover:}

- “...it's great you know that women are being promoted at the same rate as men, but it does seem to be that a lot of women are also dropping out."

- "...if you want to retain them, you have to promote them at an earlier time frame."

\section{Consistency:}

- "And I think, at least in my division it's also partially a popularity contest. I think I've seen the pre-retirement promotion. So basically, the vast majority of ZP Five promotions that I have observed have been people that are planning to retire in a year."

- "The first step is your group leader has to recommend you and until he or she makes that decision there's nothing you can do. So, the personalities of the group leader can play a role. And you have to probe to find out. So, he said, you can only make this 
discussion during the performance time. You don't know in what mood, you will catch that person... I'm just trying to say the objectivity is not there.

- "...definitely true transparency is important, but also having a consistent framework, so that people can judge their own merit based on that framework."

\section{Time to Promotion:}

- "It (the promotion process) was all just kind of confusing and it was also a very long process."

\section{Diversity:}

- "A lot of them came here as postdocs and stayed on. We need to look more beyond that channel, and bring in people who have different experiences, which would then influence how we do stuff." 


\section{Attachment E: ZP Focus Group Coding Methodology and Process}

This attachment summarizes the process for collecting and analyzing the information provided from four randomized focus groups held on November 9 and November 12, 2020. The focus groups consisted of randomly selected ZP staff using a systematic selection procedure with stratification by gender. Each focus group was held over Zoom with two members of the COACh team facilitating and moderating the conversation. Using the software's transcription services, the conversation for each group was recorded and annotated. The following is an account of the methodology used to organize and synthesize the transcriptions, along with a summary of the coded findings.

Methodology

Using Zoom's transcription services, each of the four focus groups, which were held at 1 PM and 3 PM EST on November 9 and November 12, 2020, respectively, were recorded and transcribed. Once each conversation concluded, a text file was produced with the transliteration of the video recording. This text file was thus converted into a Word document and cleaned for any errors that transpired during the recording process. Additionally, line breaks, which corresponded to individual responses, were added to increase the readability of the document. These clean documents were sent to four COACh members who reviewed, annotated, and coded each file in Word with special attention given to four previously agreed upon themes including Transparency/Communication, Accountability of Management, Organizational Structure and Culture, and Recommendations. Once the coders completed their reviews, their comments and codes were organized and synthesized into one document per focus group using NVIVO, a qualitative data analysis computer software program. This process enabled a deeper analysis of NIST as an organization through the eyes of 32 ZP staff members by counting the number of instances focus group members mentioned details pertaining to each theme.

$\underline{\text { Findings }}$

While all four themes were discussed by ZP staff during each focus group, details pertaining to Transparency were mentioned at a higher rate in two of the four groups where members expressing feelings of confusion around promotional requirements and the promotions process. Accountability of Management also had high rates of incidence with members describing moving goalposts and unclear expectations from managers. Organizational Structure and Culture were discussed at slightly lower rates with members sharing experiences of bias, unfairness and inconsistency within the promotion process, and unpopular organizational values. Recommendations that emerged from these groups included training managers, developing a mentorship program, developing career planning and professional development opportunities, and implementing tools such as rubrics for evaluations to enhance understanding and transparency. The list of codes collected from these four focus groups is included in Table E-1. 
Additionally, graphs mapping the incidences for each theme from each focus group are included in Figure E-1. The information provided from these focus groups will help guide the final recommendations given to NIST in an effort to help improve the hiring and promotion process.

\section{Table E-1}

\begin{tabular}{|c|c|c|c|c|}
\hline Name & $\begin{array}{c}\text { References } \\
\text { Nov } 91 \\
\text { PM }\end{array}$ & $\begin{array}{l}\text { References } \\
\text { Nov } 93 \text { PM }\end{array}$ & $\begin{array}{l}\text { References } \\
\text { Nov } 121 \\
\text { PM }\end{array}$ & $\begin{array}{l}\text { References } \\
\text { Nov } 123 \\
\text { PM }\end{array}$ \\
\hline Accountability & 11 & 5 & 12 & 11 \\
\hline Communication & 15 & 12 & 6 & 4 \\
\hline Culture & 6 & 16 & 11 & 5 \\
\hline Bias & 0 & 0 & 3 & 0 \\
\hline Fairness & 1 & 1 & 0 & 0 \\
\hline Points to pull out & 11 & 9 & 2 & 2 \\
\hline Recommendation & 0 & 0 & 0 & 0 \\
\hline Benchmark & 3 & 0 & 0 & 0 \\
\hline Career Planning & 0 & 4 & 2 & 3 \\
\hline Flexibility & 4 & 1 & 0 & 0 \\
\hline Information & 10 & 6 & 0 & 0 \\
\hline Mentorship & 1 & 1 & 0 & 0 \\
\hline $\begin{array}{l}\text { Performance } \\
\text { Review }\end{array}$ & & & & 1 \\
\hline Plan for Change & 0 & 0 & 1 & 1 \\
\hline Review Process & 4 & 3 & 4 & 8 \\
\hline Support & 0 & 6 & 0 & 0 \\
\hline $\begin{array}{l}\text { Terms for } \\
\text { Managers }\end{array}$ & 0 & 2 & 0 & 0 \\
\hline Training & 5 & 3 & 3 & 2 \\
\hline
\end{tabular}




\begin{tabular}{|l|r|r|r|r|r|}
\hline \multirow{2}{*}{ Name } & $\begin{array}{c}\text { References } \\
\text { Nov 9 1 } \\
\text { PM }\end{array}$ & $\begin{array}{c}\text { References } \\
\text { Nov 9 3 PM }\end{array}$ & $\begin{array}{c}\text { References } \\
\text { Nov 12 1 } \\
\text { PM }\end{array}$ & $\begin{array}{c}\text { References } \\
\text { Nov 12 3 } \\
\text { PM }\end{array}$ \\
\hline Structure & 8 & 19 & 6 & 8 \\
\hline Consistency & 3 & 3 & 0 & 0 \\
\hline Transparency & 20 & 18 & 8 & 12 \\
\hline Clarity & 0 & 4 & 0 & 6 \\
\hline
\end{tabular}

Figure E-1

11_9 1 PM Clean

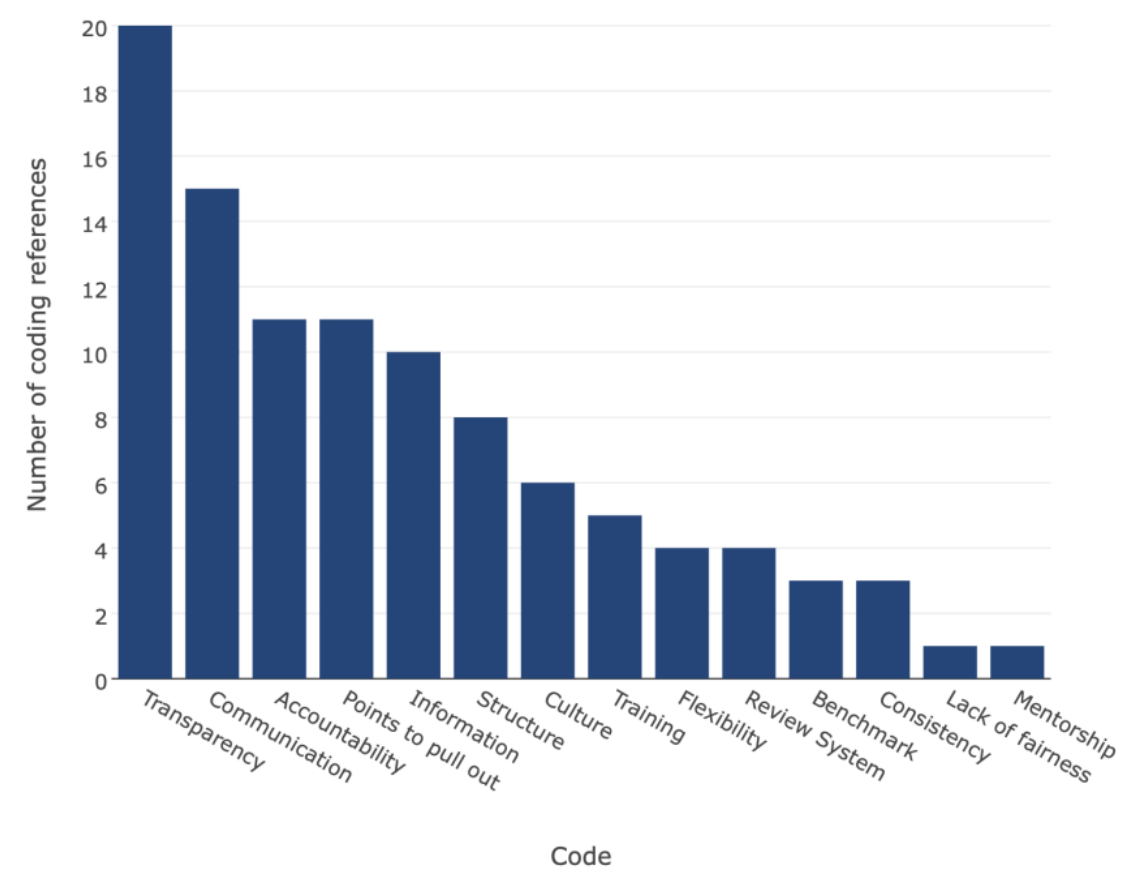




\section{1_9 3 PM Clean}

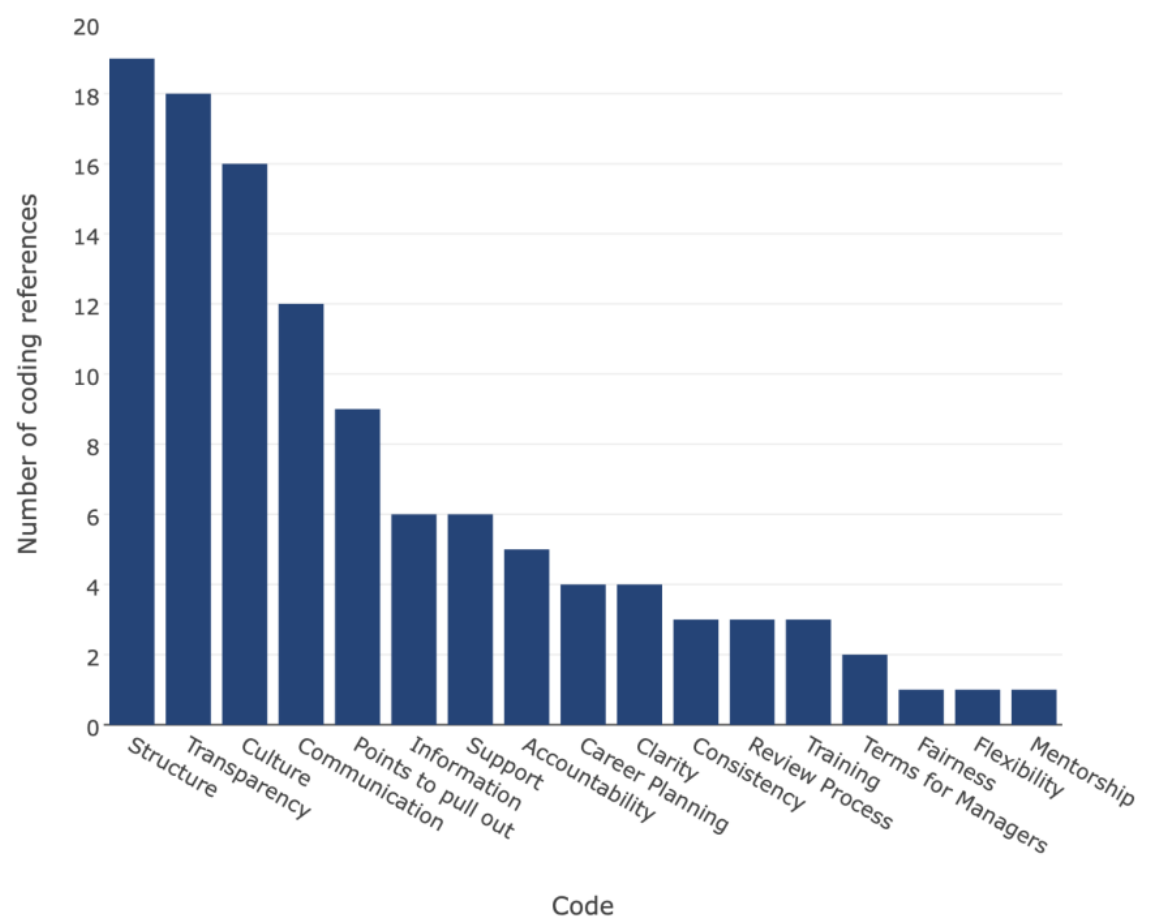

11_12 1 PM Clean

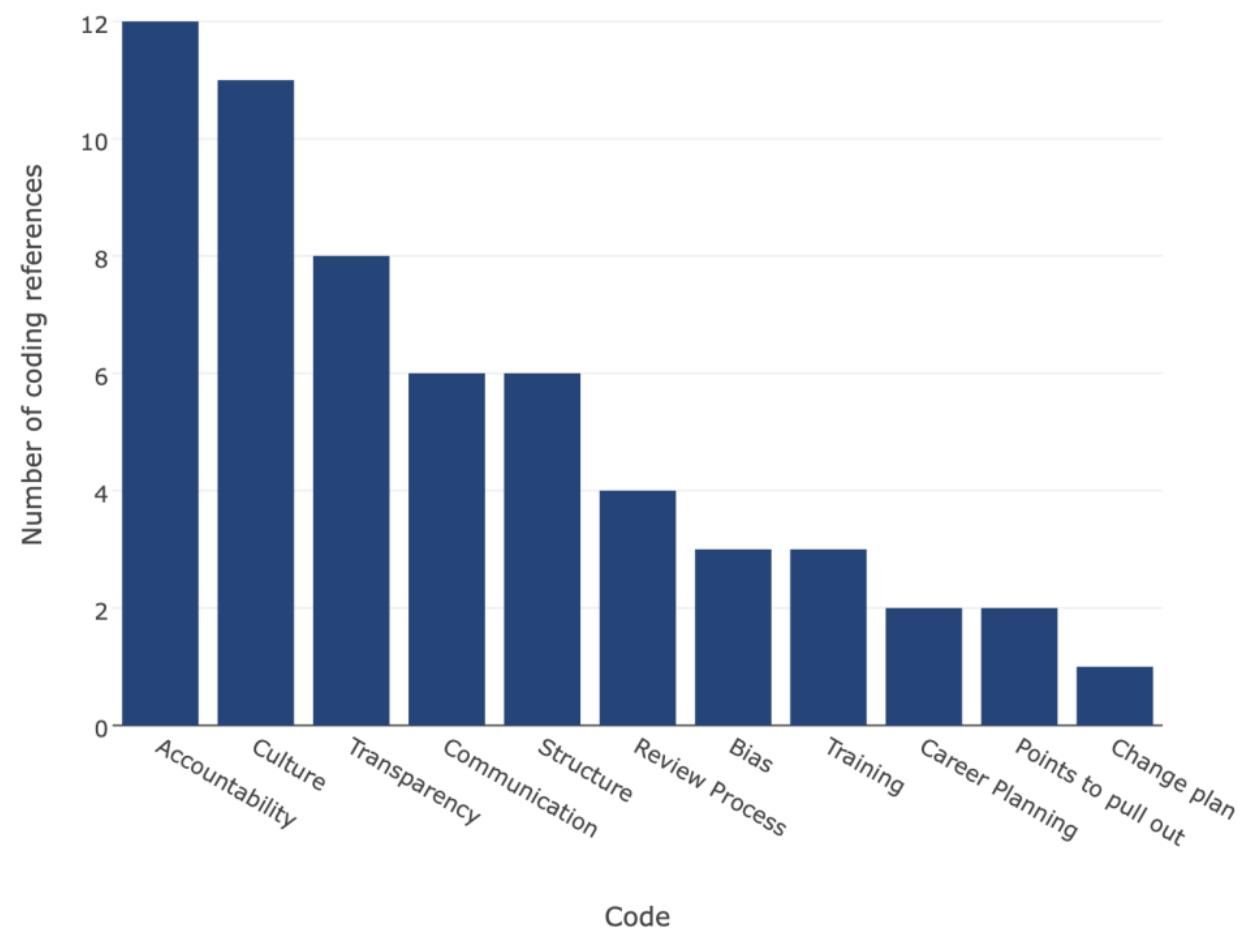


11_12 3 PM Clean

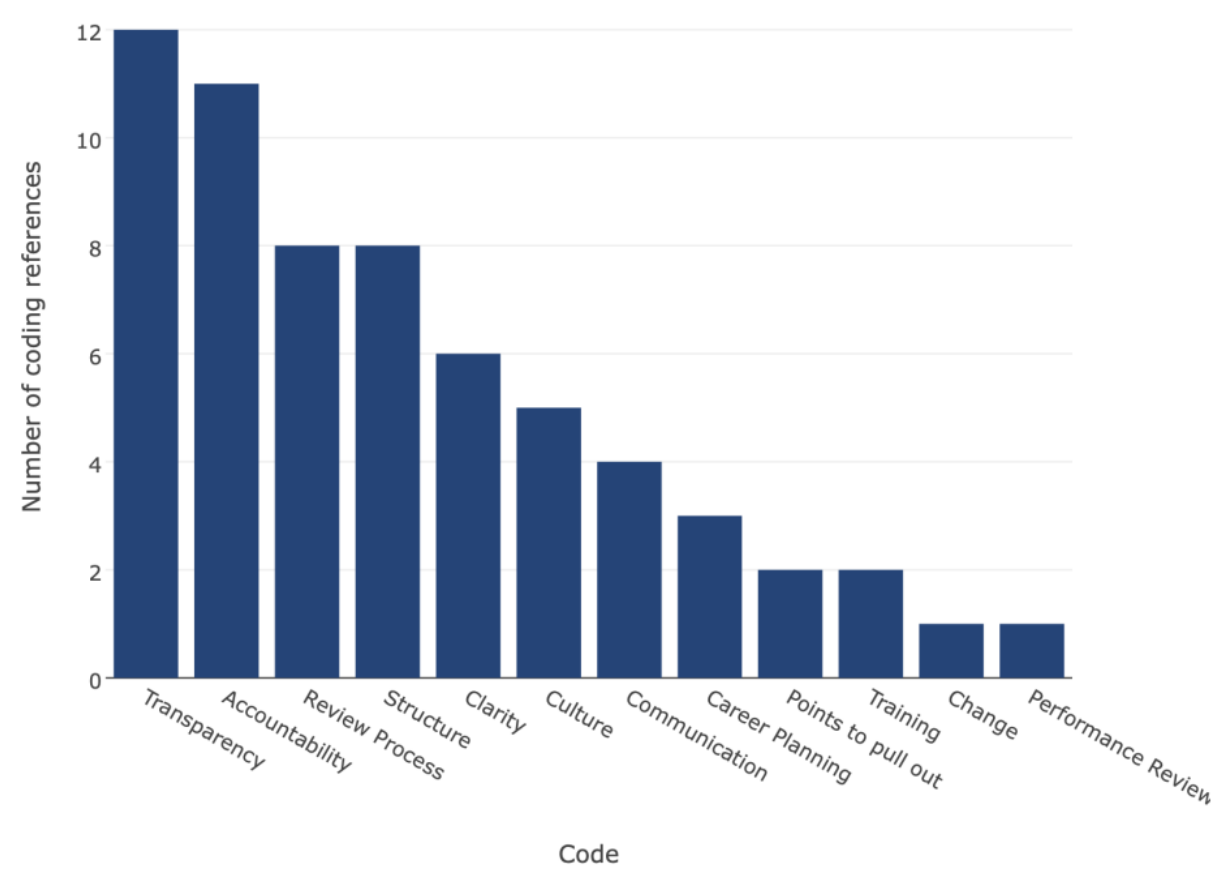




\section{Report 9: Focus Groups Conducted with Group Leaders in December $2020^{50}$}

This report summarizes results of two focus groups with Group Leaders held in December 2020. The focus groups were the third phase of data collection for COACh's analysis of concerns with the NIST promotion system. Six focus groups were held in November with staff in Bands ZPIII to ZP-V and the results of those groups are summarized in a separate report (Report 8). Subsequently, the COACh team decided that, because Group Leaders were the first-level decision-makers in the promotion process, it would be important to hear their perspectives and recommendations. This report summarizes findings from those sessions. The first major section below describes the methodology that was used, the second describes key findings, and the third lists recommendations made by participants. Four attachments are included: $A$ ) the consent form for participation, B) questions used with the focus groups, C) quotations from the sessions that illustrate key themes, and D) a quantitative analysis of themes and comments.

\section{Methodology}

The team hosted focus groups of Group Leaders on December 3 and 8, 2020. Both groups were held on Zoom and open to any interested Group Leaders. Following procedures developed by COACh for the focus groups with ZP staff, a NIST staff member identified potential participants and sent them an email, explaining the purpose of the groups. Group Leaders who expressed interest were directed to the COACh website at the University of Oregon to select a day and time to participate. Anonymity was addressed by having only the COACh registrar know the names of those who signed up. Participants were asked to not use their real names and, instead, rename themselves with a pseudonym on the Zoom screen. A Focus Group Consent form (see Attachment A) was sent to each participant and read at the beginning of the sessions, followed by ground rules, for verbal agreement from the participants. These security processes were approved by the IRB boards of both NIST and the University of Oregon.

As with the staff focus groups, the Group Leader groups were limited to a maximum of ten (10) participants per group. There were 19 participants in the two sessions: nine ( 5 male and 4 female) for the first group on December 3 rd and ten ( 5 male and 5 female) for the second. There was a waitlist of 3 males for the second group, and, as with ZP staff, they were given the opportunity to respond by email to a question about improving the NIST promotion system. Each focus group was planned for one and a half hours. Participants were encouraged to stay for that time, though they were free to leave at any point.

\footnotetext{
${ }^{50}$ This report was written by M. Noviski and J. Tucker and completed February 5, 2021.
} 
The initial question for these focus groups was carefully formulated to understand how the Group Leaders usually worked with their ZP staff in preparing for the promotion process. It was open-ended, to avoid unintentional leading of answers from the participants. Subsequent probes and additional questions were more directive in order to capture whether certain elements in the NIST promotion process, such as succession planning or separate career planning meetings, existed in various divisions. As with the staff focus groups, the moderators followed the discussions and asked clarifying questions when appropriate (see Attachment B).

Coders for the two transcripts were three experienced members of the COACh team. Units of analysis used were primarily sequences of sentences, although a single sentence or complete dialogue may have also been coded. The team required at least two coders to agree for validity. Coders also looked for illustrative comments related to themes (see Attachment C). Another member of the team used the NVIVO software program to identify frequency by codes of the Group Leader responses as well as points cited by coders (see Attachment D).

\section{Findings}

The first question for the two Group Leader focus groups was about how they typically worked with ZP staff to prepare them for the promotion process. Subsequent probes related to this preparation were: when they started working with staff on promotion; if there was succession planning in the division; if they worked with staff individually during performance reviews or at other times; whether they used career advancement plans; what the nature of the relationship was (mentor, coach, etc.) and whether their approach varied by Band. The first subsection below summarizes answers to that first query. The second subsection presents comments involving NIST practices and policies that are related to the promotion process. Attachment $C$ includes a broad selection of quotes from group members that deal with issues associated with the promotion process. Not every Group Leader answered every question; however, all contributed and some said they learned from the exchange. It is recognized that any particular comment might be classified in more than one category used for analysis. However, it is important to recognize that each of the highlighted elements reflect aspects of the Group Leaders' concerns and are important for informing recommendations for change.

\section{Preparing Staff for Promotion}

In the first group, a Group Leader talked about using structured interviews to gather information for writing the promotion package. She felt that this was a good approach and thought that the ZP staff needed someone else to write the package for them or needed help in writing it. Several others talked about starting the process in advance of the time when a staff member might be promoted. One Group Leader said that his laboratory had "certain criteria which are meant to be guidelines of what you need to do to move from one Band to another." If he thinks someone is going to be ready for promotion, he likes "to try to be sure they're ready by giving them assignments and opportunities to achieve those things and you know it can be 
different from person to person..." The Group Leaders all said that the promotions from ZP-IV to ZP-V took more work, mentoring and time than those from ZP-III to ZP-IV.

In response to when Group Leaders talk with staff about promotion, one said "it often comes up at evaluation (that) we're thinking about this and there's an opportunity in that process to provide feedback for what they should do in their own career development, so it's kind of a natural opportunity." However, another Group Leader thought that the performance planning meeting was not a good time and said: "...the performance plans are really kind of what I call an exercise in bureaucracy with a template that's used for everyone and they fill in the name of the project working on and maybe some deliverables that they have...but other than that, they're not very helpful for most people who do what they expect to do..." This person mentioned that her group brought up the idea of having an Individual Development Plan where the staff could lay out their four-to five-year goals and steps to get to those goals.

In continuing the discussion about when they started working with staff on promotion, one Group Leader said "I would say it's two different processes for me - one where the person is very aware of where they are in their band...and you have to have the conversation with them as to...what's coming up for them to be promoted; what they need to do, and oftentimes (what) ends up being the driver is being there at the cap of whatever band...that becomes their impetus." The group then talked about the staff who are unaware of the potential for promotion and one participant said: "I would say the sign of a good manager is one who can identify the person who is not aware and then lead them correctly to the path that's going to get them there or, if they're just telling you they're not interested...you identify that and make sure that they are at least challenged in what they're asked to do every year." Another participant talked about encouraging all staff to advocate for themselves and said "that's a big discussion across NIST now in general..." and that people were now coming to their supervisors asking about getting to the next band. They also talked about career conversations with a person who has been at the same band for years and one supervisor suggested to "have a conversation ...to see if they need to be excited about something different...different research. This Group Leader felt like the career conversation was currently being used as a "check-a-box exercise and not taken seriously."

\section{Organizational Policies, Practices, and Culture}

Participants raised a number of issues related to NIST policies and procedures, often very similar to those that were mentioned by ZP staff. These issues included 1) concerns about transparency and consistency of promotion-related policies and procedures, both over time and across divisions; 2 ) perceptions of fairness; 3 ) the roles and responsibilities of Group Leaders and others in the promotion process; and 4) issues related to planning and support. It is recognized that given comments could be placed within one or more grouping, but each of the areas highlighted is related to the recommendations mentioned by participants, which are highlighted in the following major section. 
1. Transparency and Consistency. The Group Leaders spoke of the lack of consistency with the promotion process among different Division Chiefs. One person gave an example of a previous Division chief requiring a Ph.D. to be promoted from ZP-III to ZP-IV and when "the new Division Chief came in...and saw all these people who were at a ZP-III for years...he instantly promoted everyone who had been sitting there forever to ZP-IV, because he didn't feel he needed to have a Ph.D..." Another participant from a different lab, with experience in a variety of roles at NIST, agreed: "I was simply appalled at all the ZP-IVs (who) had not been put in for ZPVs that were clearly working at what my lab considers a ZP-V Band - it was based on the personality of the previous Division Chief, I guess. I just remember a very senior Division Chief looking at it (promotion package) was just like a jaw dropping to the table of how on earth was this man not a ZP-V already!" In some situations, Group Leaders reported seeing that "the milepost or the goal is moved, in terms of the program or...activities, so the person is not eligible."

Many Group Leaders would agree with ZP staff about the need for more transparency and clear pathways in the criteria that the OUs have now. One said their laboratory had recently made an effort to put information on the internal web which was "very specific to promotion" and "what it takes to get promoted." Prior to that, she said you had to "dig around to find that information." Another participant said: "In my OU, the information is virtually top secret-I mean it's really hard to break that loose and it's somewhat ridiculous. In my opinion, the process ought to be a lot more well-defined and in information available." Even the list for promotion from Band III to IV can be misinterpreted because it is long and, as one Group Leader said "we're often times looking for real depth and leadership in a given area, so you don't have to check all the boxes...." Similarly, one Group Leader said: "...that points to what most of us would say is one of the problems in the system of promotions is that it's undefined across the board at NIST and each division can kind of do their own thing and, once it becomes unwritten policy within their division how it's done, then people will go to that and it's only when, as you just heard, new blood comes in and reviews things and asks questions do things change, and maybe changing for the better."

The Group Leaders also talked about the inconsistency of working with staff concerning promotions, which may be due to the lack of clarity about metrics or steps. One person called it a "variable conversation" with some staff saying OK and then not changing anything or taking more responsibility and others asking for more to do in order to get promoted right away - "like yesterday." Group Leaders would like to have other incentives to offer besides promotion "other opportunities to grow or whatever...but it's not necessarily a formal process." Another said that "some people think a promotion means you're moving into a supervisory or management position, but, actually, at NIST you get nothing financially for doing that...but a promotion from one pay band to another is in fact a financial change..." There was a discussion about caps in pay bands and they thought that the difference in salary between the maximum of ZP-IV and getting promoted to ZP-V was not very large, which reduced the incentives to put in the effort and prepare a package for promotion to ZP-V. One Group Leader also mentioned having conversations several times a year with the staff, who would rather be in the lab getting 
data than in the office writing papers. He said that it takes a long time and multiple conversations to figure out their skills so they can "attain that type of competency with their promotion package." He meets with staff several times a year, keeps folders and asks for information to prepare the promotion packages, but feels "it was said before that ZP-V is really a tough level to achieve - you have to be at the top of your game in your field."

2. Perceptions of fairness. Some of the comments addressed issues regarding fairness and perceptions of inequities. One participant observed that: "it's the younger people that tend to get promoted faster...if you don't get promoted early, then you tend to stay where you are...and one of the challenges is you get to a certain age and you have your personal commitments in your outside life." Another said that she had worked part-time for 17 years and "had a supervisor that really kept me on track and I'm trying to do the same thing with an employee who is working part-time."

One Group Leader described ZP-V as "a kind of capstone you give someone before they retire, so you give it to them and it signals that they are going to be retired in a few years and added that they would rather see the Band V given to people who are "in the stride of their careers...so that's going to lead us to even better things, but that's not the way it's being perceived." There was agreement that the promotion to Band V was the most difficult because there is "this huge chasm between the written rules and the unwritten rules...the OUs have done a nice job putting the stuff (paperwork) on line; it's when you reach that ineffable quality of being ready for Band $V$ - that's what's confusing to people...you basically have to do some detective work, usually with your Division Chief, and locate a couple of examples that have worked...the rules tell you one thing, but, in reality, what works is nuanced and it's different...in every university on the planet, the rules are clearly posted and here, it's like the Manhattan Project so very, very odd."

Some mentioned policies that might affect perceptions of person. For instance, one person reminded the group about the "accretion of duties" promotion which means that you're actually working above what's in your performance plan," which this leader said means that the write-up for a Band $V$ is not what's in a person's performance plan.

Group Leaders were concerned about several kinds of contributions that don't get attention, such as staff who are collaborative team players and staff doing measurement services where they're "creating products and services that NIST sells." They said "when you have everybody trying to be a star, because that's what it takes to get promoted, and everybody trying to make a name for themselves externally and internationally, you end up stretching the organization very thin...because those people who could be excellent collaborative team players...don't get recognized for that very important skill for an organization."

Participants recognized the variability in roles and responsibilities of ZP staff, sometimes suggesting that the current procedures could be more flexible. Some noted that Group Leaders 
are supervisors for scientific and research staff and there was, according to one participant, "a dis-connect on the performance plans...it isn't quite what we're looking for from the research scientists...and that's a place for improvement." Group Leaders also recognize, although it would be good to have some standards across divisions, there will be differences in division requirements because of differences in pathways (academia versus industry) and in outside salary competition for different scientific professions. Another supervisor talked about being in a group that was primarily doing research, noting that most of the staff were there because that's what they want to do, they preferred to move up in professional rank rather than leadership, and implying that promotion should involve recognition for scientific accomplishments rather than moving into leadership roles.

In general, the Group Leaders thought that NIST should recognize the value of collaboration and diverse kinds of accomplishments that contribute to the mission. And they thought the collaborative spirit could be even stronger if the promotion criteria/metrics were more flexible than publishing papers and having "impact" or "renown."

One Group Leader said that his Division Chief had developed two tracks with promotion that had different requirements - basic research and measurement services and the qualifications were different - which illustrates that flexibility in the promotion process can be designed. However, one issue for the Group Leader with this system is that there are people who are "hybrids" of the two paths and he asked the group "how do I put that package together?!"

3. Roles, Responsibilities, and Power. Some comments directly addressed the responsibilities for promotion processes and decisions. Although they can advocate, the Group Leaders feel that they don't have decision-making power, especially with the ZP-V promotions, since Division Chiefs have to put together a package and take it before management. One Group Leader said that the chief may not understand a package in his division, because they're not in the same field or that “...it's a moving target - l'll say this person is having good impact and then it would be like, maybe but she doesn't have international renown. Well look she's got that now; maybe, but she doesn't have impact..." Group leaders may not be clear about what the Division Chief thinks is needed to make the person ready.

One group discussed the importance of the role of Group Leader, Division Chief and other management in promoting or blocking promotion..."it can potentially be a significant barrier to an individual who, for whatever reason, isn't in favor with the people in that chain..." or ...if you don't have the energy or the outgoingness to promote yourself; get your Group Leader excited and get him or her to get the division chief excited (because), without (that)...there is no reward..." Some explicitly linked this issue to perceptions of fairness, suggesting that the Division Chief had too much power. One said ..." ultimately there is a king or queen in place and, if they don't like you, you're not going to go anywhere..." With a lack of oversight, biases will go undetected and the supervisors felt that was the reason that "people change divisions because 
it's easier to get a promotion in another division, so it's not transparency (that's) the problem; fairness is the problem."

4. Data, Planning, and Training. Several participants discussed issues related to planning for the future and support that was, or could be, given to staff and supervisors.

When asked if the Group Leaders got regular data about their employees, such as length of time in position, salaries, etc., several answered that it was available online or from the Administrative Officer. However, they liked the idea of having information about staff come to them (such as a through a "dashboard" system), rather than having to ask upper management or search online. In response to the moderator asking about whether they had succession planning, one Group Leader said "well, we're going to find out because my lab director just announced he's retiring...I think the answer is yes, there is some succession planning...many people don't want to "move upward too far because it's just not worth it."

In terms of the leadership training they received, the group said that the session on promotions was "very administratively driven...not really the steps you take...to get somebody promoted...not about how to talk to somebody about being promoted...." Concerns were frequently mentioned regarding the needs of those who were new to the group leader position, since the new supervisors don't have what the group called "institutional knowledge." They were very interested in having a repository of successful packages that was not just a paragraph or one sentence about an award, but an entire package. They were also interested in having division meetings of Group Leaders where potential promotions are presented and discussed.

A participant in one of the groups offered an interesting idea new to their division. He said that someone was being proposed for promotion to ZP-V and they had a lot of new Group Leaders who weren't clear on the criteria for promotion to a ZP-V: "the thing that we just decided to do about that was to have a meeting closer to ZP-V promotion time where we each discuss people we think might be ready and why and then, as a division...not come to consensus, but hear each other out and move forward..." One of the other members had experience with conversations about who was ready and who was not, with a division leadership team, but said it was not consistent and added: "having a process that would make it more consistent would be nice."

Another issue had to do with management skills, which they believed were more difficult for scientists. There was a long discussion about a Ph.D. being required to be a group leader and one Group Leader debunked that "rule", saying, "...so part of our process is that we just lie if we don't want to say...we make up rules...but they're not." She then went on to list several Group Leaders she knew who did not have Ph.D. $s$ and named the divisions to prove her point. Participants also discussed limitations that might be placed on those who become Group Leaders while at a Band ZP-IV. When they become Group Leaders, with additional tasks, their staff takes 
over their science projects, which helps the staff in their careers. However, it can interfere with work the leader could be doing to get to a Band ZP-V.

One group ended their session talking about flexibility in the system at NIST. One person was very appreciative of the opportunity and support she had received while working part-time. Almost all of the respondents indicated that they enjoyed their work at NIST and were proud of what they and the organization accomplished. Thus, the recommendations for change that they presented were given in the spirit of improving an organization to which they were committed.

\section{Group Leaders' Recommendations}

Throughout the discussion Group Leaders mentioned a number of recommendations for improving the NIST promotion process. These recommendations are listed below:

- Clarify the distinctions between requirements for Band ZP-IV versus ZP-V.

- Have promotion package examples for promotion from ZP-III to ZP-IV.

- Encourage Group Leaders to be willing to mentor people within their division and, with the consent of other Group Leaders, outside their divisions.

- Encourage all bands of staff to be advocates for themselves and in approaching their supervisors.

- Provide staff information, such as length of time at position, salary history, etc. to new Group Leaders.

- Provide information to new Group Leaders from the previous Group Leader about where they thought people were in their career paths and if the Leader had been thinking of a promotion in the near future.

- Include promotions in the Group Leaders' performance plans, not just how many papers they've written, so that they will also be rated on what they did for their people.

- "One of the things that I'd like to see in the promotion process is...more embracing of diversity among the researchers."

- Change the training for Group Leaders about promotion - include the steps and how to talk to staff and use instructors who have been Group Leaders for research staff.

- Change the performance plans and documents to reflect what is expected of scientific and technical staff.

- Have Group Leaders in a Division meet, closer to ZP-V promotion time and share information about the staff each would like to promote and why - not to come to a consensus, but to hear each other out, learn what might work and to share ideas.

- Have intermediate levels for promotions to give people recognizable targets.

- Re-design the promotion system within divisions with different pathways in order to recognize technical profession differences and collaborative leadership. 
- Have online examples of successful promotion packages or high-level summaries - all with personal information redacted or re-written as scenarios.

- Address the federal shrinkage of pay between the supervisory ZP-IV and ZP-V to make it worthwhile to achieve Band V.

- Have requirements for promotion that acknowledge new expertise and new projects, not just publishing papers, so that people can change as the science changes.

- Examine and reduce the conflicts for Group Leaders between their supervisory tasks and efforts required to work towards promotion to a Band ZP-V.

\section{Summary}

In general, the concerns and recommendations presented by the Group Leaders were similar to those expressed in focus groups with ZP staff. They also paralleled views expressed in listening sessions and survey data from the first two phases of COACh's data gathering. Like ZP staff, the Group Leaders were honest, with a minimum of complaining, with interest in improving the system for everyone. Like the ZP staff, they seemed to understand the complexity of NIST's organizational structure and appeared very willing to work with their leaders on the task of developing solutions to enhance the promotion process. This good will, and interest could bode well for productive change. 


\section{Attachment A: Focus Group Consent Form}

COACh is conducting research on the promotion practices of STEM Federal Workforce here at NIST. Thank you for participating in our Focus Group and by participating you are giving your consent for COACh to use your responses in their research.

Each Focus Group will be recorded and those recordings will be securely stored on the University of Oregon servers. The UO Information Services has set up a secure site on their servers, which is compliant with NIST Security requirements and the NIST Security Team has reviewed and approved our security plan. The recordings will be stored for the duration of our contract with NIST and then archived for 3 years as required by Federal Retention Rules.

All responses will be confidential and your identity or any other identifiers about you will be protected and not used in our research, any reports that are presented will use aggregate data collected from this group. Any information that is obtained in connection with this study and that can be identified with you will remain confidential and will be disclosed only with your permission.

Remember, this is completely voluntary and you may withdraw your consent at any time.

COACh is supported by the National Institute of Standards and Technology to conduct this research.

If you have any questions, please feel free to contact Dr. Geraldine Richmond, Department of Chemistry, 1253 University of Oregon, Eugene, OR 97403, (541) 346-0116 or Priscilla Lewis, COACh Manager, coach@uoregon.edu.

If you have questions regarding your rights related to participation in this survey, contact: Office of Human Subjects Compliance, University of Oregon, Eugene, OR 97403, (541) 3462510.

NIST Research Protections Office: Anne Andrews, Director of Research Protections Office, anne.andrews@nist.gov

UO IRB Protocol Number: 12092019.022

NIST IRB Protocol Number: PCO-2020-0193 


\section{Attachment B: Group Leaders Focus Group Questions}

1.How do you typically work with ZP staff to prepare them for the promotion process? Probes:

- When does the process start?

- Is there succession planning?

- Individually - during performance reviews or other times?

- Do they use career advancement plans?

- Nature of relationships; does it vary by band (e.g., mentoring, coaching, sponsorship)

2. Are there ways in which HR or higher-Band administration help you with the promotion process for ZPs? Probes (if not mentioned):

- Providing data (dashboards) about employees, such as time in rank or pay relative to others

- Guidelines on procedures:

- Training on assembling proposals ("promotion packages")

$\bullet$

3. Are there ways in which the promotion process might be improved?
a. At the group?
b. At higher administrative levels?
c. From HR?

4. Is there anything else we didn't ask that you think is important? 


\section{Attachment C: Key Themes and Quotes}

\section{Consistency}

- "...the new Division Chief came in...and saw all these people who were at a ZP-III for years...he instantly promoted everyone who had been sitting there forever to an IV, because he didn't feel they needed to have a Ph.D...."

- "I was simply appalled at all the IVs (who) had not been put in for IVs that were clearly working at what my lab considers a ZP-V band - it was based on the personality of the previous Division Chief, I guess. I just remember a very senior Division Chief looking at it (one of the promotion packages) just like a jaw dropping to the table of how on earth was this man not a V already!"

- "...that points to what most of us would say is one of the problems in the system of promotions is that it's undefined across the board at NIST and each division can kind of do their own thing and, once it becomes unwritten policy within their division how it's done, then people will go to that and it's only when, as you just heard, new blood comes in and reviews things and asks questions do things change, and maybe changing for the better."

- " "...so, the people who come in later are outsiders and there's a huge difference if they're from academia then their record is very clear, but...if they're from industry or another sector, then it's their recognition, as well as acceptance, that seems to have a significant impact."

\section{Accountability of Management}

- "I would say the sign of a good manager is one who can identify the person who is not aware and then lead them correctly to the path that's going to get them there or, if they're just telling you they're not interested...you identify that and make sure that they are at least challenged in what they're asked to do every year."

\section{$\underline{\text { Transparency }}$}

- “...I mean it's not always clear to people how to go and they would like more incremental steps along the way and know that steps they are taking are the right steps... One of the people who did actually transfer from industry came in as a Band Four...so she's doing all kinds of things because she doesn't want to say no because she's trying to develop her 'renown' - it's such a broad goal. And that's causing her a lot of stress..." 
- "In my OU, the information is virtually top secret - I mean it's really hard to break that loose and it's somewhat ridiculous. In my opinion, the process ought to be a lot more well-defined and...available to go."

- 'it's when you reach that ineffable quality of being ready for a Band V - that's what's confusing to people...you basically have to do some detective work, usually with your Division Chief, and locate a couple of examples that have worked...the rules tell you one thing, but, in reality, what works is nuanced and it's different...in every university of the planet, the rules are clearly posted and here, it's like the Manhattan project - so very, very odd."

\section{Diversity}

- "One of the things that I'd like to see in the promotion process is a better, more embracing of diversity among the researchers."

- "...you know, leadership is not really valued...someone on my staff who l'd like to get promoted and...he shows a lot of leadership inside the division and technical leadership and...serious research contributions to other projects in the division, but he doesn't travel... got this ridiculous excuse from my Division Chief that (he) didn't travel because (of) young children. He doesn't travel because he prefers not to travel...we need to be more embracing of diversity."

\section{Fairness}

- "...people change divisions because it's easier to get a promotion in another division, so it's not transparency (that's) the problem; fairness is the problem."

- "...different divisions have different criteria for how great you have to be to be a V, taking into account that you can't pay people enough to promote all their Vs.; knowing you walk on water...so it's not just sort of bias issues... people have other expectations...and is it unfair, yes, and would shining a light on the unfairness to address it...perhaps..."

\section{Organizational Structure and Culture}

- " “...we've been talking about diversity and criteria, so I think one of the problems is that literally, there are only two steps in your promotion. You can go from a ZP-III to a ZP-IV and from a ZP-IV to a ZP-V as two promotions in a forty-year career and that really doesn't give you much opportunity to move upwards. You basically have to make a tremendous leap each time. There's nothing in between and it might be worthwhile to think about having intermediate levels that you could be promoted to that would give people more recognizable targets to try to achieve."

- "...there are successful promotions, so, why don't we put them out there as examples to other people of what it takes and what a successful person at NIST looks like?" 
- " "...we had an announcement this time; it was the first one."

- "Our lab had recently started announcing the ZP-Vs; previously they weren't announced, because...people didn't want their promotion to be known because it's so competitive or they didn't want to draw attention to their package. Transparency is good, but not if it's favoritism. I have asked my lab director to publish a booklet that people could go through and say...this person got promoted because of...leadership...standards...external leadership...but the answer was no...I think it was personal information, but...they could make up scenarios..."

- "...there is inequity across operating units...partly because of career competition from the outside world of trying to be more competitive with salaries in different areas..."

Flexibility

- ...l used to work with a guy who didn't have a Ph.D. and he was a fantastic people person and...they would not let him be a group leader because he didn't have a Ph.D. and it was the only thing...they actually stated that he could not be a Group Leader." 


\section{Attachment D: Quantitative Analysis of Transcripts of Group Leader Focus Groups}

This attachment summarizes the process for collecting and analyzing the information provided from two focus groups held on December 3, 2020 and December 8, 2020. Each focus groups consisted of a maximum of 10 participants. The Group Leaders who were accepted on a first come first serve basis and there were ten in the first group and nine in the second. Each focus group was held over Zoom. Using the software's transcription services, the conversation for each group was recorded and annotated. The following is an account of the methodology used to organize and synthesize the transcriptions, along with a summary of the coded findings.

\section{Methodology}

Using Zoom's transcription services, each focus group was recorded and transcribed. Once each conversation concluded, a text file was produced with the transliteration of the video recording. This text file was thus converted into a Word document and cleaned for any errors that transpired during the recording process. These clean documents were sent to three COACh members who reviewed, annotated, and coded each file in Word with special attention given to four previously agreed upon themes including Transparency/Communication, Accountability of Management, Organizational Structure and Culture, and Recommendations. Once the coders completed their reviews, their notes were organized and synthesized into one document per focus group using NVIVO, a qualitative data analysis computer software program. This process enabled a deeper analysis of NIST as an organization through the eyes of 19 Group Leaders by counting the number of instances group members mentioned details pertaining to each theme.

\section{Findings}

While all four themes were discussed by Group Leaders during both focus groups, details pertaining to Transparency were mentioned more frequently than other themes. For example, focus group members mentioned ambiguity around the promotions process and a lack of available information regarding necessary requirements to advance. As for Organizational Structure, members noted a lack of consistency within the promotions process across different divisions and voiced wanting more diversity among researchers. Additionally, Group Leaders expressed wanting to foster a culture where promotions are celebrated. Regarding Accountability of Management, focus group members noted differences between written and unwritten rules. Recommendations that emerged from these groups included focusing on career development, developing a systematic and universal review process, investing in ways to make information more centrally available and training for Group Leaders. The list of codes collected from each focus groups is included in Table E-1. Additionally, graphs mapping the incidences for each theme from each focus group are included in Figure E-1. The information provided from 
these focus groups will help guide the final recommendations given to NIST in an effort to help improve the promotion process. 


\section{Table D-1}

\begin{tabular}{|l|r|r|}
\hline Name & References for Dec 3 & References for Dec 8 \\
\hline Accountability & 2 & 3 \\
\hline Communication & 6 & 4 \\
\hline Culture & 1 & 6 \\
\hline Fairness & 2 & 0 \\
\hline Points to pull out & 4 & 10 \\
\hline Recommendations & 0 & 0 \\
\hline Career planning & 2 & 1 \\
\hline Information & 5 & 2 \\
\hline Review Process & 3 & 3 \\
\hline Terms & 1 & 2 \\
\hline Training & 3 & 10 \\
\hline Structure & 9 & 12 \\
\hline Consistency & 3 & 7 \\
\hline Flexibility & 10 & 10 \\
\hline Transparency & 3 & 2 \\
\hline
\end{tabular}


Figure D-1

Group Leader Focus Group December 3, 2020

GL Group 1

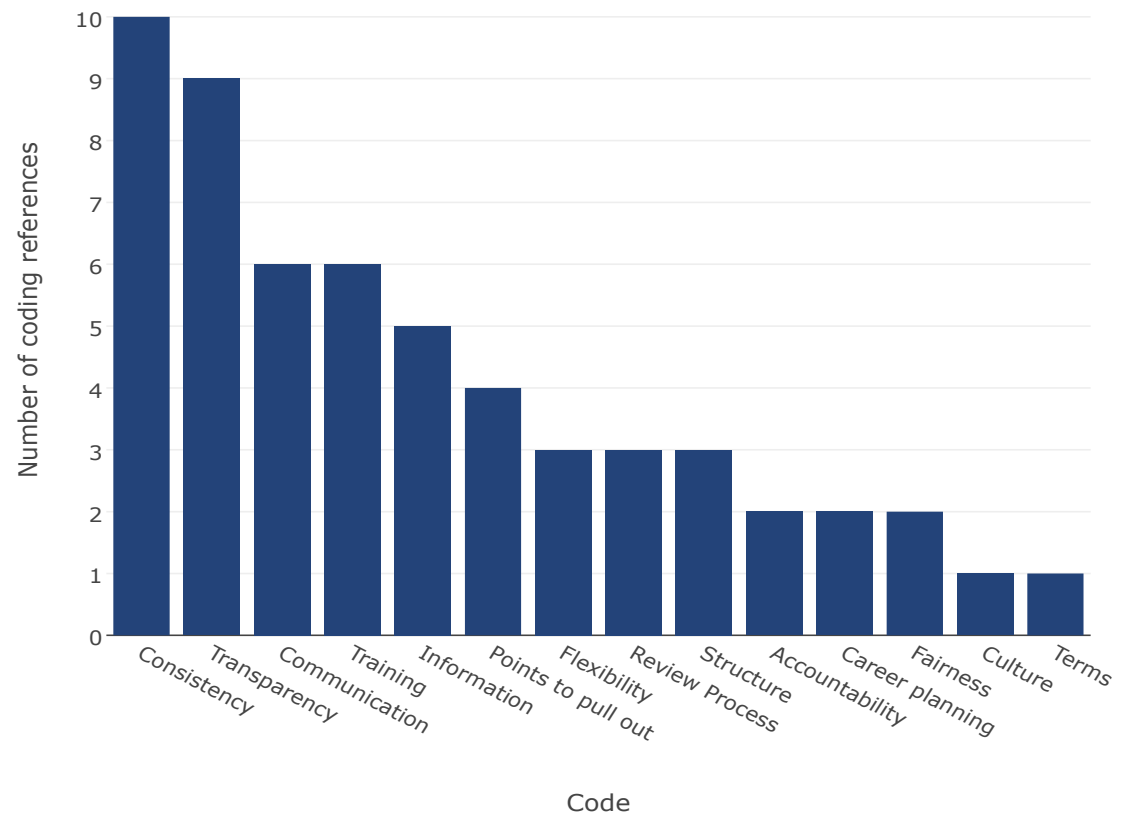

Group Leader Focus Group December $8^{\text {th }}, 2020$

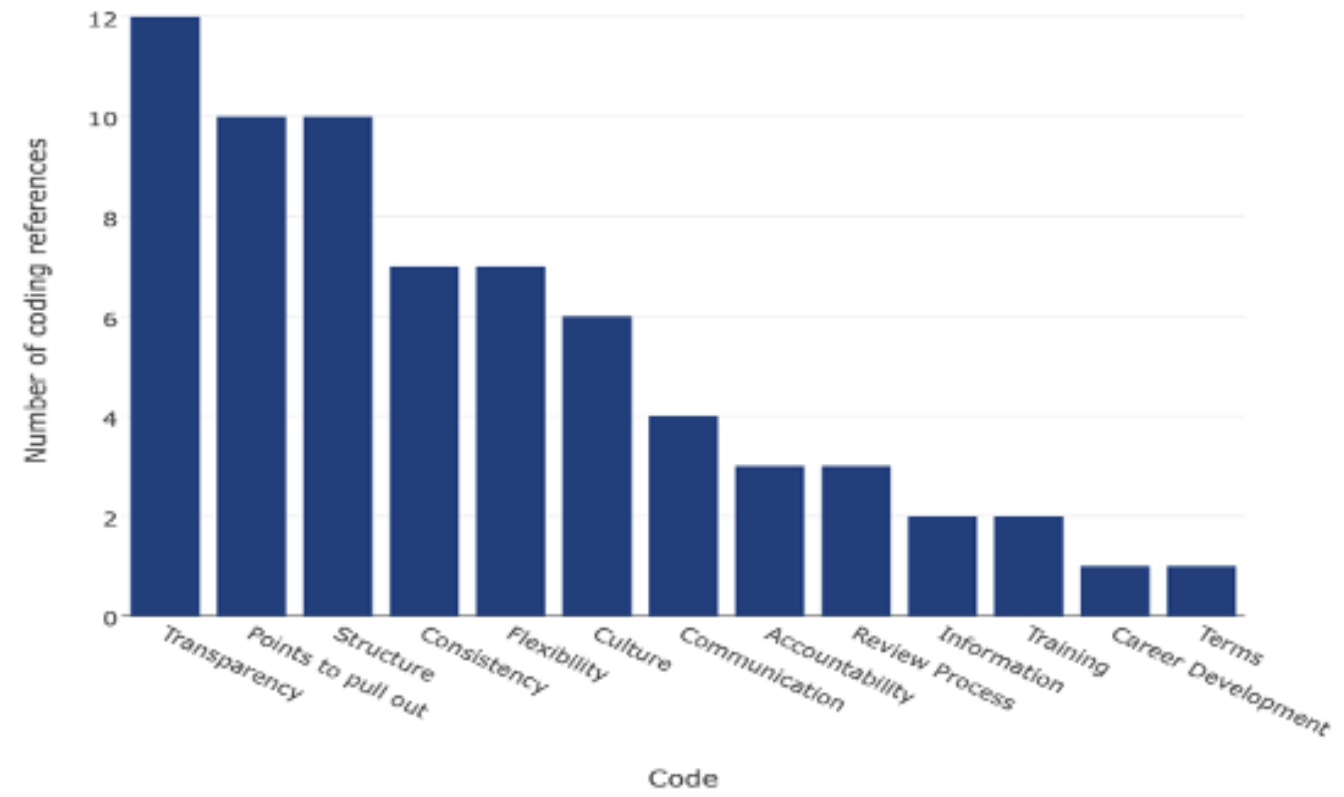




\section{Report 10: Summary of ZT Focus Groups/Interviews in October $2020^{51}$}

This report covers findings from two ZT focus groups or interviews conducted in October 2020 with ZT participants, who volunteered to meet with the data-gathering team. The decision to conduct focus groups had been proposed by the COACh Team as part of their data collection methodology for NIST in analyzing issues with the NIST promotion system, especially for women and under-represented minorities categorized as ZP and ST. COACh also decided to hold ZT focus groups (following the listening sessions early in the summer) rather than conduct a separate ZT survey. Two dates and times were made available for ZT staff to sign-up - October 21 and 22, 2020. These dates and times were communicated as open sign-up times to a list of ZT names provided to the University of Oregon contact who set up the meetings.

\section{Participants}

The ZT focus groups were scheduled after the informal "listening sessions" in June, 2020 that were open to all employees in ZT pay bands. These were well attended and we believe that the relatively low participation in the $\mathrm{ZT}$ focus groups simply reflects the probability that people felt that they had already communicated their concerns to us. Notably, the issues described in these focus groups or interviews did not differ from those expressed in the listening sessions.

\section{Methodology}

The ZT groups were open to any who were interested. Following procedures developed by COACh, a NIST staff member selected potential participants and sent an email to them that explained the purpose of the groups. Those who were interested were directed to the COACh website to select a day and time to participate. We honored the sign-ups of two ZT staff on October 21 and one participant on October 22. While the selection procedure was designed to include a gender representation similar to that of NIST employees ( $2 / 10$ women among ZTs), this was not possible with the low enrollment. No attempt was made to stratify by race-ethnicity and these two groups did not have minorities.

A Focus Group Consent form (Attachment A) was sent to each person invited and read at the beginning of the group meeting to get verbal agreement from each participant. The only person outside of NIST who knew the names of invited ZP staff and those who accepted the invitations was the COACh organizer at the University of Oregon. Throughout the process, care was taken to maintain the confidentiality of the participants, with only one person on the research team knowing the names and encouragement of participants not to use their real names. The sampling and security processes were approved by the IRB boards of both NIST and the University of Oregon (See Appendix E of this document).

\footnotetext{
${ }^{51}$ This report was written by M. Noviski and J. Tucker and completed February 5, 2021.
} 


\section{COACh Team for the Focus Groups}

The organizer started the focus group sessions and attended to NIST members logging on and off as well as working on any technical issues with Zoom. She also ran the transcript recordings and read the consent form that had been sent to all participants and asked for their agreement. There were two moderators, a lead moderator, experienced in running focus groups, and the research moderator to monitor questions and follow-up probes. After the consent reading, ground rules were read and accepted verbally by each group. In addition, the rest of the COACh team was encouraged to act as observers to be sure everyone heard answers correctly. The team was introduced to the ZT staff online during introductions and they asked follow-up questions as needed. Several team members opted out of a video to concentrate on the group.

\section{Questions}

The initial question for all the NIST focus groups was carefully formulated to be simple, focused on promotions and open-ended, to avoid unintentional leading of answers from participants. The additional probes (bulleted) were more directive and the moderators also followed the group discussions, inserting subsequent questions when appropriate (Attachment B).

\section{Analysis}

Coders for the ZT transcripts were three members of the COACh team. Units of analysis used were sequences of sentences, although a sentence or complete dialogue may have also been coded. The team required at least two coders to agree on validity.

\section{Key Themes}

\section{Communication and Transparency}

- Lack of Transparency about Promotions: “...I don't even know how to get a promotion, other than working really hard. About three years ago, I was reading some books and one of them talked about how, if you worked just a little bit harder, you can become indispensable and if you're indispensable then you can ask for more money or you can make yourself a good candidate for another job...It actually worked out really well. You know, I got a few words and a promotion from it, but I don't know how you would go about it otherwise; I don't know...there's another Band above where I'm at, but I don't know what it would take..."

- "I don't know if the $\mathrm{V}$ band even requires supervision, and I'm not even sure where I would get that information...usually the people that are getting a ZP $V$ are our high performers, so...it kind of makes sense...they do publicize when somebody gets a ZP V, but other than that, I don't know when anybody gets a promotion." 
- Inconsistency in communication by supervisors: "I was ZT III forever. That's a typical tactic by management to tell her that there's a promotion deadline. That is just a lie. They can promote anybody at any time."

- Uneven communication about training, "details" and education opportunities - may be posted but availability and relevance to their careers is not clear to ZT staff.

\section{Accountability of Management}

- Lack of consistency/accountability: - "you have to have the right supervisor." "Supervisors came and went 6/7 years ago. Kept missing the deadlines for promotion. The last supervisor who put in the paperwork for me to be promoted retired in 2019. Current supervisor came a day before the promotions; then hired a manager under him to manage four ZTs, so I have a brand-new manager though I've been at NIST 15 years."

- Dependency on individual supervisor or manager: ... "So, they start out as a IV and become a V. The ...Division Chief...looks out for those guys, that's the bottom line. The supervisor looks out for their person."

- Accountability of supervisors to perform their assigned duties - "I'm dealing with a manager who doesn't seem to want to manage - there's a potential safety issue. His direction is: go do your job."

- Ability to cut off career paths: Leader says "no" to training or educational opportunities.

- Unfair treatment: I did have to file a grievance and that did help me finally. But like I said, that's pretty shameful. I found another job...kind of reinvented myself...something completely different...if you want to get promoted, you need to move."

- Feedback

Need for individual feedback, more often than once a year at performance review time.

- Review of Promotions - "So I feel like to improve the process-yes, you get an annual look--but if your supervisor's not putting you in, you're not getting looked at. I feel like maybe from the HR or management level, they should say okay this person has been a ZT III for five years. Let's take a look at her record. Let's see what's going on with her reviews."

- Managing ZTs is different than managing the ZP staff - ZTs may want more attention.

\section{Organizational Structure and Culture}

- Too much management: "NIST is way too top heavy."

- Secrecy of Promotions (Cultural)-example: "In the last two years, prior to me getting a promotion, I won three awards, I think. I was like, I feel like I need to figure out how to take good work that I have been doing and figure out how to get a promotion and right about that time they were like, we think you deserve a promotion."

- Unfairness 
"So, every year when I'm capped out, they're like well we'll take a look at you next year (for a promotion). Yeah, well now I'm not capped out, and then I got the raise and now knocked out again. So, it's like you're playing this game with people's income and it's just not fair."

"The good old boy system is alive and well and it's worse in Gaithersburg." (belief that supervisors and directors give promotions and bonuses to "buddies")

- Budget information Lack of clear understanding about the budget - "I don't know where our bonuses are paid from..." ...we talk about pay for performance, but then when you talk about how that gets done, it's like okay, but you know, maybe the pie is dependent on how giving Congress is."

- Training and Educational Opportunities

One supervisor said "no" to safety training (industrial hygiene). "...at NIST a lot of scientists are the experts in their fields and so, I get the impression from some supervisors that they're not necessarily sure what training would help someone. They might say like, if you see a training that you think is good, come and tell me...but you're not sure where to even start."

- $\underline{\text { Details }}$

Staff may not know how many detail opportunities there are per year and how to qualify for a detail.

- Employee Responsibility

"...and you can slowly improve yourself and then you can make yourself more attractive to other employees and other employers and you'll make it so your work wants to keep you..."

\section{ZT Staff Comments and Recommendations}

- Have a policy document for a defined pathway for promotions; a user's guide and training that goes with it

- A checklist of ways you can start - "like getting a better performance review, even if it's just writing your performance review."

- Have goals and success metrics, "so that you can see if somebody has exceeded."

- Define clear criteria - "Is the expectation that you're going to get meritorious like four years in a row and then get a promotion or something else."

- Have regular feedback for employees

- Have pay increases and promotions, not just "pats on the back."

- Recognize accomplishments with "cash in a flash" (used to do that)

Note: a final comment that one ZT said: "nothing will come of it - it's just so management can check off a box that they did something because they got a badge." 


\section{Coders' Noted Recommendations}

The recommendations listed below are those that coders identified from the transcripts of the interviews/focus groups with ZT staff.

- NIST should celebrate promotions (and new hires) - why keep it a secret?

- Recognize achievements of ZTs.

- Need for regular review of promotions by higher management (beyond directors).

- Have internally posted lists of training classes (HR may have these).

- Publicize educational opportunities related to different bands and career paths.

- Increase opportunities for details that might help develop people.

- Have training for staff on how to draft their own performance review.

- Have standards across NIST for performance reviews.

- Need to be clear about where salaries and bonuses come from in the budget and that they are not transferable from e.g., the instrumentation budget.

- Train supervisors and managers in a model of how to give feedback, so that they can give regular, balanced feedback for employees.

- Pay more attention to the career paths/needs/desires of ZTs and how they relate to the mission of NIST.

- Make clear how responses to FEVS are used (employee satisfaction surveys).

- Review the number of supervisors/directors for ZTs and increase span of control.

- Evaluate managers through an outside organization (feedback now is within NIST). 


\section{Attachment A: Focus Group Consent Form}

COACh is conducting research on the promotion practices of STEM Federal Workforce here at NIST. Thank you for participating in our Focus Group and by participating you are giving your consent for COACh to use your responses in their research.

Each Focus Group will be recorded and those recordings will be securely stored on the University of Oregon servers. The UO Information Services has set up a secure site on their servers, which is compliant with NIST Security requirements and the NIST Security Team has reviewed and approved our security plan. The recordings will be stored for the duration of our contract with NIST and then archived for 3 years as required by Federal Retention Rules.

All responses will be confidential and your identity or any other identifiers about you will be protected and not used in our research, any reports that are presented will use aggregate data collected from this group. Any information that is obtained in connection with this study and that can be identified with you will remain confidential and will be disclosed only with your permission.

Remember, this is completely voluntary and you may withdraw your consent at any time.

COACh is supported by the National Institute of Standards and Technology to conduct this research.

If you have any questions, please feel free to contact Dr. Geraldine Richmond, Department of Chemistry, 1253 University of Oregon, Eugene, OR 97403, (541) 346-0116 or Priscilla Lewis, COACh Manager, coach@uoregon.edu.

If you have questions regarding your rights related to participation in this survey, contact: Office of Human Subjects Compliance, University of Oregon, Eugene, OR 97403, (541) 3462510.

NIST Research Protections Office: Anne Andrews, Director of Research Protections Office, anne.andrews@nist.gov

UO IRB Protocol Number: 12092019.022

NIST IRB Protocol Number: PCO-2020-0193 


\section{Attachment B: ZT Focus Group Questions}

1. What are your experiences with ZT promotions at NIST?

- How easy is it to get information?

- How easy is it to understand what is required?

2. What would you like to see in a defined pathway for ZT promotions?

- Does anyone have a career development plan in addition to a performance plan?

3. What could be done to increase recognition of ZTs and their contributions?

4. What practical changes can you suggest to improve job satisfaction

- What can leadership do now to make the NIST culture more inclusive?

5. Ending Question: Is there anything else we didn't ask that you think is important? 


\section{Part IV \\ Recommendations for Change}

From the results detailed in the previous sections and our review of the scholarly literature regarding successful practices in organizations, the COACh team developed recommendations to help NIST develop promotion policies and processes for scientific staff (ZT and ZP) that would be seen as fair and equitable. The recommendations (Report 11) were submitted to NIST leadership in early April 2021. A strategy for communicating the results of our work and changes to NIST staff (Appendix D) was given to NIST leadership in February 2021. It included a timeline for actions and talking points for emails.

\section{Report 11: Equity Action Plan}

\section{Introduction}

In late 2019, COACh entered a contract with NIST to conduct a data-driven study of promotion practices for scientific and technical federal employees that would result in recommendations for improvement. This Equity Action Plan briefly summarizes results of our data analysis and then presents a detailed list of recommendations. COACh is extraordinarily impressed with NIST leadership and staff: their dedication to science, their concern for fellow employees, and the extent to which they value their contributions to NIST and the nation as a whole. We make our recommendations with the greatest respect for all NIST employees and with the hope that these suggestions will help further the NIST core values of perseverance, integrity, inclusivity, and excellence.

Our data gathering efforts began with listening sessions of diverse groups of NIST scientific staff. They expressed concerns with the promotion criteria and process as well as their desires for an equitable environment, often with strong views and intense feelings. These discussions led to hypotheses that were tested in the next steps of our analysis, focusing on disparities in promotion experiences related to gender and minority status. We first examined NIST Human Resources data for personnel actions from 2000 to 2019 using a variety of statistical analyses. The proportion of ZP women at higher pay bands increased from 2000 to 2019, and by 2019 women were more likely to be at Band IV than would be expected given their representation among all ZP staff. There was no indication that women remained at band before promotion longer than men, or that members of racial-ethnic minorities experienced disparities in promotion. However, the number of minority employees changed very little over time, 
suggesting that issues with hiring and retention (which were not within the scope of our contract) require further examination.

In spring 2020, we distributed an internet-based survey to all permanent federal employees at ZP III or higher, and over 600 responded. Results regarding time at band and before the last promotion paralleled the results seen in the HR data. Based on analysis of our survey data and the open-ended comments, we concluded that concerns with the promotion process were not limited to certain types of employees, but rather were wide-spread, and voiced by both men and women and by staff at all pay bands. Only a minority voiced positive views, and earlycareer employees were least likely to believe that the promotion process was fair or transparent. In fall 2020, we conducted focus groups with ZP staff, ZT staff, and Group Leaders by videoconferencing. Most focus groups were populated by random selection, but a few were populated by volunteers. These discussions reinforced the conclusions we had derived from the survey results.

Based on the above data analyses plus a review of the scholarly literature regarding successful practices in organizations, we recommend four areas for attention in the Equity Action Plan:

- Commitment by leadership to a fair and equitable promotion system;

- Transparency in promotion criteria and processes;

- Effective and accountable supervision of staff;

- Assisting staff in promotion and professional recognition

A work environment that is seen as fair and supportive is a key element in attracting and maintaining a motivated workforce, and the recommendations that follow are designed to that aim.

We also suggest that NIST establish a steering committee to review the recommendations and guide the process of change, with representatives from all organizational units, both managers and staff, and employees at all pay bands. We also suggest a systematic review of promotion practices and procedures used in other federal science agencies to develop processes that are perceived by staff as fair and appropriate. While our contract was limited to promotion practices of permanent Federal staff, it became clear that there were significant concerns regarding hiring, retention, and conversion from temporary to permanent status. These factors can also contribute to perceptions of discrimination and inequity that were the initial impetus for this study. Thus, we recommend that NIST consider an in-depth analysis of potential equity concerns in these areas. 


\section{Recommendations}

\section{Leadership for Effective Change}

It is crucial that senior leadership express their commitment to equity and fair treatment of all employees and to providing resources that shepherd changes in NIST promotion processes and practices. Prompt action must follow to provide convincing evidence of this commitment to equity and fairness in the short- and long-term.

\section{A. Committing to Change}

1. Ensure promotion processes are built upon the mission and core values of the OUs. The development and implementation of these processes must be inclusive, transparent, fair, and accountable.

2. Regularly reinforce the importance and distinguishing features of each $\mathrm{OU}$ and each career path classification to the NIST mission.

3. Hold all managers accountable for the transparency, fairness, and accountability of their actions in promotion.

B. Increasing and Empowering Diversity and Inclusion Activities

1. The new Diversity and Inclusion (D\&I) Director will be key in ensuring that leadership commitment and plans will move forward with transparency, accountability, and impact. This position should report directly to the NIST Director.

2. Construct institutionalized methods for the D\&I Director to consult with NIST managers and staff to help analyze issues and give advice, such as: a high-level advisory committee of managers from all OUs; an advisory committee of staff from all OUs and ranks; and periodic solicitation of input and feedback from all staff.

3. The D\&I Director should spearhead a 5-year strategic plan for diversity, equity, and inclusion, including perceptions of transparency, accountability, and fairness. The plan should include milestones, implementation steps, and an annual assessment of goals.

4. Consolidate human capital services under a chief human capital officer (CHCO), formalizing a partnership between the Human Resources and Civil Rights \& Diversity Offices as co-advisors to senior leadership and the D\&I Director.

5. Support the D\&I Director and CHCO in developing and maintaining connections with $\mathrm{NIH}$ (intramural), DOE, and NASA science agencies regarding best practices for equitable advancement of women and minority science staff.

6. Create a dashboard that reports personnel actions such as promotions, hiring, separations, and changes in compensation. This tool should: identify individuals and units with outcomes that appear problematic; categorize outcomes by gender, race-ethnicity, age, and veteran status; and provide input to regular reviews of the promotion process. 


\section{Developing Transparent Promotion Criteria and Processes}

It is important to clearly communicate the criteria for promotions and the decision-making process. This will increase employee understanding and trust, and help mitigate against biased decisions and perceptions of unfair treatment.

\section{A. Criteria}

1. Periodically review and revise promotion criteria to ensure that they:

a. Reflect the broad and evolving NIST mission and values.

b. Reflect the nature of staff work and specialization (e.g., calibration, research, operations, project leadership, innovation).

c. Recognize efforts contributing broadly to NIST culture and environment (e.g., safety, diversity, integrity, collaboration, teamwork, mentorship).

d. Recognize efforts to initiate new projects and gain further expertise.

e. Clarify differences in requirements at each transition (e.g., III to IV, IV to V).

f. Incorporate consistent procedures to assess less than full-time employment.

2. Ensure that promotion criteria are explicitly discussed within performance reviews, providing staff with clear guidance on the extent to which they have met the requirements.

\section{B. Processes}

1. Transparency of the promotion process is essential to establish trust.

a. Ensure criteria for promotion, including changes to criteria, easily accessible to staff.

b. Communicate areas that are negotiable at time of promotion (e.g. salary, timeoff).

c. Announce and celebrate promotions on a regular basis.

2. Promote transparency and diversity in the filling of vacant ZP-V management positions.

a. Advertise these position openings across all of NIST.

b. Expand required skills to include general leadership criteria.

c. Involve staff in the recruitment and review of applicants.

d. Provide training for selection committees on diversity issues.

3. Promote transparency and fairness in the selection process for Fellows and Senior Research Scientists.

a. Ensure the criteria for Fellows and Senior Research Scientists is clear, distinct, and appropriate for all relevant units of NIST.

b. Expand the number of Senior Research Scientist positions, which in turn will diminish the "consolation prize" perception of not being selected as a Fellow.

c. Establish term limits (e.g., 6 years) for Fellows with a process for competitive renewal. Fellows that are not renewed revert to Senior Research Scientists. 
d. Regularly review the data regarding applications for and decisions on Fellow and Senior Research Scientist advancement to help ensure fairness and eliminate bias.

e. Consider additional methods of recognizing outstanding accomplishments of longterm NIST staff who are not selected as Fellows and Senior Research Scientists.

4. Ensure that resources for career growth are distributed broadly and that access to professional development activities and travel funding is equitable.

5. Obtain feedback through surveys or focus groups on perceived transparency and fairness in the promotion process and in access to professional development assistance. As well, conduct exit interviews with staff who choose to leave NIST. Follow up by prioritizing areas of concern, taking corrective actions, and reporting progress to staff.

\section{Accountability throughout the Supervisory Chain}

A promotion system must imbed accountability through internal checks and other mechanisms. This will require organizational policies and practices that promote effective supervision from Group Leaders to Division Chiefs to OU Directors, and are the responsibility of NIST senior leadership.

\section{A. Decision Process}

1. Design a promotion process that is data-driven with as many objective criteria as possible, and that also addresses the perceptions of favoritism.

2. Provide a mechanism for resolving disagreements in promotion decisions.

\section{B. Promoting Effective Supervision}

1. Ensure that supervisors undertake periodic leadership training and are fluent in the promotion process, procedural steps, and delivering effective feedback to staff.

2. Provide new supervisors with access to information on their staff's complete employment files, and use prior supervisors as a resource in identifying promotion readiness.

3. Institute periodic 360 assessments for all supervisors, with feedback provided by coaches.

4. Hold Group Leaders and Division Chiefs accountable for staff growth and progress, including timely promotion.

a. Establish mechanisms to promote consistency among Group Leaders in conducting performance reviews and implementing promotion criteria.

b. Lab Directors should periodically review staff growth, progress, and promotion to identify any problematic issues affecting individuals or units. When issues are identified, institute a review with potential involvement by those outside the unit as well as Human Resources.

5. To grow new leadership talent, consider restructuring Group Leader positions with term limits, (e.g., 3-5 years), renewable annually based on performance. Advertise Group 
Leader openings openly and widely, award them competitively, and compensate appropriately.

\section{Assisting Staff in Promotion and Professional Recognition}

Staff are ultimately responsible for their career progression, but they must understand both the criteria and the process. NIST can also provide resources to help further staff career advancement.

\section{A. Performance Plans}

1. Ensure staff and their supervisors have regular discussions regarding career aspirations as well as annual performance plans. Promotion criteria should be explicitly discussed.

2. Develop a method (e.g., a structured interview format) for Group Leaders to document these discussions with consistency.

3. Include actionable steps or recognizable targets in annual performance plans to help staff gauge their own track toward promotion.

\section{B. Opportunities for Internal Career Promotion}

1. Institute a succession planning process for all critical management levels at NIST, review the resulting plan annually to identify rising talent in the pipeline, and encourage developmental opportunities and training, such as Federal Executive Institute programs, to grow the talent pool. OPM provides resources for federal agency succession planning.

2. Fulfill staff requests for training related to career growth. Offer more classes at NIST and involve experienced/highly regarded facilitators. Create a consolidated, updated, and accessible list of training options at NIST, Commerce, and in the Federal Government.

3. Establish and announce a centralized budget to pay for external career development courses, along with a process by which staff can apply and be selected.

4. Expand the mentoring program and recognize efforts of those who serve as mentors.

a. Adopt evidence-based approaches such as those in NASEM's 2019 report "The Science of Effective Mentoring in STEMM."

b. Initiate a mentoring program for all new staff during their first year, possibly held in a small group setting if there aren't sufficient mentors for each individual.

c. Periodically assess the mentoring program to see if it is meeting its goals as well as ensuring diversity and inclusion.

\section{Opportunities for External Recognition}

1. Make a concerted effort to bring external recognition to employees in order to bolster the reputation of NIST and the excellence of its staff.

a. Create an accessible database of national and international awards relevant to NIST staff.

b. Establish a cross-OU committee to assist in the nomination of staff.

c. Acknowledge the value of all types of awards across different career stages. 
2. Recognize efforts of those actively involved in sponsoring and advocating for awards on behalf of their colleagues at NIST. 


\section{Additional Recommendations}

Many NIST staff have expressed interest in our work, and therefore we recommend that all COACh reports be accessible. Involving staff in the planning and development of change efforts will build on their energy and commitment to the organization and demonstrate senior leadership's pledge to greater transparency. We also suggest that NIST consider hiring an external contractor experienced in change management to work with staff and leadership in developing and shepherding the change process. 


\section{Appendix A: Professional Development Opportunities and Coursework (as requested by Group Leaders, ZP, and ZT Staff) ${ }^{52}$}

\section{Introduction}

In the COACh survey conducted in spring 2020, NIST ZP staff were asked what coursework and opportunities for professional development were desirable. Similar suggestions were elicited during the focus groups held for ZT staff, ZP staff, and Group Leaders in fall 2020. It is evident that NIST offers both courses and developmental experiences through detail experiences, which staff believe can contribute to their promotions. Staff desire the posting of all details and a review of those selected to ensure equitable distribution of these opportunities. Staff also give positive marks to the programs Leadership for All, Foundations of Leadership, New Leaders, and Project Management \& Leadership.

This report contains a summary of these requests, which confirms the success of current offerings but also provides guidance on additions/revisions that will support professional development of NIST staff.

\section{Professional Development Opportunities}

1. Detail assignments

- Opportunities of 6 months to 1 year in duration

- Leadership details such as acting project leader or Group Leader

- Opportunities outside NIST, including other Federal agencies, especially "scientific sabbaticals" at outside labs

2. Networking activities

- A first-year rotation program for new hires to work in several locations at NIST

- Management retreats across OUs to identify, build, and support connections to other units

- Career advancement networking forums, within NIST, as well as with other related agencies

- Identify and publicize potential collaborations and build connections across NIST

3. Conference attendance

- Support to present findings and to serve on/lead conference committees

${ }^{52}$ Compiled by J. Tucker and C. Rohlfing, March 2021 
- Send younger professionals to conferences guided by a seasoned NIST scientist

4. Apprenticeships and job shadowing

5. Support for ZT staff pursuing advanced degrees, and guidance on potential career pathways after successful degree completion.

\section{Coursework}

1. Orientation and Onboarding

- NIST culture: how NIST really works

- Relation to Commerce Department and Federal Government

- NIST's role in the world standards organizations such as ISO and BIPM

- Ethics in the NIST workplace

2. Computer Skills

- MS Office, including Word and Excel

- SPARQL and related language queries

- Programming

3. Project-specific Skills

- Grant proposal writing

- Patent application process

- Project management certification

- Contracting Officer's Representatives certification

- Contract writing

- Executing CRADAs and interagency agreements

- Technical training in metrology, statistics, and measurement uncertainties

4. Financial Skills

- Federal budgeting process from development through execution

- Planning and managing budgets, including for non-supervisory people

- Purchasing and procurement regulations

- How to attract outside funding for research

5. Human Resource Skills

- Hiring process, including bias training 
- Performance management: writing evaluations, giving feedback

- Managing staff on remote work, part-time, and flexible schedules

- Supervision of poor performers

- Navigating the EEO process

- Retirement planning

- Sexual harassment prevention and bystander training

6. Career Navigation

- Career management / planning within the NIST context

- Using an Individual Development Plan

- Alternate career paths to SES/ST

- Having impact with research, beyond publications and internal reports

7. General Professional Skills

- Assertiveness / self-advocacy

- Communication

- Conflict Resolution

- Delegation

- Entrepreneurship

- Emotional Intelligence

- Leading without direct authority

- Meeting management

- Mentoring, coaching, and sponsoring

- Negotiation

- Networking

- Public speaking and presentations

- Time management

- Understanding bias, multiculturalism, and institutional racism

- Work / life balance

8. NIST-specific Professional Skills

- Identifying collaboration opportunities across NIST

- Identifying collaboration opportunities with industry, other agencies, universities

- Competing for internal funding

- How to bring in external funding

- Management of research projects and technical staff 
- Research writing and publishing

- Developing external recognition, including internationally

9. Leadership Development

- Federal Executive Institute

- SES development courses

- Leadership training / programs from business schools and other organizations

- Executive coaching

- Strategic planning

- Leadership styles

- Career counseling and giving balanced feedback

- Situational leadership

- Leading change

- NIST promotion process, by OU, and taught by experienced supervisors

- Recruiting and retaining Under-represented groups, and managing diverse teams

- Team building and optimization 


\section{Appendix B: Focus Group Guide for Group Leaders ${ }^{53}$}

Recommendations:

1. Limit the size of focus groups. Findings from group literature are that groups need to be five or more people for diversity of opinions and in groups of more than twelve, some people will drop out or stay quiet.

2. Be sure that you have enough time for introductions; a discussion with comments from all and a closing. Usually, an hour and a half is a good amount of time for groups of 8-

12.

3. Make the focus groups as representative as possible of the larger group of interest. Invitations can be sent to everyone in the larger group - with first come, first served for volunteers or, if this is a research project, invitations should be sent to a random sample. You can have a mixture of some random sample and some volunteer group meetings if that is indicated in the results. In-person, use real names on folded tents or other names online.

4. If possible, have both a group moderator and someone to record. Recording in person is best on a flipchart, so that everyone can view previous comments. You can also have a technical recording, which requires the consent of the group (this can be sent in advance and confirmed in the meeting) as well as a trusted source to keep it confidential afterwards. Recorded comments will have to be transcribed, so it is helpful to also have observers.

5. If possible, have an administrator, who can send information out ahead of time and, if needed run the technical requirements of online groups. This is key for research studies.

6. Online, it is good to have more than one moderator, since it's more difficult to observe who might want to speak. This can be compounded by members of the group closing their video component. It is recommended that you say you prefer the video at the beginning by saying that some in the group may not know their video or audio is closed. However, if they are participating, don't make an issue of the video. Your focus is to get them to relax and talk.

The following script was developed for online focus groups, but can be used for in person groups.

\footnotetext{
${ }^{53}$ Written by J. Tucker, March 26, 2021
} 
Moderator: Welcome: (5 minutes)

Greet each person as they log in or come into the room. If the session is online, give them the option in an introductory email of logging in with a focus group name. The moderator and any other staff present, such as the technical administrator, note-takers, timekeeper and observers can say their names now or in the introductions.

\section{When all are present:}

"Good morning/afternoon and welcome to this focus group. Thank you for taking the time to join us to talk about both positives and challenges at work.

Reason for the focus groups: Give a sentence or two about why you're running the groups, the focus of the questions and what will be done with the results. If this is a research project, the participants will have received an invitation and a consent form before the meeting. Doublecheck that they received the form (get nods for yes).

If this is a research project, continue with: Our research administrator will tell you about the research requirements for these focus groups:

\section{Research Administrator: (5 minutes)}

Recording: we will be recording what is said in all the focus groups for our use in summarizing the major issues for reports. These recordings will stay with one person at the (name of the organization) under lock, according to IRB protocols, and we will take every measure possible to eliminate any chance of identifying anyone.

Consent: read Consent form once; ask each person to say "yes"/ "agree."

Moderator: (5 minutes) Any questions?

Allow for at least 10 seconds of silence.

Before we start, two more items:

1. Time: we have an hour and a half and will take a few minutes for introductions. If you have to leave early, please let us know now, so we won't interpret that action as a result of what is being said. Again, allow time for any responses or explanation as to why they have to leave early.

2. ___ Ground Rules (5 minutes) "let's agree on some basic ground rules..." 
In online groups, the Ground Rules are listed on the screen share. In in-person groups, they should be listed on a flip chart and posted after you go through them. These are very important for the moderator(s). If the group agrees to these rules or adds any, they are agreeing to positive behaviors and to the group leader's interventions if they don't follow the rules. Review these rules quickly (select just a sentence or two from each) and ask for agreement (nods are ok). You'll get them. Ask if anyone wants to add a ground rule. Listen and ask the group if they agree. If they do and it's reasonable, add it. See next page set up for online sharing: 


\section{Ground Rules}

- Honesty

Be real - we want to hear your authentic experiences and perspectives. Please don't mention anyone's name when you talk about an experience, just the essence of what happened and the impact on you and others.

- Anonymity

We will summarize WHAT is said in our reports, not WHO said it. What's said is not confidential - but it is anonymous. And, we ask that you

please don't share any of the comments outside this group - this is "Las Vegas - what's said here, stays here." Also, you're welcome to say Pass.

- Everyone Participates = this is a "joint discovery" and we want to hear as many of your experiences; opinions; or comments as possible. I may ask another person to speak to be sure we hear from others.

- Disagreement is OK - different perspectives are valuable and people may experience an event differently. You may not agree and can make your own comments. Perceptions are real; so let's agree to respect differences.

- No Interruptions - we'd like to hear direct comments without long backgrounds or explanations. AND, the corollary to that is:

- Be Brief. Short and straightforward. We may have time for questions or other comments later.

- Anything you'd like to add?

- Can you agree to these ground rules? 


\section{QUESTIONS (60+ minutes):}

Today, we want to put "a human face" on our information by listening directly to you about your perspectives and experiences. We encourage you to think about anything that might impact (your main subject).

Opening question (5 $\mathrm{min}$ ) (allow 30 seconds for each person):

Be sure that everyone answers. You and others on the team model this first. Trust the silence at first. You and the team with you can start. Then, you may get a silence - wait and if no one says anything, ask for volunteers or use names. Your Goal: get everyone to speak. Once they do, they're in.

This first question will be a short answer - "pretend you have a lighted match. The team and I will go first."

\section{What is something the people in this group don't know about you?}

This is a great introductory question, since anyone can answer it. You can add: "it can be an instrument you played in high school." The extroverts will go first and some people will copy what others say - that's fine - they're talking!

Other possible questions (use just one question - you want time for key questions):

What is a skill you wish you could learn? What is your favorite sport?

Moderator: The following questions target (your subject). We have 8-10 minutes for each question. Our timekeeper will warn us when we have 1-minute left.

\section{Key Questions:}

Usually, you'll have time for 4-5 questions, depending on the discussion. Always ask follow-up questions. You can add a question if time permits. Allow $\mathbf{1 0}$ minutes for the Ending Question, since people will say then what they wouldn't say earlier.

Ending Question: Is there anything else we didn't ask that you think is important?

Thank everyone for participating and team members for helping out and offer an email or text site for participants to send any additional thoughts. 


\section{Notes for the Moderators}

Helpful Phrases (you may be a pro - these are extras): to develop the conversation; elicit more information after unclear answers; control dominators; if answers go off topic; if no one responds:

Developing the conversation: "tell me when you think that's happened...";

or "...is it generalizable to the whole group?"

Eliciting more information: "Tell us more..." "say more about that..." "who else has experienced this?"

Control dominators: "thank you - we're interested in hearing how others feel..." or "We'd like to hear from others to get a variety of perspectives..."

Off topic: "thanks for that interesting idea...maybe we can discuss it later"

No one responds: Wait... allow time for people to think. Often someone will speak up. Repeat the question. Ask: anything else?

After being quiet again, you can say:" Is this question redundant?" "Is there anything anyone would like to say - if not, we can move on..." 


\section{Note Taking}

\section{For Note Takers}

Anticipate that the analysts and others will use your field notes and they may be interpreted weeks after the focus group meetings, so as much clarity and consistency that you can achieve will be very important. Attached are pages with all the final questions and space for writing under each question.

Quotes: watch for sentences or phrases that illustrate an important point of view or are eloquently phrased. Put an identifier of the group/speaker (anonymous indicator) after the quote. Capture as much as you can of the key phrases and use an indication of any missing words. If not traceable, excellent quotes will be used in the focus groups reports.

Key Points and themes for each question: participants will usually talk about several key points in their responses. These points or themes may be repeated by others or said only once, but in a way that deserves attention. (if there is time at the end of the focus group, you could confirm these with the participants)

Follow-up questions that could be asked: sometimes the moderator might not follow-up on an important point or seek an example of a critical point. You might send a private comment to the moderator on Chat or write down the point and ask the group at the end of the meeting.

Ideas or thoughts of the note-taker: sometimes a note-taker will identify a new concept or have a great insight. Make a note and share these - they can be helpful in analysis of the data collected.

Other: Make note of both verbal and non-verbal behavior: passionate comments; body language; head nodding; physical excitement; facial expressions or other cues of agreement, interest or disagreement.

\section{Note taker, Observers and Moderators: (30 minutes)}

Debrief immediately after the focus group session. Note themes, hunches, interpretations, etc. Label field notes and send to the administrator and those who will analyze the focus group comments. 


\section{Technical reminders}

This references the Zoom Web system - translate to Blue Jeans or another system:

Logging in: we will have one person controlling all invitations to log in. The invitations will go out via email from (administrator) with (name) as host. In case of issues, the moderator, note taker and observer need to log in 5- 10 minutes before time. The log in screen will also have the meeting ID and password, for those who need to log in by phone.

Muting - the host will mute all participants as they log in since they may be talking to someone in the office or at home. They can unmute themselves or the administrator can unmute them. The button is on the bottom left side of the screen in Zoom.

Audio: participants can unmute after they log in.

Video - You may have to remind a participant where the video button is located bottom of screen: lower left in Zoom.

Gallery View - Click on the square at the upper screen to allow you to see all participants.

Manage Participants - note-taker or observers can keep an eye on this to see if any anyone is waiting to ask a question (or has something on Chat).

Chat - you can decide to turn this on or not.

Positives: if a participant wants to ask a question of you or the note-taker and not disturb the group or the note-taker wants to send you a comment; Negatives: participants could have side-conversations with each other. 


\title{
Appendix C: Survey
}

\author{
(surveymonkey.com)
}

\section{NIST Promotion Survey Spring 2020}

COACh is a grass-roots organization based at the University of Oregon that works to increase the number and career success of scientists and engineers through innovative programs and strategies. The survey is being sent to all Career STEM Federal Employees at NIST in the ZPIII, ZPIV, ZPV, ST and SES pay bands. This short survey is designed to help COACh learn about your perceptions of the work environment and advancement opportunities at NIST and ways in which COACh might be able to help you and other employees. If you decide to participate you are giving consent to COACh to use your answers and comments for our research.

The survey does not ask for names or contact information and will take about 10 minutes to complete. While the survey link came from internal to NIST, no one at NIST will ever see individual answers to the survey. All aggregate data will remain with the researchers at the University of Oregon COACh Program and will not be shared with NIST. Any information you provide will only be presented in an aggregate and summary manner. We ask for some demographic information to help understand patterns in the data, but extreme care will be taken to ensure that no individual can be identified in the reports, including grouping of responses across demographic categories with fewer members. You may, of course, only choose to answer the questions that you desire. Your decision whether or not to participate is totally voluntary and will not affect your relationship with COACh in any way.

If you have any questions, please feel free to contact Dr. Geraldine Richmond, Department of Chemistry, 1253 University of Oregon, Eugene, OR 97403, (541) 346-0116 or Priscilla Lewis, COACh Manager, coach@uoregon.edu.

If you have questions regarding your rights related to participation in this survey, contact: Office of Human Subjects Compliance, University of Oregon, Eugene, OR 97403, (541) 346-2510. NIST Research Protections Office: Anne Andrews, Director of Research Protections Office, anne.andrews@nist.gov

UO IRB Protocol Number: 12092019.022

NIST IRB Protocol Number: PCO-2020-0193

Thank you for helping COACh in our work with NIST.

\section{NIST Promotion Survey Spring 2020}


1. Please indicate the extent to which you agree or disagree with the following statements regarding the promotion process for ZP employees at NIST from GRADE III to GRADE IV:

\begin{tabular}{|c|c|c|c|c|c|c|}
\hline & $\begin{array}{l}\text { Strongly } \\
\text { Disagree }\end{array}$ & Disagree & $\begin{array}{l}\text { Neither Agree } \\
\text { nor Disagreee }\end{array}$ & Agree & Strongly Agree & Don't Know \\
\hline $\begin{array}{l}\text { I understand what is } \\
\text { needed to gain } \\
\text { promotion from III to IV. }\end{array}$ & & & & & & \\
\hline $\begin{array}{l}\text { Most NIST ZP } \\
\text { employees understand } \\
\text { what is needed to gain } \\
\text { promotion from III to IV. }\end{array}$ & & & & & & \\
\hline $\begin{array}{l}\text { The promotion criteria } \\
\text { for promotion from III to } \\
\text { IV are fairly applied. }\end{array}$ & & & & & & \\
\hline $\begin{array}{l}\text { The prom otion criteria } \\
\text { from III to IV reflect the } \\
\text { stated mission of NIST. }\end{array}$ & & & & & & \\
\hline
\end{tabular}

2. Please indicate the extent to which you agree or disagree with the following statements regarding the promotion process for ZP employees at NIST from GRADE IV TO GRADE V:

\begin{tabular}{|c|c|c|c|c|c|c|}
\hline & Strongly & \multicolumn{3}{|c|}{ Neither Disagree } & \multirow{2}{*}{ Strongly Agree } & \multirow[b]{2}{*}{ Don't Know } \\
\hline & Disagree & Disagree & nor Agree & Agree & & \\
\hline $\begin{array}{l}\text { I understand what is } \\
\text { needed to gain } \\
\text { promotion from IV to V. }\end{array}$ & 0 & 0 & 0 & 0 & 0 & 0 \\
\hline $\begin{array}{l}\text { Most NIST ZP } \\
\text { employees understand } \\
\text { what is needed to gain } \\
\text { promotion from IV to V. }\end{array}$ & & & & & & \\
\hline $\begin{array}{l}\text { The promotion criteria } \\
\text { for promotion from IV to } \\
\text { V are fairly applied. }\end{array}$ & 0 & 0 & 5 & 5 & 5 & 5 \\
\hline $\begin{array}{l}\text { The prom otion criteria } \\
\text { from IV to V are } \\
\text { appropriate for people in } \\
\text { my operating unit. }\end{array}$ & o & $r$ & $\mathrm{r}$ & $r$ & $\mathrm{r}$ & $r$ \\
\hline $\begin{array}{l}\text { The promotion criteria } \\
\text { from IV to } V \text { reflect the } \\
\text { stated mission of NIST. }\end{array}$ & 5 & o & 0 & 6 & 0 & 6 \\
\hline
\end{tabular}


3. Are you aware of the ST category (Fellows and Senior Research Scientists)?

Yes

No

\section{NIST Promotion Survey Spring 2020}

4. Please indicate the extent to which you agree or disagree with the following statements regarding the promotion process for ZP employees at NIST from GRADE V TO Senior Scientist or Fellow:

\begin{tabular}{|c|c|c|c|c|c|c|}
\hline & $\begin{array}{l}\text { Strongly } \\
\text { Disagree }\end{array}$ & Disagree & $\begin{array}{c}\text { Neither Agree } \\
\text { nor Disagree }\end{array}$ & Agree & Strongly Agree & Don't Know \\
\hline $\begin{array}{l}\text { I understand what is } \\
\text { needed to gain } \\
\text { promotion from } V \text { to } \\
\text { Senior Scientist or } \\
\text { Fellow. }\end{array}$ & & & & & & \\
\hline $\begin{array}{l}\text { Most NIST ZP } \\
\text { employees understand } \\
\text { what is needed to gain } \\
\text { promotion from V to } \\
\text { Senior Scientist or } \\
\text { Fellow. }\end{array}$ & & & & & & \\
\hline $\begin{array}{l}\text { The promotion criteria } \\
\text { for promotion from } V \text { to } \\
\text { Senior Scientist or } \\
\text { Fellow are fairly applied. }\end{array}$ & & & & & & \\
\hline $\begin{array}{l}\text { The promotion criteria } \\
\text { from } V \text { to Senior } \\
\text { Scientist or Fellow are } \\
\text { appropriate for people in } \\
\text { my operating unit. }\end{array}$ & & & & & & \\
\hline $\begin{array}{l}\text { The promotion criteria } \\
\text { from } V \text { to Senior } \\
\text { Scientist or Fellow } \\
\text { reflect the stated mission } \\
\text { of NIST. }\end{array}$ & & & & & & \\
\hline
\end{tabular}

\section{NIST Promotion Survey Spring 2020}


5. Now a few questions about your own experience with the NIST promotion process. Please indicate the extent to which you agree or disagree with each of the following statements.

\begin{tabular}{|c|c|c|c|c|c|c|}
\hline & $\begin{array}{l}\text { Strongly } \\
\text { Disagree }\end{array}$ & Disagree & $\begin{array}{c}\text { either Disagr } \\
\text { nor Agree }\end{array}$ & Agree & Strongly Agree & Don't Know \\
\hline \multicolumn{7}{|l|}{$\begin{array}{l}\text { I am confident that my } \\
\text { accomplishments will be } \\
\text { recognized and } \\
\text { rewarded in the } \\
\text { promotion process in the } \\
\text { future. }\end{array}$} \\
\hline \multicolumn{7}{|l|}{$\begin{array}{l}\text { I have productive } \\
\text { conversations with my } \\
\text { supervisor about my } \\
\text { career progress on an } \\
\text { annual basis. }\end{array}$} \\
\hline \multicolumn{7}{|l|}{$\begin{array}{l}\text { Other employees at } \\
\text { NIST who I know have } \\
\text { had positive experiences } \\
\text { with the NIST promotion } \\
\text { process. }\end{array}$} \\
\hline $\begin{array}{l}\text { I have had positive } \\
\text { experiences with the } \\
\text { NIST promotion process }\end{array}$ & & & & & & \\
\hline
\end{tabular}

6. Please feel free to add any other comments or information that you believe will help COACh understanding more about promotion processes at NIST.

\section{NIST Promotion Survey Spring 2020}

7. Since beginning your career at NIST have you ever held a position of leadership with formal supervisory authority over others?
Yes
No 
8. The federal government offers a number of courses to help those in supervisory positions or thinking about becoming supervisors. Please indicate courses that you have taken or plan to take in the future related to the following areas.

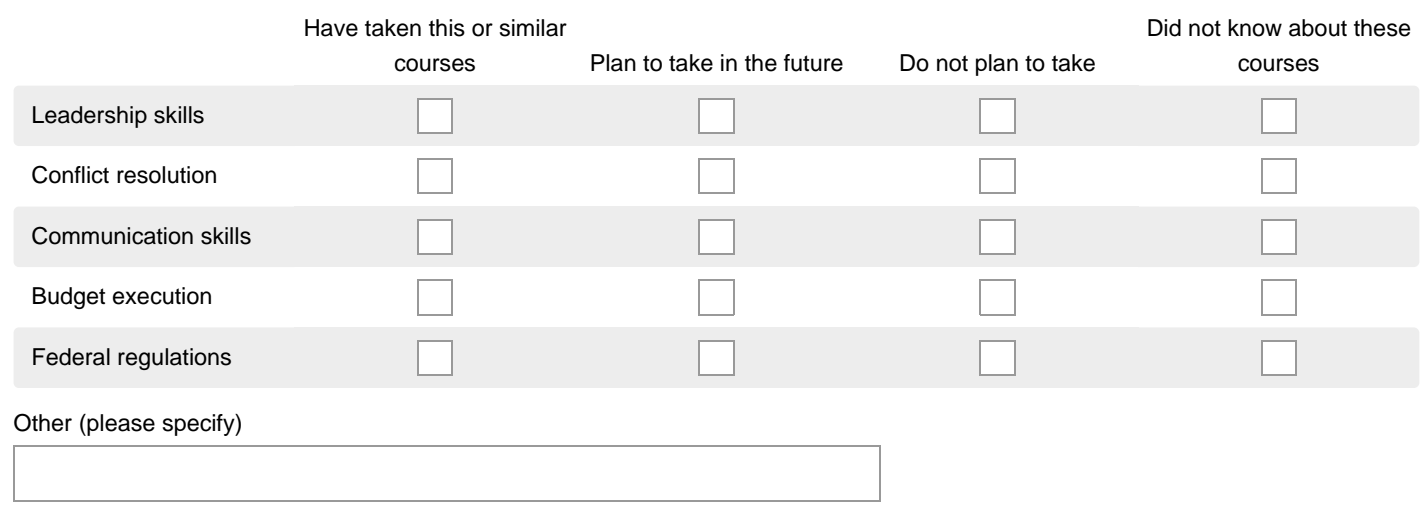

9. Have you had any other professional development opportunities at NIST, such as non-supervisory leadership roles, training, or detail assignments?

Yes

No

\section{NIST Promotion Survey Spring 2020}

10. Please describe these opportunities

\section{NIST Promotion Survey Spring 2020}

11. What type of professional development opportunities or courses would be helpful in your NIST career? 


\section{NIST Promotion Survey Spring 2020}

Finally, we have a few questions about you and your current position. These questions are important to help us understand why responses might vary from one employee to another. Please remember that any reports from this survey will be aggregate in nature. All responses will be grouped in ways that won't allow individuals to be identified.

12. What is your age?

Under 25 years

45 to 54 years

25 to 34 years

55 to 64 years

35 to 44 years

65 years or older

13. How long have you worked at NIST as a federal employee?
Less than a year
1 to 2 years
3 to 5 years
6 to 10 years

11 to 15 years

16 to 20 years

More than 20 years

14. Before becoming a career federal employee at NIST, did you hold any of the following positions? (Please mark all that apply.)

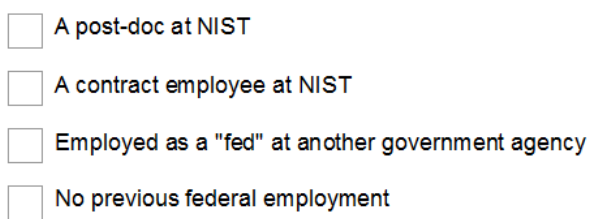

NIST Promotion Survey Spring 2020

15. How long were you in the position(s)?
Less than a year
11 to 15 years
1 to 2 years
16 to 20 years
3 to 5 years
More than 20 years
5 to 10 years 


\section{NIST Promotion Survey Spring 2020}

16. What is your highest degree?
Bachelors
Masters
Ph.D.
Other (please specify)

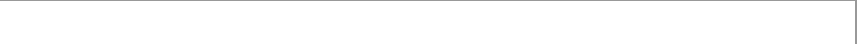

17. What is the discipline in which you received highest degree?

\begin{tabular}{ll} 
Biology & Mathematics \\
Chemistry & Material Sciences \\
Computer Science & Physics \\
Engineering & Social Sciences \\
Other (please specify) & \\
\hline
\end{tabular}

18. What is the Operating Unit (OU) in which you are employed?

Communications Technology Laboratory (CTL)

Material Measurement Laboratory (MML)

Engineering Laboratory (EL)

NIST Center for Neutron Research (NCNR)

Information Technology Laboratory (ITL)

Physical Measurement Laboratory (PML)

Other (please specify)

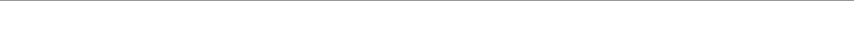

19. What is your current grade?
D III
IV
) $V$
ST
Other (please specify) 


\section{NIST Promotion Survey Spring 2020}

20. How long have you been at this grade?

Less than one year

1 to 5 years

6 to 10 years
11 to 15 years

16 years or more

NIST Promotion Survey Spring 2020

21. How long have you been at grade IV

Less than one year

1 to 5 years

6 to 10 years

\section{1 to 15 years}

16 years or more

22. How long were you at grade III before promotion to grade IV?

Less than 1 year

1 to 5 years

6 to 10 years
11 to 15 years

16 years or more

Not applicable, was hired at grade IV

\section{NIST Promotion Survey Spring 2020}

23. How long have you been at grade $V$ or higher?
Less than one year
1 to 5 years
6 to 10 years

11 to 15 years

16 years or more

24. How long were you at your previous grade before your promotion to this grade?
Less than 1 year
1 to 5 years
6 to 10 years

11 to 15 years

16 years or more

Not applicable, was hired at this grade 
NIST Promotion Survey Spring 2020

25. What is your race/ethnicity? (Please check all that apply)

\author{
African American/Black \\ Asian/Pacific Islander \\ Caucasian/White
}

26. Do you identify as
Hawaiian/Pacific Islander

Latino/Latina/Hispanic

Native American/ Indian/Alaska Native

Thank you for participating in the COACh survey! 


\section{Appendix D: COACh Communication Plan for Roll-Out of Equity Action Plan}

In February 2021, COACh presented, via PowerPoint, a "Communication Plan" for disseminating the Equity Action Plan (in Report 11) to NIST staff. It included a three step timeline for the sequence of actions and talking points for two recommended emails. It was also suggested that a summary of the Equity Action Plan be attached to the emails.

\section{Timeline}

Step 1:

- COACh presents Equity Action Plan to NIST Executive Board

- NIST Exec. Board informs OU/Lab Directors, HR, D\&I Director, \& others

- Via email using talking points and Equity Action Plan slide deck provided by COACh

- NIST Exec. Board meets with OU/Lab Directors, HR, D\&I Director \& others to:

- Decide on a plan forward

- Select which recommendations to pursue

- Prioritize those selected recommendations

- Assign sponsor(s)/owner(s) to each recommendation

- Select one impactful recommendation to adopt immediately

- Modify COACh slide deck to reflect these decisions and to create the NIST Equity Action Plan

- Use "RACl" tool provided by COACh to assist with defining roles \& responsibilities for tasks necessary for implementation of each recommendation

Step 2:

- OU/Lab Directors, with NIST Exec. Board, provide the NIST Equity Action Plan by email to Division Chiefs \& Group Leaders

- OU/Lab Directors meet with Division Chiefs \& Group Leaders to

- Discuss NIST Equity Action Plan

- Recognize the Group Leaders as the front line of change

- Recruit a highly regarded lead person per OU/Lab, preferably a ZP-IV or V, to be a local envoy for the NIST Equity Action Plan

- OU/Lab Directors provide feedback from these meetings to NIST Exec. Board, and modify NIST Equity Action Plan accordingly

Step 3:

- NIST Director communicates by email to all staff 
- Use talking points provided by COACh

- Announce all-hands meetings at appropriate level (OU/Lab or Division) to present and discuss NIST Equity Action Plan

- At all-hands meetings, arrange for HR, Ombuds, CRDO, union, \& others as appropriate to have representatives present

- Be ready to encourage dialogue, especially if using videoconferencing

- Post NIST Equity Action Plan to internal website and/or newsletter after allhands meetings are completed

- Post COACh reports and analyses, as vetted by NIST Exec. Board and HR, to internal website accessible to employees

\section{Email talking points}

\section{Email to Lab Directors}

- Recap original assumptions and contract focus on promotion for NIST's Federal STEM workforce

- Summarize COACh's subsequent plan of action/activities, stressing its evidence-based methodology

- Set expectation that OU/Lab Directors will commit to change in their OU/Lab, devoting time and resources as needed

- Set meeting date/time to discuss COACh Equity Action Plan and implementation of its recommendations

- Refer to attached slide deck for details in formulating a NIST Equity Action Plan

\section{Email to staff}

- Recap original assumptions and contract focus on promotion for NIST's Federal STEM workforce

- Summarize COACh's subsequent plan of action/activities, stressing its evidence-based methodology

- Highlight a few of the statistical analyses' findings and debunk a few myths, but without dismissing the need for change/progress (COACh will provide examples)

- Encourage attendance at all-hands meetings (OU/Lab or Division?) for presentation and discussion of NIST Equity Action Plan

- Announce one impactful recommendation that will be implemented immediately

- Commit to regular communication about progress on implementing recommendations (from Director or NIST Exec. Board, from internal newsletter, from internal website) 
- Name a point of contact for overall effort, for follow-up questions, as well as a NIST Equity Plan envoy for each OU/Lab

- Commit to walking the talk, setting new expectations, evaluating success 


\section{Appendix E: IRB Approval}

Our work was approved by the Institutional Review Boards at the University of Oregon and NIST and documentation of those approvals are given in this appendix. The explanations and consent materials for the survey are in Appendix $\mathrm{C}$ and those for the focus groups are in attachments to Reports 8, 9, and 10. 
TO: $\quad$ Geraldine Richmond, Principal Investigator Department of Chemistry

RE: $\quad$ Protocol entitled, “Analysis of Equity Disparity and Resolution to Known Equity Disparity Regarding STEM Career Advancement at NIST"

\section{Notice of Review and Exempt Determination}

The above protocol has been reviewed and determined to qualify for exemption. The research is approved to be conducted as described in the attached materials. Any change to this research will need to be assessed to ensure the study continues to qualify for exemption, therefore an amendment will need to be submitted for verification prior to initiating proposed changes.

For this research, the following determinations have been made:

- This study has been reviewed under the 2018 Common Rule and determined to qualify for exemption under Title 45 CFR 46.104(d)(2) and Title 45 CFR 46.104(d)(4).

\section{Approval period: January 30, 2020 - March 31, 2021}

If you anticipate the research will continue beyond the approval period, you must submit a Progress Report at least 45-days in advance of the study expiration. Without continued approval, the protocol will expire on September 15, 2021 and human subject research activities must cease. A closure report must be submitted once human subject research activities are complete. Failure to maintain current approval or properly close the protocol constitutes non-compliance.

You are responsible for the conduct of this research and adhering to the Investigator Agreement as reiterated below. You must maintain oversight of all research personnel to ensure compliance with the approved protocol.

The University of Oregon and Research Compliance Services appreciate your commitment to the ethical and responsible conduct of research with human subjects.

Sincerely,

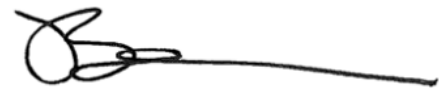

Daniel Berman, MS

Research Compliance Administrator

CC: Priscilla Lewis 


\section{National Institute of}

\section{Standards and Technology}

U.S. Department of Commerce

February 27, 2020

MEMORANDUM FOR Heather M Evans

Federal Program Officer

From: Anne Andrews

Director, Research Protections Office

Subject: Administrative Review Approval of PCO-2020-0193 "Analysis of Equity Disparity and Resolution to Known Equity Disparity Regarding STEM Career Advancement at NIST (NIST financial award 1333ND19PNB670633 to University of Oregon) "

The above referenced study was received for final administrative review by the Research Protections Office (RPO) on 02/25/2020.

This protocol has been reviewed in accordance with 15 CFR 27.112, Protection of Human Subjects: Review by Institution. The study is funded under a NIST award \#1333ND19PNB670633 to University of Oregon (UO).

This study was reviewed by the UO Research Compliance Services and was determined to be exempt human subjects research (45 CFR 46.104(d)(2) and _.104(d)(4)) with an expiration date of 31 March 2021. The RPO concurs with the Institution's determination. The RPO confirmed from the Office of Human Research Protection (OHRP) website that the UO has an IRB is registered with OHRP and an active Federalwide Assurance [FWA00005914].

With regard to the review comments, I confirmed with the UO Research Compliance Services (phone call with Daniel Berman on 27 February 2020), that they do not require final versions of surveys or instruments for studies that have been determined to be exempt, unless there are substantial changes to the drafts that were initially reviewed. The NIST RPO notes that the COR has since provided the final version of the survey instrument to RPO in this submission. While the UO may not require an amendment for final versions, we request any future changes to the survey(s) and focus group questions are submitted for RPO review prior to implementation.

The following documents were reviewed with this submission:

\begin{tabular}{|l|l|l|}
\hline \multicolumn{2}{|l|}{ Submission Components } \\
\hline Form Name & Version & Outcome \\
\hline $\begin{array}{l}\text { Review Response Form - } \\
\text { IRB }\end{array}$ & Version 1.0 & Approved \\
\hline $\begin{array}{l}\text { Initial Review Submission } \\
\text { Packet }\end{array}$ & Version 1.0 & Approved \\
\hline NIST External Application & Version 1.0 & Approved \\
\hline \multicolumn{2}{|l}{} \\
\hline
\end{tabular}


National Institute of

Standards and Technology

U.S. Department of Commerce

\begin{tabular}{|c|c|c|c|}
\hline \multicolumn{4}{|l|}{ Study Document } \\
\hline Title & Version \# & Version Date & Outcome \\
\hline Final Survey & Version 1.0 & $02 / 25 / 2020$ & \\
\hline \begin{tabular}{|l} 
Approval of IT \\
Security Plan \\
\end{tabular} & Version 1.0 & $02 / 25 / 2020$ & \\
\hline $\begin{array}{l}\text { Privacy Review of } \\
\text { HR Data Released, } \\
\text { Summary of Data }\end{array}$ & Version 1.0 & $02 / 25 / 2020$ & \\
\hline $\begin{array}{l}\text { ATO for Survey } \\
\text { Monkey }\end{array}$ & Version 1.0 & $02 / 25 / 2020$ & \\
\hline \begin{tabular}{|l} 
2020-01-30 IR \\
Determination \\
12092019.022 \\
\end{tabular} & Version 1.0 & $02 / 10 / 2020$ & \\
\hline
\end{tabular}

If anything with the study changes, please submit an update for review by RPO, or contact RPOffice@nist.gov for assistance.

Please forward this memo to the Contracting Officer.

Signature applied by Anne M Andrews on 02/27/2020 03:50:48 PM EST 


\section{Appendix F: The NIST Request for Proposal, Selected Excerpts}

This Appendix includes excerpts from the Request for Proposal (RFP) that resulted in the work described in this volume. We decided that it was important to include these excerpts to help guide others who would like to use a data-driven approach to analyzing issues within their organizations. The material below comprised the first two elements of the "Statement of Work": background information and the scope of work. Because the COVID-19 Pandemic occurred during the work period some adjustments were made (e.g. substituting meetings via the internet for inperson visits), but the general outline of tasks was adhered to.

\section{BACKGROUND INFORMATION}

The National Institute of Standards and Technology (NIST) is committed to creating and sustaining an equitable working environment for its employees so that it can attract and retain the best possible workforce. A critical component of this commitment is ensuring equitable promotion practices. Equitable promotion practices are defined as promotion practices that provide equal opportunity for all qualified candidates to advance within the NIST organization. NIST requires the equity and diversity issues related to Science, Technology, Engineering, and Math (STEM) career development be addressed by identification of root causes, recommendations for organizational resolution, and benchmarks to measure equity progress against organizational goals.

In January 2018, a group of NIST scientists and managers delivered a summary memorandum to the NIST Associate Director of Laboratory Programs titled Recommendations to Improve Equity in the Scientific and Engineering Promotions Process at NIST. On March 16, 2018 the Associate Director established a Steering Group on Equity in Career Advancement composed of two entities: The Data Focus Group and The Research Foundations Focus Group. The Data Focus Group is responsible to (1) collect and analyze NIST's demographic data and (2) commission an expert, outside party to design and implement a data-driven study to examine the causes of inequity in promotions at NIST, and to develop draft recommendations. The acquisition of an outside party to perform the study is the sole focus of this Statement of Work (SOW).

\section{SCOPE OF WORK}

A. OBJECTIVES/PURPOSE: The Contractor shall execute an analysis of the NIST career advancement process for STEM disciplines by identifying critical factors in promotion disparity among NIST federal employees to include causes and trends. The Contractor shall also provide recommendations and organizational strategies that support career advancement for NIST federal employees to include women and under-represented minorities.

B. GENERAL: The Contractor shall provide all support for project oversight, administration, and technical execution. 
C. SPECIFIC REQUIREMENTS: The Contractor shall complete the following tasks:

1. Task 1: Evaluate the January 2018 memorandum titled Recommendations to Improve Equity in the Scientific and Engineering Promotions Process at NIST and its associated database.

a. Identify and analyze past promotion disparity issues/trends and recommend issues/trends to be subjected to further analysis under Task 2.

b. Recommend promotion disparity interventions that NIST can implement immediately to address existing inequities.

2. Task 2: Develop Data Collection Plan. The plan shall clearly outline the methods and procedures for data collection and evaluation. Methods for statistical analysis must also be clearly outlined and procedures for coding qualitative data must be described. This Data Collection Plan will form the basis for quantitative benchmarks by which NIST can evaluate its progress towards organizational goals. Present the plan in-person to leaders at NIST in Gaithersburg, Maryland, for review and approval. This presentation shall be between 45-60 minutes in length plus 30 minutes for questions and answers. NIST feedback will be used to modify the plan, as needed, prior to implementation.

3. Task 3: Develop Milestone Plans for each of the Task 5 through Task 11. Each plan should clearly indicate the time-phasing and path to completion.

4. Task 4: Provide Bi-monthly Progress Reports that document project status in accordance with the Milestone Plans, Task 3. Bi-Monthly Progress Reports shall include, at a minimum, the following program areas of interest: activities accomplished, status of on-going activities, deliverables completed, outstanding deliverables, project delays, reasons for delays, and recommended corrective actions relative to any project concerns. The reports shall be in writing and formatted at the Contractor's discretion subject to change when and if the Technical Point of Contact (TPOC) deems it necessary. The method of delivering each report shall be agreed upon by both parties prior to its due date.

5. Task 5: Conduct Literature Review. The review shall identify approaches, methods, and models established as best practices for equitable advancement of women and minorities in scientific laboratory environments. The focus of this review shall be literature from any accredited source and shall focus on federal scientific laboratory environments similar to NIST (e.g., the National Science Foundation, the National Institutes of Health, the Department of Energy).

6. Task 6: Conduct NIST Data Collection. Identify institutional trends that impact equity factors 
among the pool of qualified NIST staff for STEM leadership positions with emphasis on representation of women and underrepresented minorities such that the fraction of NIST staff is representative of the fraction of STEM degrees granted to these groups.

7. Task 7: Develop Equity Action Plan. The plan shall develop sustainable approaches, methods, and models that can be replicated and/or built upon by NIST that improve career advancement for all staff, with emphasis on women and under-represented minorities.

8. Task 8: Develop Communication Plan. The plan shall share project information, results, and outcomes with NIST. The plan shall include a communication strategy for NIST stakeholders to increase engagement among NIST supervisors and staff to promote transparency and equity in career advancement process.

9. Task 9: Write Final Summary Report of major accomplishments and conclusions that describes the project and its importance, explains the project goal, describes the project outcomes, and reports the findings, lessons learned, and recommended approaches, methods, and models for improving equity in career advancement at NIST based on Literature Review and NIST Data Collection.

10. Task 10: Present Final Summary Report in-person to leaders at NIST in Gaithersburg, Maryland. This presentation shall be between 45-60 minutes in length plus 30 minutes for questions and answers. Stand ready to respond to further discussions as well as answer questions through the 24-month period-of-performance 